AUTARQUIA ASSOCIADA À UNIVERSIDADE DE SÃO PAULO

Caracterização da reatividade das ligas alumínio AA2024-T3 e AA7475-T651 soldadas por fricção (FSW)

Caio Palumbo de Abreu

Tese apresentada como parte dos requisitos para obtenção do Grau de Doutor em Ciências na Área de Tecnologia Nuclear - Materiais

Orientadora:

Profa. Dra. Isolda Costa

Orientador:

Prof. Dr. Vincent Vivier 


\section{INSTITUTO DE PESQUISAS ENERGÉTICAS E NUCLEARES}

Autarquia associada à Universidade de São Paulo

Caracterização da reatividade das ligas alumínio AA2024-T3 e AA7475-T651 soldadas por fricção (FSW)

Caio Palumbo de Abreu

Tese apresentada como parte dos requisitos para obtenção do Grau de Doutor em Ciências na Área de Tecnologia Nuclear - Materiais

Orientadora:

Profa. Dra. Isolda Costa

Orientador:

Prof. Dr. Vincent Vivier

Versão Original

São Paulo

2016 


\section{AGRADECIMENTOS}

A Deus, sob todas as suas formas.

À minha orientadora, Profa. Dra. Isolda Costa, pela amizade, auxílios, dedicação, confiança, por cada ensinamento e pela paciência ao longo deste trabalho. Eternamente agradecido.

Ao meu orientador, Dr. Vincent Vivier, pela amizade, confiança, respeito, por todos os ensinamentos e pela paciência em manter a paciência e ajudas, mesmo quando eu já estava longe.

Ao Prof. Dr. Hercílio Gomes de Melo, pela amizade e por inúmeros auxílios e dedicação no projeto do trabalho.

À Profa. Dra. Mireille, por todo o auxílio na realização e no tratamento de dados da técnica de medida de ângulo de contato aliada à espectroscopia de impedância.

À minha querida família: aos meus pais, Tomás e Narriman, por todo o amor, carinho e dedicação de toda a vida. À minha Fernanda, por todo o amor e carinho de sempre; e pela imensa força e compreensão durante essa jornada. Ao meu irmão, Rafael, pelo amor e companheirismo. À minha querida sobrinha, Marina, uma anjinha. À miha cunhada, Cris, pela força e carinho. Ao Gabriel, pelo carinho e força em 'segurar a casa'. À minha irmãzinha Naná. À Babi, minha maior companheira de estudos. E um agradecimento especial aos meus amados avós, que já partiram dessa estação, Carlos, Myrthes e Carminha (in memorian), pelo amor que me deram.

Aos grandes amigos que não dispensaram um segundo de atenção e de amizade: Marcelo (Djow), Daniel, Zé Mario, Wagner e ao Làlà (Larbi).

Aos amigos do IPEN: Dr. Jesualdo, Giuseppe, Maurílio, Chico, Luis, Caru, Mariana, Fernanda e Maysa.

Aos amigos do LISE: Patrícia, Stèphane, Bea, Nour, David, Carlos, Simon, Achraf, Marie, Pierre e Wenchao. 
Aos amigos de todas as horas: Favela, Pietro, Denden, Jeron, Serginho, Bevi, Artur e Portuga.

Aos amigos do S. Antonio: Dudu, Rafael, Marcel e ao próprio S. Antonio, por todas as risadas.

Às grandes amigas Camila e Rocio, do laboratório de corrosão da Escola Politécnica da USP.

Ao Cebola, Glauson, Dra. Larissa e Flavia, por todos os auxílios no TEM e SEM.

À Françoise, por inúmeras sessões e ajudas no SEM e ao Axel, pelas ajudas nas confecções de aparatos para a realização dos ensaios no LISE.

Aos amigos e ex-orientadores Prof. Dr. Tersio Guilherme e Profa. Dra Sonia Faldini.

Aos amigos do PPL.

À Dra. Duclerc, do CQMA do IPEN, e ao Olandir, do CCTM, pela ajuda nos ensaios de DSC.

Ao Prof. Dr. Richard Landers e à Sra. Rita de Cassia G. Vinhas, do IFGW da Unicamp, pela realização e ajuda no tratamento dos dados das análises de XPS.

À Coodenação de Aperfeiçoamento de Pessoal de Nível Superior (CAPES), pelo financiamento da bolsa de doutorado no exterior, por meio do Programa CAPES/COFECUB (processo n 806-14).

Ao Instituto de Pesquisas Energéticas e Nucleares - IPEN, pela disponibilidade de lotação, materiais e conhecimento científico.

Ao LISE, em nome do Dr. François Huet, pelo acolhimento no laboratório e por terem colocado todo o material necessário para a realização deste trabalho. 
"Porque eu só preciso de pés livres, de mãos dadas, e de olhos bem abertos"

Guimarães Rosa 


\title{
CARACTERIZAÇÃO DA REATIVIDADE DAS LIGAS DE ALUMÍNIO AA2024-T3 E AA7475-T651 SOLDADAS POR FRICÇÃO (FSW)
}

\author{
CAIO PALUMBO DE ABREU
}

\begin{abstract}
RESUMO
A soldagem por fricção (Friction Stir Welding - FSW) é um processo eficiente de unir ligas de alumínio de alta resistência evitando defeitos que são usualmente criados quando técnicas convencionais de soldagem são utilizadas. A indústria aeronáutica tem mostrado grande interesse neste método de soldagem, tanto para a união de ligas similares como dissimilares. Entretanto, este processo causa modificações microestruturais dependentes das condições de tratamento térmico ou termomecânico. Contato elétrico entre zonas de microestruturas diferentes, por sua vez, pode resultar em acoplamento galvânico. No presente estudo, a soldagem por FSW foi usada para unir duas ligas de alumínio dissimilares, AA2024-T3 e AA7475-T651 e o efeito desta soldagem na resistência à corrosão das juntas soldadas e na microestrutura das ligas foi avaliada. $\mathrm{Na}$ investigação da resistência à corrosão foram utilizados ensaios eletroquímicos, especificamente, medidas de potencial de circuito aberto (OCP) em função do tempo de exposição ao meio corrosivo, ensaios de polarização e de espectroscopia de impedância eletroquímica, global (EIS) ou local (LEIS), em duas soluções, seja 0,1 $\mathrm{M} \mathrm{Na}_{2} \mathrm{SO}_{4}$ ou $0,1 \mathrm{M} \mathrm{Na}_{2} \mathrm{SO}_{4}+1 \mathrm{mM} \mathrm{NaCl}$. Os ensaios eletroquímicos evidenciaram efeito de acoplamento galvânico nas juntas soldadas. A caracterização microestrutural foi realizada por microscopia ótica, microscopia eletrônica de varredura, microscopia eletrônica de transmissão e por calorimetria diferencial. As zonas afetadas pela solda tiveram importantes modificações na microestrutura indicadas pela precipitação e dissolução de precipitados que afetam a resistência à corrosão localizada. A resistência à corrosão intergranular e a resistência à esfoliação das juntas soldadas também foram avaliadas e comparadas com as das ligas AA2024-T3 e AA7475-T651 não soldadas. Os resultados mostraram aumento da suscetibilidade das juntas soldadas a estas formas de corrosão em comparação com as ligas não soldadas sendo observado ataque mais severo na liga AA7475-T651. A identificação das áreas anódicas e catódicas resultantes do acoplamento galvânico nas juntas soldadas foi realizada por teste que consistiu na deposição de camada de gel (ágar-ágar) com indicador universal na superfície das ligas soldadas. A liga AA2024-T3 atuou como cátodo, enquanto a AA7475-T651, como ânodo no par galvânico. Além disso, evolução de hidrogênio foi observada na região de interface entre a zona termomecanicamente afetada e a termicamente afetada da liga AA7475-T651 mostrando que reações catódicas também ocorreram localmente nesta última liga. Resultados de LEIS obtidos nas diferentes zonas das duas ligas soldadas por FSW mostraram acoplamento galvânico na interface entre elas para tempos curtos de ensaio e deslocamento da região mais ativa com o tempo de ensaio para a liga AA7475-T651, mais precisamente para a interface entre a zona termomecanicamente afetada e a térmicamente afetada desta liga.
\end{abstract}

Palavras-chave: Soldagem por fricção (Friction Stir Welding), Ligas de alumínio, FSW de ligas dissimilares, Acoplamento galvânico, LEIS (espectroscopia de impedância eletroquímica localizada). 


\title{
CHARACTERIZATION OF THE REACTIVITY OF ALUMINIUM ALLOYS AA2024-T3 AND AA7475-T651 WELDED BY FRICTION STIR WELDING (FSW)
}

\author{
CAIO PALUMBO DE ABREU
}

\begin{abstract}
Friction Stir Welding (FSW) is an efficient process of joining high strength aluminum alloys avoiding defects that are usually created when conventional welding techniques are used. The aircraft industry has shown great interest in this welding method, both for welding of similar or dissimilar alloys. However, this process causes microstructural changes that are dependent on the thermal or thermomechanical conditions applied. Electrical contact between zones of different microstructures, in turn, can result in galvanic coupling. In the present study, FSW was used to join two dissimilar aluminum alloys, AA2024-T3 and AA7475-T651 and the effect of this process on the corrosion resistance of the welded joints and on the microstructure of the alloys was evaluated. For corrosion resistance evaluation, electrochemical tests were used, specifically, open circuit potential measurements (OCP) as a function of time of exposure time to the corrosive environment, polarization tests, and electrochemical impedance spectroscopy, global (EIS) or local (LEIS), in two solutions, either $0.1 \mathrm{M} \mathrm{Na}_{2} \mathrm{SO}_{4}$ or $0.1 \mathrm{M} \mathrm{Na} 2 \mathrm{SO}_{4}+1 \mathrm{mM} \mathrm{NaCl}$. The electrochemical tests showed galvanic coupling effects in the welded joints. Microstructural characterization was carried out by optical microscopy, scanning electron microscopy, transmission electron microscopy and differencial scanning calorimetry. The welded affected zones showed significant microstructural changes indicated by precipitation and dissolution of precipitates that affect the localized corrosion resistance. Intergranular and exfoliation corrosion resistance of the welded joints were also evaluated and compared to those of unwelded AA2024T3 and AA7475-T651 alloys. The results showed increased susceptibility of welded joints to these forms of corrosion in comparison with the unwelded alloys with more severe attack associated to the AA7475-T651 alloy. Identification of anodic and cathodic areas due to galvanic coupling in the welded joints was evaluated by a test consisting in depositing a gel layer (ágar-ágar) with universal indicator on the surface of the welded alloys. The AA2024-T3 alloy worked as cathode, while the AA7475-T651 as anode in the galvanic coupling. Furthermore, hydrogen evolution was observed at the interface region between the thermomechanically affected zone and the heat affected alloy AA7475-T651 showing that cathodic reactions also occurred on this last alloy. LEIS results obtained in different zones of the two FSW welded alloys showed galvanic coupling at the interface between them for short test times and displacement of the most active region to the AA7475-T651 alloy, at longer periods of test, specifically to the interface between the thermomechanically affected and the heat affected zones of this last alloy.
\end{abstract}

Keywords: Friction Stir Welding, Aluminum Alloys, FSW of dissimilar alloys, Galvanic coupling, LEIS (Localized Electrochemical Impedance Spectroscopy). 


\title{
CARACTÉRISATION DE LA RÉACTIVITÉ DES ALLIAGES D'ALUMINIUM AA2024-T3 ET 7475-T651 SOUDÉS PAR FRICTION (FSW)
}

\author{
CAIO PALUMBO DE ABREU
}

\begin{abstract}
RÉSUMÉ
Le soudage par friction (Friction Stir Welding - FSW) est un processus efficace de se joindre des alliages d'aluminium à haute résistance en évitant les défauts que l'on trouve habituellement lorsque les techniques de soudage classiques sont utilisés. L'industrie de l'aviation a montré un grand intérêt pour cette méthode de soudage, tant pour l'union des alliages semblables comme pour dissemblables. Cependant, ce processus entraîne des changements de microstructure dépendantes des conditions de traitement thermique ou thermomécanique. Le contact électrique entre les différentes zones de microstructures, à son tour, peut conduire à un couplage galvanique entre les différentes zones. Dans la présente étude, le soudage FSW a été utilisé pour joindre deux alliages d'aluminium dissemblables, AA2024-T3 et AA7475-T651. La résistance à la corrosion des joints soudés a été évaluée par des tests électrochimiques, en particulier, les mesures de potentiel en circuit ouvert (OCP), les courbes de polarisation, et des mesures de spectroscopie d'impédance électrochimique, soit globale (EIS) ou local (LEIS) en solution de $0,1 \mathrm{M} \mathrm{Na}_{2} \mathrm{SO}_{4}$ ou $0,1 \mathrm{M}$ $\mathrm{Na}_{2} \mathrm{SO}_{4}+1 \mathrm{mM} \mathrm{NaCl}$. Les tests électrochimiques ont montré l'effet de couplage galvanique dans les joints soudés. La résistance à la corrosion intergranulaires et la résistance à corrosion par exfoliation des joints soudés ont également été évaluées et comparées à celles du AA2024-T3 et les alliages AA7475-T651 non soudées. Les résultats ont montré une réactivité accrue des joints soudés en comparaison avec les alliages non soudés en notant l'attaque plus intense sur l'alliage AA7475-T651. L'identification des zones cathodiques et anodiques dans les joints soudées ont été évaluée par un test consistant à déposer un gel (agar) avec l'indicateur universel et il a été observé que l'alliage AA2024-T3 a agi en tant que cathode, tandis que la AA7475- T651 comme anode. Par ailleurs, le dégagement d'hydrogène a été observée dans la région d'interface entre la zone affectée thermomécaniquement et l'alliage AA7475-T651 affectée par la chaleur. Les résultats des essais de LEIS effectuées dans différentes zones des deux alliages soudés par FSW ont montré l'engagement galvanique à l'interface entre eux pour de courtes durées d'analyse et de déplacement de la région la plus active dans le temps de test pour l'alliage AA7475-T651, plus précisément à l'interface entre la zone affectée thermomécaniquement et la thérmique affectée de cette alliage.
\end{abstract}

Mots clés: Soudage par friction (Friction Stir Welding), Alliages d'aluminium, FSW d'alliages dissimilaires, Couplage galvanique, LEIS (Spectroscopie d'Impédance Électrochimique Locale). 


\section{SUMÁRIO}

Lista de Figuras.....................................................................

Lista de Tabelas.......................................................................... XVII

Lista de Abreviaturas................................................................. XIX

1.

2.

3.

3.1.

3.1 .1

3.1 .2

3.1 .3

3.1 .4

3.1 .5

3.2

3.3

3.4

3.4 .1

3.4 .2

3.4.2.1

3.4.2.2

3.4.2.3

3.4.2.4

3.4 .3

3.4 .4

3.5

3.6

3.7

INTRODUÇÃO.

OBJETIVO E JUSTIFICATIVA

\section{5}

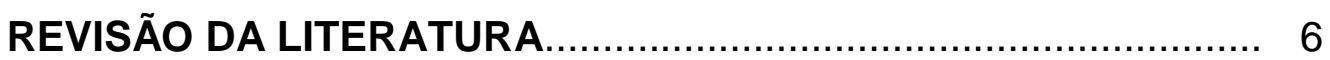

O alumínio e suas ligas........................................................ 6

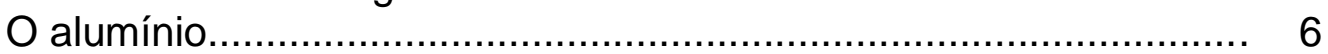

Ligas de alumínio.................................................................. 6

Microestrutura e endurecimento estrutural das ligas de alumínio....... 8

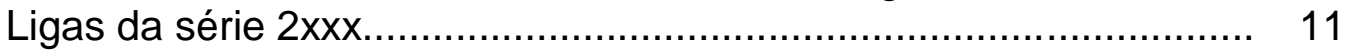

Ligas da série 7xxx.............................................................. 17

Soldagem por fricção linear com mistura (Friction Stir Welding -

FSW) ............................................................................... 20

Características microestruturais de ligas de alumínio soldadas por FSW.....

Corrosão do alumínio e suas ligas.......................................... 28

Corrosão do alumínio.......................................................... 28

Corrosão localizada das ligas de alumínio................................. 28

Corrosão galvânica.......................................................... 29

Corrosão por pites................................................................ 31

Corrosão intergranular.......................................................... 32

Corrosão por esfoliação.............................................................. 33

Aspetos gerais da corrosão localizada de ligas de alumínio da série 2xxx.

Aspetos gerais da corrosão localizada de ligas de alumínio da série $7 \mathrm{xxx}$

Corrosão das ligas de alumínio soldadas por fricção (FSW) ............... 38

Métodos de estudo da corrosão localizada...................................... 41

Uso de técnicas locais para o estudo da corrosão de materiais 43 soldados.

4.

MATERIAIS E MÉTODOS.

4.1

Materiais.

4.1.1

Ligas de alumínio...

Soluções. 
4.2.6 Ensaio de microdureza........................................................ 50

4.2.7 Exposição em solução de ágar-ágar...................................... 50

4.2.8 Corrosão intergranular..................................................... 51

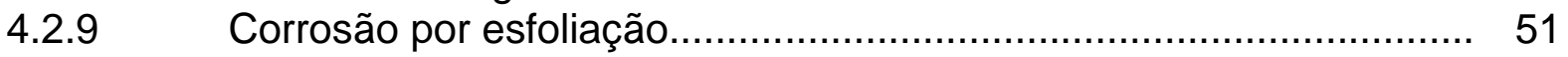

4.2.10 Preparação da célula eletroquímica para os ensaios........................ 52

4.2.11 Medidas de potencial em circuito aberto..................................... 52

4.2.12 Curvas de polarização.......................................................... 53

4.2.13 Espectroscopia de impedância eletroquímica (EIS) ........................ 53

4.2.14 Espectroscopia de impedância eletroquímica local (Local Electrochemical Impedance Spectroscopy - LEIS)....................... 54

4.2.14.1 Definições e cálculos de impedância locais...................................... 58

4.2.14.1.1 Cálculos de impedância locais (local, local interfacial e local ôhmica), medidas com o bi-eletrodo...................................................... 58

4.2.14.1.2 Detecção de sinais em LEIS e seus limites.................................. 60

4.2.14.1.3 Validação do sistema de medidas para LEIS ................................. 62

4.2.15 Microscopia eletroquímica de varredura (SECM) ............................ 63

4.2.16 Espectroscopia de fotoelétrons de raios-X (XPS) .......................... 65

5. RESULTADOS E DISCUSSÃO.

5.1 Caracterização microestrutural das ligas 2024-T3 e 7475-T651, soldadas por FSW.................................................................. 69

5.1.1 Microscopia óptica e definição dos limites das zonas

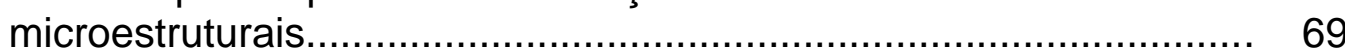

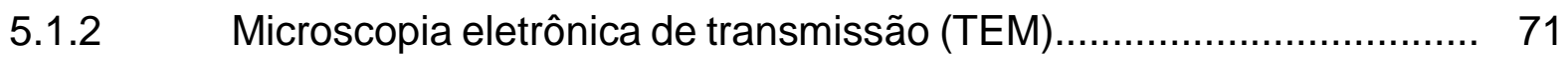

5.1.3 Calorimetria exploratória diferencial (DSC) ................................ 78

5.1.4 Ensaio de microdureza..................................................... 80

5.1.5 Microscopia eletrônica de varredura (SEM) ................................ 81

5.2 Avaliação da resistência a diferentes formas de

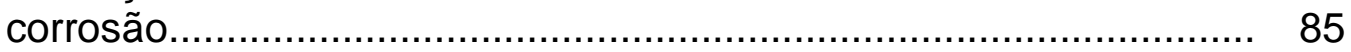

5.2.1 Ensaio de imersão em solução de ágar-ágar.................................. 85

5.2.2 Verificação da corrosão intergranular............................................. 88

5.2.3 Verificação da corrosão por esfoliação....................................... 90

5.2.4 Ensaios de imersão em solução de $0,1 \mathrm{M}$ de $\mathrm{Na}_{2} \mathrm{SO}_{4}+1 \mathrm{mM}$ de $\mathrm{NaCl}$..

5.3 Caracterização eletroquímica da resistência à corrosão das ligas soldadas..................................................................... 104

5.3.1 Caracterização eletroquímica local................................................. 113

5.3.1.1 Caracterização eletroquímica com micro-célula (abertura de $\varnothing$ 1,0

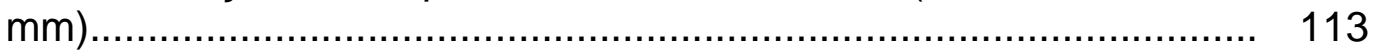

5.3.1.2 Espectroscopia de impedância local (LEIS) ................................. 117

$5.4 \quad$ Comportamento à corrosão na seção transversal........................... 126

5.4.1 Ensaio de imersão em solução de ágar-ágar................................... 126

5.4.2 Espectroscopia eletroquímica de varredura (SECM) ...................... 127

5.5 Comportamento superficial antes e após exposição à corrosão.......... 131

5.5.1 Análise superficial por XPS................................................. 133

5.5.1.1 Análise por XPS da camada de passivação da liga 2024-T3............. 136

5.5.1.2 Análise por XPS da camada de passivação da liga 7475-T651.......... 138

5.5.1.3 Análise por XPS da camada de passivação do nugget das ligas 2024-T3 e 7475-T651 soldadas por FSW..................................... 140 
6.

CONCLUSÕES.

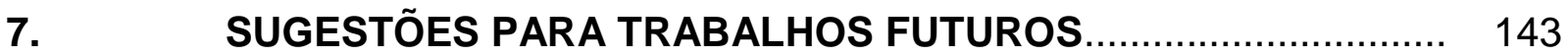

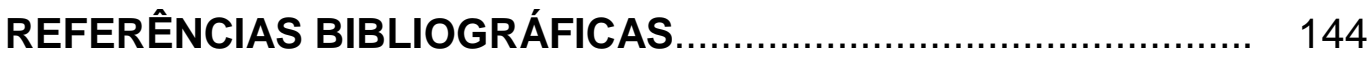




\section{LISTA DE FIGURAS}

Figura 3.1: Classificação das ligas de alumínio.

Figura 3.2: Diagrama de fases hipotético de uma liga endurecível por precipitação

Figura 3.3: $\quad$ Diagrama de fase Al-Cu, mostrando as zonas GP metaestáveis, $\theta^{\prime \prime}$ e $\theta^{\prime}$ (Russel e Aaronson, 1978).

Figura 3.4: $\quad$ Diagrama DSC de uma liga Al-1,53\%Cu-0,79\%Mg. Representação dos picos: (A) formação das zonas GPB; (B) dissolução das zonas GPB; (C) dissolução das zonas GPBII ou S"; (D) formação da fase S'(S) e; (E) dissolução da fase S'(S) (adaptado de Jena, 1989).

Figura 3.5: Apresentação dos tipos de dispersóides e precipitados endurecedores encontrados na liga 2024-T3: (a) dispersóides $\mathrm{Al}_{20} \mathrm{Cu}_{2} \mathrm{Mn}_{3}$ (Totten e MacKenzie, 2003); (b) precipitado intragranular $\mathrm{S}\left(\mathrm{Al}_{2} \mathrm{CuMg}\right)$ e; (c) precipitado intergranular $\mathrm{S}\left(\mathrm{Al}_{2} \mathrm{CuMg}\right)$ (Zhang e Frankel, 2003).

Figura 3.6: $\quad$ Diagrama DSC de uma liga 7075-T6 adaptado do trabalho de MacAskill et al. (2009).....

Figura 3.7: $\quad$ Apresentação dos tipos de precipitados endurecedores encontrados na liga 7075-T6: (a) zonas GP e precipitados intragranulares de fase $\eta^{\prime} ;$ (b) precipitado intragranular $\eta$; (c) precipitados intragranulares de fases $\eta$ e $\eta$ $\left(\mathrm{MgZn}_{2}\right)$ (Aval, 2015) e; (d) precipitados intergranulares e PFZ (zona livre de precipitados) (Ranganath et al., 2013).

Figura 3.8: Ilustração esquemática do processo de soldagem por FSW (Cole, 2013)

Figura 3.9: $\quad$ Regiões formadas na liga 2024 após processo de soldagem por FSW: (a) MB; (b) ZTA; (c) ZTMA e (d) ZM (Nandan, 2008).

Figura 3.10: $\quad$ Micrografias obtidas por MET, dos precipitados intragranulares formados após o processo de soldagem por FSW na liga 2024-T3 (Bousquet et al., 2011)

Figura 3.11 Micrografias obtidas por MET, dos precipitados intragranulares formados após o processo de soldagem por FSW na liga 7050-T651 (Su et al., 2003)

Figura 3.12: Diferença entre (a) corrosão uniforme e (b) corrosão localizada de um metal (Landolt, 1993)...

Figura 3.13: Ilustração esquemática do processo de corrosão por pites em ligas de alumínio (Davis, 1999)....

Figura 3.14: Micrografia óptica de corrosão intergranular na liga 2024-T3 (Hoffman et al., 2004). 
Figura 3.15: Fotomicrografia por SEMde uma liga 2024-T351 após sofrer corrosão por esfoliação (Kuntz-Laguerre, 1997).

Figura 3.16: Ilustração do mecanismo de redistribuição do cobre por dissolução de partículas de fase S proposto por Buchheit et al. (Buchheit et al., 2000)

Figura 3.17 Curva de polarização da liga 2024 em solução de $\mathrm{NaCl}$ (1 M) (Guillaumin et al.,1999).

Figura 4.1: Esquema da organização dos ensaios realizados

Figura 4.2: $\quad$ Ilustração esquemática da região onde foram realizadas as medidas de microdureza destacada pelas linhas tracejadas em vermelho.

Figura 4.3: $\quad$ Ilustração esquemática da célula eletroquímica utilizada para as medidas de EIS.

Figura 4.4: Fotografias da célula eletroquímica, com $\varnothing 1 \mathrm{~mm}$ de abertura, utilizada para a análise em diferentes zonas formadas após o processo de soldagem por FSW.

Figure 4.5: $\quad$ Esquema do sistema de medidas de LEIS e EIS, do LISE.

Figura 4.6: Ilustração esquemática da célula eletroquímica utilizada para as medidas de LEIS.

Figura 4.7: Fotografias de um bi-eletrodo e um tri-eletrodo, confeccionados no LISE.

Figura 4.8: Esquema de representação do (a) bi-eletrodo e sua atuação, em LEIS; e (b) ilustração esquemática das pontas do bi-eletrodo.

Figura 4.9: Diferenças de potenciais calculadas para um eletrodo de disco plano de $0,25 \mathrm{~cm}$, mantendo fixo ' $h$ ' (distância entre a superfície do eletrodo de trabalho e a ponta inferior do bi-eletrodo) em $100 \mu \mathrm{m}$ e 'd' (distância entre as pontas do bi-eletrodo) em $50 \mu \mathrm{m}$. Para a realização destes cálculos, foram mantidos fixos os seguintes parâmetros: $k=0,01 \mathrm{Scm}^{-1} ; r_{0}=0,25$ $\mathrm{cm} ; \mathrm{C}_{0}=10 \mu \mathrm{F} ; \mathrm{R}=$ infinito (capacitor puro) e $\mathrm{R}=\mathrm{k} \Omega ; \Delta \mathrm{V}=30 \mathrm{mV}_{\mathrm{pp}}$ (Huang et al., 2011)

Figura 4.10: Diferenças de potenciais calculadas para um eletrodo de disco plano de $0,25 \mathrm{~cm}$, mantendo fixo ' $h$ ' (distância entre a superfície do eletrodo de trabalho e a ponta inferior do bi-eletrodo) em $50 \mu \mathrm{m}$ e variando 'd' (distância entre as pontas do bi-eletrodo). Para a realização destes cálculos, foram mantidos fixos os seguintes parâmetros: $\mathrm{k}=0,01 \mathrm{Scm}^{-1}$; $\mathrm{r}_{0}=0,25 \mathrm{~cm} ; \mathrm{C}_{0}=10 \mu \mathrm{F} ; \mathrm{R}=$ infinito (capacitor puro) e $\mathrm{R}=\mathrm{k} \Omega ; \Delta \mathrm{V}=30$ $\mathrm{mV}_{\mathrm{pp}}$ (Huang et al., 2011).

Figura 4.11: Ilustração esquemática do equipamento utilizado para realizar ensaios de microscopia eletroquímica de varredura (SECM)... 
Figura 4.12: Representação do modo 'feedback negativo' (substrato isolante) e ‘feedback positivo' (substrato condutor).....

Figura 4.13: Efeito fotoelétrico.

Figura 4.14: Espectro de XPS, em alta resolução, mostrando as diferentes energias de ligação dos picos de alumínio (Al2p), alumínio metálico e óxido de alumínio, obtidos de uma liga de alumínio 5086 (adaptado de Strohmeier, 1990)

Figura 5.1: $\quad$ Macrografia das ligas 2024 e 7475 soldadas por FSW.....

Figura 5.2: Micrografias ópticas das diferentes regiões formadas na superfície da amostra das ligas 2024-T3 e 7475-T651, soldadas por FSW, com aumento de 10 vezes: (a) MB da 2024-T3; (b) ZTA/ZTMA da 2024-T3; (c) nugget; (d) ZTA/ZTMA da 7475-T651; (e) MB da 7475T651.

Figura 5.3 : Micrografias ópticas das diferentes regiões formadas na seção transversal da amostra das ligas 2024-T3 e 7475-T651, soldadas por FSW

Figura 5.4: Micrografias obtidas por TEM das diferentes regiões da liga 2024-T3 formadas após a soldagem por FSW das ligas 2024-T3 e 7475T651.....

Figura 5.5: Micrografias obtidas por HAADF-STEM de precipitados encontrados no MB da liga 2024-T3.

Figura 5.6: Micrografias obtidas por HAADF-STEM de precipitados encontrados na ZTMA da liga 2024-T3.

Figura 5.7 Micrografias obtidas por TEM das diferentes regiões da liga 7475-T651 formadas após a soldagem por FSW das ligas 2024-T3 e 7475-T651

Figura 5.8 Micrografias obtidas por HAADF-STEM de precipitados encontrados no MB (a) e na ZTMA (b) da liga 7475-T651.

Figura 5.9: Análises por DSC das diferentes zonas da liga 2024-T3, formadas após o processo de soldagem por FSW.

Figura 5.10: $\quad$ Análises por DSC das diferentes zonas da liga 7475-T651, formadas após o processo de soldagem por FSW.

Figura 5.11: Perfis de microdureza, obtidos pela área varrida das ligas 2024-T3 e 7475T651, soldadas por FSW.

Figura 5.12: Fotomicrografias obtidas por microscopita eletrônica de varredura das diferentes regiões formadas após a soldagem, por FSW, das ligas 2024 e 7475: (a) MB da 2024; (b) ZTA da 2024; (c) ZTMA da 2024; (d) nugget da 2024; (e) nugget da 7475; (f) ZTMA da 7475; (g) ZTA da 7475 e; (h) MB da 7475 .

Figura 5.13: Análises das distribuições de precipitados, das diferentes regiões das ligas após soldagem por FSW, através das imagens obtidas por 
microscópio eletrônico de varredura, com o auxílio do software ImageJ

Figura 5.14: Análises dos tipos de precipitados principais, nas diferentes ligas e as respectivas regiões após soldagem por FSW

Figura 5.15: Imagens, seguidas por tempo de exposição em solução de ágarágar

Figura 5.16: Aumento da imagem da amostra exposta em solução de ágar-ágar, após 8 horas de imersão

Figura 5.17: Macrografia da superfície da amostra das ligas 2024-T3 e 7475-T651, soldadas por FSW, durante os primeiros minutos em exposição ao ensaio do comportamento à corrosão intergranular. Abaixo, as micrografias obtidas por MEV, após o ataque.

Figura 5.18: Imagens obtidas por micoscopia óptica da seção transversal da amostra após o ataque para verificação do comportamento à corrosão intergranular.

Figura 5.19: Macrografia da amostra após 10 minutos em solução para verificação do comportamento à corrosão por esfoliação.

Figura 5.20: Fotografias das amostras dos MB das ligas 2024 e 7475 e da amostra das ligas 2024 e 7475 soldadas por FSW, após ataque para verificação do comportamento à corrosão por esfoliação.

Figura 5.21: Micrografias ópticas das seções transversais das ligas 2024 e 7475 separadas e soldadas por FSW, após ataque para verificação do comportamento à corrosão por esfoliação.

Figura 5.22: Macrografias ópticas das superfícies das amostras das ligas 2024-T3 e 7475-T651, soldadas por FSW: (a) antes da exposição; (b) após 8 horas e; (c) 24 horas de exposição em solução de 0,1 M de $\mathrm{Na}_{2} \mathrm{SO}_{4}+1 \mathrm{mM}$ de $\mathrm{NaCl}$

Figura 5.23: Micrografias obtidas por SEM do MB da liga 2024-T3, antes de exposição, após 8 horas e após 24 horas de exposição em solução de $0,1 \mathrm{M}$ de $\mathrm{Na}_{2} \mathrm{SO}_{4}+1 \mathrm{mM}$ de $\mathrm{NaCl}$. As fotos à direita foram tiradas com maior aumento da mesma região das fotos à esquerda.

Figura 5.24: Micrografias obtidas por SEM da ZTMA da liga 2024-T3, antes de exposição, após 8 horas e após 24 horas de exposição em solução de 0,1 $\mathrm{M}$ de $\mathrm{Na}_{2} \mathrm{SO}_{4}+1 \mathrm{mM}$ de $\mathrm{NaCl}$. As fotos à direita foram tiradas com maior aumento da mesma região das fotos à esquerda

Figura 5.25: Micrografias obtidas por SEM do nugget das ligas 2024-T3 e 7475-T651, soldadas por FSW, antes de exposição, após 8 horas e após 24 horas de exposição em solução de $0,1 \mathrm{M}$ de $\mathrm{Na}_{2} \mathrm{SO}_{4}+1 \mathrm{mM}$ de $\mathrm{NaCl}$. As fotos à direita foram tiradas com maior aumento da mesma região das fotos à esquerda, referentes à parte da liga 2024-T3. 
Figura 5.26: $\quad$ Micrografias obtidas por SEM do nugget das ligas 2024-T3 e 7475-T651, soldadas por FSW, antes de exposição, após 8 horas e após 24 horas de exposição em solução de $0,1 \mathrm{M}$ de $\mathrm{Na}_{2} \mathrm{SO}_{4}+1 \mathrm{mM}$ de $\mathrm{NaCl}$. As fotos à direita foram tiradas com maior aumento da mesma região das fotos à esquerda, referentes à parte da liga 7475-T651.

Figura 5.27: Micrografias obtidas por SEM da ZTMA da liga 7475-T651, antes de exposição, após 8 horas e após 24 horas de exposição em solução de 0,1 $\mathrm{M}$ de $\mathrm{Na}_{2} \mathrm{SO}_{4}+1 \mathrm{mM}$ de $\mathrm{NaCl}$. As fotos à direita foram tiradas com maior aumento da mesma região das fotos à esquerda.

Figura 5.28: Micrografias obtidas por SEMdo MB da liga 7475-T651, antes de exposição, após 8 horas e após 24 horas de exposição em solução de 0,1 $\mathrm{M}$ de $\mathrm{Na}_{2} \mathrm{SO}_{4}+1 \mathrm{mM}$ de $\mathrm{NaCl}$. As fotos à direita foram tiradas com maior aumento da mesma região das fotos à esquerda.

Figura 5.29: Imagens obtidas por microscopia eletrônica de varredura, seguidas por tempo de exposição em solução de $0,1 \mathrm{M}$ de $\mathrm{Na}_{2} \mathrm{SO}_{4}+1 \mathrm{mM}$ de $\mathrm{NaCl}$, durante 8 horas.

Figura 5.30: Curvas de potencial em circuito aberto das ligas 2024-T3 e 7475-T651, e destas soldadas por FSW, em solução de $0,1 \mathrm{M}$ de $\mathrm{Na}_{2} \mathrm{SO}_{4}+1 \mathrm{mM}$ de $\mathrm{NaCl}$.

Figura 5.31: Curvas de polarização catódica das ligas 2024-T3 e 7475-T651, e destas soldadas por FSW, em solução de $0,1 \mathrm{M}$ de $\mathrm{Na}_{2} \mathrm{SO}_{4}+1 \mathrm{mM}$ de $\mathrm{NaCl}$.

Figura 5.32: Curvas de polarização anódica das ligas 2024-T3 e 7475-T651, e destas soldadas por FSW, em solução de $0,1 \mathrm{M}$ de $\mathrm{Na}_{2} \mathrm{SO}_{4}+1 \mathrm{mM}$ de $\mathrm{NaCl}$.....

Figura 5.33: Especroscopias de impedância (globais) das ligas: (a) 2024-T3; (b) 2024T3 e 7475-T651, soldadas por FSW, e; (c) 7475-T651, em solução de 0,1 $\mathrm{M}$ de $\mathrm{Na}_{2} \mathrm{SO}_{4}+1 \mathrm{mM}$ de $\mathrm{NaCl}$

Figura 5.34: Espectroscopias de impedância (global) das ligas 2024-T3 e 7475-T651, soldadas por FSW, durante 44 horas, em solução de $0,1 \mathrm{M}$ de $\mathrm{Na}_{2} \mathrm{SO}_{4}+$ $1 \mathrm{mM}$ de $\mathrm{NaCl}$.

Figura 5.35: Espectroscopias de impedância da liga 2024-T3, após 2 horas em OCP (azul), e após 2 horas em potencial de $-500 \mathrm{mV}_{\mathrm{Ag} / \mathrm{AgCl}}$ (vermelho), em solução de $0,1 \mathrm{M}$ de $\mathrm{Na}_{2} \mathrm{SO}_{4}+1 \mathrm{mM}$ de $\mathrm{NaCl}$.

Figura 5.36: Espectroscopias de impedância da liga 7475-T651, após 2 horas em OCP (azul), e após 2 horas em potencial de $-500 \mathrm{mV}_{\mathrm{Ag} / \mathrm{AgCl}}$ (vermelho), em solução de $0,1 \mathrm{M}$ de $\mathrm{Na}_{2} \mathrm{SO}_{4}+1 \mathrm{mM}$ de $\mathrm{NaCl}$.

Figura 5.37: Esquema de posicionamento da micro-célula nas distintas zonas formadas após o processo de soldagem por FSW das ligas 2024-T3 e 7475-T651. 
Figura 5.38: Curvas de potencial em circuito aberto das diferentes regiões formadas após o processo de soldagem por FSW das ligas 2024-T3 e 7475-T651, em solução de $0,1 \mathrm{M}$ de $\mathrm{Na}_{2} \mathrm{SO}_{4}+1 \mathrm{mM}$ de NaCl.

Figura 5.39: Curvas de polarização anódica das diferentes regiões formadas após o processo de soldagem por FSW das ligas 2024-T3 e 7475-T651, em solução de $0,1 \mathrm{M}$ de $\mathrm{Na}_{2} \mathrm{SO}_{4}+1 \mathrm{mM}$ de $\mathrm{NaCl}$.

Figura 5.40: Espectroscopias de impedância locais das diferentes regiões formadas após o processo de soldagem por FSW das ligas 2024-T3 e 7475-T651, em solução de $0,1 \mathrm{M}$ de $0,1 \mathrm{M}$ de $\mathrm{Na}_{2} \mathrm{SO}_{4}+1 \mathrm{mM}$ de $\mathrm{NaCl}$.

Figura 5.41: Esquema de posicionamento das gotas, assim como do eletrodo de referência e do contra-eletrodo.

Figura 5.42: Espectroscopias de impedância (global) das ligas 2024-T3 e 7475-T651, destas soldadas por FSW, durante 44 horas, em solução de $0,1 \mathrm{M}$ de $\mathrm{Na}_{2} \mathrm{SO}_{4}$

Figura 5.43: Espectroscopias de impedância local (Nyquist) das ligas 2024 e 7475, destas soldadas por FSW, após 2 horas de imersão em solução de 0,1 M de $\mathrm{Na}_{2} \mathrm{SO}_{4}$

Figura 5.44: Espectroscopias de impedância local (Nyquist) das ligas 2024 e 7475, destas soldadas por FSW, após 6 horas de imersão em solução de 0,1 M de $\mathrm{Na}_{2} \mathrm{SO}_{4}$.....

Figura 5.45: Espectroscopias de impedância local (Nyquist) das ligas 2024 e 7475, destas soldadas por FSW, após 8 horas de imersão em solução de 0,1 M de $\mathrm{Na}_{2} \mathrm{SO}_{4}$

Figura 5.46: Espectroscopias de impedância local (Bode) das ligas 2024 e 7475, destas soldadas por FSW, em solução de 0,1 $\mathrm{M}$ de $\mathrm{Na}_{2} \mathrm{SO}_{4}$ : (a) após 2 horas de imersão; (b) após 6 horas de imersão e; (c) após 8 horas de imersão.

Figura 5.47: Imagens, seguidas por tempo de exposição em solução de ágar-ágar, na seção transversal da amostra.

Figura 5.48: Esquema de posicionamento da sonda (ultra micro-eletrodo) do microscópio eletroquímico de varredudra nas distintas zonas formadas após o processo de soldagem por FSW das ligas 2024-T3 e 7475T651......

Figura 5.49: Curvas de aproximação obtidas por microscopia eletroquímica de varredura nas diferentes regiões da seção transversal da amostra das $\begin{array}{lllll}\text { ligas } & 2024 & \mathrm{e} & 7475 & \text { soldadas }\end{array}$ FSW.

Figura 5.50: Corrente final de cada ponto medido com o auxílio de curvas de aproximação obtidas por SECM nas diferentes regiões da amostra das ligas 2024-T3 e 7475-T651, soldadas por FSW, após 7 minutos de 
exposição em solução de $0,1 \mathrm{M}$ de $\mathrm{Na}_{2} \mathrm{SO}_{4}+0,01 \mathrm{M}$ de Hidroquinona + $5 \mathrm{mM}$ de $\mathrm{H}_{2} \mathrm{SO}_{4}$

Figura 5.51: Curvas de aproximação obtidas por microscopia eletroquímica de varredura nas diferentes regiões da seção transversal da amostra das ligas 2024 e 7475 soldadas por FSW, indicadas na Figura 5.48, após 52 minutos de exposição em solução de $0,1 \mathrm{M}$ de $\mathrm{Na}_{2} \mathrm{SO}_{4}+0,01 \mathrm{M}$ de Hidroquinona $+5 \mathrm{mM}^{\mathrm{N}}$ de $\mathrm{H}_{2} \mathrm{SO}_{4}$

Figura 5.52: Corrente final de cada ponto medido com o auxílio de curvas de aproximação obtidas por SECM nas diferentes regiões da amostra das ligas 2024-T3 e 7475-T651, soldadas por FSW, após 52 minutos de exposição em solução de $0,1 \mathrm{M}$ de $\mathrm{Na}_{2} \mathrm{SO}_{4}+0,01 \mathrm{M}$ de Hidroquinona + $5 \mathrm{mM}$ de $\mathrm{H}_{2} \mathrm{SO}_{4}$

Figura 5.53: Micrografias obtidas por SEM, do MB da liga 2024-T3, da ZTMA da liga 2024-T3, do nugget, do ZTMA da liga 7475-T651 e do MB da liga 7475T651, respectivamente, após 144 horas de exposição em solução de 0,1 $\mathrm{M}$ de $\mathrm{Na}_{2} \mathrm{SO}_{4}+1 \mathrm{mM}$ de $\mathrm{NaCl}$

Figura 5.54: Espectros de alta resolução para o alumínio (Al2p) obtidos por XPS, da liga 2024-T3, (a) sem solda antes da exposição, (b) sem solda após $8 \mathrm{~h}$, (c) sem solda após $24 \mathrm{~h},(\mathrm{~d})$ com solda após $8 \mathrm{~h}$ e, (e) com solda após 24 h em solução $0,1 \mathrm{M}$ de $\mathrm{Na}_{2} \mathrm{SO}_{4}+1 \mathrm{mM}$ de $\mathrm{NaCl}$.

Figura 5.55: Espectros de alta resolução para o alumínio (Al2p), obtidos por XPS para a superfície da liga 7475-T651, (a) sem solda antes da exposição, (b) sem solda após $8 \mathrm{~h}$, (c) sem solda após 24 h, (d) com solda após 8 h e, (e) com solda após $24 \mathrm{~h}$ de exposição em solução de $0,1 \mathrm{M}$ de $\mathrm{Na}_{2} \mathrm{SO}_{4}+1$ $\mathrm{mM}$ de $\mathrm{NaCl}$

Figura 5.56: Espectros de alta resolução para o alumínio (Al2p), obtidos por XPS para a superfície do nugget das ligas 2024-T3 e 7475-T651 soldadas por FSW, (a) antes da exposição, (b) após 8 horas de exposição e, (c) após 24 horas de exposição em solução de $0,1 \mathrm{M}$ de $\mathrm{Na}_{2} \mathrm{SO}_{4}+1 \mathrm{mM}$ de $\mathrm{NaCl}$ 


\section{LISTA DE TABELAS}

Tabela 3.1: Mostrações de temperaturas atingidas no centro da solda, durante o processo de soldagem por FSW.

Tabela 3.2: Potencial de corrosão em água do mar de algumas partículas intermetálicas (Reboul, 1997; Vargel, 1999)....

Tabela 4.1: Composição química da liga 2024-T3

Tabela 4.2: Composição química da liga 7475-T651

Tabela 4.3: Composições químicas das ligas 2024-T3 e AA7475-T651, obtidas por espectrometria de fluorescência de raios-X por dispersão de comprimento de onda.....

Tabela 4.4: Soluções utilizadas em cada ensaio apresentado na Figura 4.1.

Tabela 5.1: Análises das distribuições dos precipitados nas diferentes zonas formadas após a soldagem, por FSW, das ligas 2024-T3 e 7475T651

Tabela 5.2: Microanálises semi-quantitativas por EDS, das regiões da liga 2024T3.

Tabela 5.3: Microanálises semi-quantitativas por EDS, das regiões da liga 7475T651

Tabela 5.4: Composições químicas dos produtos de corrosão encontrados sobre as partículas intermetálicas do MB, da ZTMA e do nugget da liga 2024-T3 (ver Figuras 5.23, 5.24 e 5.25), após 24 horas de exposição em solução de 0,1 M de $\mathrm{Na}_{2} \mathrm{SO}_{4}+1 \mathrm{mM}$ de $\mathrm{NaCl}$

Tabela 5.5: Composições químicas das partículas encontradas nas diferentes zonas formadas nas ligas 2024-T3 e 7475-T651, soldadas por FSW, após 144 horas de exposição em solução de $0,1 \mathrm{M}$ de $\mathrm{Na}_{2} \mathrm{SO}_{4}+1 \mathrm{mM}$ de $\mathrm{NaCl}$

Tabela 5.6: Composições químicas das superfícies das amostras, obtidas por XPS, do MB da liga 2024-T3, soldadas e não soldadas por FSW, sem exposição, após 8 horas e 24 horas de exposição em solução de de $0,1 \mathrm{M}$ de $\mathrm{Na}_{2} \mathrm{SO}_{4}+1$ $\mathrm{mM}$ de $\mathrm{NaCl}$

Tabela 5.7: Composições químicas das superfícies das amostras, obtidas por XPS, do MB da liga 7475-T651, soldadas e não soldadas por FSW, sem exposição, após 8 horas e 24 horas de exposição em solução de $0,1 \mathrm{M}$ de $\mathrm{Na}_{2} \mathrm{SO}_{4}$ $+1 \mathrm{mM}$ de $\mathrm{NaCl}$

Tabela 5.8: Composições químicas das superfícies das amostras, obtidas por XPS, do nugget das ligas 2024-T3 e 7475-T651, soldadas por FSW, sem exposição, após 8 horas e 24 horas de exposição em solução de de 0,1 M de $\mathrm{Na}_{2} \mathrm{SO}_{4}+1 \mathrm{mM}$ de $\mathrm{NaCl}$ 
Tabela 5.9: Valores normatizados dos fittings dos espectros das Figuras 5.54, 5.54 e 5.55 do MB da liga 2024-T3, in natura e soldada com a liga 7475-T651 por FSW, após diferentes tempos de exposição em solução de $0,1 \mathrm{M}$ de $\mathrm{Na}_{2} \mathrm{SO}_{4}+1$ $\mathrm{mM}$ de $\mathrm{NaCl}$

Tabela 5.10: Valores normatizados dos fittings dos espectros das Figuras 5.55, 5.57 e 5.58 do MB da liga 7475-T651, in natura e soldada com a liga 2024-T3 por FSW, após diferentes tempos de exposição em solução de $0,1 \mathrm{M}$ de $\mathrm{Na}_{2} \mathrm{SO}_{4}+1$ $\mathrm{mM}$ de $\mathrm{NaCl}$

Tabela 5.11: Valores normatizados dos fittings dos espectros das Figuras 5.56 do nugget das ligas 2024-T3 e 7475-T651, soldadas por FSW, após diferentes tempos de exposição em solução de $0,1 \mathrm{M}$ de $\mathrm{Na}_{2} \mathrm{SO}_{4}+1 \mathrm{mM}$ de $\mathrm{NaCl}$ 


\title{
LISTA DE ABREVIATURAS
}

\author{
AA Aluminium Association (Associação do Alumínio) \\ AFM Atomic Force Microscope (Microscópio de Força Atômica) \\ DRX Difração de raios-X \\ EDS Energy Dispersive $X$-ray Spectroscopy (Espectroscopia de raios-X por dispersão em \\ energia) \\ EDX Energy Dispersive $X$-ray Spectroscopy (Espectroscopia de raios-X por dispersão em \\ energia) \\ EIS Electrochemical Impedance Spectroscopy (Espectroscopia de Impedância \\ Eletroquímica) \\ FSW Friction Stir Welding (Soldagem por Fricção com Mistura Mecânica) \\ GP Zonas de Guinier-Preston \\ GPB Zonas de Guinier-Preston-Bagaryatsky \\ HAADF High Angle Annular Dark Field (Imagem de Campo Escuro de Alto Ângulo) \\ LEIS Local Electrochemical Impedance Spectroscopy (Espectroscopia de Impedância \\ Eletroquímica Localizada) \\ MB $\quad$ Metal Base (em inglês: BM - Base Metal) \\ OCP Open Circuit Potential (Potencial em Circuito Aberto)
}

SECM Scanning Electrochemical Microscopy (Microscopia Eletroquímica de Varredura)

SEM Scanning Electron Microscopy (Microscópio Eletrônico de Varredura)

SKPFM Scanning Kelvin Probe Force Microscopy (Microscopia de Varredura por Sonda Kelvin)

SRET Scanning Reference Electrode Technique (Técnica de Varredura por Eletrodo de Referência)

STEM Scanning Transmission Electron Microscopy (Microscópio Eletrônio de Varredura por Transmissão)

STM Scanning Tunneling Microscope (Microscópio de Tunelamento com Varredura)

SVET Scanning Vibrating Electrode Technique (Técnica de Varredura do Eletrodo Vibratório) 
TEM Transmission Electron Microscope (Microscopia Eletrônica de Transmissão)

TWI The Welding Institute (Instituto de Soldagem)

WDS Wavelength Dispersive $X$-Ray Spectroscopy (Espectroscopia por Dispersão de Comprimento de Onda)

XPS X-ray Photoelectron Spectroscopy (Espectroscopia de fotoelétrons excitados por raios$\mathrm{X})$

ZM Zona Misturada

ZTA Zona Termicamente Afetada (em inglês: HAZ: Heat Affected Zone)

ZTMA Zona Termomecanicamente Afetada (em inglês: TMAZ: Thermo-Mechanically Affected Zone) 


\section{INTRODUÇÃO}

Há pouco mais de cem anos, o brasileiro Alberto Santos Dumont realizou o primeiro vôo público, sobrevoando alguns metros, com o seu avião '14-bis'. O '14-bis' era composto, em sua grande parte, por varas de bambu e revestimentos de seda japonesa. Até meados da década de 30, pouco antes da Segunda Guerra Mundial, houve uma revolução estrutural na fabricação de aviões, onde o metal tomou o lugar da madeira e se tornou o principal material. Com isso, foi possível uma evolução da aerodinâmica e das resistências mecânica e à corrosão das aeronaves. A partir de então, há uma disputa incessante entre as empresas fabricantes de aeronaves, a fim de produzir a tecnologia mais eficiente e barata (Jakab, 1999).

Basicamente, o avanço da tecnologia da indústria aeronáutica se concentra na pesquisa sobre a redução de peso e a durabilidade das peças utilizadas nas aeronaves, que permite um maior tempo de vida útil, redução da quantidade de reparos e do consumo de combustível, além de diminuir a emissão de gases nocivos à atmosfera (Dursun, 2013).

Há duas maneiras principais para se reduzir o peso das aeronaves. A primeira maneira é a redução da densidade dos materiais utilizados, por exemplo, a substituição de materiais por ligas de alumínio mais leves. A segunda é a utilização de novas técnicas de soldagem, que substituam a utilização de material adicional, como sobreposição de chapas ou rebites. Esses processos alternativos, em substituição ao processo tradicional de rebitagem, têm sido estudados desde o final do século passado. Com o desenvolvimento da soldagem ao lugar de rebites e da utilização de materiais mais leves e resistentes, especialistas da área estimam que a redução do peso total de uma aeronave possa chegar a $15 \%$ (Dittrich, 2011).

O alumínio puro possui dois fatores fundamentais para ser utilizado em aeronaves: massa específica relativamente baixa $\left(2,7 \mathrm{~g} / \mathrm{cm}^{3}\right.$, em comparação com $7,9 \mathrm{~g} / \mathrm{cm}^{3}$ para o aço) e excelente resistência à corrosão em ambientes comuns, incluindo a atmosfera, em virtude de possuir um filme passivo (protetor) muito fino - da ordem de nanômetros e invisível a olho nu - composto por $\mathrm{Al}_{2} \mathrm{O}_{3(s)}$. Entretanto, possui propriedades mecânicas inadequadas para sua utilização. Em razão disso, a indústria metalúrgica tem desenvolvido uma variedade de ligas de alumínio, que são compostas pela adição de diferentes elementos químicos da tabela periódica (os principais elementos de liga incluem o cobre, o magnésio, o silício, o 
manganês e o zinco) ao alumínio puro, a fim de preservar as virtudes do alumínio, aliadas a uma maior resistência mecânica. Contudo, a adição de elementos químicos tende a diminuir a resistência à corrosão do alumínio e, por isso, é necessário uma série de cuidados na fabricação de uma liga, a fim de selecionar um material que possua baixa densidade e elevadas resistências mecânica e à corrosão. (Vargel, 2004, p. 10; Callister, 2006, p. 272).

As composições químicas das ligas são designadas por meio de um número de quatro dígitos, o qual indica as principais impurezas presentes e, em alguns casos, o nível de pureza. O duralumínio foi o precursor das ligas denominadas da série 2xxx, incluindo a liga 2024, que são ligas Al-Cu, com teores de magnésio relativamente altos (aproximadamente 1,5\%) e são empregadas em estruturas internas e externas de aeronaves. O outro grupo de ligas usadas na indústria aeronáutica são as ligas da série $7 x x x(\mathrm{Al}-\mathrm{Zn}-\mathrm{Mg}-\mathrm{Cu})$, que possuem excelentes propriedades mecânicas, e podem ser encontradas tanto em estrutura de asas, como em partes da fuselagem. As ligas que não são tratáveis termicamente, são monofásicas e um aumento na resistência dessas ligas é obtido através do endurecimento por solução sólida. Outras ligas são tornadas termicamente tratáveis (capazes de serem endurecidas por precipitação) como resultado da formação de ligas, caso das ligas das séries 2xxx e 7xxx (Vargel, 2004, p. 10; Callister, 2006, p. 272).

Em várias dessas ligas, o endurecimento por precipitação ocorre devido à precipitação de dois elementos outros para formar um composto intermetálico tais como Al$\mathrm{Cu}-\mathrm{Mg}$ e o MgZn2. Tais compostos intermetálicos, com dimensões entre nanômetros e 30 $\mu \mathrm{m}$, exibem comportamento eletroquímico diferente da matriz, podendo gerar problemas de corrosão localizada (Callister, 2006, p. 272).

As técnicas de soldagem que utilizam processo de fusão não são efetivas para as ligas de alumínio, inclusive para as ligas das séries 2xxx e 7xxx, pois não são formadas soldas isentas de defeitos, causados pela diferença entre os coeficientes de dilatação térmica das regiões solidifcadas e o filme da fase líquida cuja composição se assemelha ao eutético, atribuindo uma série de trincas na fase final da solidificação dos cordões de solda, ou seja, ocorre uma grande diferença de resistência mecânica entre o metal base e a junta soldada (Fioravanti, 2009; Junior, 2003).

Com o intuito de resolver esse problema, o Sr. Wayne Thomas, do TWI (The Welding Institute), Inglaterra, desenvolveu em 1990, e patenteou em 1991, o processo de soldagem por atrito linear com mistura (SALM) ou Friction Stir Welding (FSW). Nesse processo não 
ocorre a fusão do metal base (MB), ou seja, é um processo que ocorre no estado sólido, assim como o processo de soldagem por atrito, o que causa menos distorção, redução das alterações de propriedades mecânicas e metalúrgicas, além das tensões residuais serem minimizadas. Para realizá-lo, uma ferramenta rotativa e não consumível promove calor devido ao atrito com os materiais a serem soldados e, em seguida, atravessa ao longo da junta sob condições apropriadas. Nos primeiros anos após o advento de sua invenção, a técnica era utilizada apenas como curiosidade de laboratório, até que foi verificada a eficácia do processo no uso de ligas de alumínio endurecíveis por precipitação, como as ligas das séries 2xxx e 7xxx, em virtude do processo ser realizado no estado sólido e, portanto, não gerar os problemas causados nos processos de soldagem por fusão, onde são formados poros ou trincas de solidificação associadas à composição química das ligas (Strombeck, 1999; TWI, 2007).

O processo de soldagem por FSW leva à superfície heterogeneidades e gera quatro zonas microestruturais distintas: a zona de mistura (ZM) ou nugget, a zona termomecanicamente afetada (ZTMA), a zona termicamente afetada (ZTA) e o metal base (MB). A presença dessas diferentes microestruturas induz a uma mudança de comportamento no processo corrosivo em relação ao metal base (MB).

Devido à conhecida influência das características microestruturais e tensões residuais no comportamento à corrosão de ligas e metais, diversos trabalhos têm buscado investigar a corrosão de ligas de alumínio soldadas por FSW. A grande maioria dos resultados apresentados na literatura têm apresentado que a região da solda é mais suscetível à corrosão em comparação ao metal base (MB). Além disso, as pesquisas realizadas têm mostrado claramente que as regiões menos resistentes podem ser em razão da qualidade da liga ou dos parâmetros de soldagem (Threadgrill et al., 2009). Por exemplo, Lumdsen et al. (2003) mostraram que a interface entre a ZTA e a ZTMA eram preferencialmente corroídas para a liga AA7050-T651, similarmente ao resultado encontrado por Wadeson et al. (2006), que estudaram a resistência à corrosão de chapas da liga AA7108 soldadas por FSW. Por outro lado, Paglia e Buccheit (2008) verificaram um grande ataque corrosivo entre a interface da ZTMA e do nugget de chapas da liga AA7050-T7451 soldadas por FSW. Em outra investigação, Ju Kang et al. (2010) realizaram ensaios de imersão em chapas da liga AA2024-T3 soldadas por FSW, onde verificaram que a corrosão por pites se iniciava e era mais intensa na região central da solda, diferentemente de Bousquet el al. (2011), que verificaram que a região entre a ZTA e a ZTMA era preferencialmente corroída para a solda 
da mesma liga (AA2024-T3). Por fim, Jariyaboon et al. (2007) verificaram também, para a mesma liga, que a suscetibilidade à corrosão em diferentes regiões era influenciada pelos parâmetros de soldagem.

Apesar de serem mais escassos, alguns grupos também têm investigado a suscetibilidade à corrosão de ligas dissimilares de alumínio soldadas por FSW. Donatus et al. (2015) estudaram a suscetibilidade à corrosão das ligas AA5083 e AA6082 soldadas por FSW. Os autores verificaram que as regiões mais suscetíveis à corrosão foram as respectivas ZTAs, mesmo embora por diferentes mecanismos de corrosão. Também verificaram uma alta suscetibilidade na interface entre as duas ligas, em razão de um forte acoplamento galvânico. Além disso, verificaram que a suscetibilidade à corrosão aumentava conforme se aumentava a velocidade de avanço da ferramenta de soldagem por FSW. Bertoncello et al. (2015) estudaram o comportamento à corrosão das ligas AA7050 e AA2024, soldadas sobrepostas por FSW, usando técnicas eletroquímicas convencionais e SVET em solução de $0,1 \mathrm{M}$ de $\mathrm{NaCl}$, onde encontraram grande suscetibilidade à pites na zona do nugget da liga AA7075 (região anódica) em potenciais de circuito aberto, que foram em razão da maior intensidade do acoplamento galvânico nessa região.

A fim de analisar esses possíveis defeitos causados pelas zonas microestruturais distintas, diversas técnicas eletroquímicas locais têm sido desenvolvidas. Entre as técnicas utilizadas neste trabalho, a microscopia eletroquímica de varredura (SECM) foi utilizada no estudo de transferência cinética de elétrons sobre a superfície do alumínio e suas ligas (Davoodi et al., 2008), como por exemplo no trabalho de Jensen et al. (2008), que avaliou a redução e oxidação de processos sobre a vizinhança de partículas ricas em cobre na liga 2024-T3 e Sidane et al. (2015), que avaliaram o comportamento à corrosão de diferentes zonas formadas durante a soldagem por FSW das ligas dissimilares AA2050-T8 e AA7449T79. A técnica de espectroscopia de impedância eletroquímica local (LEIS) tem mostrado ser extremamente útil para descrever o acoplamento galvânico entre dois domínios adjacentes (Lacroix et al., 2009; Blanc et al., 2010), como na análise da liga modelo de Al$\mathrm{Cu} / \mathrm{Al}-\mathrm{Cu}-\mathrm{Mg}$, num estudo que simulou o comportamento entre as partículas $\mathrm{Al}_{2} \mathrm{CuMg}$ e a matriz de alumínio, nas ligas AA2024 (Lacroix et al., 2012). 


\section{OBJETIVO E JUSTIFICATIVA}

Este trabalho tem como objetivo estudar o comportamento à corrosão localizada das diferentes regiões formadas nas ligas de alumínio 2024-T3 e 7475-T651, após soldagem por fricção (processo FSW), em soluções distintas, numa pouco agressiva contendo íons sulfato com pequeno acréscimo de íons cloretos, que foi escolhida por não ser tão agressiva à camada passiva e em soluções agressivas.

O processo de soldagem por friç̧ão, mesmo não fornecendo altas energias térmicas, quando comparado a outros processos de soldagem, em razão de ser um processo de soldagem do estado sólido, modifica as microestruturas das ligas de alumínio, que possuem compostos intermetálicos para melhorarem suas propriedades mecânicas.

O estudo é baseado em trabalhos descritos na literatura, que visam analisar as interações locais de corrosão das ligas de alumínio, ou seja, o comportamento das interações entre os compostos intermetálicos e as matrizes das ligas, das diferentes microestruturas formadas após o processo de soldagem por FSW e do possível acoplamento galvânico formado quando duas ligas com composições químicas distintas são unidas.

O presente trabalho visa entender o comportamento à corrosão dessas regiões microestruturais, formadas após o processo de soldagem por fricção (FSW). As técnicas eletroquímicas utilizadas neste trabalho buscam esclarecer os possíveis problemas locais, visto que as técnicas eletroquímicas mais utilizadas, como a espectroscopia de impedância (EIS), mostram resultados médios das amostras como um todo, não permitindo analisar dessa maneira os problemas que originam a corrosão. Foram utilizadas, portanto, as seguintes técnicas: espectroscopia de impedância eletroquímica local (LEIS), microscopia eletroquímica de varredura (SECM) e EIS usando célula eletroquímica com abertura de 1 $\mathrm{mm}$ de diâmetro, todas elas aliadas à análise das microestruturas após exposição às soluções, via microscópio eletrônico de varredura (SEM) e análise superficial por espectroscopia de fotoelétrons de raios-X (XPS). 


\section{REVISÃO DA LITERATURA}

\subsection{0 alumínio e suas ligas}

\subsubsection{0 alumínio}

O alumínio é o terceiro metal mais abundante e o segundo metal mais consumido do mundo, logo abaixo do ferro (Davis, 1993). Apesar de ser encontrado em argilas, rochas e em alguns outros minerais, na maioria deles a alta reatividade dificulta sua obtenção. $A$ bauxita (uma rocha contendo vários hidróxidos de alumínio), cujo Brasil possui a terceira maior reserva do mundo, é um minério considerado comercialmente viável, apesar do ponto de fusão elevado e da baixa capacidade de condução elétrica. Para se fabricar o alumínio metálico, utiliza-se a bauxita para a obtenção da alumina anidra pura $\left(\mathrm{Al}_{2} \mathrm{O}_{3}\right)$, via processo Bayer, e esta anidra pura é submetida a uma redução eletrolítica pelo processo Hall-Hércult. Após o alumínio metálico ser fabricado, há diversos processos para a concepção do produto de consumo final: estampagem, extrusão, trefilação, forjamento, laminação, usinagem e soldagem (ABAL, 2007). Ressalta-se que, todos esses processos causam modificações na estrutura e nas propriedades do alumínio.

O alumínio puro é um material leve (sua densidade é um terço da do aço), dúctil, possui boas condutividades elétrica e térmica, e apresenta boa resistência à corrosão sob atmosferas de baixa agressividade (Mendoza e Corvo, 2000), podendo ser utilizado nos mais variados setores, de embalagens à indústria de construção. Essa boa resistência à oxidação é devida a formação de um filme muito fino, de óxido de alumínio $\left(\mathrm{Al}_{2} \mathrm{O}_{3}\right)$, formado em sua superfície quando exposta à ação de agentes oxidantes, como a água ou o ar. Entretanto, o alumínio puro possui baixa resistência mecânica, o que torna inviável a sua utilização em estruturas de qualquer tipo.

\subsubsection{Ligas de alumínio}

Pensando em resolver a limitação da resistência mecânica do alumínio puro, mas se aproveitando de sua baixa densidade, o alemão Alfred Wilm, em 1903, verificou que poderia endurecer a liga de alumínio, sob o fenômeno de endurecimento por precipitação, ao inserir 4\% de cobre a uma liga de alumínio. Em continuação aos seus estudos e experimentos, seis 
anos mais tarde, ao adicionar pequenas quantidades de magnésio e manganês à sua liga inicial, desenvolveu uma liga de alumínio com alta resistência mecânica, denominada 'duralumínio', que é a liga precursora das ligas da série 2xxx (Dwight, 1999).

Daí em diante, os estudos para o desenvolvimento de ligas de alumínio, que obtivessem melhores propriedades mecânicas e mantendo ótimas resistências à corrosão não cessou até o seu ápice, pouco antes da Segunda Guerra Mundial. Em 1939, Alfred Wilm, novamente, apresentou uma liga ainda mais resistente, também da série 2xxx, denominada 'superdural'. Entretanto, os elementos químicos adicionados ao alumínio eram zinco e magnésio. Essa liga foi a precursora das ligas da série 7xxx (Dwight, 1999).

Em linhas gerais, ao adicionar outros elementos químicos (elementos de liga) ao alumínio puro, são formadas as ligas de alumínio, obtendo-se dessa maneira melhores propriedades mecânicas, transformando-o num metal extremamente atrativo para a fabricação de estrutura de aviões e da indústria automotiva, por exemplo, em razão de sua baixa densidade, que implica em economia de energia, efeitos de vibração e eficiência (Callister, 2006). A adição de elementos de liga, porém, pode causar modificações na resistência à corrosão das ligas de alumínio, pois os elementos de segunda fase formados apresentam potenciais de corrosão diferentes à matriz.

As ligas de alumínio são divididas em duas categorias principais, segundo sua utilização: composições para ligas fundidas (fabricadas por processos de fundição) e composições para ligas trabalháveis (processos de fabricação por usinagem). O sistema de identificação das ligas de alumínio foi desenvolvido pela Aluminum Association (AA), e emprega nomenclaturas diferentes para ligas trabalháveis e fundidas, além de simplificar o entendimento, com a divisão das ligas em famílias.

Há duas maneiras para se aumentar a resistência mecânica das ligas: por tratamento térmico ou por deformação à frio (encruamento), conforme as famílias às quais pertencem. As ligas da primeira família, das séries 2xxx, 6xxx, 7xxx e grande parte da série 8xxx, têm as suas resistências mecânicas modificadas após passarem por tratamentos térmicos. As ligas da segunda família, das séries 1xxx, 3xxx, 4xxx e 5xxx, sofrem um ganho de resistência mecânica após passarem por deformação à frio. 
A Figura 3.1 apresenta um esquema da classificação das ligas de alumínio, conforme a norma brasileira ABNT NBR 6834 (Alumínio e suas ligas - Classificação), além das nomenclaturas usadas para tratamentos térmicos.

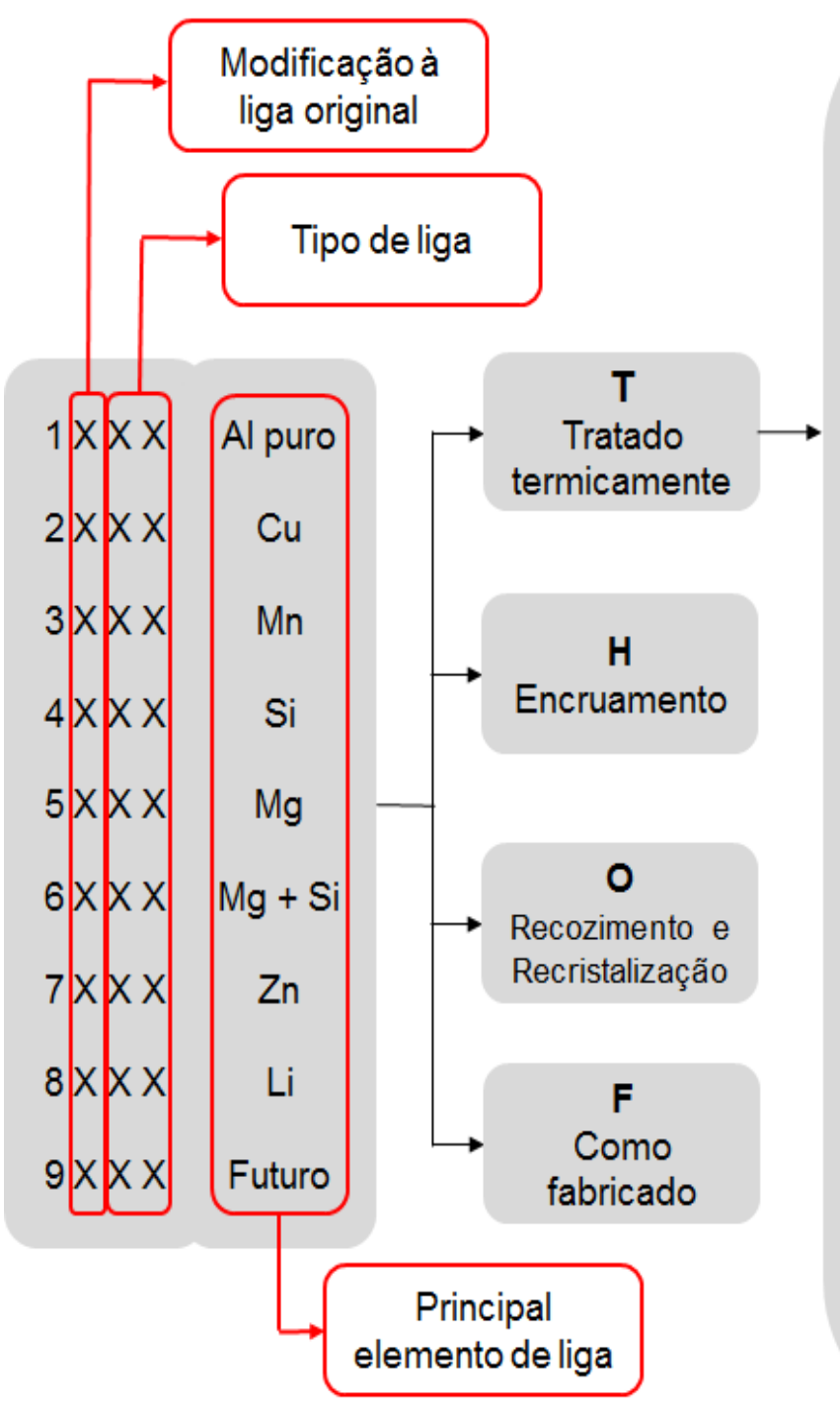

1: Conformadoem alta temperatura e envelhecido naturalmente.

2: Conformadoem alta temperatura, resfriado, deformado a frio e envelhecido naturalmente.

3: Solubilizado, trabalhado a frio e envelhecido naturalmente.

4: Solubilizado e envelhecido naturalmente.

5: Conformadoem alta temperatura $e$ envelhecido artificialmente.

6: Solubilizado e envelhecido artificialmente.

7: Solubilizado e estabilizado.

8: Solubilizado, deformadoa frio e envelhecido artificialmente.

9: Solubilizado, envelhecido artificialmente e trabalhado a frio.

10: Conformadoem alta temperatura, resfriado, trabalhado a frio e envelhecido artificialmente

Figura 3.1: Classificação das ligas de alumínio

Conhecendo as nomenclaturas das classificações e dos tratamentos térmicos, designa-se as ligas de alumínio utilizadas neste trabalho, da seguinte maneira: a liga AA7475-T651, como uma liga cujo elemento de liga principal é o zinco e que foi solubilizada, submetida a alívio de tensão por estiramento e superenvelhecida; a liga AA2024-T3, possui como principal elemento de liga o cobre e foi solubilizada, trabalhada à frio e envelhecida naturalmente. Ressalta-se que, daqui em diante, a nomenclatura AA não será utilizada, de maneira a simplificar a leitura. 


\subsubsection{Microestrutura e endurecimento estrutural das ligas de alumínio}

A metalurgia física das ligas de alumínio se preocupa com os trabalhos mecânicos, tratamentos térmicos e os efeitos de composição, que contribuem com a mudança da resistência mecânica do material. O endurecimento por precipitação é comum em ligas de alumínio de alta resistência. Esse aumento de resistência mecânica é obtido por um tratamento que se divide de acordo com as seguintes etapas (Callister, 2006):

- Primeira etapa (ver posição 2 da Figura 3.2-b): uma liga hipotética $\mathrm{C}_{0}$ é colocada a uma temperatura superior à temperatura $\left(\mathrm{T}_{0}\right)$ da linha solvus $M N$ (ver Figura 3.2-a), dentro do campo de fase a e aguarda um tempo suficiente para alcançar o equilíbrio termodinâmico, no qual todos os átomos de soluto (B) são dissolvidos para formar uma solução sólida monofásica, em equilíbrio. A temperatura To para ao alumínio é colocada, geralmente, entre $400 \stackrel{\circ}{\mathrm{C}}$ e 550 $\stackrel{\circ}{ } \mathrm{C}$.

- Segunda etapa (ver posição 3 da Figura 3.2-b): tratamento térmico de têmpera (resfriamento rápido da liga) até a temperatura $T_{1}$, localizada dentro da região bifásica $(\alpha+\beta)$, onde as taxas de difusão tornam-se consideráveis e há um impedimento da decomposição da solução sólida com a formação de precipitados de equilíbrio grosseiros. Dessa maneira, é obtida uma solução sólida supersaturada (denominadas de substituição) em átomos de soluto (B), que são posicionados de maneira aleatória às redes de corpo cúbico de face centrada (CFC) do alumínio.

- Terceira etapa [a] (ver posição 4-a da Figura 3.2-b): maturação ou envelhecimento natural, que é a manutenção, após a têmpera, à temperatura ambiente ou inferior. Esta etapa permite uma decomposição lenta da solução sólida supersaturada e a formação de pequenos aglomerados de solutos, denominadas zonas de Guinier-Preston ou zonas GP. A etapa de precipitação pode ser acompanhada por um endurecimento (ou tração controlada) de 1\% a $2 \%$ de deformação do material, de maneira a relaxar as restrições e a aumentar a densidade de lacunas por deformação plástica e então aumentar a densidade de sítios de germinação de precipitados endurecíveis. 
- Terceira etapa [b] (ver posição 4-b da Figura 3.2-b): revenimento ou envelhecimento artificial, onde eleva-se novamente a temperatura $\left(T_{2}\right)$, após a têmpera, acima de $\mathrm{T}_{1}$ e abaixo da linha solvus, conhecida como temperatura de revenimento, onde é possível observar um endurecimento da liga. A dureza obtida é função do tempo e da temperatura de manutenção.
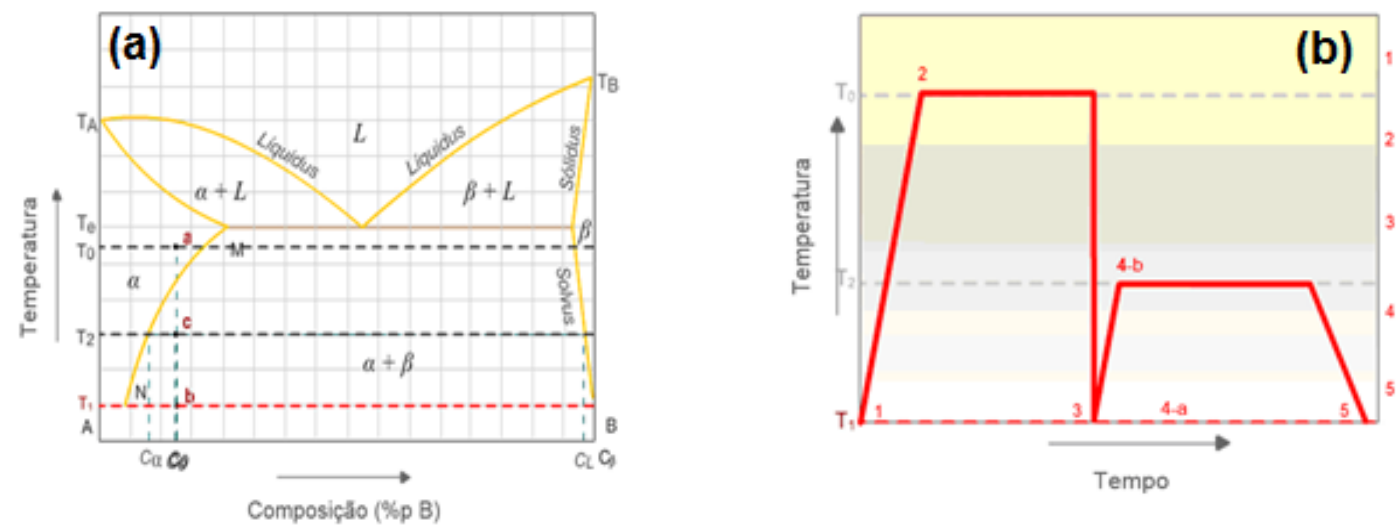

Figura 3.2: Diagrama de fases hipotético de uma liga endurecível por precipitação

Na prática, o controle da precipitação possibilita triplicar a resistência mecânica útil das ligas de alumínio (Callister, 2006). Os tratamentos termomecânicos conduzem a uma microestrutura complexa composta de uma grande quantidade de compostos intermetálicos, os quais são classificados em três categorias (Dubost e Stainfort, 1991):

- Precipitados endurecedores: possuem dimensões entre nanômetro a centenas de nanômetros. São formados durante a têmpera ou de maneira controlada durante o revenimento. Eles se constituem de aglomerados de átomos ou de fases metaestáveis resultantes da sua precipitação. Os mecanismos de endurecimento estrutural são complexos, mas é possível verificar que suas partículas façam o papel de freio no movimento de discordâncias, em parte, responsável pela deformação plástica.

- Dispersóides (precipitados muito finos): possuem dimensões que variam entre vinte e algumas centenas de nanômetros e se formam por precipitação no estado sólido. Esses precipitados não podem ser dissolvidos após sua formação, não são coerentes com a matriz e não participam diretamente do endurecimento estrutural.

- Partículas intermetálicas (ou partículas grosseiras): suas dimensões superam a ordem de micrômetros. Essas partículas atingem dimensões da ordem de 
cerca de vinte micrômetros e, por isso, não participam do endurecimento da liga. No entanto, elas desempenham um papel importante na suscetibilidade à corrosão localizada. Elas são produzidas de fases ordenadas (composições definidas: $\mathrm{Al}_{2} \mathrm{Cu}, \mathrm{Al}_{2} \mathrm{CuMg}, \mathrm{Al}_{2} \mathrm{CuLi}$ para as ligas da série 2xxx ou de $\mathrm{MgZn} 2$ para as ligas da série $7 \times x x$ ) ou de partículas resultantes de uma decomposição eutetóide (AICu, AIMn, AIFe e outras) e, portanto, na composição em geral não homogênea.

Ressalta-se que a avaliação da microestrutura das ligas de alumínio é uma ferramenta muito útil para a compreensão dos mecanismos de corrosão, em razão das fases segregadas da solução sólida da matriz, que geralmente apresentam potenciais diferentes da matriz e estão intimamente ligadas ao processo de corrosão localizada, pois são responsáveis pela sua iniciação até mesmo em meios considerados não agressivos.

As ligas utilizadas neste trabalho, das séries 2xxx e 7xxx, consideradas de elevada resistência mecânica, possuem microestruturas complexas, devido a necessidade da realização de tratamentos térmicos e mecânicos utilizados para aumentarem suas resistências mecânicas, que provocam a precipitação de diferentes compostos intermetálicos grosseiros que se alojam na microestrutura da matriz. Entretanto, estas partículas intermetálicas não exercem efeito primário na determinação do potencial de corrosão, pois a matriz é rica em alumínio (solução sólida) e constitui a maior quantidade de área e volume na microestrutura, e que domina, portanto, os potenciais medidos (Davis, 1999, p. 27).

A quantidade de compostos intermetálicos presentes nas ligas, bem como sua distribuição, varia para cada uma delas, o que permite explicar os diferentes desempenhos de resistência à corrosão de ligas diferentes. A densidade de compostos intermetálicos de uma liga da série $2 x x x$, por exemplo, pode ser algumas vezes maior do que as de uma liga da série 7xxx (Wei, Liao e Gao, 1998).

\subsubsection{Ligas da série $2 x x x$}

O cobre (com teores entre 3,8\% e 4,9\%) e o magnésio (teores entre 1,2\% e 1,8\%) são os principais elementos de liga da série 2xxx. O papel principal da adição de elementos de liga, principalmente o cobre, é o aumento da resistência mecânica, pois após passar pelo 
processo de envelhecimento controlado, ocorre a formação de pequenos precipitados endurecedores finamente dispersos e coerentes com a matriz, que interferem no movimento das discordâncias (Buchheit, 1997; Barbucci, 2000; Blanc, 1997; Campestrini, 2002). Ressalta-se que, apesar da influência positiva dos compostos intermetálicos na resistência mecânica, eles são diretamente responsáveis pela redução na resistência à corrosão destas ligas (Dursun, 2014).

Durante a nucleação heterogênea, as regiões que apresentam desordem atômica são preferenciais para a formação de precipitados, como os contornos de grãos, as discordâncias, as inclusões, entre outros. Em razão de sua excelente resistência mecânica e baixa densidade, a liga 2024, que faz parte da subfamília de Al-Cu-Mg da série 2xxx, com teores de magnésio relativamente altos $(1,5 \%)$, elemento este utilizado para aumentar o envelhecimento natural e a resistência à tração, é muito utilizada pela indústria aeronáutica para a fabricação de portas, fuselagem e componentes da asa e do leme (Guillaumin, 1999). Em virtude desse alto teor de magnésio, ao invés de possuir apenas contribuições para o endurecimento por precipitação das fases precursoras, $\Theta^{\prime}$ e $\theta^{\prime \prime}$, e da fase $\Theta\left(\mathrm{Al}_{2} \mathrm{Cu}\right)$, esta liga também tem contribuição da fase $S^{\prime}$, precursora da fase $S\left(\mathrm{Al}_{2} \mathrm{CuMg}\right)$.

A Figura 3.3 apresenta o diagrama de fase Al-Cu com as fases GP (Guinier-Preston), Ө" e $\Theta^{\prime}$ metaestáveis e a fase de equilíbrio $\Theta$ (Russel e Aaronson, 1978).

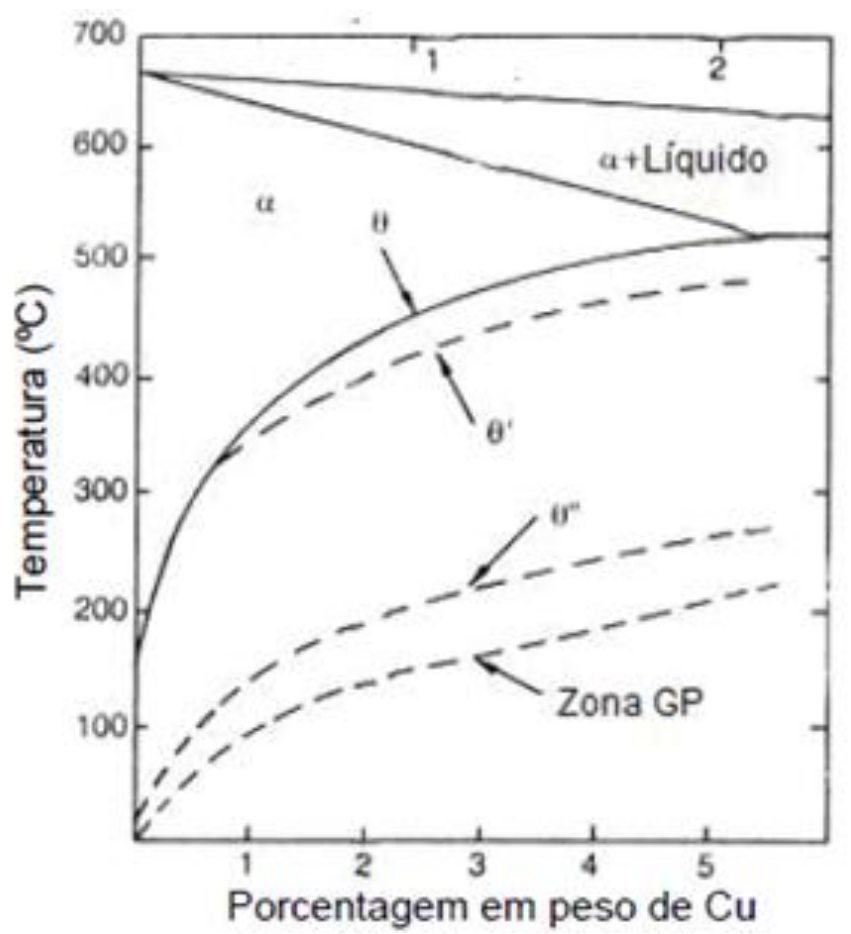

Figura 3.3: Diagrama de fase Al-Cu, mostrando as zonas GP metaestáveis, $\Theta^{\prime \prime}$ e $\Theta^{\prime}$ (Russel e Aaronson, 1978). 
Observa-se pela Figura 3.3 que, a zona GP é formada em menor temperatura (190 ${ }^{\circ} \mathrm{C}$ ), e a linha tracejada indica ser uma fase metaestável. As fases $\theta^{\prime \prime}$ e $\Theta$ ' também são metaestáveis e indicadas por linhas tracejadas. Com o aumento da temperatura ou tempos longos de tratamentos térmicos, estas se transformam em compostos de equilíbrio termodinâmico $(\Theta)$, ou seja, linha sólida.

O tratamento térmico, T3, que a liga estudada neste trabalho é submetida, consiste em solubilizá-la em aproximadamente $500^{\circ} \mathrm{C}$, seguido de uma têmpera até a temperatura ambiente, a fim de se obter uma solução supersaturada de cobre em alumínio e posterior trabalho à frio. Em seguida, realiza-se um envelhecimento artificial a $190 \stackrel{\circ}{ } \mathrm{C}$, onde iniciamse as precipitações de fases, que podem ser divididas de duas maneiras para a liga 2024T3. A primeira sequência de precipitação é mostrada abaixo, e representa as fases formadas sem a incorporação do magnésio.

$$
\text { i. } \quad \mathrm{SSS} \rightarrow \text { zonas } \mathrm{GP} \rightarrow \Theta^{\prime \prime}\left(\mathrm{Al}_{3} \mathrm{Cu}\right) \rightarrow \Theta^{\prime}\left(\mathrm{Al}_{2} \mathrm{Cu}\right) \rightarrow \theta^{\left(\mathrm{Al}_{2} \mathrm{Cu}\right)} \text {; }
$$

Onde, SSS significa solução sólida supersaturada e GP significa zonas de GuinierPreston. Nos tempos iniciais do envelhecimento artificial, para temperaturas moderadamente elevadas, ocorre a redistribuição de átomos de soluto dentro da solução sólida, onde são formadas as zonas GP ou clusters, ricas em soluto. O efeito de endurecimento deve-se a uma maior necessidade de tensão para movimentar as linhas de discordâncias nas zonas GP. Ao aumentar a temperatura de envelhecimento, as zonas GP se convertem ou se substituem por partículas com estruturas cristalinas diferentes à solução sólida, partículas estas que são chamadas de precipitados de transição ou metaestáveis ( $\theta^{\prime \prime}$ e $\left.\theta^{\prime}\right)$. Estes precipitados, então, ao serem endurecidos provocam deformações na rede, que impedem o movimento das discordâncias, aumentando a dureza da liga (Hatch, 1983).

A segunda sequência de precipitação da liga 2024-T3, se refere às precipitações formadas pela interferência do Mg:

$$
\text { ii. } \quad \text { SSS } \rightarrow \text { zonas GPB } \rightarrow \mathrm{S}^{\prime \prime} \rightarrow \mathrm{S}^{\prime} \rightarrow \mathrm{S}\left(\mathrm{Al}_{2} \mathrm{CuMg}\right)
$$

Onde, GPB significa zonas de Guinier-Preston-Bagariastkij.

As fases S" e S' apresentam a mesma estrutura da fase S e o que as diferenciam são pequenas distorções e diferentes parâmetros de rede, além de apresentarem uma morfologia de agulhas paralelas, diferentemente das fases $\theta^{\prime \prime}$ e $\Theta$ ', que se apresentam como plaquetas (Schneider e Nunes, 2003; Song e Kovacevic, 2003). Destaca-se que, esta 
segunda sequência de precipitação (da fase S) ainda é controversa, pois alguns autores concordam que ela possa ser dividida em outras duas (Shih, 1996; Zahra, 2002), em razão da fase S" poder ser formada de maneira heterogênea sobre as discordâncias, gerando um novo mecanismo de deformação, que favorece o estágio inicial de endurecimento por precipitação. As zonas GPB (clusters de de Cu/Mg), apesar de se apresentarem também no estágio inicial, apresentam menor contribuição do que os precipitados da fase $S$ ", além de não apresentarem nenhuma ligação entre si durante a sua formação no início do envelhecimento, e por esse motivo a sequência de precipitação pode ser didivida em outras duas partes. As zonas GPB ou clusters se formam uniformemente na matriz do alumínio, enquanto a fase S" se forma de maneira heterogênea sobre as discordâncias e que, mais tarde, se transformam em fase S'. Em síntese, a segunda sequência de precipitação é dividida nas duas sequências, mostradas abaixo:

iii. $\quad$ SSS $\rightarrow$ clusters ricos em $\mathrm{Cu} \rightarrow$ GPB $\rightarrow$ GPBII ou S";

iv. $\quad$ SSS $\rightarrow$ clusters ricos em $\mathrm{Mg} \rightarrow \mathrm{S}^{\prime} \rightarrow \mathrm{S}$.

Sabe-se que, a liga 2024-T3 endurece à temperatura ambiente (naturalmente), após tratamento térmico, e como consequência é endurecida por zonas GPB, que se formam em temperaturas próximas à $80^{\circ} \mathrm{C}$ e se dissolvem à $200^{\circ} \mathrm{C}$ e, cuja estrutura geralmente se compõe de arranjamentos de Cu e Mg.

Como as zonas GPB não são observadas por TEM convencional, Jena et al. (1989) realizaram um estudo complementar usando DSC (Differential Scanning Calorimetry) no estudo da liga Al-1,53\%Cu-0,79\%Mg. Apareceram então 5 picos no diagrama DSC (ver Figura 3.4), onde o pico A representa a formação das zonas GPB e o pico B, sua dissolução. O pico C apresenta diferentes linhas de raciocínio, pois para alguns autores (Bagaryatskii, 1952; Ratchev, 1998) ele seria referente à uma dissolução da fase metaestável S", enquanto outros autores (Silcock, 1960; Jena, 1989; Ringer, 1998) se referem à dissolução das zonas GPBII. O pico D se refere à formação da fase $S^{\prime}(S)$ e o pico $E$ à sua dissolução. Em nosso estudo, tomamos como referência o trabalho de Genevois et al. (2006), que consideraram os pontos B e C como uma só fase, de zonas GPB. 


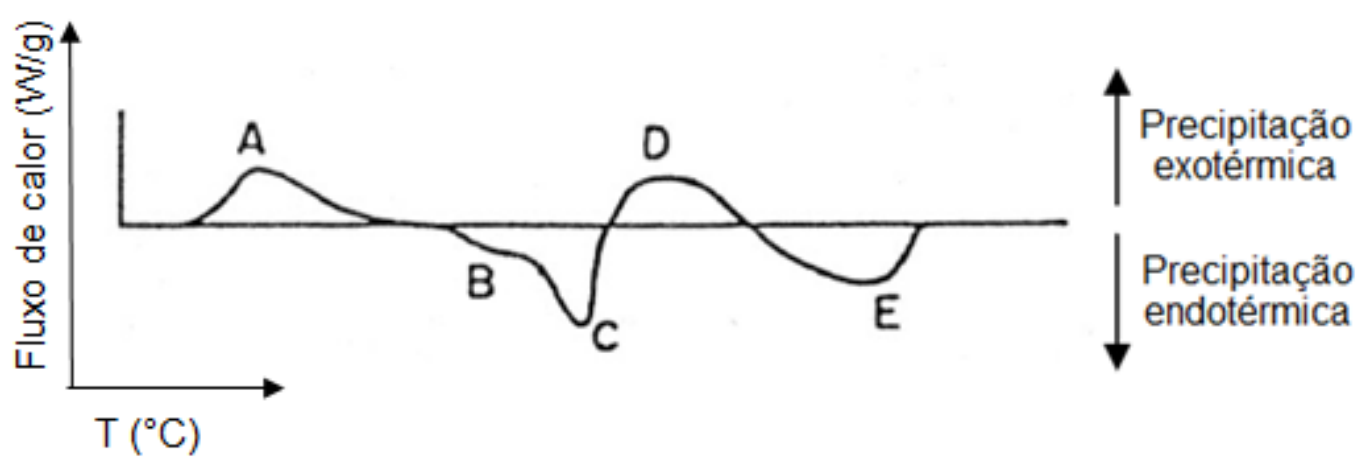

Figura 3.4: Diagrama DSC de uma liga $\mathrm{Al}-1,53 \% \mathrm{Cu}-0,79 \% \mathrm{Mg}$. Representação dos picos: (A) formação das zonas GPB; (B) dissolução das zonas GPB; (C) dissolução das zonas GPBIl ou S"; (D) formação da fase $S^{\prime}(S)$ e; (E) dissolução da fase $S^{\prime}(S)$ (adaptado de Jena, 1989).

Além dos precipitados endurecedores, a liga 2024 também contém uma certa quantidade de partículas intermetálicas grosseiras, bem maiores do que os precipitados endurecedores, que não interferem no processo de endurecimento da liga, mas interferem significamente na corrosão localizada. A liga 2024 ainda possui uma composição complexa devido à adição de diversos elementos de liga e à presença de impurezas (Buchheit et al., 1997), que podem atingir uma densidade média de 323.000 partículas por $\mathrm{cm}^{2}$ (Chen et al., 1996). Em um dos trabalhos pioneiros para a caracterização da microestrutura da liga 2024T3, foram identificados quatro tipos de compostos intermetálicos diferentes, todos com diâmetros superiores a 0,2 $\mu \mathrm{m}$. Entretanto, mesmo tendo utilizado equipamentos com alto poder de resolução, os quais foram EDS, WDS (microssonda eletrônica), difração de raios$X(D R X)$ e considerações termodinâmicas, não foi possível identificar aproximadamente 17\% das partículas do material investigado (Buchheit et al., 1997). Além disso, em trabalho ulterior a este, o mesmo grupo de pesquisadores verificou a existência de compostos intermetálicos com estequiometrias diferentes das anteriormente propostas (Buchheit et al., 2001). A identificação da estequiometria de compostos intermetálicos com pequenas dimensões é complicada, pois ocorre a excitação de raios-X característicos da matriz (Buchheit et al., 1997). Também deve ser levado em conta, em relação à composição e distribuição dos compostos intermetálicos na liga, a origem das amostras que influencia no tamanho dos compostos intermetálicos (Buchheit et al., 1997; Liao et al., 1998).

Apresar de toda a complexidade das microestruturas e dos compostos intermetálicos da liga 2024-T3, na grande maioria dos trabalhos revisados, esses compostos intermetálicos podem ser divididos em três grandes grupos (Buchheit et al., 1997; Campestrini, 2002):

- $\mathrm{Al}-\mathrm{Cu}($ fase $\theta)$ - com estequiometria $\mathrm{Al}_{2} \mathrm{Cu}$; 
- Al-Cu-Fe-Mn-(Si);

- Al-Cu-Mg (fase S - $\left.\mathrm{Al}_{2} \mathrm{CuMg}\right)$.

A fase $\mathrm{S}\left(\mathrm{Al}_{2} \mathrm{CuMg}\right)$ é o tipo de composto intermetálico predominante na liga 2024-T3, ou seja, corresponde a aproximadamente $61 \%$ dos intermetálicos com mais de 0,2 $\mu \mathrm{m}$ de diâmetro (Shao et al., 2003). A razão disso, segundo Buchheit et al. (2001), é que os os compostos intermetálicos de fase $\mathrm{S}\left(\mathrm{Al}_{2} \mathrm{CuMg}\right)$, que possuem diâmetros entre 0,2 $\mu \mathrm{m}$ e $5 \mu \mathrm{m}$, são formados durante o processo de solidificação e não são dissolvidos pelos procedimentos de tratamentos térmicos posteriores. Entretanto, estes compostos não devem ser confundidos com as partículas dispersóides e com os precipitados endurecedores, que apresentam composições semelhantes, mas são formados durante o processo de envelhecimento natural ou artificial. Em relação aos compostos intermetálicos nanométricos, foram encontradas as seguintes fases: dispersóides $\mathrm{Al}_{20} \mathrm{Cu}_{2} \mathrm{Mn}_{3}$, que se apresentam em forma de bastonetes, com dimensões de aproximadamente $20 \mathrm{~nm}$; os precipitados endurecedores intragranulares de fase $S\left(\mathrm{Al}_{2} \mathrm{CuMg}\right)$, sob a forma de agulhas, com dimensões entre 8 e 30 nm, e as zonas GPB, sob a forma de plaquetas, com dimensões de aproximadamente 0,2 $\mathrm{nm}$ (muito difíceis de serem visualizadas, até mesmo por microscopia eletrônica de transmissão); além dos precipitados intergranulares de fase $\mathrm{S}\left(\mathrm{Al}_{2} \mathrm{CuMg}\right)$, sob a forma de ripas e dimensões entre 100 e 400 nm (Guillaumin e Mankowski, 1999; Zhang e Frankel, 2003; Genevois, 2004). A Figura 3.5 apresenta algumas imagens, obtidas por microscopia eletrônica de transmissão, mostrando as fases presentes na liga 2024-T3.
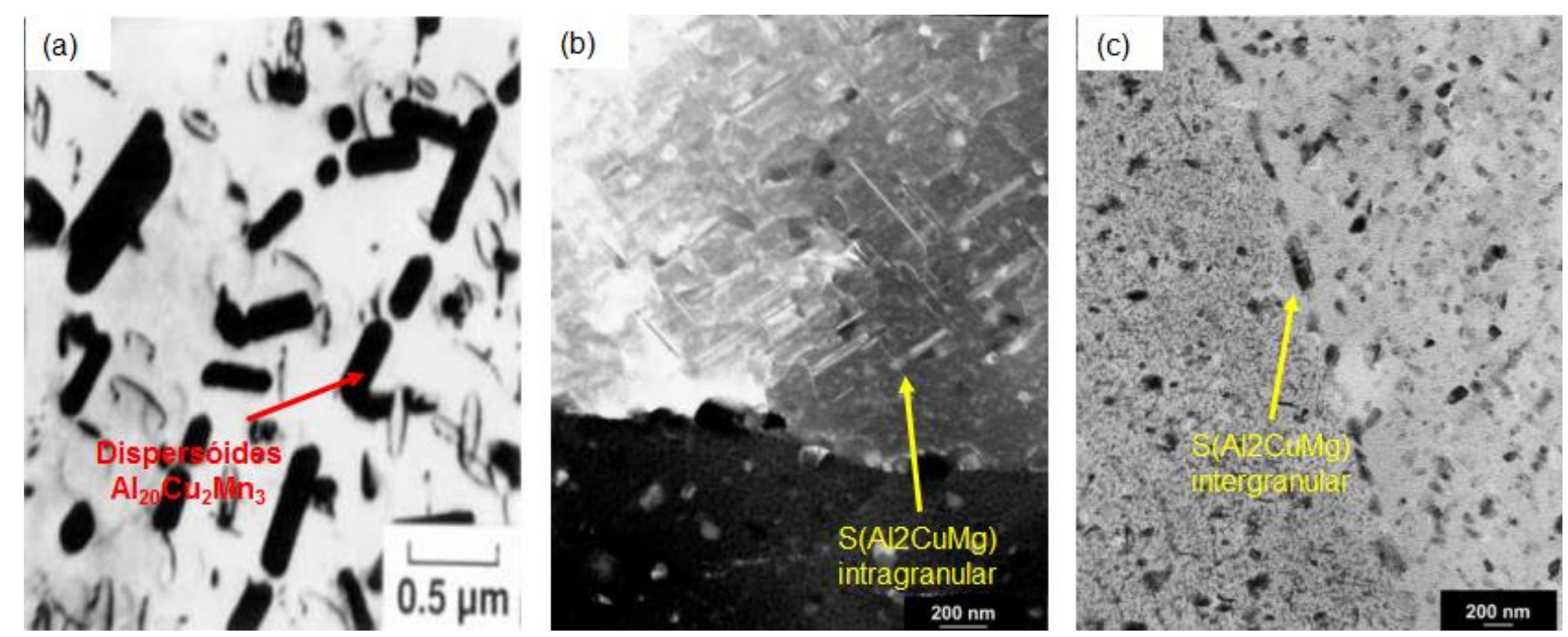

Figura 3.5: Apresentação dos tipos de dispersóides e precipitados endurecedores encontrados na liga 2024-T3: (a) dispersóides $\mathrm{Al}_{20} \mathrm{Cu}_{2} \mathrm{Mn}_{3}$ (Totten e MacKenzie, 2003); (b) precipitado intragranular $\mathrm{S}\left(\mathrm{Al}_{2} \mathrm{CuMg}\right)$ e; (c) precipitado intergranular $\mathrm{S}\left(\mathrm{Al}_{2} \mathrm{CuMg}\right)$ (Zhang e Frankel, 2003). 
As partículas intermetálicas de $\mathrm{Al}-\mathrm{Cu}-\mathrm{Mg}$ possuem formas arredondadas e são, geralmente, menores do que as partículas intermetálicas de Al-Fe-Mn-Cu (Blanc et al., 1997). Os compostos intermetálicos de Al-Fe-Mn-Cu possuem composição bastante complexa e podem, ou não, possuir Si em sua composição, além do Fe e Mn poderem estar ausentes em alguns casos (Buchheit, 1997; Obispo, 2000; Buchheit, 2001). Essas diferenças de composição são responsáveis pelo comportamento eletroquímico complexo, exibido por essas partículas intermetálicas quando expostos a meio corrosivos. Um exemplo disso é a presença de Si nas partículas intermetálicas Al-Cu-Fe-Mn, que pode torná-los anódicos em relação à matriz, em virtude do baixo potencial destes elementos, que é bem inferior ao potencial do Mn (Obispo et al., 2000).

Como a liga 2024 é endurecida por precipitação, naturalmente se torna difícil soldála por processos convencionais, devido à formação de trincas a quente e perda de resistência mecânica no cordão de solda (Matrukanitz, 1990), por isso a melhor opção é a soldagem dessas ligas por FSW.

\subsubsection{Ligas da série $7 x x x$}

As ligas da série $7 \mathrm{xxx}$ detêm os níveis mais altos de resistência mecânica entre todas as famílias das ligas de alumínio, e por este motivo, destacam-se na indústria aeronáutica, principalmente na fabricação da parte superior da asa, longarinas e estabilizadores (horizontais e verticais). Apresentam uma menor temperatura de solubilização (480 ${ }^{\circ} \mathrm{C}$ ), e para algumas ligas desta família pode haver completa dissolução das fases ricas em zinco (Hatch, 1990).

O zinco é o principal elemento de liga na série $7 x x x$, com teores que variam de $0,8 \%$ a $8,2 \%$. Trata-se de um elemento químico altamente solúvel no alumínio e não exerce influência significativa em suas microestruturas (Davis, 1993, p. 494). Entretanto, apenas a adição de zinco ao alumínio não melhora significativamente as propriedades mecânicas da liga de alumínio e, portanto, as ligas binárias Al-Zn não apresentam nenhum interesse da indústria aeronáutica. Além do zinco, outros dois elementos químicos possuem quantidades consideráveis nas ligas da série 7xxx: o magnésio, com teores entre $0,1 \%$ e 3,7\%; e o cobre, com teores entre $0,05 \%$ e 2,6\% (Davis, 1999, p. 24). Com a adição destes elementos, as ligas da série 7xxx passam a ser muito interessantes pela indústria aeronáutica, por suas 
altas propriedades mecânicas, em razão do magnésio aumentar a sensibilidade ao revenimento, favorecendo a difusão de precipitados endurecedores. Entretanto, estas ligas apresentam baixa resistência à corrosão sob tensão e, em razão disso, são muitas vezes superenvelhecidas para obter melhor combinação de força, resistência à corrosão e à fratura (Hatch, 1990). A razão para a baixa resistência à corrosão é a alta quantidade de zinco, que torna estas ligas mais anódicas em relação ao alumínio comercialmente puro, pois de acordo com a série galvânica, o zinco é mais anódico do que o alumínio (Davis, 1999, p. 35).

A seguir, serão citados trabalhos da liga 7075, referentes à série 7xxx, em razão da liga 7475, objeto deste estudo, não possuir muito trabalhos na literatura sobre sua microestrutura. Ressalta-se que, a liga 7475 é uma evolução da liga 7075 , e foi elaborada para reduzir os teores de impurezas e assim, aumentar a sua tenacidade.

Na maior parte das ligas comerciais da série 7xxx, a sequência de decomposição da solução sólida é apresentada da seguinte maneira:

$$
\text { i. } \quad \mathrm{SSS} \rightarrow \text { zonas GP } \rightarrow \eta^{\prime}\left(\mathrm{MgZn}_{2}\right) \rightarrow \eta\left(\mathrm{MgZn}_{2}\right)
$$

A composição das fases $\eta$ ' e $\eta$ é dependente do tratamento térmico e da composição da liga. A fase $\eta$ 'é semi-coerente com a matriz, tem uma estrutura hexagonal, se transforma em fase $\eta$ após um certo raio crítico (Park e Ardell, 1984), se apresenta sob a forma de pequenas plaquetas paralelas ao plano [111], e é a principal fase endurecedora (Werenskiold et al., 2000). A fase $\eta$ é a fase de equilíbrio da liga, sendo incoerente com a matriz e tem uma estrutura hexagonal parecida àquela da fase de equilíbrio MgZn2 (Dubost e Stainfort, 1991). Ela se apresenta sob diversas formas: precipitados endurecedores intergranulares e intragranulares e como dispersóides, e sua formação é responsável por um amolecimento do material (Deschamps, 1997).

MacAskill et al. (2009) usaram a técnica de DSC (Differential Scanning Calorimetry) no estudo da liga 7075-T6. Apareceram então 4 picos no diagrama DSC (ver Figura 3.6), onde o pico A representa a dissolução das zonas GP, o pico B a formação combinada das fases $\eta$ ' e $\eta$, o pico $\mathrm{C}$ o crescimento da fase $\eta$ e o pico $\mathrm{D}$ a dissolução das fases $\eta$ ' e $\eta$. 


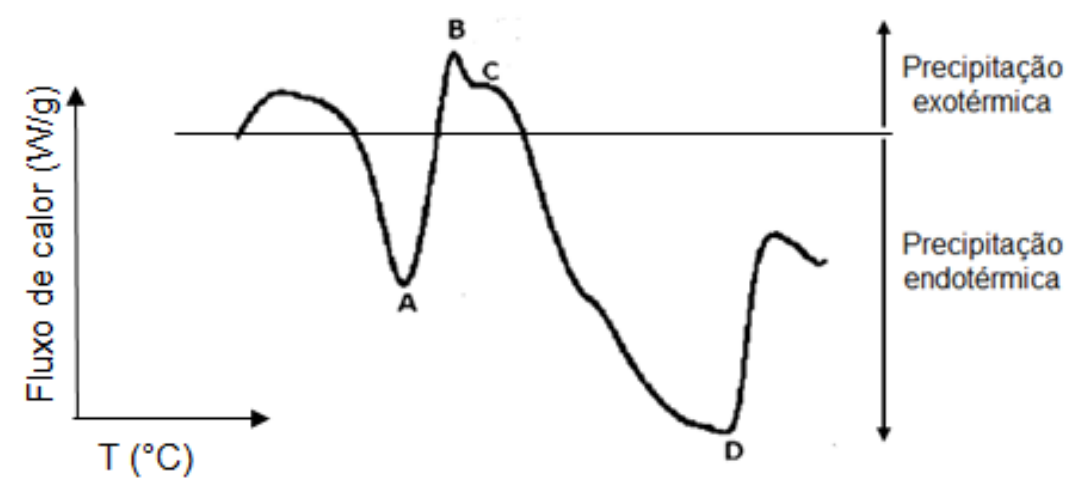

Figura 3.6: Diagrama DSC de uma liga 7075-T6 adaptado do trabalho de MacAskill et al. (2009).

A liga 7475 pertence às ligas da família $\mathrm{Al}-\mathrm{Zn}-\mathrm{Mn}-\mathrm{Cu}$, as quais possuem compostos intermetálicos que variam suas dimensões de nanômetros (fase $\eta$ : $M g Z n_{2}$ ) a micrômetros $\left(\mathrm{Al}_{7} \mathrm{Cu}_{2} \mathrm{Fe}\right.$ ) (Davis, 1993 p. 494). As partículas $\mathrm{Al}_{7} \mathrm{Cu}_{2} \mathrm{Fe}$, que possuem formatos irregulares, são as maiores da família Al-Zn-Mn-Cu das ligas da série 7xxx, com dimensões que atingem até $10 \mu \mathrm{m}$ e podem representar até $65 \%$ de todos os compostos intermetálicos das ligas desta família, como para a liga 7075, por exemplo (Wloka e Virtanen, 2007). Em análise realizada por SEM-EDS, De Witt (2004) encontrou outros três compostos intermetálicos de dimensões micrométricas, entre $1 \mu \mathrm{m}$ e $10 \mu \mathrm{m}$, os quais foram: (Al,Cu)6(Fe,Cu,Mn), Mg2Si e (Al,Cu,Fe,Mn,Si), sendo que para a liga 7075, por exemplo, os intermetálicos mais abundantes são os que contêm $\mathrm{Cu}$ e $\mathrm{Fe}$, e que os compostos intermetálicos de $(\mathrm{Al}, \mathrm{Cu}, \mathrm{Fe}, \mathrm{Mn}, \mathrm{Si})$ são ausentes. Em relação aos compostos intermetálicos nanométricos, Aval (2015) encontrou as seguintes fases: $\mathrm{Al}_{3} \mathrm{Zr}$, que se apresentam em forma esférica, com dimensões de aproximadamente $50 \mathrm{~nm}$; os precipitados endurecedores intragranulares de fase $\eta^{\prime} / \eta\left(\mathrm{MgZn}_{2}\right)$, com dimensões entre 5 e $75 \mathrm{~nm}$, e também as zonas GPB, sob a forma de plaquetas, com dimensões entre 5 e 20 nm; além dos precipitados intergranulares $\eta / \eta$ (MgZn2), sob a forma de bastonetes e dimensões entre 10 e $30 \mathrm{~nm}$ (Li, 2009).

Aval (2015), conforme mostra a Figura 3.7, realizou um estudo sobre a formação de fases de precipitados endurecedores da liga 7075-T6, após o processo de soldagem por FSW, onde constatou a presença de diferentes fases nas diferentes zonas formadas, como por exemplo: no MB, a formação de zonas GP, em dimensões muito pequenas, menores do que $5 \mathrm{~nm}$, e precipitados intragranulares de fase $\eta$ ', com dimensões maiores do que $10 \mathrm{~nm}$ e sob formas arredondadas. Na ZTA, a formação de precipitados de fase $\eta$, sob formas arredondadas. Na ZTMA, a formação de pequenos precipitados de fase $\eta$, em forma de agulhas, e precipitados de fase $\eta^{\prime}$, sob formas arredondadas. Em outro estudo, sobre a formação de fases da liga 7075-T6, Ranganath et al. (2013) mostraram a formação de uma 
zona livre de precipitados, nos contornos de grãos, com a formação de precipitados intergranulares de fase $\eta^{\prime} / \eta\left(M^{\prime} Z_{2}\right)$.
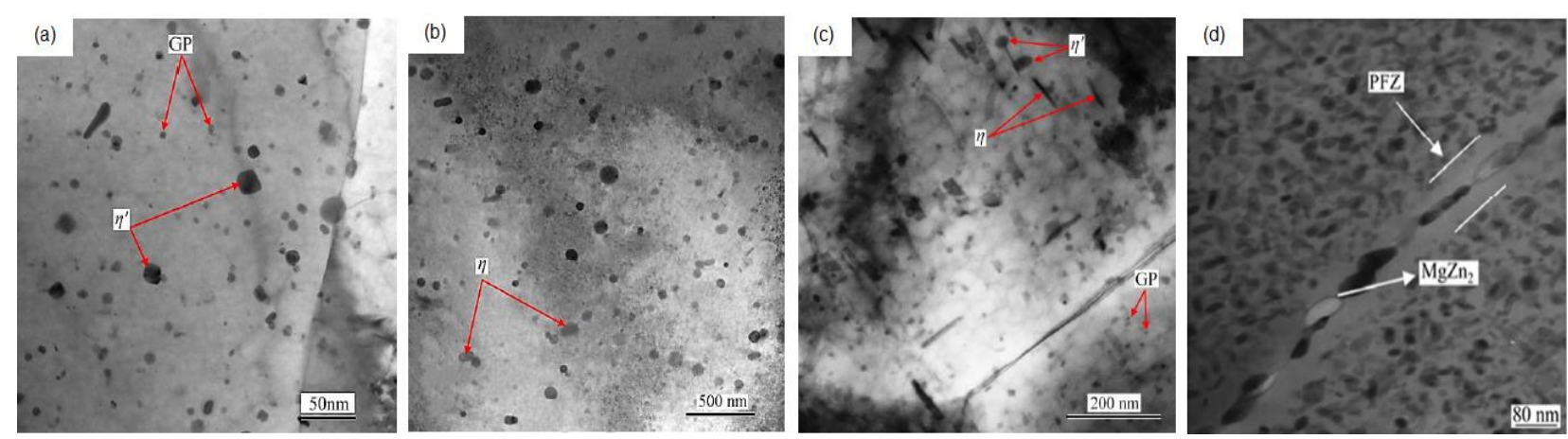

Figura 3.7: Apresentação dos tipos de precipitados endurecedores encontrados na liga 7075-T6: (a) zonas GP e precipitados intragranulares de fase $\eta^{\prime}$; (b) precipitado intragranular $\eta$; (c) precipitados intragranulares de fases $\eta$ e $\eta^{\prime}\left(\mathrm{MgZn}_{2}\right)($ Aval, 2015) e; (d) precipitados intergranulares e PFZ (zona livre de precipitados) (Ranganath et al., 2013).

Assim como para as ligas da série 2xxx, as ligas da série $7 x x x$ e todas as outras ligas de alumínio são soldadas com mais facilidade e livre de inúmeras interferferências, referentes aos processos de soldagem convencionais, quando são soldadas por FSW.

\subsection{Soldagem por fricção linear com mistura (Friction Stir Welding - FSW)}

O processo de soldagem por fricção linear com mistura (Friction Stir Welding - FSW) é um método de soldagem desenvolvido em 1991, pelo The Welding Institute (TWI), situado em Cambridge, Reino Unido. Trata-se de um processo idealizado para realizar a soldagem em ligas de difícil soldabilidade, como as ligas de alumínio das séries 2xxx e 7xxx. Neste processo não ocorre a fusão (as temperaturas atingem até $80 \%$ deste ponto) do material, o que faz com que sejam eliminados os defeitos provenientes da solidificação, e sejam atingidas boas propriedades mecânicas e baixa distorção (Olea, 2008).

O desenvolvimento do processo de soldagem por FSW tem grande apelo da indústria aeronáutica, que utiliza em grande parte as ligas de alumínio e rebites para realizar a junção das peças. Há pouco mais de 10 anos, a FAA (Federal Aviation Administration) autorizou a utilização deste tipo de soldagem para o jato comercial, modelo eclipse-500, que reduziu aproximadamente $60 \%$ dos rebites (auxílio à redução do peso) utilizados em toda a aeronave, diminuindo também o tempo, em até dez vezes, de realização dessas uniões (TWI Magazine, n. 122, 2003). 
A ferramenta de soldagem, não consumível, é composta por uma camisa ou ombro (do inglês shoulder), que se estabiliza entre as superfícies das chapas a serem soldadas, e pela ponta da ferramenta, que apresenta um diâmetro menor à camisa e penetra entre as chapas. Há diversos tipos de camisas, de acordo com os tipos de chapas, geometria e materiais a serem utilizados. Entretanto, não serão detalhados neste trabalho. A Figura 3.8 mostra a ilustração esquemática do processo de soldagem por FSW.

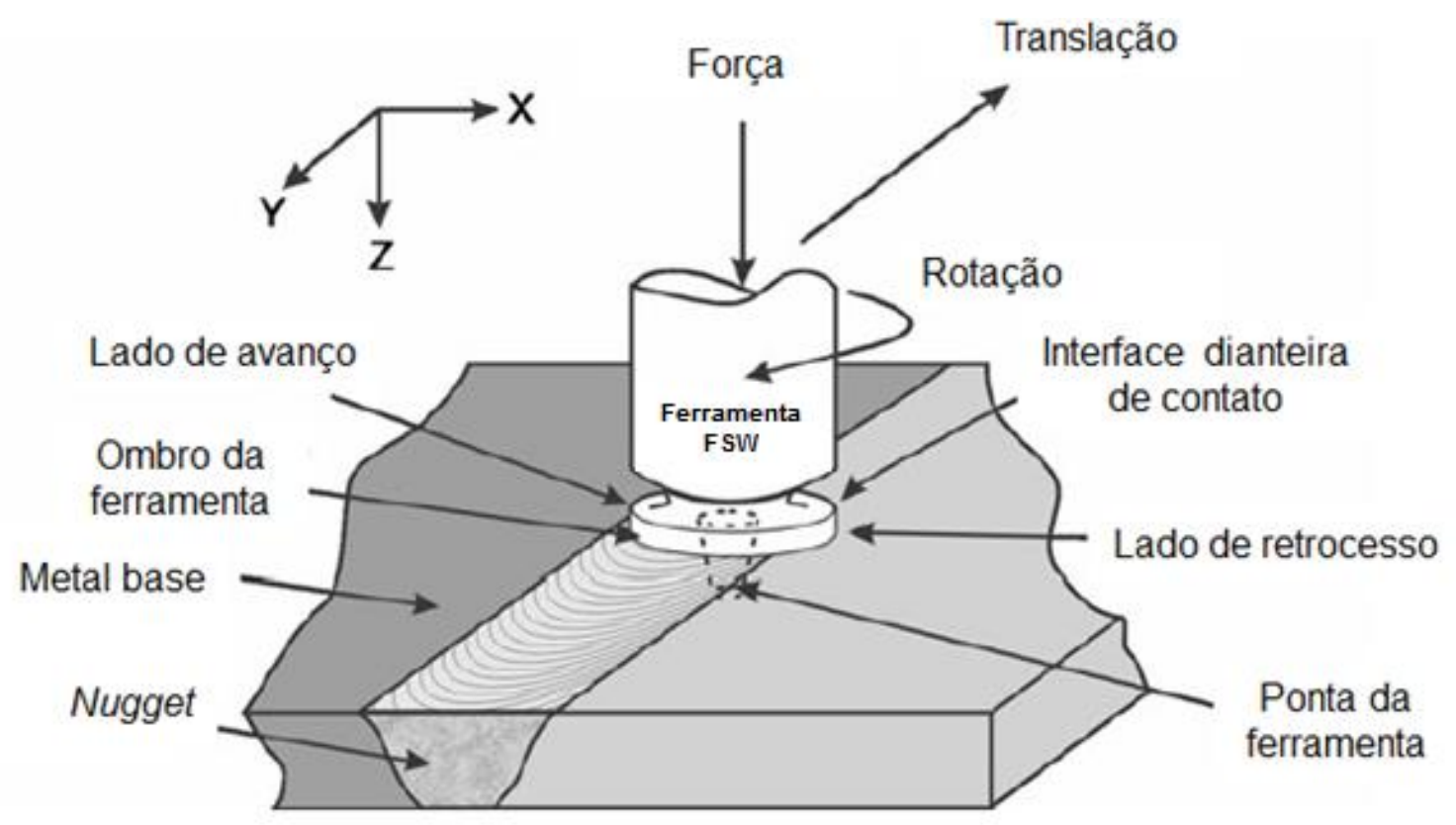

Figura 3.8: Ilustração esquemática do processo de soldagem por FSW (Cole, 2013)

Conforme ilustrado na Figura 3.8, a camisa e a ponta, que compõem o conjunto da ferramenta rotativa, são alimentadas eletricamente. Já em rotação, a ponta é inserida entre as laterais das espessuras das duas chapas, de forma que a camisa seja acoplada perfeitamente às superfícies das chapas, agindo como barreira para o fluxo vertical do metal amolecido. A rotação contínua da ferramenta, em atrito às chapas, é a fonte suficiente de energia do processo de soldagem para amolecê-lo.

O movimento rotacional arrasta o material amolecido do lado do retrocesso ao lado do avanço da ferramenta, ou seja, de sua parte dianteira para a sua parte traseira. Então ocorre um coalescimento do material de ambas as chapas e forma-se a região soldada, em estado sólido, que seguindo o movimento transversal da ferramenta, forma o cordão da junta soldada.

Os parâmetros de soldagem são responsáveis pela modificação da microestrutura e as propriedades da junta soldada. Os parâmetros principais são: velocidade de rotação da ponta da ferramenta, força axial e velocidade de soldagem. A velocidade de rotação da ponta 
da ferrramenta é a responsável por gerar mais calor, ou seja, é proporcional ao aporte térmico. A força axial, além de contribuir para a geração de calor, consolida a junta pela pressão exercida. A velocidade de soldagem pode ser levada em conta quando se necessita um aumento de produtividade do processo (Kim et al., 2006).

\subsection{Características microestruturais de ligas de alumínio soldadas por FSW}

Embora as temperaturas atingidas durante o processo de soldagem por FSW sejam consideradas baixas quando comparadas a outros processos de soldagem, estas são suficientes para modificar a estrutura cristalina das regiões adjacentes às chapas soldadas. Em razão da ótima transferência de calor que apresentam as ligas de alumínio, suas regiões adjacentes são aquecidas e resfriadas ao serem expostas ao processo de soldagem, o que leva a um gradiente microestrutural diferenciado ao longo da seção transversal da solda obtida. Esse processo todo pode afetar a microestrutura do material, interferindo nas propriedades mecânicas, como por exemplo as ligas de alumínio das séries 2xxx e 7xxx, que dependem de precipitados endurecedores para manterem suas propriedades.

As zonas das ligas de alumínio, resultantes do processo FSW, são conhecidas e apresentadas pela literatura. As regiões são divididas conforme mostra a Figura 3.9.

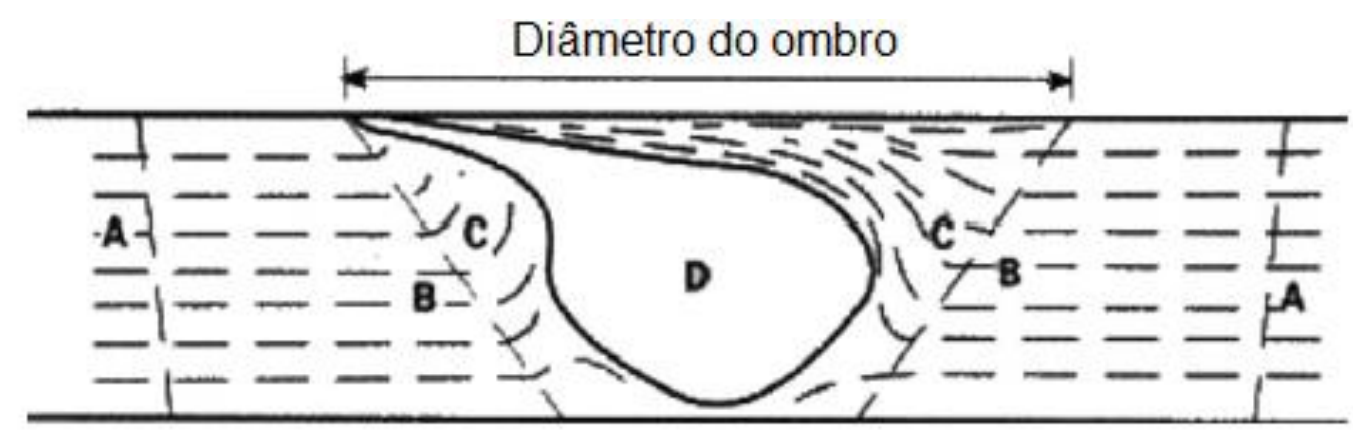

Figura 3.9: Regiões formadas na liga 2024 após processo de soldagem por FSW: (a) MB; (b) ZTA; (c) ZTMA e (d) ZM ou nugget (Nandan, 2008).

Conforme ilustrado na Figura 3.9, há quatro regiões diferentes (Threadgrill, 2009):

a) Região do metal base (MB);

b) Zona termicamente afetada (ZTA);

c) Zona termomecanicamente afetada (ZTMA);

d) Região da zona de mistura (ZM) ou nugget. 
Em geral, a região do metal base (MB), pela sua distância do centro de soldagem, não é afetada pelo processo, ou seja, não ocorre diferença em sua microestrutura. A zona termicamente afetada (ZTA) não apresenta diferença microestrutural em relação à região do $M B$, entretanto apresenta alteração na dureza e na resposta ao ataque químico. A zona termomecanicamente afetada (ZTMA) sofre deformação plástica oriunda da ferramenta, entretanto não ocorre recristalização. A região da zona de mistura (ZM) ou nugget apresenta uma microestrutura composta, geralmente, por grãos equiaxiais finamente distribuídos devido ao processo de recristalização dinâmica, em razão de ser submetida a uma maior deformação e temperatura do processo de soldagem (Threadgrill, 2009; Bousquet, 2011).

Em relação às mudanças microestruturais causadas às ligas submetidas ao processo de soldagem FSW, destaca-se que, nas zonas altamente deformadas ocorrem recuperação e recristalização dinâmica. O alumínio apresenta forte defeito de empilhamento, e por isso as discordâncias não têm interesse energético em se dissociarem, ficando dessa maneira intactas, aguardando uma grande mobilidade, que permite que sejam aniquiladas facilmente. Como a recuperação e a recristalização competem entre si durante um tratamento térmico, no caso do alumínio, a recuperação será privilegiada, porém a recristalização é favorecida pelo aumento da temperatura e rapidez da deformação, pois uma mínima deformação plástica é necessária para ativar a recristalização (Humpherys, 1995).

Durante os primeiros estágios de deformação, uma estrutura de sub-grãos é desenvolvida, pois logo no início do processo as discordâncias crescem, aumentando dessa forma o estresse e a força motriz de recuperação. Após certa deformação, a criação e eliminação de discordâncias se igualam, por recuperação, chegando a um equilíbrio dinâmico. Durante a recuperação estática, são formados grãos fracamente desorientados, só que neste caso, a aplicação de uma pressão sobre os contornos de grãos estimula-os a se movimentarem, fazendo com que cresçam em direções opostas, conservando dessa maneira uma forma equiaxial, durante a deformação. Contrariamente à recristalização estática, durante a recristalização dinâmica a densidade de discordâncias aumenta nos novos grãos, porque o material continua a se deformar. Como dito anteriormente, em razão do alumínio apresentar forte defeito de empilhamento, sua recuperação dinâmica será rápida, em razão da alta temperatura durante o processo de soldagem FSW (Humpherys, 1995).

As Figuras 3.10 e 3.11 apresentam imagens por microscopia eletrônica de transmissão das diferentes regiões formadas após soldagem por FSW, das ligas 2024-T3 e 
7050-T651, respectivamente, onde são mostradas as diferenças entre os precipitados formados ou dissolvidos após os tratamentos termomecânicos e térmicos, causados pela soldagem por FSW.

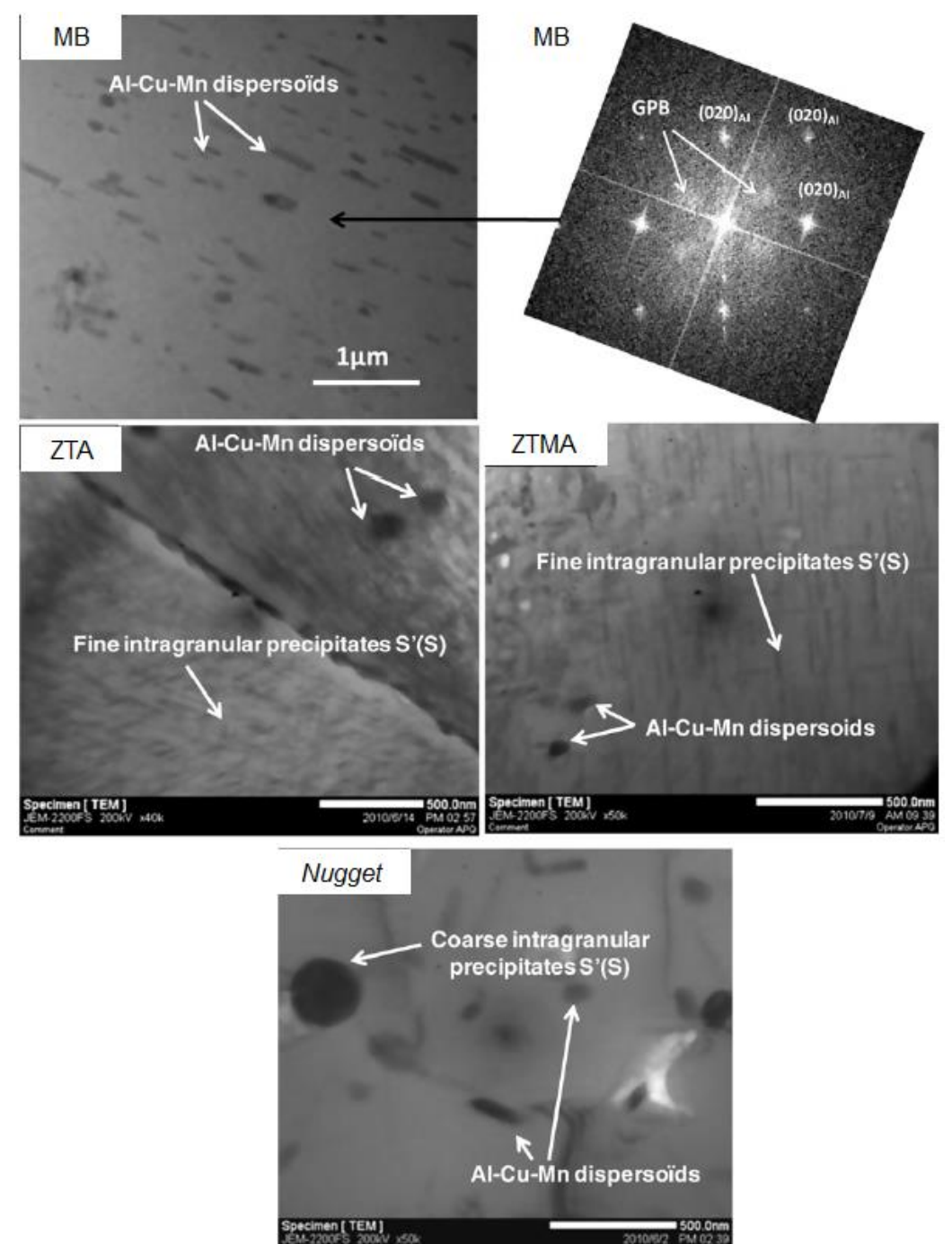

Figura 3.10: Micrografias obtidas por TEM, dos precipitados intragranulares formados após o processo de soldagem por FSW na liga 2024-T3 (Bousquet et al., 2011).

De acordo com a Figura 3.10, Bousquet et al. (2011) mostraram que o MB da liga 2024-T3 apresentou uma alta quantidade e densidade de dispersóides ricos em Cu e Mn dentro dos grãos, com dimensões entre 200 e 500 nm e sob forma de bastonetes. A ZTA e ZTMA também apresentaram esses dispersóides dentro de seus grãos, além de finos precipitados intragranulares de fase S'(S). No nugget, esses dispersóides apresentaram-se em menor quantidade e não distribuídos uniformemente. Além disso, apareceram precipitados intragranulares grosseiros de fase $S^{\prime}(S)$.

Su et al. (2003), em análise na zona da mistura da liga 7075-T651, verificaram a presença de grãos menores aos dos sub-grãos, considerando dessa forma que os grãos do 
nugget não podem ser resultados de uma recristalização dinâmica contínua. Supuseram então que, durante o ciclo termomecânico há a introdução de discordâncias e o crescimento de grãos. Os pequenos sub-grãos, fracamente desorientados, se formariam por recuperação dinâmica e, em seguida, a introdução contínua de discordâncias nesses sub-grãos resultaria uma recristalização dinâmica contínua. O nugget teria então uma recuperação como na ZTMA, ao fim do ciclo térmico. Conclui-se então que, ocorre uma recristalização dinâmica, entretanto ela é ligada à uma recuperação dinâmica, que permite a criação de novos subgrãos muito finos (ver Figura 3.11).
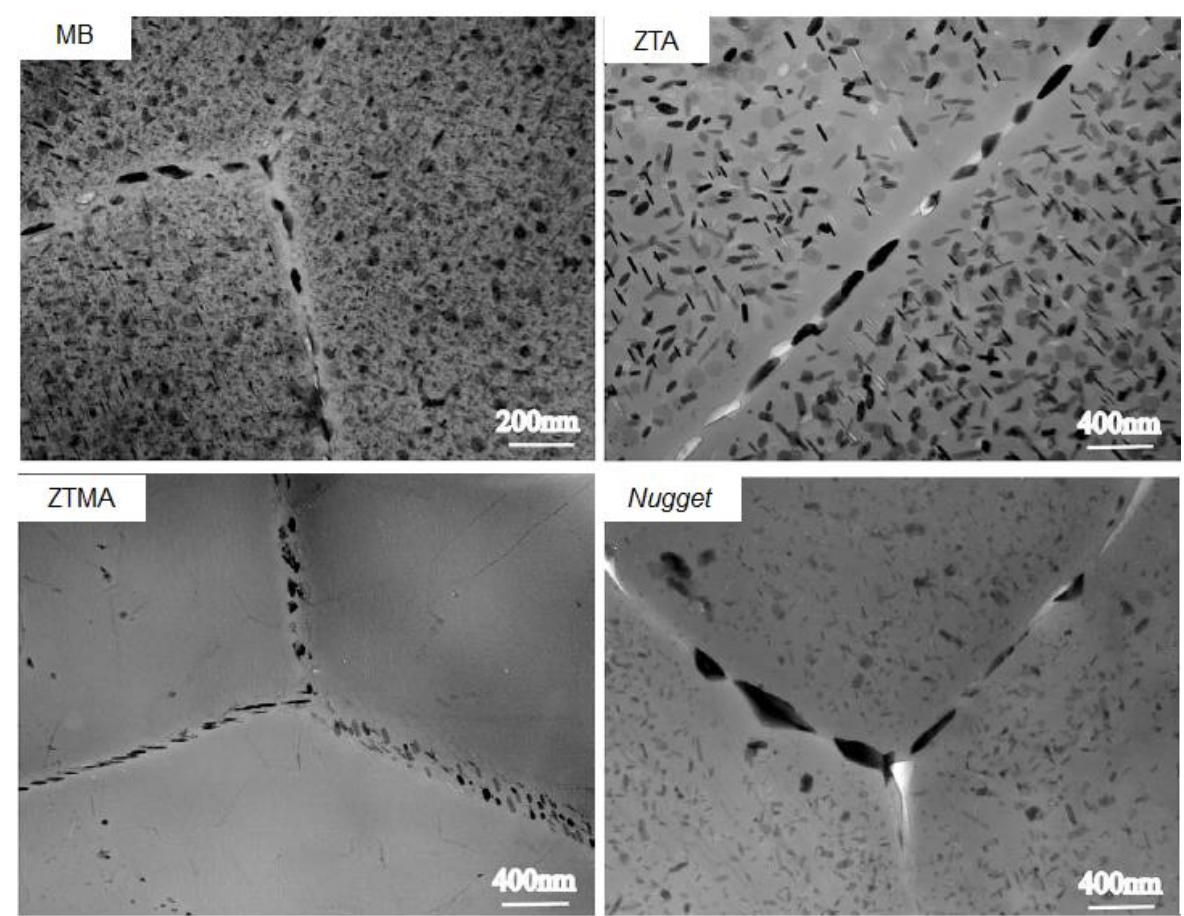

Figura 3.11: Micrografias obtidas por MET, dos precipitados intragranulares formados após o processo de soldagem por FSW na liga 7050-T651 (Su et al., 2003).

Conforme a Figura 3.11, foi encontrada uma finíssima distribuição de precipitados intragranulares no MB da liga 7050-T651, com dimensões menores do que $50 \mathrm{~nm}$ e sob forma de bastonetes. Na ZTA, os precipitados intragranulares, principalmente compostos das fases $\eta$ 'e $\eta$, continuaram sendo distribuídos homogeneamente, enquanto que houve um crescimento da zona livre de precipitados e os precipitados intergranulares engrossaram. $\mathrm{Na}$ ZTMA, houve uma dissolução completa e uma reprecipitação preferencial, de precipitados da ordem de 10 a $20 \mathrm{~nm}$, ao longo dos contornos de grãos, com uma maior quantidade. No nugget, os precipitados parecem ter ido à solução e terem reprecipitado durante o ciclo termomecânico de soldagem, com a redistribuição dos precipitados fortemente dependentes da estrutura de discordâncias, pois na maioria dos grãos que continham uma alta densidade de discordâncias, as imagens obtidas por TEM revelaram uma alta densidade de 
precipitados, da ordem de 60 a $100 \mathrm{~nm}$, dispersos realtivamente uniformes pela matriz, além de uma zona livre de precipitados entre 50 e 100 nm (Su et al., 2003).

Aval (2015), em estudo da caracterização dos precipitados endurecedores, após o processo de soldagem por FSW da liga 7075-T6, conforme imagens apresentadas na Figura 3.7, demonstrou que os precipitados endurecedores do MB, que apresentavam dimensões menores que $20 \mathrm{~nm}$ eram as zonas GP, e os precipitados grosseiros eram a fase $\eta$ '. $\mathrm{Na}$ ZTMA, os pequenos precipitados foram dissolvidos e somente partículas redondas com diâmetros entre 70 e 250 nm permaneceram. O nugget apresentou 3 diferentes precipitados, que foram identificados como zonas GP, precipitados intragranulares arredondados de fase $\eta$ ' e forma de agulhas de fase $\eta$, além dos precipitados intergranulares de fase $\eta\left(\mathrm{MgZn}_{2}\right)$, mostrado por Ranganath et al. (2013).

Sabe-se, entretanto, que as temperaturas atingidas nos materiais soldados variam conforme os parâmetros de soldagem utilizados, as espessuras das chapas a serem soldadas, as composições das ligas, e que as temperaturas máximas sempre são atingidas no centro da solda. E com isso, as zonas formadas, bem como suas microestruturas, são dependentes desses parâmetros. Algumas demonstrações de temperaturas atingidas nos centros das soldas, obtidas por FSW, de ligas de alumínio, são mostradas na Tabela 3.1 .

Tabela 3.1: Demonstrações de temperaturas atingidas no centro da solda durante o processo de soldagem por FSW

\begin{tabular}{ccc}
\hline Ligas soldadas & $\begin{array}{c}\text { Temperatura atingida } \\
\text { (no centro da solda) }\end{array}$ & Autor \\
\hline $2024-\mathrm{T} 3 / 6056-\mathrm{T} 4$ & Entre $300^{\circ} \mathrm{C}$ e $400^{\circ} \mathrm{C}$ & Amancio-Filho et al., 2008 \\
$2024-\mathrm{T} 3 / 2024-\mathrm{T} 3$ & Entre $450^{\circ} \mathrm{C}$ e $500^{\circ} \mathrm{C}$ & Jaryiaboon et al., 2007 \\
$6061-\mathrm{T} 6 / 6061-\mathrm{T} 6$ & Entre $400^{\circ} \mathrm{C}$ e $410^{\circ} \mathrm{C}$ & Hwang et al., 2008 \\
$2024 / 6061$ & Entre $425^{\circ} \mathrm{C}$ e $475^{\circ} \mathrm{C}$ & Li et al., 1999 \\
\hline
\end{tabular}

Essas transformações de fases ocorridas após a soldagem por FSW interferem nas propriedades mecânicas das ligas de alumínio e há uma ligação direta entre microestrutura e microdureza.

Genevois et al. (2004) avaliaram a relação entre microestrutura e propriedades mecânicas ao longo das diferentes zonas formadas após a soldagem por FSW de chapas da liga 2024-T3. No MB, as zonas GPB permitiram o bloqueamento da movimentação das discordâncias, provocando dessa maneira o endurecimento do material. 
A ZTA, nesse caso, apresentou $15 \mathrm{~mm}$ de comprimento e foi dividida em três partes, sendo que em todas elas o gradiente de temperatura fez os estados de precipitação variarem, sem que as microestruturas tenham sido alteradas. Na região mais próxima ao $\mathrm{MB}$, devido ao baixo aquecimento, as zonas GPB começam a se dissolver e não voltam ao seu estado inicial ao serem resfriadas à temperatura ambiente, por falta de pontos de nucleação ou de enriquecimento da solução sólida, e que faz com que a microdureza e as propriedades mecânicas sejam reduzidas nessa região. No centro da ZTA, a temperatura atingida permite a completa dissolução das zonas GPB e também a precipitação dos precipitados endurecedores de fase $S^{\prime}(S)$, de dimensões inferiores à $10 \mathrm{~nm}$, aumentando a microdureza.

$\mathrm{Na}$ região da ZTA próxima à ZTMA, o aquecimento é elevado e extremamente importante, pois permite a dissolução rápida das zonas GPB e a precipitação das fases S'(S) mais grosseiras, que leva a uma diminuição da microdureza e das propriedades mecânicas, sucessivamente.

Na ZTMA, ocorre um processo termomecânico e essa deformação mecânica gera uma deformação dos grãos, que tendem a aumentar a resistência do material. Entretanto, o alto aquecimento faz com que as fases $S^{\prime}(S)$ precipitem de forma grosseira, com dimensões de até $30 \mathrm{~nm}$, que levam a um amolecimento. A microestrutura do nugget foi totalmente recristalizada, formando grãos de $4 \mu \mathrm{m}$, e os compostos intermetálicos foram fragmentados. As altas temperaturas atingidas no centro da solda permitem que uma parte da fase $S^{\prime}(S)$ seja dissolvida. Cerca de $1 \%$ dos precipitados de fase $S^{\prime}(S)$ não dissolvidas coalescem, com dimensões de até $62 \mathrm{~nm}$, e se tornam incoerentes com a matriz. Ao resfriar e retornar à temperatura ambiente, as zonas GPB são formadas. Essa junção de fenômenos, em razão das transformações termomecânicas, ou seja, a criação de pequenos grãos e a formação de zonas GPB permitem um aumento da microdureza, em comparação à ZTMA.

$\mathrm{Na}$ avaliação entre a microestrutura e as propriedades mecânicas ao longo das diferentes zonas formadas de uma liga da série 7xxx após soldagem por FSW, mais especificamente de chapas da liga 7449-TAF, Sulivan et al. (2003) mostraram que havia uma ligação entre a microestrutura e a microdureza entre as zonas formadas após a soldagem, onde notaram uma queda de dureza da ZTA em relação ao MB e da ZTMA em relação à ZTA, assim como um aumento da dureza na região do nugget, em relação à ZTMA. Para os autores, essas diferenças de dureza ao longo das diferentes zonas seriam relacionadas à distribuição dos diferentes tamanhos de precipitados endurecedores formados. No MB 
houve uma grande densidade de precipitados de fase $\eta^{\prime} / \eta\left(\mathrm{MgZn}_{2}\right)$ de raios inferiores à 7 $\mathrm{nm}$. Na ZTA, os precipitados foram menos numerosos, mas de raios maiores, com dimensões entre 10 e $50 \mathrm{~nm}$. Na ZTMA, houve somente uma baixa densidade de precipitados grosseiros, com dimensões entre 20 e $75 \mathrm{~nm}$. Por fim, no nugget, houve um aumento da densidade de precipitados de pequenas dimensões, que eram menores do que $18 \mathrm{~nm}$.

\subsection{Corrosão do alumínio e suas ligas}

\subsubsection{Corrosão do alumínio}

O alumínio tem forte tendência a retornar ao seu estado natural, ou seja, possui ótima capacidade de oxidação, em razão de sua alta instabilidade termodinâmica. Na prática, isso contribui para que este elemento e suas ligas, em contato com meios oxidantes, como o ar ou a água, formem um filme protetor (usualmente $\mathrm{Al}_{2} \mathrm{O}_{3}$ ), quase que instantaneamente (Vargel, 1999). Esse filme é da ordem de até $10 \mathrm{~nm}$ de espessura. É denominado camada de passivação e pode ser dividido em duas partes: a mais interna é mais compacta, enquanto a mais externa é composta por óxidos hidratados e é mais porosa (Trompette, 2010; Vargel, 2004, p. 101; Davis, 1999 - p. 26).

A camada de passivação do alumínio e de suas ligas é estável em ambientes aproximadamente neutros (Pourbaix, 1963), podendo ser atacada em ambientes básicos ou ácidos. Ressalta-se, entretanto, que mesmo no domínio de passivação, dependendo do meio ao qual o material é exposto, a auto-regeneração da camada passiva sobre o alumínio pode não ocorrer, gerando corrosão localizada, como os pites formados em soluções que contenham íons cloreto.

\subsubsection{Corrosão localizada das ligas de alumínio}

Além da agressividade do meio ao qual o material é exposto, a corrosão localizada também pode ocorrer em razão das heterogeneidades da microestrutura dos materiais, como no caso das ligas de alumínio que apresentam diversos compostos intermetálicos em suas microestruturas. 
A corrosão é denominada localizada quando as zonas catódicas e anódicas são fisicamente e continuamente separadas, o que a difere da corrosão uniforme (generalizada), onde todas as áreas da superfície do metal apresentam tendência similar à oxidação e as áreas anódicas e catódicas se alternam sobre a superfície (Favre, 1993; Frankel, 1998), conforme ilustração esquemática mostrada na Figura 3.12.

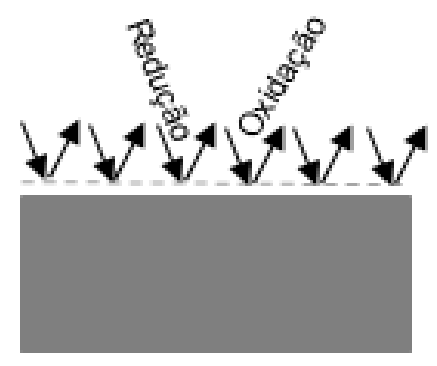

(a)

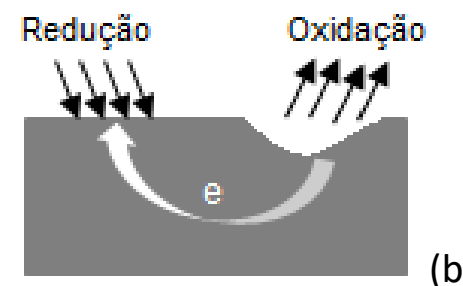

Figura 3.12: Diferença entre (a) corrosão uniforme e (b) corrosão localizada de um metal (Favre, 1993).

A microestrutura das ligas de alumínio com a presença de muitas heterogeneidades, como os compostos intermetálicos favorece a ocorrência de corrosão localizada. Os compostos intermetálicos podem atuar como cátodos ou ânodos em relação à matriz, dependendo de suas composições. Há uma grande variedade de formas de corrosão localizada e, abaixo, serão descritos os mecanismos dos principais tipos observados nas ligas de alumínio das séries 2xxx e 7xxx.

\subsubsection{Corrosão galvânica}

A corrosão galvânica pode ocorrer quando os precipitados apresentam potenciais de eletrodo diferentes à matriz ou quando há união de duas ligas com composições químicas e, consequentemente, potenciais de corrosão distintos. Entretanto, para que a corrosão galvânica ocorra, três condições devem acontecer simultaneamente:

1. Os dois materiais devem ter composições químicas diferentes. O mais nobre será o cátodo (responsável pelas reações de redução), e o menos nobre será o ânodo (responsável pelas reações de oxidação), desde que os metais tenham pelo menos $100 \mathrm{mV}$ de diferença entre seus potenciais (Vargel, 1999), o que dá início à pilhas galvânicas;

2. Os materiais devem estar em contato elétrico que assegure o transporte de elétrons entre eles; 
3. Um eletrólito deve estar em contato com os materiais, ou partes dos materiais de potenciais diferentes, para que o transporte de espécies iônicas e, consequentemente, a corrente elétrica seja garantida.

Uma tabela com os potenciais de corrosão de partículas intermetálicas pode indicar, para cada caso, se haverá reação com a matriz de $\mathrm{Al}$, e quem será o ânodo ou o cátodo na pilha. Na tabela prática em solução de água do mar, apresentada por Gentil (2012 - p.28), a sequência dos principias elementos químicos presentes nas ligas 2024-T3 e 7475-T651, do mais anódico (menos nobre e mais corrosivo) ao mais catódico (mais nobre) é a seguinte: $\mathrm{Mg}<\mathrm{Zn}<\mathrm{Al}<\mathrm{Cu}$.

A Tabela 3.2 apresenta os potenciais de corrosão de partículas intermetálicas de ligas de alumínio, inclusive de algumas encontradas nas ligas 2024 e 7475, em relação ao alumínio puro (Reboul, 1997; Vargel, 1999).

Tabela 3.2: Potencial de corrosão em água do mar de algumas partículas intermetálicas (Reboul, 1997; Vargel, 1999).

\begin{tabular}{|c|c|c|c|}
\hline & & Partícula & $\mathrm{E}_{\mathrm{CORR}}\left(\mathrm{mV}_{\mathrm{ECS}}\right)$ \\
\hline \multirow{6}{*}{ 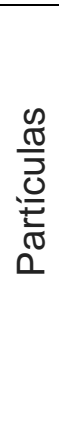 } & \multirow{6}{*}{ 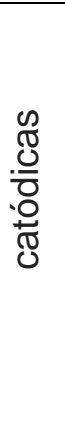 } & $\mathrm{Si}$ & -170 \\
\hline & & $\mathrm{Al}_{3} \mathrm{Ni}$ & -430 \\
\hline & & $\mathrm{Al}_{2} \mathrm{Cu}$ & -440 \\
\hline & & $\mathrm{Al}_{3} \mathrm{Fe}$ & -470 \\
\hline & & $\mathrm{Al}_{6} \mathrm{Mn}$ & -760 \\
\hline & & Al & -840 \\
\hline \multirow{5}{*}{ 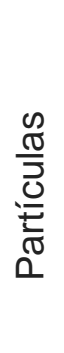 } & \multirow{5}{*}{ 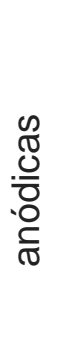 } & $\mathrm{Al}_{2} \mathrm{CuMg}$ & -910 \\
\hline & & $\mathrm{MgZn}_{2}$ & -960 \\
\hline & & $\mathrm{Al}_{3} \mathrm{Mg}_{2}$ & -1150 \\
\hline & & $\mathrm{Mg}_{2} \mathrm{Si}$ & -1190 \\
\hline & & $\mathrm{Al}_{8} \mathrm{Mg}_{5}$ & -1240 \\
\hline
\end{tabular}

As diferenças entre os potenciais de corrosão das partículas intermetálicas e a matriz das ligas de alumínio são a força motriz para iniciar da corrosão localizada na forma de pites, intergranular ou esfoliação, assumindo-se que as duas últimas podem iniciar pelos pites. 


\subsubsection{Corrosão por pites}

A corrosão por pites pode ocorrer nos metais que possuem camada de passivação e são expostos em meios agressivos, a partir de um certo potencial, conhecido como potencial de pite ou de ruptura. Esta se caracteriza pela formação de pequenas cavidades na superfície do metal, com dimensões micrométricas em seus diâmetros e com profundidades milimétricas, o que faz com que esse tipo de corrosão seja responsável pelo início de fissuras em componentes estruturais, fabricados em ligas de alumínio, por exemplo, da indústria aeronáutica (DuQuesnay, 2003).

Nas ligas de alumínio, a corrosão por pites inicia-se, geralmente, em volta das partículas intermetálicas presentes na superfície do material, as quais podem agir como zonas catódicas ou anódicas em relação à matriz. Sendo os potenciais diferentes, os pites podem se originar de uma dissolução completa de uma partícula intermetálica anódica em relação à matriz, ou por dissolução da matriz no entorno de uma partícula intermetálica catódica. O processo de iniciação do pite ainda é um fenômeno não completamente entendido. Uma suposição desse processo é ilustrada no esquema mostrado pela Figura 3.13.

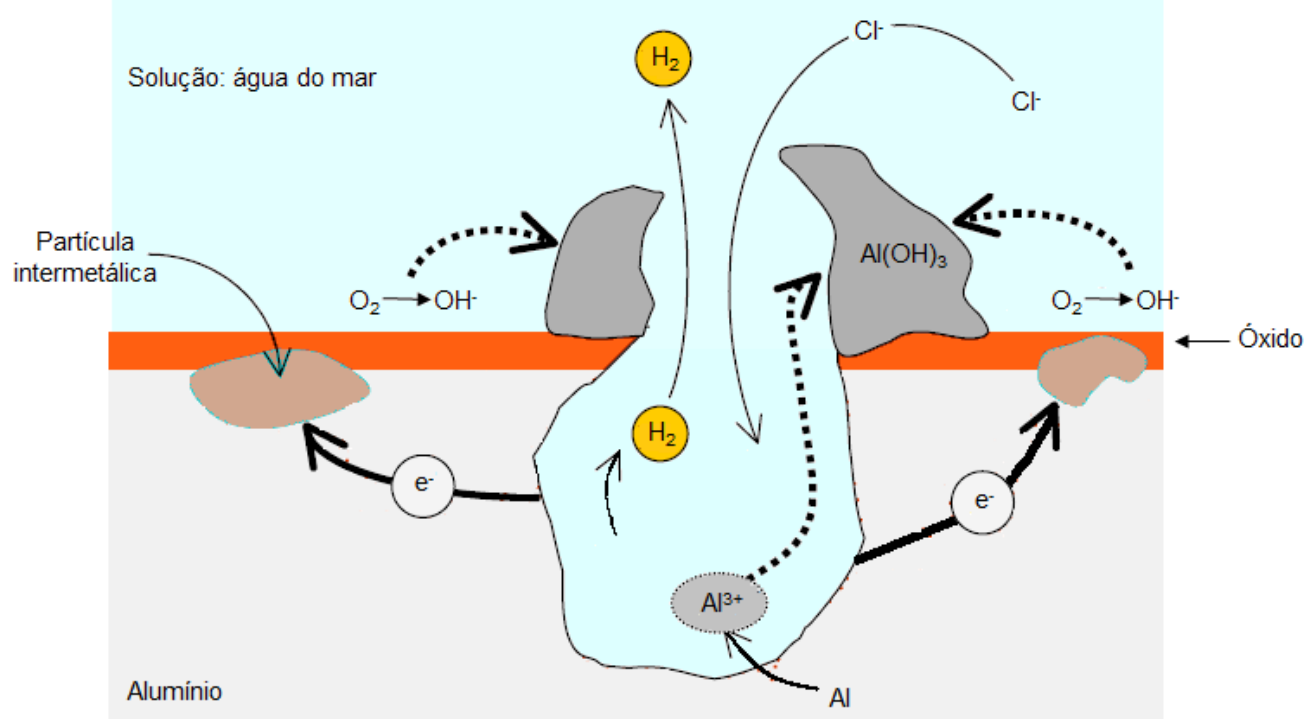

Figura 3.13: Ilustração esquemática do processo de corrosão por pites em ligas de alumínio (Davis, 1999).

Supõe-se que ocorra a adsorção de íons cloreto ao nível dos defeitos do filme de óxido de alumínio, suportada por um forte campo elétrico através da camada passiva. A redução lenta do $\mathrm{O}_{2}$ sobre a superfície catódica gera uma ruptura dielétrica do filme de alumínio nas regiões de microdefeitos. Com a quebra do filme, o alumínio fica exposto 
diretamente ao eletrólito, formando cloretos complexos e hidroxicloretos, seguidos por dissolução de cloretos complexos e repassivação do pite. O fundo do pite formado se enriquece em íons $\mathrm{Cl}^{-}$e uma camada estável de cloretos e oxicloretos de alumínio é formada. Estes sofrem hidrólise e acidificam o fundo do pite, levando o pH para valores inferiores a 3 . Em seguida, os íons $\mathrm{Al}^{3+}$ do fundo do pite se difundem e, em contato com o meio externo mais alcalino precipitam na forma de $\mathrm{Al}(\mathrm{OH})_{3}$, na boca do pite e sobre as paredes laterais. Ocorre então a manutenção do pite, por dissolução do alumínio na solução ácida de cloreto de alumínio, ocorrendo também a produção de hidrogênio gasoso. Por fim, o pite pode ser repassivado por obstrução ou perda da estabilidade da camada de cloreto, e inicia-se todo o processo novamente (Davis, 1999). Os pites podem ainda ser responsáveis pela propagação de outros tipos de corrosão localizada, como a corrosão intergranular e a corrosão por esfoliação.

\subsubsection{Corrosão intergranular}

A corrosão intergranular é um tipo de corrosão que se propaga pelos contornos dos grãos do metal. As ligas de alumínio, tanto da série 2xxx como da 7xxx, são sensíveis a este tipo de corrosão, em razão dela ser causada pela diferença de potencial de eletrodo entre 0 interior do grão e o contorno do grão. Dependendo do tratamento térmico ou mecânico, pode ocorrer a precipitação preferencial de precipitados nos contornos de grãos, o que pode aumentar a suscetibilidade da liga a esta forma de ataque (Vargel et al., 2014). Um exemplo de corrosão intergranular da liga 2024-T3 é apresentado na Figura 3.14.

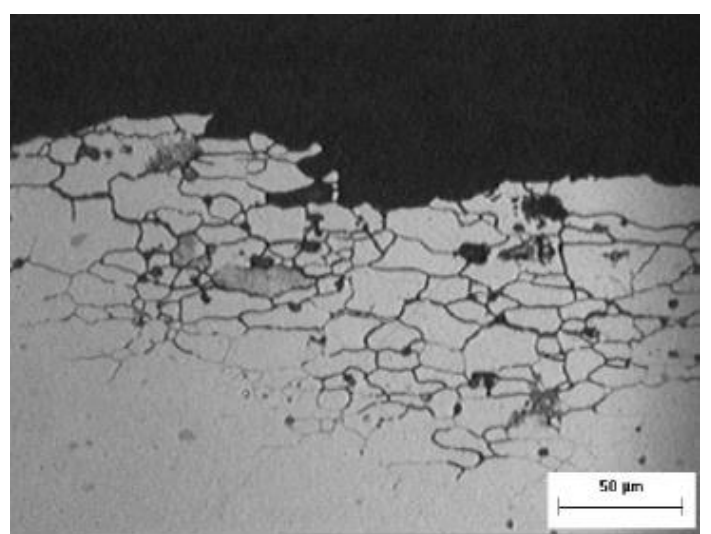

Figura 3.14: Micrografia óptica de corrosão intergranular na liga 2024-T3 (Hoffman et al., 2004).

Ressalta-se que, a corrosão intergranular ocorre apenas se as três condições indicadas a seguir se desenvolverem mutualmente (Vargel et al., 2004): 
1. Presença de um meio corrosivo;

2. Diferença de potencial da ordem de $100 \mathrm{mV}$ entre as partículas intermetálicas e a solução sólida;

3. Precipitação contínua de partículas intermetálicas.

\subsubsection{Corrosão por esfoliação}

A corrosão por esfoliação (ver Figura 3.15) é uma forma de corrosão intergranular onde os grãos das ligas de alumínio, em geral deformados em consequência de trabalho à frio, são destacados de sua microestrutura.

A evolução da corrosão intergranular gera produtos de corrosão que se acumulam na região entre os grãos formados, ocasionando um campo de tensão que induz a evolução desse tipo de corrosão. Esse tipo de corrosão apresenta o mesmo mecanismo da corrosão intergranular cujo pré-requisito é a diferença de potencial entre os precipitados endurecedores e ricos em $\mathrm{Cu}$, que atuam como cátodos e as regiões adjacentes empobrecidas em $\mathrm{Cu}$, portanto, anódicas em relação à vizinhança, levando à corrosão por esfoliação (Robinson, 1982).

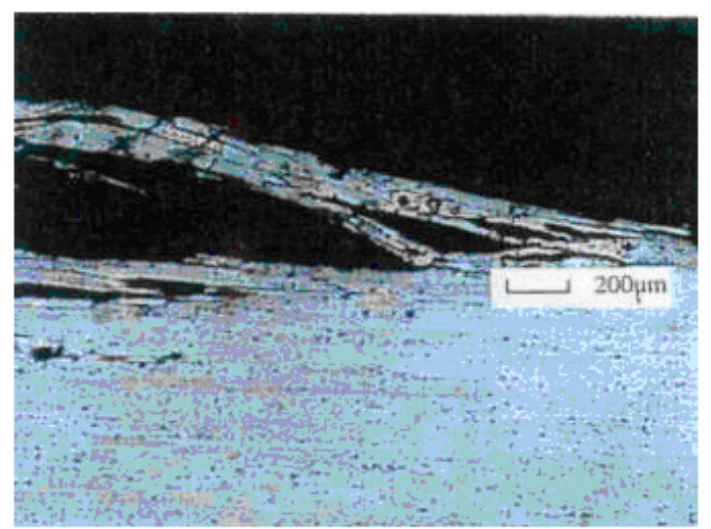

Figura 3.15: Fotomicrografia por SEM de uma liga 2024-T351 após sofrer corrosão por esfoliação (Kuntz-Laguerre, 1997).

\subsubsection{Aspectos gerais da corrosão localizada de ligas de alumínio da série 2xxx}

As ligas da série 2xxx, em grande parte, não possuem boa resistência à corrosão, em situações diversas, e estão sujeitas à corrosão por pites e intergranular (Zhang e Frankel, 2003). Essa suscetibilidade ocorre principalmente em virtude das partículas intermetálicas formadas durante 0 endurecimento por precipitação, que apresentam dimensões 
micrométricas, atuarem como ânodos ou cátodos em relação à matriz, conforme apresentado na Tabela 3.2.

Buchheit et al. (1997) caracterizaram os diferentes tipos de partículas intermetálicas presentes na liga 2024-T3, onde as duas principais partículas encontradas, que representavam $3 / 4$ de todas as partículas, foram: as partículas de fase $\mathrm{S}$ ( $\mathrm{Al}_{2} \mathrm{CuMg}$ ), com $61 \%$ de incidência, e as partículas $\mathrm{Al}_{6}(\mathrm{Cu}, \mathrm{Fe}, \mathrm{Mn})$, com $12 \%$ de incidência.

Chen et al. (1996), e Guillaumin e Mankowski (1999) também encontraram os mesmos constituintes como partículas intermetálicas principais da liga 2024-T3: Al-Cu-Fe$\mathrm{Mn}$ e Al-Cu-Mg, sendo que as partículas de Al-Cu-Mg apresentavam formatos mais ou menos arredondados, enquanto que as partículas de Al-Cu-Fe-Mn eram grandes e irregulares.

Chen et al. (1996), em estudo de avaliação da influência dos microconstituintes da liga 2024-T3, em solução de $0,5 \mathrm{M}$ de $\mathrm{NaCl}$ e diferentes valores de $\mathrm{pH}$ (3, 7 e 11), observaram que as partículas de composição Al-Cu-Fe-Mn atuavam como cátodos em relação à matriz, deixando leves depressões na região da matriz em sua volta. Notaram ainda a presença de regiões que indicavam redeposição de cobre devido à redução de íons cúpricos dissolvidos na solução. As partículas de Al-Cu-Mg, por sua vez, foram atacadas nas soluções com diferentes valores de pH, ou seja, atuaram sempre como áreas anódicas em relação à matriz.

Buchheit et al. (1997) buscaram compreender o comportamento das partículas de fase $\mathrm{S}\left(\mathrm{Al}_{2} \mathrm{CuMg}\right)$, ou seja, se estas atuavam como partículas catódicas ou anódicas em relação à matriz de alumínio. Também buscaram o entendimento de como produtos de corrosão ricos em cobre se depositavam em volta das partículas intermetálicas, tendo estes sofrido dissolução, sendo que o potencial da corrosão da liga era inferior ao potencial de corrosão do cobre (Pourbaix, 1963). Mostraram então que, as partículas de fase $\mathrm{S}$ ( $\mathrm{Al}_{2} \mathrm{CuMg}$ ) sofriam uma dissolução seletiva dos elementos $\mathrm{Mg}$ e Al. Ressalta-se que, como consequência deste fenômeno, as partículas atacadas apresentaram estruturas porosas. Estes pesquisadores, entretanto, admitiram a hipótese, sem poder demonstrá-la, que a partícula enriquecida em cobre pode se comportar como cátodo levando à dissolução da matriz do alumínio adjacente. 
Em continuação aos seus estudos, Buchheit et al. (2000), e também Dimitrov et al., (1999), mostraram a possibilidade de aglomerados (clusters) de cobre, de 10 a $100 \mathrm{~nm}$, se separarem dos compostos intermetálicos, seguidos pela oxidação do cobre e, por fim se reduzirem e se depositarem nas bordas das partículas, como esquematizado na Figura 3.16.

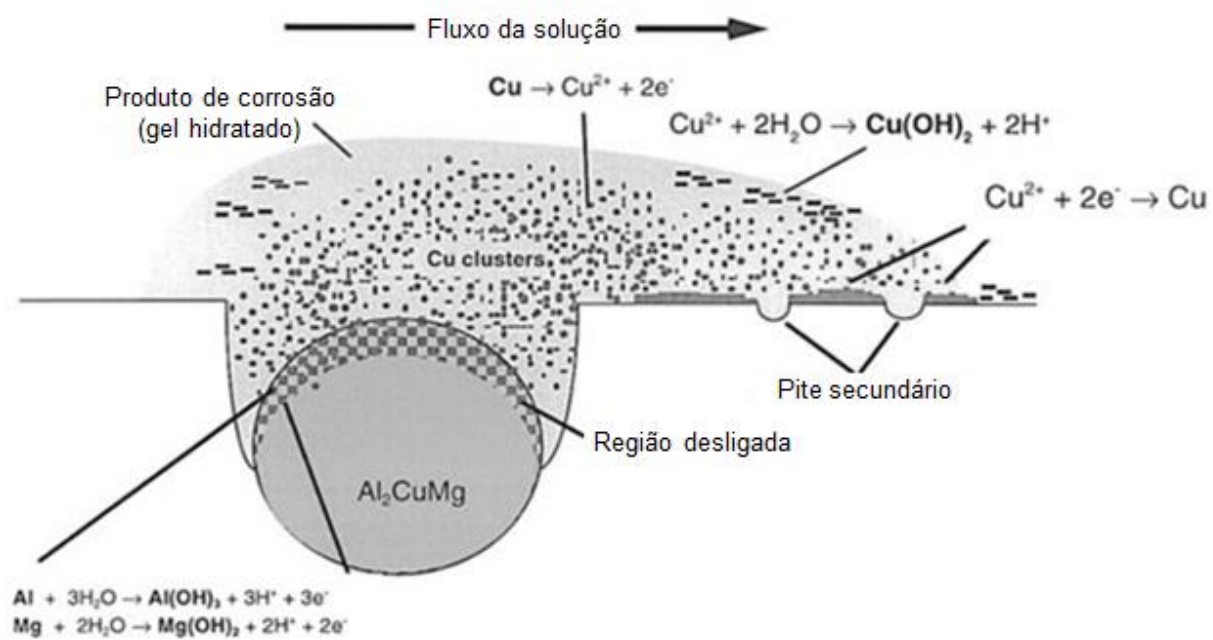

Figura 3.16: Ilustração do mecanismo de redistribuição do cobre por dissolução de partículas de fase $S$ proposto por Buchheit et al. (Buchheit et al., 2000).

Após a compreensão do mecanismo de dissolução da fase $\mathrm{S}\left(\mathrm{Al}_{2} \mathrm{CuMg}\right)$ realizado por Buchheit et al. (1997), Guillaumin e Mankowski (1999) com o auxílio das técnicas SEM, EDS e TEM, estudaram a evolução da composição das partículas intermetálicas e dos precipitados endurecedores intergranulares, ambos de fase $\mathrm{S}$ ( $\mathrm{Al}_{2} \mathrm{CuMg}$ ), na liga 2024-T351, sob potenciais selecionados a partir da curva de polarização potenciodinâmica, em meio contendo $\mathrm{NaCl}(1 \mathrm{M})$.

Guillaumin e Mankowski (1999) observaram dois potenciais de ruptura para a liga 2024-T351 em solução de $1 \mathrm{M}$ de $\mathrm{NaCl}$ ao analisarem a curva potenciodinâmica ilustrada na Figura 3.17. 


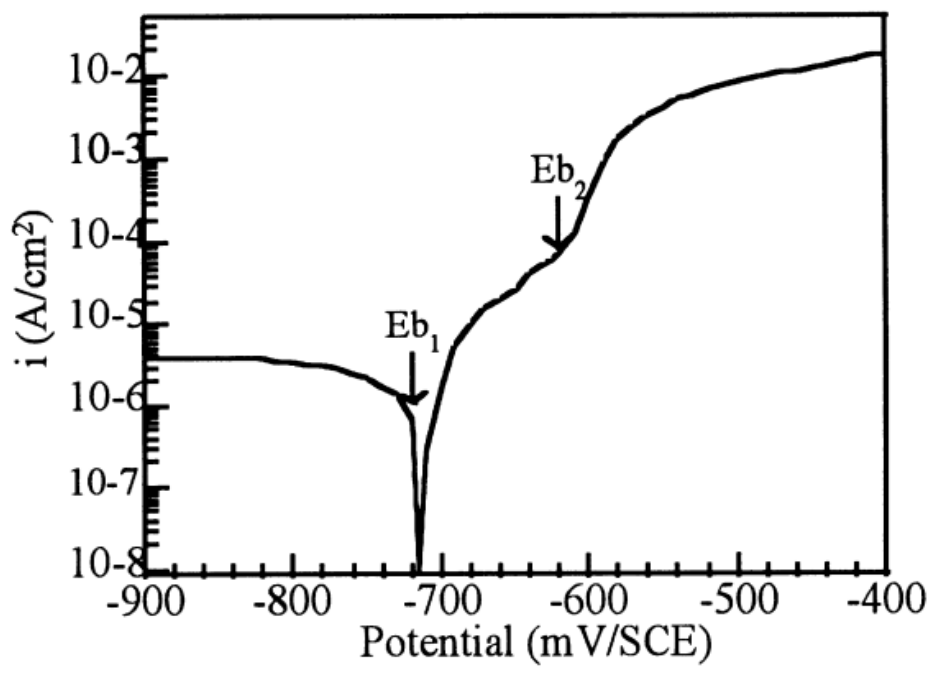

Figura 3.17: Curva de polarização da liga 2024 em solução de $\mathrm{NaCl}$ (1 M) (Guillaumin et al.,1999).

Atribuíram os dois potenciais de ruptura, seja o mais ativo, Eb 1 (-720 mV/SCE) ou o mais nobre, $\mathrm{Eb}_{2}(\sim-620 \mathrm{mV} / \mathrm{SCE})$ à dissolução de fases metalúrgicas. O primeiro potencial de ruptura, Eb1, foi relacionado com a dissolução das partículas intermetálicas de fase $S$ $\left(\mathrm{Al}_{2} \mathrm{CuMg}\right)$. Essa dissolução ocorreria da seguinte maneira: inicialmente haveria dissolução preferencial dos elementos mais ativos das partículas de fase $\mathrm{S}$, em razão do alto teor de $\mathrm{Mg}$, o que favoreceria o enriquecimento em cobre do resíduo do precipitado.

Com o auxílio de microscopia eletrônica de transmissão (TEM) ainda verificaram que, para potenciais inferiores a Eb 1 , houve dissolução da matriz, nos entornos da partícula de fase S. Os autores mostraram então que, a região da matriz no entorno às partículas intermetálicas de fase $\mathrm{S}$ era livre de dispersóides que contêm $\mathrm{Cu}$ em sua composição $\left(\mathrm{Al}_{20} \mathrm{Mn}_{3} \mathrm{Cu}_{2}\right)$. Essas regiões livres de dispersóides possuíam menor teor de $\mathrm{Cu}$, tanto em relação à matriz quanto em relação às partículas intermetálicas. Portanto, foram formados dois pares galvânicos: o primeiro entre a região livre de dispersóides e aglomerados de Cu/matriz; o segundo entre a região livre de dispersóides e aglomerados de Cu/partícula de fase S. Ou seja, a dissolução preferencial da matriz no entorno das partículas intermetálicas de fase $S$ estaria relacionada à existência de pares galvânicos e não ao ataque da partícula.

O segundo potencial de ruptura, Eb2 (mais nobre), foi relacionado à dissolução dos contornos de grãos e, consequentemente, o potencial de início da corrosão intergranular (Guillaumin,1999; Zhang, 2003). Como os contornos de grãos são anódicos em relação ao interior do grão, eles foram preferencialmente atacados, pois já haviam sido fragilizados durante o processo de dissolução das partículas de fase $S$, em Eb$b_{1}$. Isso porque os precipitados endurecedores, presentes nos contornos de grãos, seriam de fase $\mathrm{S}\left(\mathrm{Al}_{2} \mathrm{CuMg}\right)$ 
e, portanto, também sofreriam dissolução no potencial de ruptura Eb1. Assim sendo, no segundo potencial de ruptura, Eb2, ocorreria formação dos pites e propagação da corrosão intergranular.

Com relação à influência das partículas intermetálicas Al-Cu-Fe-Mn, os autores também verificaram que elas são associadas a uma região livre de dispersóides em seus entornos e, consequentemente, poderia ocorrer dissolução seletiva da matriz nessas regiões. Entretanto, a dissolução preferencial para essas partículas intermetálicas necessita sobrepotenciais mais anódicos. Dessa forma, supuseram ser mais natural a prevalência da dissolução das partículas intermetálicas de fase S em relação às partículas de Al-Cu-Fe-Mn.

\subsubsection{Aspectos gerais da corrosão localizada em ligas de alumínio da série 7xxx}

Após revisão extensiva da literatura, não foram encontrados trabalhos relacionados ao efeito dos compostos intermetálicos na resistência à corrosão da liga 7475. Por esta razão, será dado enfoque aos efeitos das partículas em ligas da série 7xxx, em especial à liga 7075, que apresenta o Al-Cu-Fe como partícula intermetálica principal, da mesma forma que a liga 7475.

Com o auxílio de uma microcélula capilar, Andreatta et al. (2004) obtiveram curvas de polarização para a liga 7075 , em solução de $\mathrm{NaCl}(3,5 \%)$ e pH igual a 4 . Duas regiões distintas foram ensaiadas, uma com compostos intermetálicos e outra sem. Foi mostrado que a região isenta de compostos intermetálicos apresentava potencial médio de quebra da película passivadora, em média $160 \mathrm{mV}$ maior do que para a região com compostos intermetálicos. Isso se deve ao fato da formação de pares galvânicos entre os compostos intermetálicos e a matriz, o que foi confirmado pela técnica de SKPFM. Também relacionando o potencial Volta com o comportamento à corrosão, De Witt (2004) demonstrou que o composto intermetálico $\mathrm{Mg}_{2}$ Si possui caráter anódico em relação à matriz da liga 7075, enquanto que os compostos intermetálicos $\mathrm{Al}_{7} \mathrm{Cu} 2 \mathrm{Fe},(\mathrm{Al}, \mathrm{Cu})(\mathrm{Fe}, \mathrm{Cu}, \mathrm{Mn})$ e (Al,Cu,Fe,Mn,Si) possuem caráter catódico. Para a liga 7075, ocorreu comportamento semelhante em relação aos compostos intermetálicos de $\mathrm{Al}_{7} \mathrm{Cu}_{2} \mathrm{Fe}$, ou seja, houve corrosão preferencial nos entornos destas partículas, em solução de $\mathrm{NaCl}$, mostrando que os compostos intermetálicos possuíam caráter catódico em relação à matriz (Birbilis, Cavanaugh e Buchheit, 2006). 
Birbilis et al. (2006), mostraram que a fase $\eta\left(\mathrm{MgZn}_{2}\right)$, encontrada nos contornos de grãos das ligas 7075 e 7475 apresentavam, em solução de 3,5\% de $\mathrm{NaCl}$, potencial mais negativo do que o da matriz. Li et al. (2007), estudaram o acoplamento galvânico dessa fase em relação à matriz, antes e após uma hora em solução de 3,5\% de $\mathrm{NaCl}$, e evidenciaram a dissolução desses precipitados nos contornos de grãos.

Além da composição química dos compostos intermetálicos e de seus potenciais, Robinson e Jackson (1999) mostraram que a morfologia dos grãos também exerce influência na corrosão por esfoliação das ligas da série 7xxx. Quanto mais alongado é o composto intermetálico e maior as forças de compressão exercidas, mais suscetível à corrosão por esfoliação se torna o material. Um exemplo disso é a suscetibilidade à corrosão por esfoliação entre o centro do material e a superfície, onde os grãos são mais alongados. Tal tendência pode ser explicada por uma zona de depleção, devido à precipitação de cobre junto aos contornos de grãos. A zona empobrecida em cobre atuaria como ânodo conduzindo a uma propagação intergranular do fenômeno (Reboul e Develay, 1997).

O modelo de propagação da corrosão por esfoliação pela presença de uma fase anódica (zona de depleção em cobre devido à precipitação da partícula Al-Cu-Fe) é explicada pela anisotropia da degradação da liga AA7075 nos planos paralelos ao plano de laminação, e à ausência de fase catódica nos planos transversais a esta direção (Posada et al., 1997).

\subsection{Corrosão das ligas de alumínio soldadas por fricção (FSW)}

Ao serem soldadas por FSW, as ligas de alumínio formam zonas com microestruturas e propriedades diferentes às das ligas antes da soldagem. Quando são soldadas ligas dissimilares, há tendência em se formar um acoplamento galvânico entre essas zonas distintas e dependendo e entre as ligas soldadas, dependendo de suas composições químicas. As características microestuturais de cada zona podem se diferenciar dependendo dos parâmetros de soldagem e, portanto, os comportamentos à corrosão também podem ser alterados, mesmo quando são soldadas ligas similares.

Ju Kang et al. (2010), realizaram ensaios de imersão de chapas da liga 2024-T3 soldadas por FSW, em solução de EXCO (4,0 M NaCl + 0,5 $\mathrm{M} \mathrm{KNO}_{3}+$ 0,1 $\left.\mathrm{M} \mathrm{HNO}_{3}\right)$, com $\mathrm{pH}$ igual a 0,4 . Observaram que a corrosão por pites se iniciava pela dissolução de 
precipitados da fase $\mathrm{S}\left(\mathrm{Al}_{2} \mathrm{CuMg}\right)$ e era mais intensa na região central da solda, em razão da maior quantidade destes precipitados nesta região. Outros pesquisadores avaliaram a resistência à corrosão dessas diferentes zonas com microestruturas diferenciadas, como Jariyaboon et al. (2007) que mediram o potencial de duas chapas da liga 2024-T351 soldadas por FSW, em diferentes pontos, e constataram que, para alta velocidade de rotação do pino da ferramenta de solda FSW, as ZTAs referentes aos lados de avanço e retrocesso eram mais suscetíveis à corrosão, em consequência da formação de precipitados intergranulares de fase $\mathrm{S}\left(\mathrm{Al}_{2} \mathrm{CuMg}\right)$. Esses precipitados são anódicos em relação à matriz, e para baixas velocidades de rotação o nugget era mais suscetível à corrosão, em razão da reprecipitação de partículas finas de fase S nos contornos de grãos. Bousquet et al. (2011), por sua vez, mostraram que a ZTA próxima à ZTMA da região soldada por FSW de ligas similares 2024-T3 era preferencialmente corroída. Isso se daria em virtude da presença de grande quantidade de precipitados intergranulares de fase $S^{\prime}(S)$, que são anódicos em relação à matriz.

Assim como para as ligas da série 2xxx, Lumsden et al. (2003), mostraram que a interface entre a ZTA e a ZTMA era corroída preferencialmente quando se utilizava a soldagem por FSW de duas chapas da liga 7050-T7651. Isto também foi constatado por Wadeson et al. (2006) que, com as mesmas condições de ensaio, avaliaram o comportamento de duas chapas da liga 7108, soldadas por FSW. Explicaram que a corrosão preferencial entre essas zonas se devia a uma distribuição não uniforme de precipitados de fase $\eta\left(\mathrm{MgZn}_{2}\right)$ na ZTMA. Paglia e Buchheit (2008), em estudo sobre a suscetibilidade à corrosão de duas chapas da liga 7050-T7451 soldadas por FSW, mostraram que a região da solda era mais suscetível à corrosão, e que o ataque corrosivo ocorria geralmente na interface entre o nugget e a ZTMA. Para esta liga da série 7xxx, houve a sensitização ao longo dos contornos de grãos, na região entre o nugget e a ZTMA, em razão de precipitados ricos em $\mathrm{Cu}-\mathrm{Zn}$, responsáveis pela corrosão intergranular.

Alguns grupos têm dado importância à investigação da suscetibilidade à corrosão de ligas dissimilares soldadas por FSW, como a solda de ligas Al/Cu (Akinlabi, 2014; Sarcghad, 2014), Al/Mg (Strass, 2014) e diferentes ligas de alumínio.

Sidane et al. (2015) avaliaram o comportamento frente à corrosão das diferentes zonas formadas durante a soldagem por FSW das ligas 2050-T8 e 7449-T79, com auxílio de microscópio eletroquímico de varredura (SECM). Utilizaram um meio pouco corrosivo e 
verificaram diferença de comportamento cinético na camada passiva da região do nugget entre as duas ligas, o que foi atribuído a um forte acoplamento galvânico nessa região. Nesse mesmo estudo, a técnica de impedância localizada (LEIS) foi utilizada em meio pouco corrosivo, confirmando a hipótese de que a região de interface entre as ligas era a mais reativa, em razão do acoplamento galvânico mais intenso nessa região.

Donatus et al. (2015) estudaram a suscetibilidade à corrosão das ligas 5083 e 6082 soldadas por FSW, em solução de 3,5\% de $\mathrm{NaCl}$, em duas diferentes velocidades de avanço da ferramenta da solda FSW: $300 \mathrm{~mm} / \mathrm{min}$ e $400 \mathrm{~mm} / \mathrm{min}$. No geral, as amostras soldadas com a velocidade maior de avanço da ferramenta $(400 \mathrm{~mm} / \mathrm{min})$ foram mais suscetíveis à corrosão em relação às amostras soldadas com menor velocidade de avanço (300 mm/min). Isto foi explicado pela menor velocidade de movimentação gerar maior fluxo de calor e a mistura dos materiais ser mais intensa, ou seja, a maior velocidade de movimentação resulta em menores diferenças entre as diferentes zonas formadas.

Os autores verificaram, por meio de ensaios eletroquímicos e por microscopia eletrônica de varredura, que as regiões mais suscetíveis à corrosão foram:

- as ZTAs de ambas as ligas, para as duas velocidades de movimentação da ferramenta, sendo que no caso da liga 5083, a razão pode ser a formação de precipitados anódicos intergranulares de fase $\beta\left(\mathrm{Al}_{3} \mathrm{Mg}_{2}\right)$. Estes são geralmente formados em temperaturas entre $50{ }^{\circ} \mathrm{C}$ e $250{ }^{\circ} \mathrm{C}$. A ZTA da liga 6082 sofre corrosão intergranular em razão da dissolução inicial do $\mathrm{Mg}$, presente nos precipitados intergranulares de fase $\mathrm{Mg}$-Si, que são anódicos em relação à matriz. A dissolução destes deixa um sítio catódico de Si que, consequentemente, causa a dissolução adjacente da matriz. Além disso, as zonas livres de precipitados também foram maiores nessa região;

- Para as duas velocidades houve maior suscetibilidade à corrosão no nugget (interface) entre as duas ligas, em razão de um forte acoplamento galvânico nesta região. A corrosão foi iniciada nos contornos de grãos de ambas as ligas, na interface entre elas, e se espalhou, preferencialmente, para a liga 5083 que é anódica em relação à liga 6082;

- Para a velocidade de avanço da ferramenta de $400 \mathrm{~mm} / \mathrm{min}$, houve ainda uma nova região suscetível à corrosão, que foi a interface entre a ZTMA e o nugget 
da liga 6082. Isso ocorreu em virtude da influência das partículas de fase Mg$\mathrm{Si}$, distribuídas ao longo dessa interface, que é mais heterogênea com a menor mistura dos materiais e menor fluxo de calor.

Bertoncello et al. (2015) estudaram o comportamento à corrosão das ligas 7050 e 2024 sobrepostas e soldadas por FSW, utilizando técnicas convencionais e SVET em solução de $0,1 \mathrm{M}$ de $\mathrm{NaCl}$. Verificaram que a maior intensidade de pites ocorria preferencialmente na zona do nugget da liga 7050 para condições em potencial de circuito aberto. Atribuíram este resultado provavelmente ao intenso acoplamento galvânico nessa região. Para longos tempos em potencial em circuito aberto, ocorreu corrosão intergranular em todas as zonas. Esta forma de corrosão, todavia, foi mais intensa na ZTA da liga 2024, apesar desse ataque ser menos intenso do que o observado na liga 2024 não soldada. Esta diferença foi atribuída ao acoplamento galvânico com a liga 7075.

\subsection{Métodos de estudo da corrosão localizada}

A corrosão em ligas de alumínio tem início devido aos diferentes potenciais de corrosão de seus precipitados em relação às respectivas matrizes (ver Tabela 3.2). Contudo, as técnicas eletroquímicas convencionais e mais utilizadas na avaliação da resistência à corrosão, como por exemplo, os ensaios de espectroscopia de impedância eletroquímica (EIS) e de voltametria cíclica, apresentam limitações no estudo de processos eletroquímicos que não se distribuem homogeneamente na superfície, como a corrosão localizada (Mansfeld, 1982; Queiroz, 2008). A fim de resolver essas limitações, um grande esforço tem sido feito desde o início da década de 1980 para o desenvolvimento de técnicas que superem as limitações espaciais das técnicas eletroquímicas, tanto pela melhoria dos dispositivos eletrônicos, quanto pela evolução na fabricação de micro-eletrodos metálicos (Sun, 2007).

Antes de apresentar as novas técnicas que foram introduzidas nesse período, é importante lembrar que, em 1938, Evans e Thornhill introduziram a técnica de varredura do eletrodo de referência (SRET - Scanning Reference Electrode Technique). Inicialmente esta era usada por biólogos na medição de corrente de estado estacionário perto de células vivas (Evans, 1938; Jaffe, 1974). A partir da década de 1970, a técnica passou a ser usada para análise de processos corrosivos, pois com o auxílio de um capilar de Luggin tornava-se possível medir a distribuição do potencial em solução, em diferentes posições ao longo da 
superfície do eletrodo de trabalho, permitindo dessa maneira o mapeamento das heteregeoneidades da amostra (Campbell, 1996). Nesta técnica, basicamente, o eletrodo de referência é varrido sobre a superfície, com o auxílio de um segundo eletrodo de referência que é usado para monitorar o potencial de corrosão geral. Assim sendo, pequenas diferenças no potencial podem ser visualizadas. A evolução dessa técnica no uso de avaliação de corrosão localizada, por apresentar uma sensibilidade maior, foi a técnica de varredura do eletrodo vibratório (SVET - Scanning Reference Electrode Technique), onde a diferença entre as linhas de potencial (gradiente de potencial) em região de corrosão localizada é medida pela vibração de uma pequena ponta. Se esta ponta vibra numa região de gradiente de potencial, a diferença de potencial resultante é facilmente detectada (modo de corrente alternada) com eletrônicos sensíveis. O desenvolvimento desse equipamento continuou posteriormente, na revolucionária década de 1980, através da evolução dos microeletrodos e dos microscópios eletroquímicos (Bard, 1989; Gabrielli, 2004).

No que se refere à resolução espacial, a grande descoberta desse período foi o advento do microscópio de tunelamento (STM - Scanning Tunneling Microscope), criado em 1981, por Binnig e Rohrer, que permitiu a resolução na ordem nanométrica, onde uma ponta move-se até a proximidade de uma amostra condutora, sem que ambas se toquem. A tensão de polarização entre a ponta e a amostra permite o fluxo de corrente entre elas, devido ao tunelamento quântico (Binnig et al., 1982). Baseado no STM, o mesmo inventor, Gerd Binnig, criou em 1982 o microscópio de força atômica (AFM - Atomic Force Microscope), que permite resoluções nanométricas com melhores definições do que o STM. A diferença é que nesta técnica, a ponta toca mecanicamente a amostra e, através de piezoleletricidade permite a interação e leitura da superfície da amostra (Binnig et al., 1986). A utilização da técnica de microscopia de força atômica permitiu um avanço significativo no estudo do desenvolvimento de pites nas ligas de alumínio.

Entretanto, essas novas técnicas ainda eram insuficientes para avaliar minuciosamente os efeitos eletroquímicos ocasionados pela corrosão localizada. A técnica de varredura do eletrodo vibratório (SVET), por exemplo, que mede a densidade de corrente contínua e permite identificar as heteregeoneidades da superfície da amostra, mas não pode explicar a reatividade local, assim como os microscópios de alta resolução, que permitem as análises visuais dos processos, mas não analisam os processos eletroquímicos envolvidos. 
Com o intuito de resolver esses problemas, diversas técnicas têm sido refinadas, visando o aprimoramento das análises de corrosão local, como a espectroscopia de impedância eletroquímica localizada (LEIS - Local Electrochemical Impedance Spectroscopy), que permitem análises mais apuradas sobre a reatividade local, em razão de trabalharem com corrente alternada (Lillard, 1992; Zou, 1997; Annergren, 1999) e a microscopia eletroquímica de varredura (SECM - Scanning Electrochemical Microscopy), uma outra técnica que permite fornecer informações químicas, que não são possíveis pela técnica de varredura do eletrodo vibratório (SVET).

Neste trabalho, as técnicas utilizadas para a verificação da corrosão localizada nas diferentes zonas formadas após o processo de soldagem por FSW, nas ligas de alumínio 2024-T3 e 7475-T651, foram: SECM, LEIS e EIS usando célula eletroquímica com abertura de $1 \mathrm{~mm}$ de diâmetro.

\subsection{Uso de técnicas locais para o estudo da corrosão de materiais soldados}

Um fator limitante na análise de resultados de espectroscopia de impedância eletroquímica para as ligas de alumínio é que por este ser um metal passivo, os diagramas de EIS representam variadas respostas das regiões, tanto das regiões submetidas à corrosão localizada, como da região ao redor da camada passiva. Dessa maneira, a detecção da corrosão localizada apenas é possível após tempos relativamente longos de ensaio, isto é, num momento onde o eletrodo encontra-se muito corroído, dificultando ainda mais a avaliação da influência dos fenômenos locais de corrosão (Annergren et al., 1999). As principais técnicas utilizadas neste trabalho visam analisar os primeiros sinais da corrosão localizada.

A espectroscopia de impedância eletroquímica local (LEIS) tem mostrado ser extremamente útil para descrever o acoplamento galvânico entre dois domínios adjacentes, como a união entre alumínio puro/cobre puro. Jorcin et al. (2008) observaram um aumento da atividade catódica na interface entre os dois metais, desde os primeiros momentos de imersão em solução de $10^{-3} \mathrm{M}$ de $\mathrm{Na}_{2} \mathrm{SO}_{4}$.

Usando a mesma solução e o mesmo princípio, Lacroix et al. (2009) estudaram a união entre alumínio puro/magnésio puro, que seria a primeira etapa de dissolução das partículas de fase $\mathrm{S}\left(\mathrm{Al}_{2} \mathrm{CuMg}\right)$ da liga 2024. A técnica de LEIS permitiu revelar um efeito prejudicial do acoplamento galvânico nos dois metais, sendo o resultado bastante 
consistente com o comportamento eletroquímico das partículas de fase $\mathrm{S}$, que apresentam uma dissolução do magnésio e uma depassivação na matriz de alumínio, no contorno da partícula de fase $S$.

Em continuação a esse estudo, Lacroix et al. (2012) ainda utilizando solução de $10^{-3}$ $\mathrm{M}$ de $\mathrm{Na}_{2} \mathrm{SO}_{4}$, produziram uma junção entre ligas individuais e produzidas em laboratório de Al-Cu e Al-Cu-Mg, simulando o comportamento à corrosão da liga 2024, que ocorre entre as partículas de fase $S$ e a matriz. A técnica de LEIS demonstrou um comportamento capacitivo da liga Al-Cu, enquanto que a liga Al-Cu-Mg foi o local onde apareceu forte reatividade. Os resultados mostraram que a técnica é eficiente no estudo dos mecanismos de corrosão envolvendo acoplamento galvânico.

Sidane et al. (2015), utilizaram a técnica de LEIS para estudar o comportamento das ligas de alumínio comerciais 2050-T8 e 7449-T79 soldadas por FSW, em solução de 60 mM de $\mathrm{NaCl}$. Os experimentos confirmaram a existência de uma corrente local maior na zona interfacial entre as diferentes ligas e também entre as diferentes zonas formadas pelo processo de soldagem FSW.

O microscópio eletroquímico de varredura (SECM) também tem sido utilizado com o objetivo de estudar a cinética da transferência de elétrons em ligas de alumínio. Serebrennikova e White (2001) buscaram identificar as naturezas física e química dos defeitos encontrados no filme de óxido de alumínio puro, de modo a determinar a relação entre a quebra do filme passivo e a corrosão localizada. Os autores mostraram que a reação de redução ocorria nas falhas eletrônicas presentes no óxido nativo do alumínio puro.

Blanc et al. (2010), estudaram a união entre alumínio puro/cobre puro, usando a combinação das técnicas SECM e microbalança eletroquímica de cristal de quartzo (EQCM). Os resultados obtidos mostraram a dissolução do cobre, mesmo quando o potencial do sistema era negativo, em relação ao potencial de corrosão do cobre puro.

Jensen et al. (2008), estudaram a transferência de elétrons na superfície da liga 2024T3, pela técnica SECM com auxílio das técnicas SEM/EDS, em solução pouco corrosiva de sulfato e mediador. Foi revelado que as partículas intermetálicas que continham cobre exibiram atividade de transferência de elétrons significativamente maior do que a matriz.

Sidane et al. (2015), utilizaram a técnica de SECM para estudar o comportamento das ligas de alumínio comerciais 2050-T8 e 7449-T79 soldadas por FSW, em solução pouco 
corrosiva. Os resultados obtidos mostraram que houve uma diferença da cinética eletroquímica sobre a camada passiva do nugget, ou seja, na interface dos materiais. Esta variação foi atribuída à existência de um acoplamento galvânico entre as duas ligas. 


\section{MATERIAIS E MÉTODOS}

Os ensaios realizados foram divididos em quatro partes: caracterização microestrutural, avaliação da resistência a várias formas de corrosão, caracterização eletroquímica e análise superficial. O esquema de organização e a descrição de todos os ensaios realizados são apresentados pela Figura 4.1.
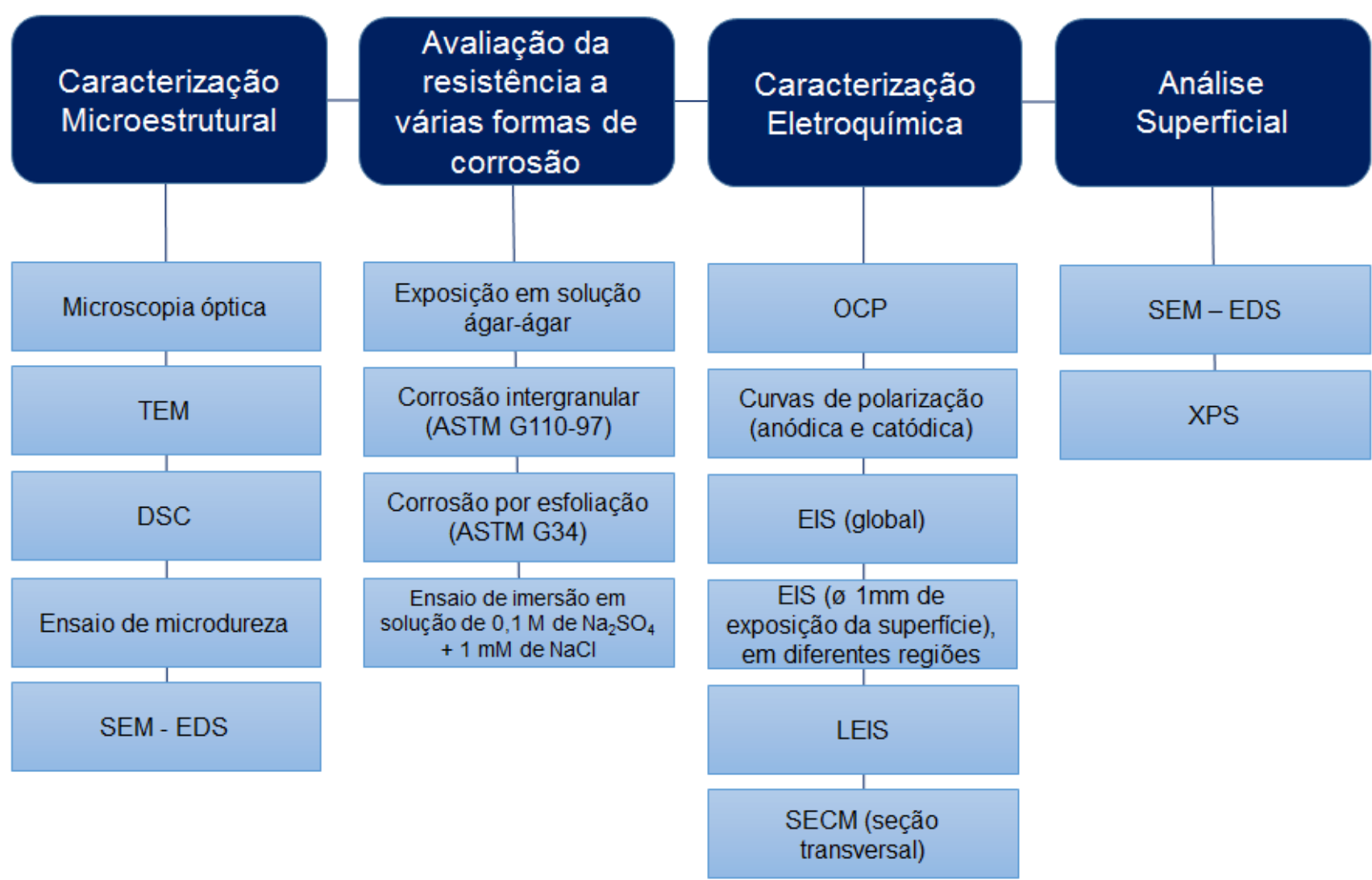

Figura 4.1: Esquema da organização dos ensaios realizados

\subsection{Materiais}

\subsubsection{Ligas de alumínio}

As chapas das ligas de alumínio 2024-T3 e 7475-T651, com espessuras de 2 mm, foram fornecidas pela EMBRAER, já soldadas pela técnica de soldagem por fricção (FSW). As amostras utilizadas neste trabalho foram cortadas de uma mesma chapa, ou seja, os corpos de prova pertencem a um mesmo lote de chapas e possuem os mesmos parâmetros de soldagem. 
As composições químicas das ligas 2024-T3 e 7475-T651, conforme as respectivas especificações, são apresentadas nas Tabelas 4.1 e 4.2 .

Tabela 4.1: Composição química da liga 2024-T3

\begin{tabular}{cccccccccc}
\hline Elemento químico & $\mathbf{C u}$ & $\mathbf{M g}$ & $\mathbf{M n}$ & $\mathbf{F e}$ & $\mathbf{S i}$ & $\mathbf{Z n}$ & $\mathbf{C r}$ & $\mathbf{T i}$ & Outros \\
\hline Teor \% $(\mathbf{m} / \mathbf{m})$ & $3,8-4,9$ & $1,2-1,8$ & $0,3-0,9$ & 0,50 & 0,50 & 0,25 & 0,10 & 0,15 & 0,15 \\
& & & & máx & máx & máx & máx & máx & máx \\
\hline
\end{tabular}

\% de alumínio é o balanço para $100 \%$

Tabela 4.2: Composição química da liga 7475-T651

\begin{tabular}{cccccccc}
\hline Elemento químico & $\mathbf{Z n}$ & $\mathbf{M g}$ & $\mathbf{C u}$ & $\mathbf{C r}$ & $\mathbf{F e}$ & $\mathbf{M n}$ & $\mathbf{T i}$ \\
\hline Teor \% $(\mathbf{m} / \mathbf{m})$ & $5,2-6,2$ & $1,9-2,6$ & $1,2-1,9$ & $0,18-$ & 0,12 & 0,06 & 0,06 \\
& & & & 0,25 & máx & máx & máx \\
\hline
\end{tabular}

\% de alumínio é o balanço para 100\%

A fim de verificar se as amostras fornecidas continham as composições especificadas, foi realizado o ensaio direto e não destrutivo, através da técnica de espectrometria de fluorescência de raios-X por dispersão de comprimento de onda, em amostras das ligas 2024-T3 e 7475-T651, respectivamente. Os resultados do ensaio são apresentados na Tabela 4.3.

Tabela 4.3: Composições químicas das ligas 2024-T3 e 7475-T651, obtidas por espectrometria de fluorescência de raios-X por dispersão de comprimento de onda

\begin{tabular}{ccc}
\hline Elemento & 2024-T3 & 7475-T651 \\
& Teor (\%) & Teor (\%) \\
\hline $\mathbf{M g}$ & $92,3 \pm 0,5$ & $89,4 \pm 0,5$ \\
$\mathbf{S i}$ & $0,11 \pm 0,02$ & $0,15 \pm 0,02$ \\
$\mathbf{P}$ & $0,03 \pm 0,01$ & $0,03 \pm 0,01$ \\
$\mathbf{S}$ & $0,02 \pm 0,01$ & $0,05 \pm 0,01$ \\
$\mathbf{C a}$ & $0,04 \pm 0,01$ & $0,06 \pm 0,01$ \\
$\mathbf{T i}$ & $0,05 \pm 0,01$ & $0,04 \pm 0,01$ \\
$\mathbf{C r}$ & $0,04 \pm 0,02$ & $0,22 \pm 0,01$ \\
$\mathbf{M n}$ & $0,64 \pm 0,06$ & $0,02 \pm 0,01$ \\
$\mathbf{F e}$ & $0,16 \pm 0,01$ & $0,12 \pm 0,02$ \\
$\mathbf{C u}$ & $4,5 \pm 0,5$ & $1,7 \pm 0,2$ \\
$\mathbf{Z n}$ & $0,03 \pm 0,01$ & $6,2 \pm 0,6$ \\
\hline
\end{tabular}

Destaca-se que os resultados são normalizados para 100\% e referem-se à média e desvio padrão estimados para um nível de confiança de $95 \%$. Conforme comparação entre 
as Tabelas 4.1, 4.2 e 4.3, foi possível observar que as amostras fornecidas continham as composições químicas conforme as respectivas especificações.

\subsubsection{Soluções}

As soluções foram preparadas com reagentes de grau analítico de pureza e água destilada. As soluções utilizadas são apresentadas na Tabela 4.4.

Tabela 4.4: Soluções utilizadas em cada ensaio apresentado na Figura 4.1 Ensaio Solução

\begin{tabular}{|c|c|}
\hline Ensaio & Solução \\
\hline Microscopia óptica & $\begin{array}{l}\text { Reagente Keller ( } 10 \mathrm{ml} \text { de } \mathrm{HF}+15 \mathrm{ml} \text { de } \mathrm{HCl}+25 \mathrm{ml} \text { de } \mathrm{HNO}_{3}+50 \\
\mathrm{ml} \text { de água destilada) }\end{array}$ \\
\hline TEM & $20 \%$ de $\mathrm{HNO}_{3}+80 \%$ de metanol, à $-30{ }^{\circ} \mathrm{C}$ \\
\hline SEM & $0,1 \mathrm{M}$ de $\mathrm{Na}_{2} \mathrm{SO}_{4}+1 \mathrm{mM}$ de $\mathrm{NaCl}$ \\
\hline Exposição em ágar-ágar & $\begin{array}{l}0,7 \mathrm{M} \text { de } \mathrm{NaCl}+7 \mathrm{ml} \text { de indicador universal com } 5 \mathrm{~g} \text { de ágar-ágar, } \\
\text { em água destilada à } 100^{\circ} \mathrm{C}\end{array}$ \\
\hline Corrosão por esfoliação & 4,0 M de $\mathrm{NaCl}+0,5 \mathrm{M}$ de $\mathrm{KNO}_{3}+0,1 \mathrm{M}$ de $\mathrm{HNO}_{3}$ \\
\hline Corrosão intergranular & $\begin{array}{l}57 \mathrm{~g} \text { de } \mathrm{NaCl}+10 \mathrm{~mL} \text { de } \mathrm{H}_{2} \mathrm{O}_{2}(30 \%) \text {, diluído em } 1 \mathrm{~L} \text { de água } \\
\text { destilada }\end{array}$ \\
\hline Ensaios eletroquímicos & $0,1 \mathrm{M}$ de $\mathrm{Na}_{2} \mathrm{SO}_{4}+1 \mathrm{mM}$ de $\mathrm{NaCl}$ e $0,1 \mathrm{M}$ de $\mathrm{Na}_{2} \mathrm{SO}_{4}$ \\
\hline SECM & $0,1 \mathrm{M}$ de $\mathrm{Na}_{2} \mathrm{SO}_{4}+0,01 \mathrm{M}$ de Hidroquinona $+5 \mathrm{mM}$ de $\mathrm{H}_{2} \mathrm{SO}_{4}$ \\
\hline XPS & $0,1 \mathrm{M}$ de $\mathrm{Na}_{2} \mathrm{SO}_{4}+1 \mathrm{mM}$ de $\mathrm{NaCl}$ \\
\hline
\end{tabular}

A solução de reagente Keller foi utilizada para revelar os grãos e, dessa maneira, eles puderam ser visualizados pela microscopia óptica. A solução de ácido nítrico e metanol foi utilizada no eletropolimento das amostras analisadas por TEM. A solução para o ensaio de exposição em ágar-ágar foi realizada à $100^{\circ} \mathrm{C}$, de forma a misturar o gel ágar-ágar à solução de cloreto de sódio e ao indicador universal. As soluções para os ensaios de verificação da corrosão intergranular e por esfoliação foram soluções bem ácidas e agressivas. A solução de sulfato de sódio, hidroquinona e ácido sulfúrico foi utilizada no ensaio de SECM, e este acréscimo de hidroquinona para a estabilização do meio. A solução de $0,1 \mathrm{M}$ de $\mathrm{Na}_{2} \mathrm{SO}_{4}+$ 
$1 \mathrm{mM}$ de $\mathrm{NaCl}$ continha como reagente principal o sulfato de sódio, que é utilizado em ensaios de corrosão, a fim de se verificar uma corrosão generalizada das ligas, ou seja, diminuir as interferências de corrosão por pites que possam ser formadas. A adição de $1 \mathrm{mM}$ de cloreto de sódio na composição do eletrólito, se deu em razão do eletrodo de referência utilizado ser de $\mathrm{Ag} / \mathrm{AgCl}$, que se favorece de uma quantidade mínimia de cloreto na solução, para a estabilização do potencial.

\subsection{Métodos}

\subsubsection{Preparação das amostras}

Para todos os ensaios, com exceção do DSC e do TEM, as amostras foram embutidas em resina epoxídica, via processo de embutimento à frio. A fim de evitar problemas causados por frestas - possivelmente - geradas por falhas no embutimento, antes de serem embutidas as amostras passaram por um processo de cataforese, que deposita uma camada plástica (revestimento orgânico) sobre a amostra e ajuda a isolá-la.

As amostras foram lixadas com lixas de carbeto de silício na seguinte ordem: 400, 600, 1200 e P4000. Em seguida, foram polidas com solução de alumina e água destilada. Após cada lixamento e o polimento final, as amostras eram lavadas com água destilada e secadas em jato de ar.

\subsubsection{Caracterização microestrutural por microscopia óptica}

Para revelar a microestrutura de cada zona individual da solda, utilizou-se ataque metalográfico de Keller (solução descrita na Tabela 4.4), durante 30 segundos. Em seguida, as amostras eram lavadas com água destilada e secadas em jato de ar.

\subsubsection{Caracterização microestrutural por TEM}

As imagens obtidas por microscopia eletrônica de transmissão (TEM) foram obtidas utilizando o equipamento da marca JEOL, modelo JEM-2100, operando em $200 \mathrm{kV}$. As amostras analisadas no TEM foram lixadas, em lixa de carbeto de silício 1200, com extremo cuidado, até que a espessura da amostra tivesse aproximadamente $100 \mu \mathrm{m}$. Em seguida, 
foram preparados pequenos discos, de aproximadamente $20 \mathrm{~mm}$ de diâmetro, por processo de eletroerosão. Novamente as amostras foram lixadas, manualmente, até que os discos tivessem espessuras mais finas $e$ isso facilitasse $o$ polimento eletrolítico, feito no equipamento da Tenupol-Struers, com a solução indicada na Tabela 4.4. A determinação da composição dos precipitados intragranulares e intergranulares foram realizadas por STEM, com o auxílio de um detector EDX, modelo Oxford X-MaxN SDD.

\subsubsection{Caracterização microestrutural por SEM/EDS}

As imagens obtidas por microscopia eletrônica de varredura (SEM) foram obtidas utilizando o equipamento da marca $\mathrm{FEI}$, modelo Quanta 600. A tensão de aceleração utilizada para a obtenção das imagens foi de 15 ou $20 \mathrm{keV}$. Ambos os equipamentos estavam acoplados a um espectrômetro de energia dispersiva de raios $X$ (EDS), com limite de detecção da ordem de $1 \%(\mathrm{~m} / \mathrm{m})$, de modo que era possível a realização de microanálises químicas semiquantitativas elementares (com penetração de feixe e resolução lateral estimada da ordem de $1 \mu \mathrm{m}$ a $3 \mu \mathrm{m})$. As imagens foram obtidas com elétrons retroespalhados e elétrons secundários. As amostras foram obtidas de amostras polidas em alumina ou após serem expostas às soluções de ensaio.

\subsubsection{Calorimetria exploratória diferencial (DSC)}

A calorimetria exploratória diferencial (DSC) é uma técnica que avalia a diferença de temperatura entre a amostra analisada e uma referência, enquanto ambas são submetidas a uma programação de rigoroso controle e temperatura (Machado e Matos, 2004). Essa diferença de temperatura permite medir as liberações e absorções de energia durante um ciclo térmico, por exemplo, durante a transformação de fases, recuperação e recristalização de uma liga metálica.

As medidas de DSC foram obtidas pelo aparelho 822 Mettler-Toledo, sob atmosfera de nitrogênio com grau de pureza de $99,999 \%$, na faixa de temperatura entre $50^{\circ} \mathrm{C}$ e $550^{\circ} \mathrm{C}$, a uma taxa de aquecimento de $10^{\circ} \mathrm{C} / \mathrm{min}$.

As amostras foram cortadas de cada zona formada após a soldagem por FSW, em quadrados com dimensões de $4 \mathrm{~mm} \times 4 \mathrm{~mm}$ e espessura de $2 \mathrm{~mm}$. As amostras eram 
colocadas em cadinhos de alumínio, com elevada pureza, de $5 \mathrm{~mm}$ de diâmetro. Os cadinhos vazios foram usados como referência, pois são compostos de alumínio. Tanto a amostra inserida no cadinho quanto o cadinho vazio (referência) foram colocados sobre um disco metálico, com o fluxo do calor diferencial sendo controlado por termopares. Como resultado, foram obtidas as curvas de DSC de cada amostra, apresentadas como fluxo de calor em função da temperatura ou do tempo.

\subsubsection{Ensaio de microdureza}

O ensaio de microdureza Vickers HV 0.5, com carga de $50 \mathrm{gf}$, foi realizado pelo microdurômetro modelo DuraScan 70, marca Emco-Test. As medidas de microdureza foram obtidas ao longo da superfície da amostra, no sentido do MB da liga 2024-T3 ao MB da liga 7475-T651, conforme indica a Figura 4.2.

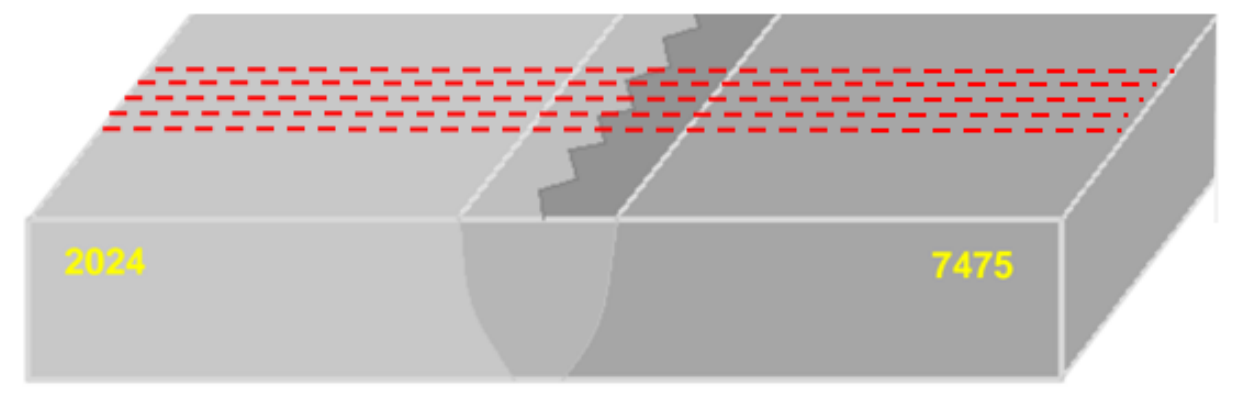

Figura 4.2: Ilustração esquemática da região onde foram realizadas as medidas de microdureza destacada pelas linhas tracejadas em vermelho

Todas as impressões geraram um mapa de microdureza, realizado pelo software Ecos Workflow (versão V.2.11.0). A partir desse mapa de dureza, foi feito um gráfico do perfil das microdurezas ao longo das diferentes regiões formadas após o processo de soldagem por FSW.

\subsubsection{Exposição em solução de ágar-ágar}

Este procedimento foi utilizado com o objetivo de identificar macroscopicamente a a variação de $\mathrm{pH}$ entre as diferentes regiões formadas após a solda, bem como entre as diferentes ligas, e seguir sua evolução em função do tempo de exposição a um ambiente corrosivo. A solução de ágar-ágar foi preparada misturando-se $5 \mathrm{~g}$ deste componente em $100 \mathrm{ml}$ de solução de $0,7 \mathrm{M}$ de $\mathrm{NaCl} 0,7 \mathrm{M}$ contendo $7 \mathrm{ml}$ de indicador universal de $\mathrm{pH}$ e o 
restante de água deionizada, à $100^{\circ} \mathrm{C}$. Para a realização do ensaio, as amostras polidas foram colocadas em uma placa de Petri, sendo recobertas com a solução de ágar-ágar com uma espessura entre 1 e $2 \mathrm{~mm}$. As modificações na coloração da solução sobre a superfície foram registradas, fotograficamente, durante 8 horas.

\subsubsection{Corrosão intergranular}

O ensaio de corrosão intergranular foi realizado conforme a norma ASTM G110-97, a fim de analisar quais eram as regiões mais suscetíveis a este tipo de corrosão, após o processo de soldagem por FSW. A amostra polida, e embutida em resina, foi submetida à solução de $57 \mathrm{~g}$ de $\mathrm{NaCl}+10 \mathrm{~mL}$ de $\mathrm{H}_{2} \mathrm{O}_{2}$ (30\%), diluído em $1 \mathrm{~L}$ de água destilada, durante 6 horas à temperatura ambiente e em recipiente inerte.

Após as 6 horas de exposição na solução supracitada, a amostra foi limpa com água destilada e seca em jato de ar, onde foram tiradas fotografias e realizadas imagens, por SEM, da superfície das diferentes zonas microestruturais. Em seguida, foi retirada da resina, de maneira bem delicada e embutida de maneira com que ficasse evidenciada a sua seção transversal, a fim de analisar o ataque profundamente. Após o embutimento, a seção transversal foi lixada até a lixa P4000, polida em solução de alumina e água e atacada com reagente Keller. Por fim, foram realizadas imagens, por microscopia óptica, de todas as regiões da seção transversal da amostra.

\subsubsection{Corrosão por esfoliação}

O ensaio de corrosão por esfoliação foi realizado conforme a norma ASTM G34-01, a fim de analisar quais eram as regiões, formadas após o processo de soldagem por FSW, mais suscetíveis a este tipo de corrosão. A amostra polida, e embutida em resina, foi submetida à solução de 4,0 $\mathrm{M}$ de $\mathrm{NaCl}+0,5 \mathrm{M}_{\text {de }} \mathrm{KNO}_{3}+0,1 \mathrm{M}$ de $\mathrm{HNO}_{3}$, durante 48 horas à temperatura ambiente e em recipiente inerte. Além da amostra das ligas 2024-T3 e 7475T651 soldadas por FSW, também foram analisadas amostras dos MB das ligas 2024-T3 e 7475-T651, como forma de comparação do comportamento.

Após as 48 horas de exposição na solução supracitada, as amostras foram limpas com água destilada e secas em jato de ar, onde foram tiradas fotografias. Em seguida, foram 
retiradas da resina, de maneira bem delicada e embutidas de maneira com que ficassem evidenciadas as respectivas seções transversais, a fim de analisar o ataque profundamente. Após o embutimento, as seções transversais foram lixadas até a lixa P4000, polidas em solução de alumina e água e atacadas com reagente Keller. Por fim, foram realizadas imagens, por microscopia óptica, de todas as regiões das respectivas seções transversais das amostras.

\subsubsection{Preparação da célula eletroquímica para os ensaios}

A célula eletroquímica, utilizada para todos os ensaios eletroquímicos, era composta de vidro, com abertura de $30 \mathrm{~mm}$ para o encaixe do eletrodo de trabalho, em sua parte inferior. O contra-eletrodo utilizado foi uma rede de platina, que era capaz de circundar toda a célula e, assim, permitir a distribuição uniforme de corrente. O eletrodo de referência utilizado foi de prata/cloreto de prata (solução saturada de $\mathrm{KCl}$ ). A Figura 4.3 apresenta uma ilustração esquemática da célula eletroquímica utilizada.

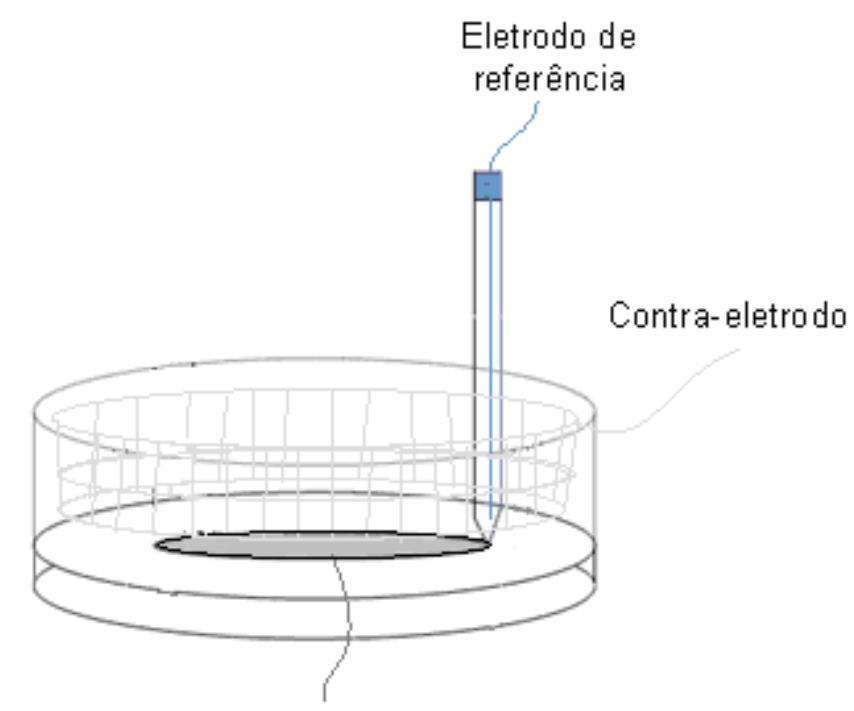

Eletrodo de trabalho

Figura 4.3: Ilustração esquemática da célula eletroquímica utilizada para as medidas de EIS

\subsubsection{Medidas de potencial em circuito aberto (OCP) em função do tempo de ensaio}

Com o intuito de verificar o tempo de estabilização das ligas utilizadas, foram realizados ensaios de potencial de circuito aberto. Os ensaios foram realizados utilizando 
um potenciostato modelo Parstat 2273, conectados a um microcomputador e controlados por meio do software PowerSuite.

\subsubsection{Curvas de polarização}

As curvas de polarização potenciodinâmicas, anódicas e catódicas, foram obtidas com velocidade de varredura de $0,166 \mathrm{mV} \mathrm{s}^{-1}$, utilizando um potenciostato modelo Parstat 2273, conectados a um microcomputador e controlados por meio do software PowerSuite. As curvas anódicas e catódicas foram obtidas em áreas de 4,8 cm², como forma de comparação entre as amostras das ligas 2024-T3 e 7475-T651 sem solda e com solda. As varreduras catódicas e anódicas foram iniciadas em $30 \mathrm{mV}$, respectivamente, acima ou abaixo do OCP. As curvas de polarização catódicas foram até um potencial de $\eta=-1.500$ $\mathrm{mV}$ ocp $/ \mathrm{Ag} / \mathrm{AgCl} / \mathrm{KCl}_{\text {(sat) }}$, e as curvas de polarização anódicas foram até um potencial de $\eta=$ + $400 \mathrm{mVocp} / \mathrm{Ag} / \mathrm{AgCl} / \mathrm{KCl}_{(\mathrm{sat})}$.

As curvas de polarização anódicas realizadas pela célula eletroquímica com pequena abertura foram obtidas com velocidade de varredura de $0,500 \mathrm{mV} \mathrm{s}^{-1}$, utilizando os mesmos equipamentos, porém em áreas de $0,8 \mathrm{~mm}^{2}$, a fim de se compreender o comportamento isolado de cada zona formada nas ligas, após o processo de soldagem por FSW. As varreduras foram iniciadas em $-30 \mathrm{mV}$ abaixo do OCP e foram até um potencial de $\eta=+400$ $\mathrm{mVocP} / \mathrm{Ag} / \mathrm{AgCl} / \mathrm{KCl}_{\text {(sat). }}$

\subsubsection{Espectroscopia de impedância eletroquímica (EIS)}

Os diagramas de impedância global foram obtidos no modo potenciostático, na faixa de frequência de $63 \mathrm{kHz}$ à $10 \mathrm{mHz}$, com 9 pontos por década e $20 \mathrm{mV}$ (rms) de amplitude de perturbação. Os equipamentos de controle foram definidos no item anterior. Assim como para as curvas de polarização potenciodinâmicas, foram realizados ensaios em amostras das ligas 2024-T3 e 7475-T651 com e sem solda, em áreas de 4,8 cm², como forma de comparação entre os respectivos comportamentos.

Ainda com os mesmos equipamentos e seguindo os mesmos parâmetros, os diagramas de impedância foram realizados numa célula eletroquímica com dimensões menores em relação à célula (área de $0,8 \mathrm{~mm}^{2}$ ) apresentada na Figura 4.3. O intuito desse 
ensaio era a avaliação isolada das diferentes zonas formadas após o processo de soldagem, por FSW, nas ligas de alumínio 2024-T3 e 7475-T651. A abertura da célula, junto à superfície do eletrodo de trabalho tinha $1,0 \mathrm{~mm}$ de diâmetro. As fotografias da Figura 4.4 apresentam a célula eletroquímica supracitada.
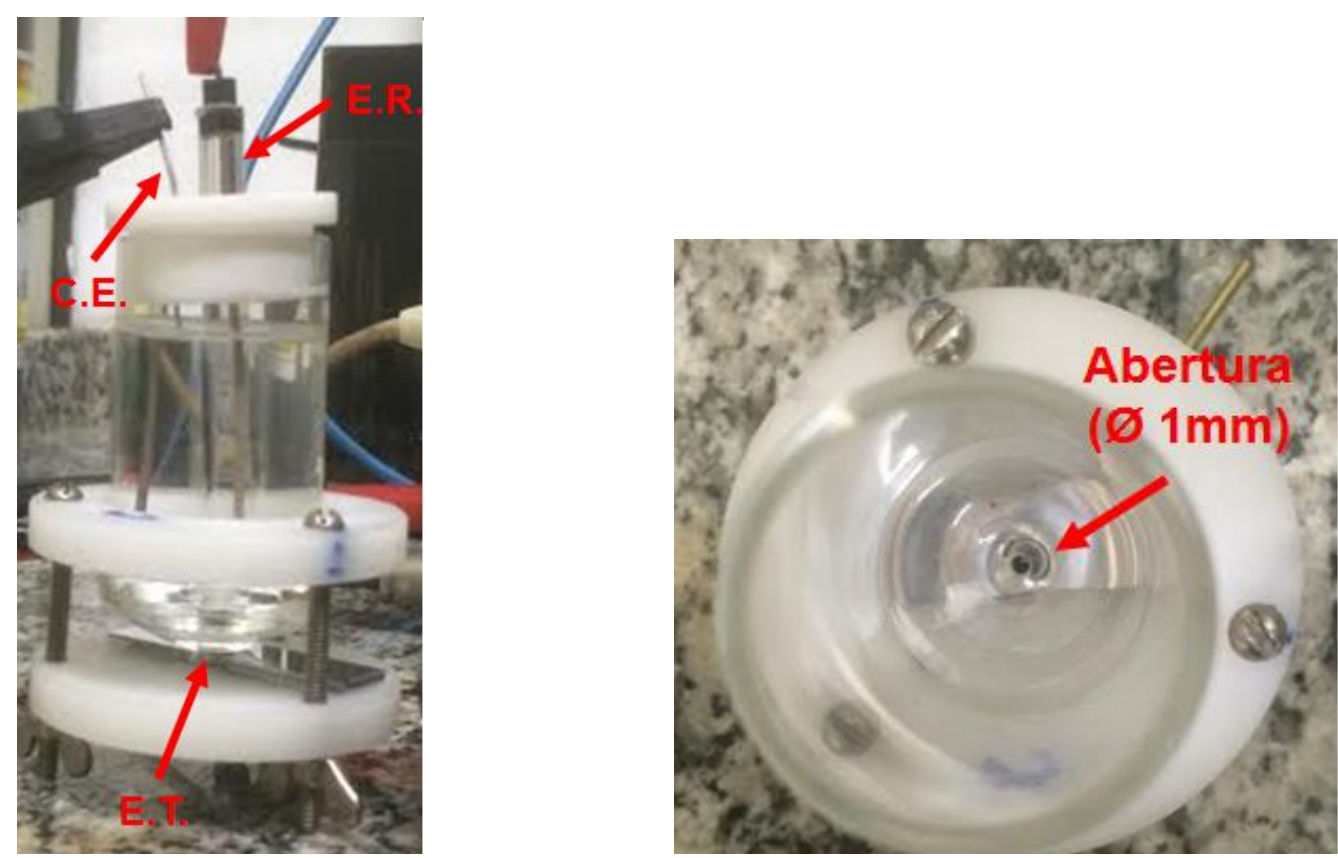

Figura 4.4: Fotografias da célula eletroquímica, com $\varnothing 1,0 \mathrm{~mm}$ de abertura, utilizada para a análise em diferentes zonas formadas após o processo de soldagem por FSW.

\subsubsection{Espectroscopia de impedância eletroquímica local (Local Electrochemical Impedance Spectroscopy - LEIS)}

A técnica de espectroscopia de impedância eletroquímica local (LEIS) é uma evolução da espectroscopia de impedância eletroquímica (EIS). Esta permite obter informações em escalas muito menores, utilizando exatamente os mesmos princípios da espectroscopia de impedância eletroquímica. A utilização desta técnica surgiu da necessidade de se conhecer o comportamento em defeitos locais (início de ataque ou mecanismos da quebra do filme passivo, por exemplo), em razão da espectroscopia de impedância eletroquímica (EIS) avaliar apenas o comportamento médio de toda a superfície exposta da amostra (Lillard, et al., 1992).

Há duas formas de realizar medidas com a técnica de espectroscopia eletroquímica de impedância local (LEIS). A primeira é por adaptação do SVET à polarização em corrente alternada (Bayet et al., 1997). A segunda é pela utilização de uma sonda (bieletrodo), como utilizado neste trabalho (Galicia, 2006). 
De maneira simplificada, a utilização desta sonda permite avaliar a diferença de potencial em regime alternado (potencial CA) entre as duas pontas da sonda (bi-eletrodo), que é colocada em distâncias milimétricas da superfície do eletrodo de trabalho (Zou et al., 1997; Bayet et al., 1997). Como essa diferença de potencial pode ser considerada proporcional ao gradiente de potencial nas vizinhanças das pontas do bi-eletrodo, a densidade de corrente local pode ser calculada usando uma relação relativamente simples oriunda da lei de Ohm (Bayet et al., 1997).

As medidas de espectroscopia de impedância local (LEIS) foram realizadas no Laboratoire Interfaces et Systèmes Electrochimiques (LISE), por um sistema não comercial, constituído por um analisador de resposta de frequência (FRA) de quatro canais da marca Solartron (modelo 1254), que permite medir as impedâncias global e local, paralelamente. O esquema de montagem e funcionamento do sistema é demosntrado na Figura 4.5.

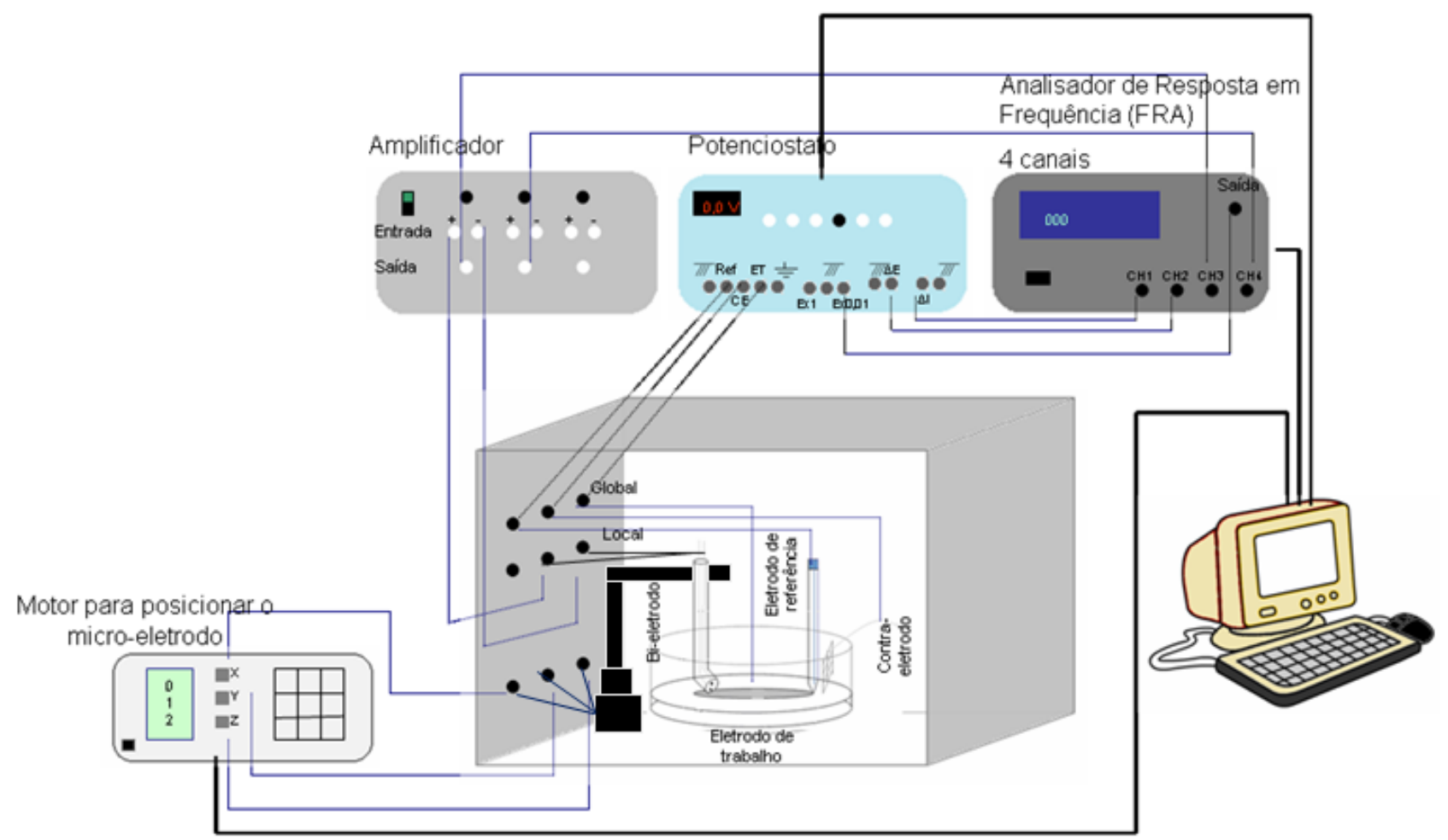

Figura 4.5: Esquema do sistema de medidas de LEIS e EIS, do LISE (Laboratoire Interfaces et Systemes Electrochimiques)

O FRA é ligado a um potenciostato fabricado no próprio laboratório, que possibilita a obtenção de medidas de correntes relativamente baixas em razão de sua alta impedância de entrada, e a um amplificador diferencial de ganho variável (de 10 à 2000 vezes), utilizado para amplificar as variações locais de potencial. Para a movimentação do bi-eletrodo, foi utilizado um motor de posicionamento da marca Newport (modelo UTM 25), que apresenta 
uma resolução espacial de 0,2 $\mu$ m por passo. A aquisição de dados foi possível pelo software Fracon, desenvolvido pelo LISE.

A célula eletroquímica utilizada nos ensaios de espectroscopia de impedância eletroquímica local era composta da mesma maneira do que a célula utilizada para os ensaios de EIS (ver Figura 4.3), porém com a inserção do bi-eletrodo (Figura 4.6), ou seja, com o bi-eletrodo a célula passava a contabilizar cinco eletrodos no total.

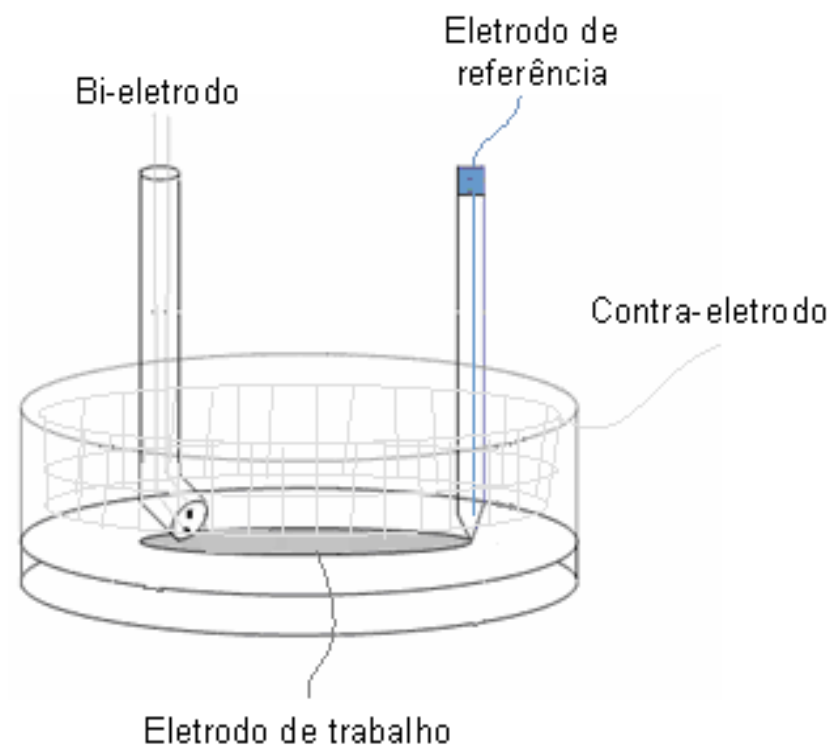

Figura 4.6: Ilustração esquemática da célula eletroquímica utilizada para as medidas de LEIS.

As medidas locais foram obtidas por um bi-eletrodo, sendo as medidas locais denominadas local e local interfacial. Todas as medidas de LEIS foram realizadas com controle potenciostático, ou seja, a cada medida o potencial em circuito aberto era ajustado no potenciostato, e numa faixa de frequência entre $63 \mathrm{kHz}$ e $10 \mathrm{mHz}$ (EIS), e entre $63 \mathrm{kHz}$ e alguns $\mathrm{Hz}$ (LEIS), com 7 pontos por década logartítmica e $30 \mathrm{mV}$ (rms) de amplitude de perturbação. A não exatidão da faixa de baixa frequência, em LEIS, será explicada no item 4.2.5.2 (Detecção de sinais em LEIS e seus limites)

O bi-eletrodo foi confeccionado da seguinte maneira: utilizava-se um micro tubo teta (ø $1,5 \mathrm{~mm}$ ) de borossilicato, com uma divisória interna e aquecia-se sua extremidade, a fim de modelar e deixar o micro tubo com uma curva, praticamente um 'L', que permitia que a sua face ficasse à 90 em relação à superfície do eletrodo de trabalho e, assim, se medisse as diferenças de campos elétricos gerados (discutidos no próximo item). Após a modelagem do micro tubo, soldavam-se dois fios pequenos de prata (ø $160 \mu \mathrm{m})$ a dois fios maiores de cobre (ø $200 \mu \mathrm{m})$, respectivamente, a fim de dar maior sustentação aos fios presos pelos 
conectores jacarés do equipamento e também para evitar o desperdício dos fios de prata. Em seguida, esses fios soldados passavam por um processo de cataforese e secagem, em forno, para manterem-se isolados, em seu estado final. Então, os fios isolados eram inseridos cada um em uma parte do micro tubo, com a ponta dos fios de prata expostas na face modelada. Posteriormente, com o auxílio de uma seringa, inseria-se resina epóxi (utilizada para embutimento à frio) e esperava-se a secagem. Após o tempo de cura da resina, lixava-se a ponta do micro-tubo com lixa de carbeto de silício \#1200. A Figura 4.7 apresenta as fotografias de um bi-eletrodo confeccionado durante este trabalho.

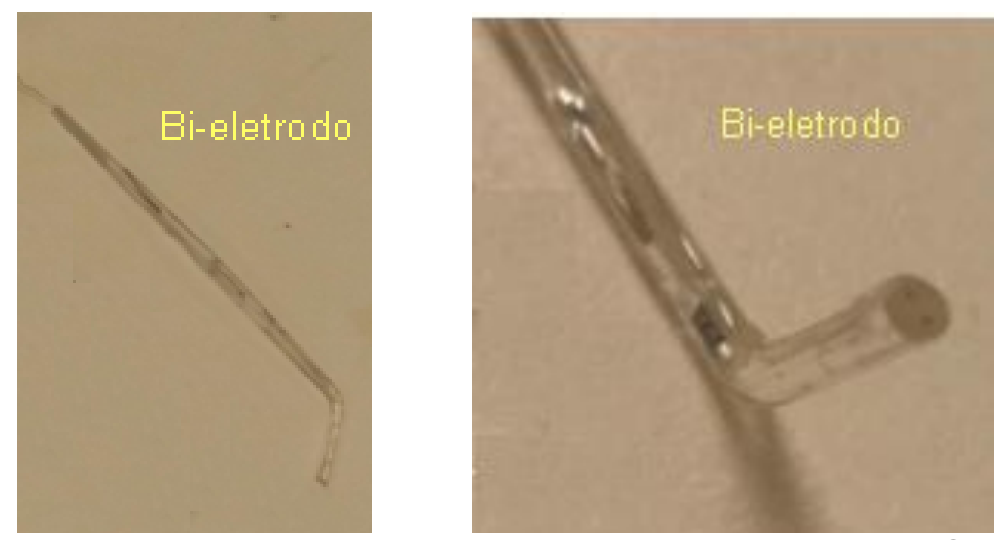

Figura 4.7: Fotografias de um bi-eletrodo, confeccionado no LISE

As pontas de prata (inertes) do bi-eletrodo ou agem como eletrodos de referência, ao medir a diferença de potencial CA, na solução. A Figura 4.8 apresenta um esquema de representação do funcionamento do bi-eletrodo e seus parâmetros, como as distâncias entre a superfície do eletrodo de trabalho e a ponta inferior do bi-eletrodo (h), o diâmetro das pontas dos fios de prata e a distância entre as pontas (d), para o bi-eletrodo. O entendimento desses parâmetros será fundamental para a compreensão dos cálculos para a avaliação da impedância local.
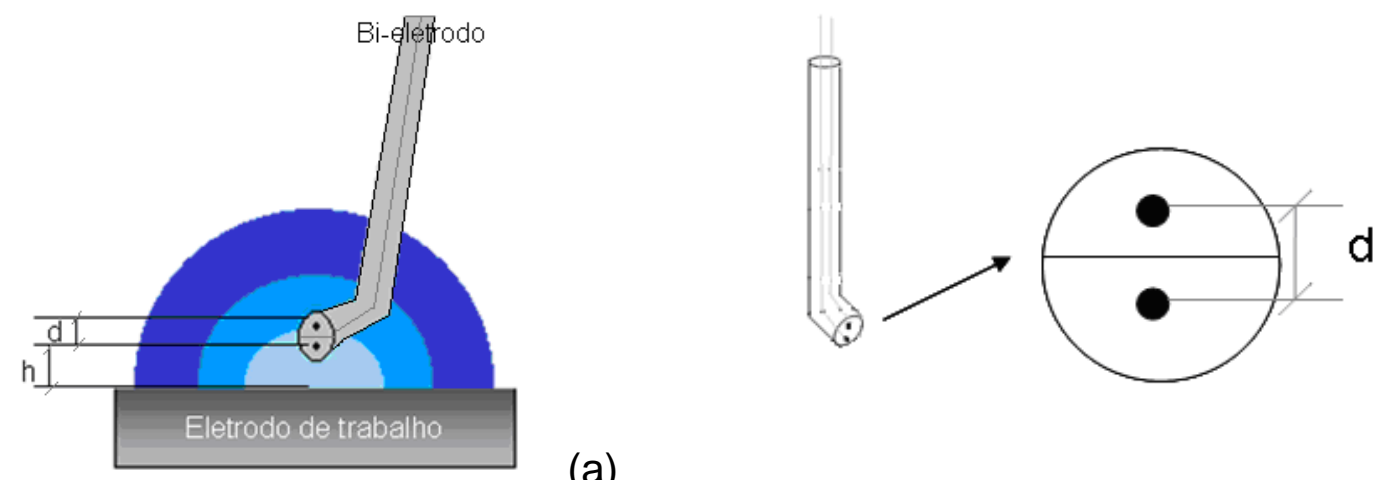

(a)

(b)

Figura 4.8: Esquema de representação do (a) bi-eletrodo e sua atuação, em LEIS; e (b) ilustração esquemática das pontas do bi-eletrodo. 
A corrente local é então obtida pela medida da diferença de potencial entre as duas pontas do bi-eletrodo ('d', da Figura 4.8 (b)), enquanto que o potencial local é medido pela diferença de potencial entre o eletrodo de trabalho e o micro-eletrodo de referência mais próximo à sua superfície ('h', da Figura 4.8 (a)).

\subsubsection{Definições e cálculos de impedâncias locais}

Conforme descrito anteriormente, e proposto por Huang et al. (2011), com a utilização do FRA quatro canais e do bi-eletrodo, é possível medir, simultaneamente, as impedâncias global, local e local interfacial.

\subsection{Cálculos de impedâncias locais (local, local interfacial e local ôhmica), medidas com o bi-eletrodo}

A seguir, serão apresentados os cálculos de dedução das impedâncias locais (local, local interfacial e local ôhmica). Essas impedâncias locais serão representadas, daqui em diante, com a letra z minúscula, de maneira a serem diferenciadas da impedância (global), cujo o símbolo é o Z maiúsculo.

Para as medidas eletroquímicas locais, a densidade de corrente CA local - iloc $(\omega)$ pode ser obtida através da lei de ohm (eq. 4.1).

$$
i_{\text {loc }}(\omega)=\frac{\Delta V_{\text {pontas }}(\omega) \times k}{d}
$$

onde, $\mathrm{k}$ representa a condutividade elétrica, $\Delta \mathrm{V}_{\text {pontas }}(\omega)$ a diferença de potencial $C A$ entre as duas pontas do bi-eletrodo e d a distância entre as duas pontas do bi-eletrodo (ver Figura 5).

A impedância local (z) é obtida através do cálculo entre o potencial medido entre o eletrodo de trabalho e o eletrodo de referência padrão, conforme medido em EIS, porém em relação à corrente local (eq. 4.2).

$$
z(\omega)=\frac{\widetilde{V}(\omega)-\emptyset_{\text {ref }}}{i_{\text {loc }}(\omega)}=\frac{\widetilde{V}(\omega)}{\Delta V_{\text {pontas }}(\omega)} x \frac{d}{k}
$$


onde, $\tilde{V}(\omega)-\emptyset_{\text {ref }}$ representa o potencial CA entre o eletrodo de trabalho e o eletrodo de referência padrão, em solução.

A impedância local interfacial $\left(z_{0}\right)$ é obtida através do cálculo do potencial medido entre o eletrodo de trabalho e o eletrodo de referência posicionado mais próximo ao limite da dupla camada difusa, no caso a ponta inferior do bi-eletrodo, em relação à corrente local (eq. 4.3)

$$
z_{0}(\omega)=\frac{\widetilde{V}(\omega)-\widetilde{\emptyset}_{0}(\omega)}{i_{\text {loc }}(\omega)}=\frac{\widetilde{V}(\omega)-\widetilde{\emptyset}_{0}(\omega)}{\Delta V_{\text {pontas }}(\omega)} \times \frac{d}{k}
$$

onde, $\tilde{V}(\omega)-\widetilde{\emptyset}_{0}(\omega)$ representa o potencial CA entre o eletrodo de trabalho e o eletrodo de referência mais próximo da camada difusa (ponta inferior do bi-eletrodo), em solução.

Porém, quando se realiza o ensaio, torna-se impossível posicionar a ponta inferior do bi-eletrodo, que funciona como eletrodo de referência, nessa posição exata do limite da camada difusa e, portanto, não é possível verificar as diferenças de potencial nessas condições (Huang et al., 2011). Entretanto, leva-se em conta essa diferença de altura entre a superfície do eletrodo de trabalho e a ponta mais baixa do bi-eletrodo ('h', da Figura 5-a), de acordo com a equação 4.4 .

$$
z_{h}(\omega)=\frac{\widetilde{V}(\omega)-\widetilde{\emptyset}_{h}}{i_{\text {loc }}(\omega)}=\frac{\widetilde{V}(\omega)-\widetilde{\emptyset}_{h}}{\Delta V_{\text {pontas }}(\omega)} \times \frac{d}{k}
$$

onde, $\tilde{V}(\omega)-\widetilde{\emptyset}_{h}$ representa a diferença de potencial CA entre o eletrodo de trabalho e a ponta inferior do bi-eletrodo (ponta mais próxima à superfície do eletrodo de trabalho) localizada à distância 'h' (ver Figura 5). Entretanto, a equação 4.4 só é válida sob a suposição de que a propagação de corrente na solução pode ser negligenciada, como previu Zou et al. (1997).

Por fim, pode-se calcular a impedância ôhmica local $\left(Z_{e}\right)$, que é a diferença entre a impedância local (z) e a impedância local interfacial (zo), de acordo com a equação 4.5.

$$
z_{e}(\omega)=z(\omega)-z_{0}(\omega)
$$

Contudo, conforme explicado anteriormente, sob o ponto de vista prático, a impedância interfacial local ( $\left.z_{0}\right)$ deve ser considerada em função da diferença de altura entre a ponta inferior do bi-eletrodo e a superfície do eletrodo de trabalho ('h', da Figura 5-a), ou 
seja, $\mathrm{zh}_{\mathrm{h}}(\omega)$. Dessa maneira, a impedância ôhmica local $\left(\mathrm{z}_{\mathrm{e}}\right)$ também deve levar em consideração o ponto de vista prático, de acordo com a equação 4.6.

$$
z_{e, h}(\omega)=z(\omega)-z_{h}(\omega)
$$

Como a montagem experimental permite obter, simultaneamente, as impedâncias local e local interfacial, a impedância ôhmica local (ze) pode ser calculada com o auxílio de cálculo indireto.

\subsection{Detecção de sinais em LEIS e seus limites}

A técnica de espectroscopia de impedância local (LEIS) apresenta falha na aquisição de dados em baixa frequência. Ressalta-se que, a técnica é sempre baseada na medida de diferença de potencial realizada pelo bi-eletrodo, em solução, em regiões muito próximas à interface do eletrodo de trabalho. O principal fator limitante da técnica é o valor da detecção de diferenças potenciais - da ordem de $1 \mathrm{nV}$ - às quais os equipamentos comerciais são limitados. O aumento da impedância interfacial nessa região, em solução, reduz a corrente, dificultando dessa maneira a aquisição de dados em baixa frequência.

A fim de entender o problema na prática, Huang et al. (2011) realizaram diferentes ensaios, seja verificando a interferência entre as distâncias das pontas dos bi-eletrodos, seja a interferência do valor da capacitância, e também pela associação, em paralelo, do capacitor e uma resistência.

Os autores (Huang et al., 2011) simularam medidas de LEIS, num eletrodo de trabalho com diâmetro de $0,5 \mathrm{~cm}$ e mantiveram fixas as distâncias entre a superfície do eletrodo de trabalho (h), em $100 \mu \mathrm{m}$, e entre as pontas do bi-eletrodo (d), em $50 \mu \mathrm{m}$. Com isso, foi possível observar que, se for considerado que a interface funciona como um capacitor puro com capacitância de $10 \mu \mathrm{F}$, o limite de frequência para detecção de um sinal $1 \mathrm{nV}$ é de cerca de $0,5 \mathrm{~Hz}$ (ver Figura 4.9). 


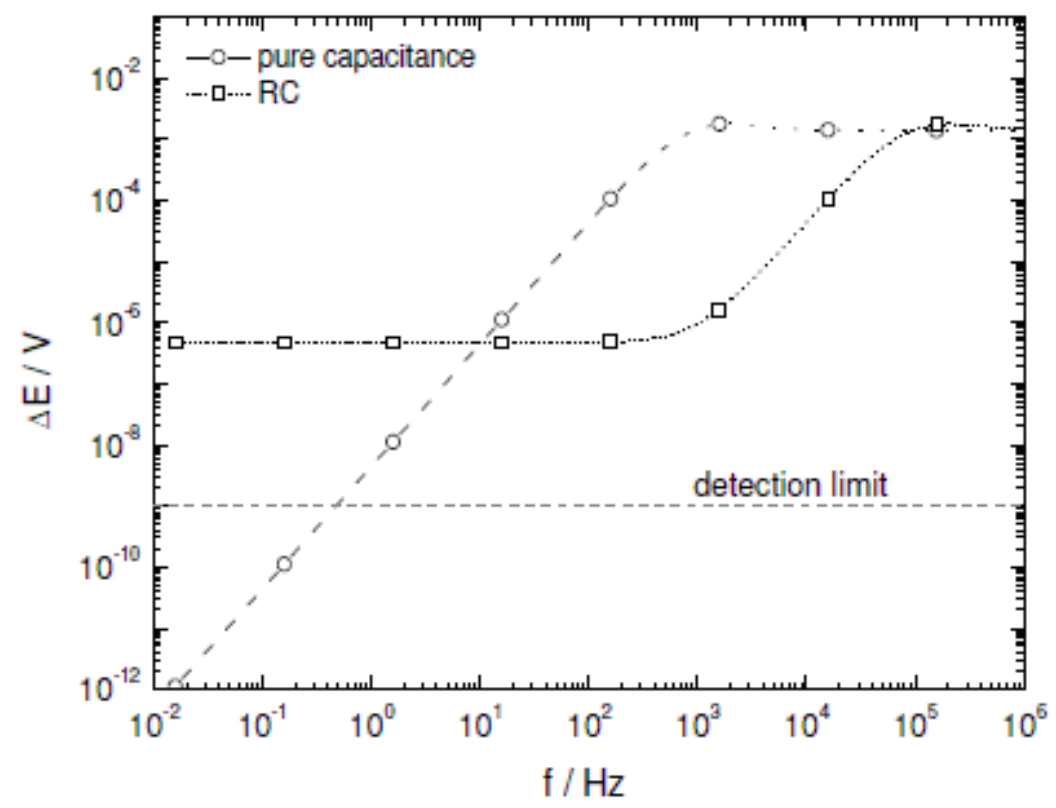

Figura 4.9: Diferenças de potenciais calculadas para um eletrodo de disco plano com raio de 0,25 $\mathrm{cm}$, mantendo fixo ' $\mathrm{h}$ ' (distância entre a superfície do eletrodo de trabalho e a ponta inferior do bieletrodo) em $100 \mu \mathrm{m}$ e 'd' (distância entre as pontas do bi-eletrodo) em $50 \mu \mathrm{m}$. Para a realização destes cálculos, foram mantidos fixos os seguintes parâmetros: $\mathrm{k}=0,01 \mathrm{Scm}^{-1} ; \mathrm{r}_{0}=0,25 \mathrm{~cm} ; \mathrm{C}_{0}=10$ $\mu \mathrm{F} ; \mathrm{R}=$ infinito (capacitor puro) e $\mathrm{R}=\mathrm{k} \Omega ; \Delta \mathrm{V}=30 \mathrm{mV}_{\mathrm{pp}}$ (Huang et al., 2011).

Como esta situação representa um eletrodo idealmente polárizavel ou bloqueado, supõe-se que ao diminuir o valor da capacitância, o limite em frequência tende a aumentar e, ao aumentar o valor de capacitância, o limite de frequência tende a diminuir, pois o aumento da capacitância diminui a impedância da interface e aumenta a corrente em solução, o que facilita a medida do sinal. Além disso, quando se associa este capacitor com uma resistência (de $1 \mathrm{k} \Omega$ ), ou seja, onde a reação é controlada por transferência de carga, a diferença de potencial detectada em baixas frequências se estabiliza em $500 \mathrm{nV}$, e assim encontra-se acima do limite de detecção dos potenciostatos comerciais. Neste caso, podese presumir que aliado a esse aumento no valor da resistência do sistema, em paralelo, ocorrerá uma redução da diferença de potencial medida em baixas frequências, pois ocorrerá um aumento da impedância interfacial, que diminui a corrente em solução e, consequentemente, dificulta a detecção de sinais pelo bi-eletrodo (Huang et al., 2011).

Em seguida, Huang et al. (2011), verificaram a interferência no limite de detecção da diferença de potencial em função da distância entre as pontas do bi-eletrodo (d) e a frequência, conforme apresenta a Figura 4.10. 


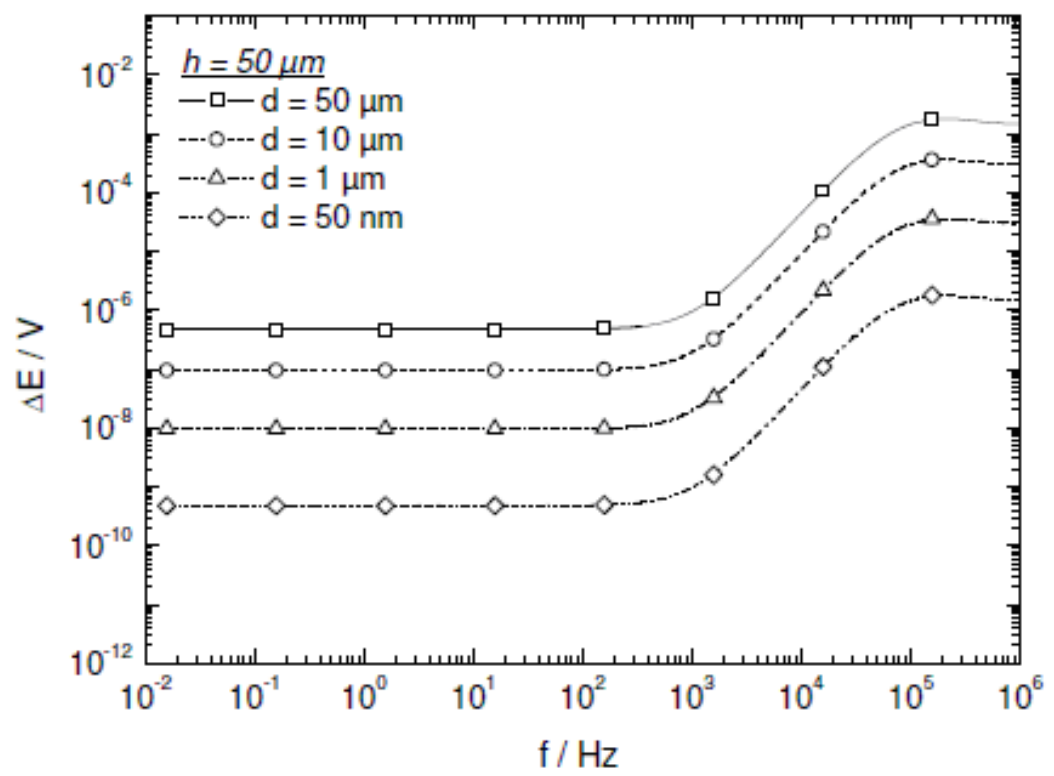

Figura 4.10: Diferenças de potenciais calculadas para um eletrodo de disco plano com raio de 0,25 $\mathrm{cm}$, mantendo fixo ' $\mathrm{h}$ ' (distância entre a superfície do eletrodo de trabalho e a ponta inferior do bieletrodo) em $50 \mu \mathrm{m}$ e variando 'd' (distância entre as pontas do bi-eletrodo). Para a realização destes cálculos, foram mantidos fixos os seguintes parâmetros: $k=0,01 \mathrm{Scm}^{-1} ; r_{0}=0,25 \mathrm{~cm} ; \mathrm{C}_{0}=10 \mu \mathrm{F} ; \mathrm{R}$ $=$ infinito (capacitor puro) e $\mathrm{R}=\mathrm{k} \Omega ; \Delta \mathrm{V}=30 \mathrm{mV}_{\mathrm{pp}}$ (Huang et al., 2011).

Considerando o mesmo eletrodo de trabalho do ensaio descrito anteriormente a uma capacitância de $10 \mu \mathrm{F}$ e uma resistência de $1 \mathrm{k} \Omega$, em paralelo, com distância fixa de $50 \mu \mathrm{m}$, entre o bi-eletrodo e o eletrodo de trabalho, Huang et al. (2011) verificaram que havia uma diminuição da diferença de potencial, quando se diminuia a distância entre as duas pontas do bi-eletrodo (d), atingindo o limite de $1 \mathrm{nV}$ para uma distância um pouco inferior a $1 \mu \mathrm{m}$. É interessante compreender que, caso o bi-eletrodo esteja posicionado, por exemplo, a uma distância mais longe à superfície do eletrodo de trabalho (aumento de ' $h$ '), as correntes sentidas pelo bi-eletrodo serão menores e, portanto, o valor de 'd' deverá ser maior, para superar o limite de detecção de diferença de potencial.

\subsection{Validação do sistema de medidas para LEIS}

Após a confecção do bi-eletrodo e ajuste na aparelhagem, torna-se necessária a conferência de medida, que foi realizada através dos ensaios simultâneos, de EIS e LEIS, num eletrodo de trabalho de Pt $(\varnothing 1 \mathrm{~cm})$ e solução de ferri/ferrocianeto de potássio $\left(\mathrm{K}_{3} \mathrm{Fe}(\mathrm{CN})_{6} / \mathrm{K}_{4} \mathrm{Fe}(\mathrm{CN})_{6}\right)$, que é um sistema com comportamento eletroquímico conhecido e que possui o par redox $\mathrm{Fe}^{3+} / \mathrm{Fe}^{2+}$, cuja a reação interfacial é controlada por difusão, conforme a equação 4.7 . 


$$
\mathrm{Fe}^{3+}+\mathrm{e}^{-} \rightarrow \mathrm{Fe}^{2+}
$$

Como o eletrodo de trabalho e soluções são idênticas para as medidas, o diagrama global (Z) deve estar de acordo com o diagrama local (z). A solução utilizada para as medidas de avaliação do sistema, neste trabalho, foi composta de ferri/ferrocianeto de potássio 0,01 mol L-1 em KCl 0,5 $\mathrm{mol} \mathrm{L}^{-1}$.

\subsubsection{Microscopia eletroquímica de varredura (SECM)}

A microscopia eletroquímica de varredura (SECM) é uma técnica que utiliza um ultramicroeletrodo (UME) como sensor local. Este deve ser levado à vizinhança de uma superfície a fim de sondar suas reatividades locais (Mirkin et al., 2011; Wittstock et al., 2007). Trata-se de uma técnica derivada do microscópio de varredura por tunelamento eletrônico (STM) e do microscópio de força atômica (AFM), cuja diferença principal em relação a estas técnicas é sua sensibilidade química e o uso de íons em solução, utilizado como gerador de resposta. Uma ilustração esquemática do equipamento é apresentada na Figura 4.11.

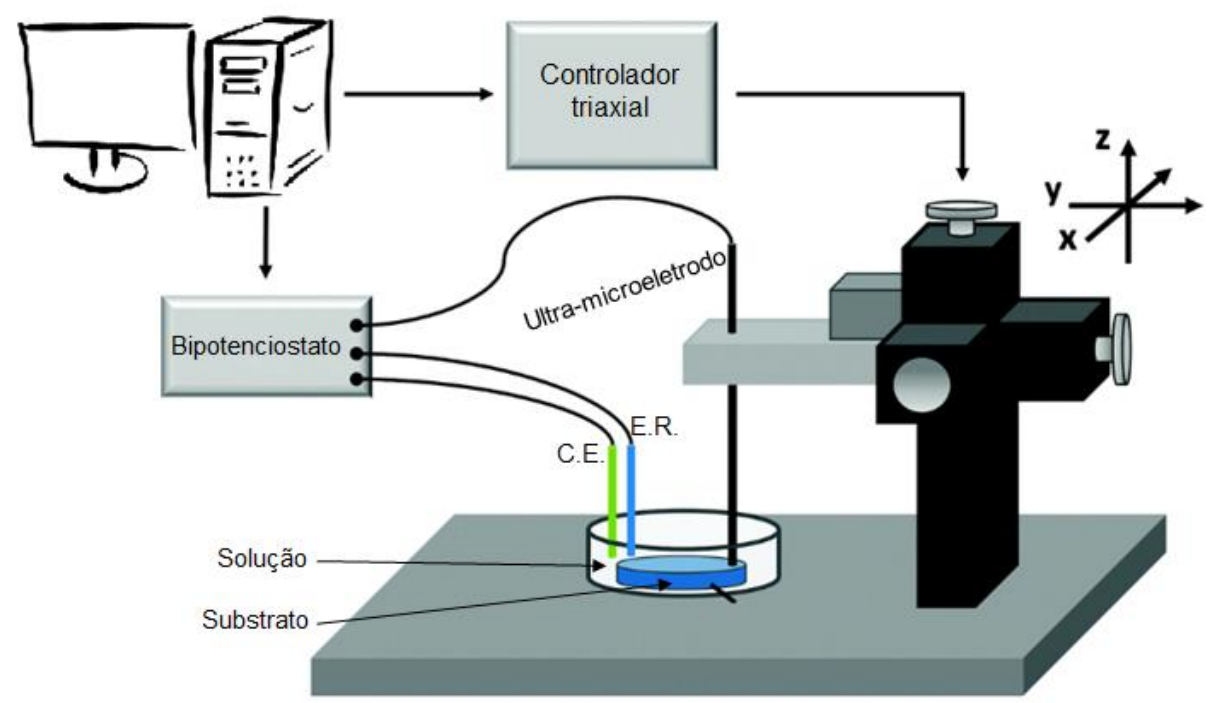

Figura 4.11: Ilustração esquemática do equipamento utilizado para realizar ensaios de microscopia eletroquímica de varredura - SECM (adaptado de Ventosa e Schuhmann, 2015).

Conforme ilustrado na Figura 4.11, o ultra-microeletrodo (eletricamente ativo), que foi produzido pelo próprio usuário no LISE, se aproxima da superfície do substrato a ser analisada, auxiliado pelas reações que ocorrem entre o eletrólito e a superfície do substrato, e capta a corrente faradáica gerada pelas reações eletroquímicas das espécies em solução. 
A técnica é baseada no deslocamento da sonda (ultra-microeletrodo) acima do substrato, em regiões muito próximas a ele, sem que ambas se toquem. O substrato pode ser isolante ou condutor. No modo amperométrico, a sonda é polarizada a um potencial tal que o mediador redox (um oxidante, por exemplo) seja reduzido. Logo que a sonda se distancia do substrato, a corrente obtida é a corrente estacionária, i $^{\infty}$ sonda (eq. 4.8), limitada pela difusão (Ver Figura 4.12).

$$
\mathrm{i}^{\infty} \text { sonda }=4 \mathrm{nFDCa}
$$

onde, n é o número de elétrons trocados, F é Faraday, D o coeficiente de difusção e Ca a concentração da espécie eletroativa.

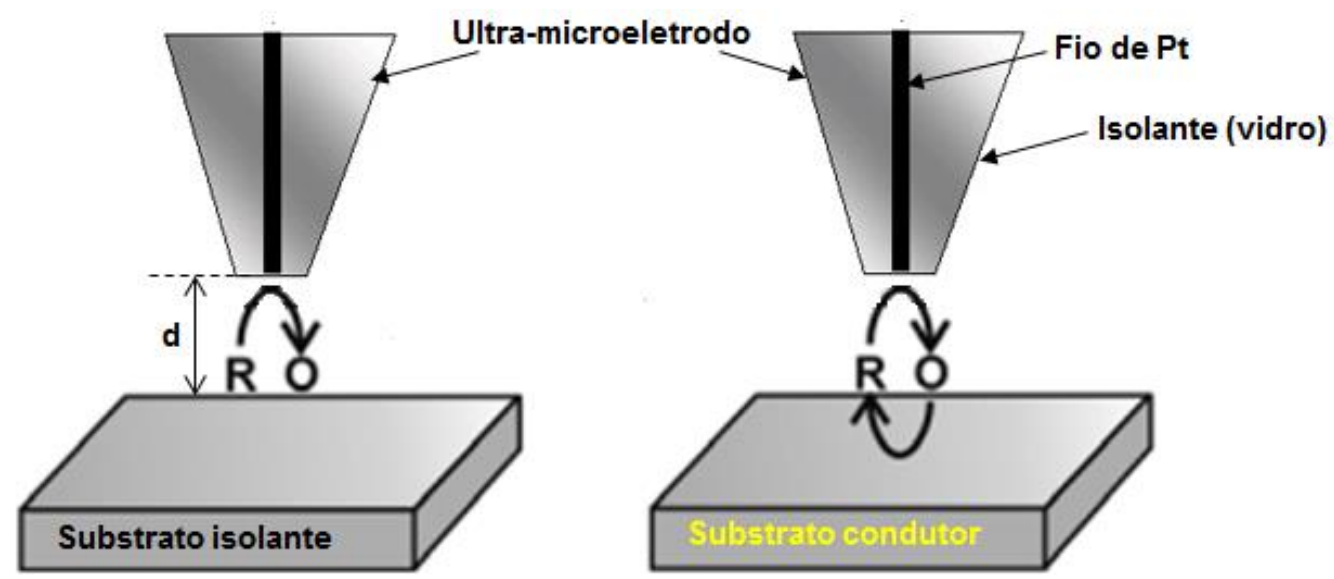

Figura 4.12: Representação do modo 'feedback negativo' (substrato isolante) e 'feedback positivo' (substrato condutor)

O deslocamento do eletrodo em direção perpendicular à superfície do substrato permite traçar as curvas de aproximação, que representam a variação de corrente da sonda (ultra-microeletrodo) em função de sua distância ao substrato (d). Quando o ultramicroeletrodo se aproxima de um substrato isolante, a difusão das espécies é impedida, provocando uma diminuição da corrente. Isso pode ser visto num gráfico como uma curva que vai de um valor maior a um valor menor ('feedback negativo'). Quando o ultramicroeletrodo se aproxima de um substrato condutor, as espécies reduzidas na ponta do ultra-microeletrodo podem reagir com o substrato para se oxidar e retomar dessa forma o oxidante. Nesse caso, há um aumento de corrente, que pode ser visto num gráfico como uma curva que vai de um valor menor a um valor maior ('feedback' positivo).

Em virtude de sua resolução espacial e sensibilidade eletroquímica, o SECM é capaz de estudar minuciosamente as reações eletroquímicas, e tem capacidade de solucionar problemas complexos que ocorrem durante a corrosão de um metal (Bastos et al., 2005), 
medindo os valores de corrente relacionados às reações eletroquímicas que ocorrem na superfície do substrato (entre o metal a ser estudado e o eletrólito escolhido). Cada reação apresenta um potencial característico. Se o ensaio for realizado em soluções adequadas, é possível a detecção de gradientes de concentração de espécies das reações (reagentes ou produtos) que ocorrem na superfície do substrato, ou seja, uma forma localizada, indireta e não intrusiva no estudo do processo corrosivo. Como as medidas são extremamente localizadas, as eventuais mudanças de corrente e a resistência da solução não causam efeitos significativos nos resultados. Diversas análises podem ser realizadas pelo método, como curvas de aproximação (nosso caso), voltametria cíclica, potencial de circuito aberto, entre outras (Mirkin e Horrocks, 2000).

\subsubsection{Espectroscopia de fotoelétrons de raios-X (XPS)}

Com o intuito de compreender o comportamento eletroquímico das ligas 2024-T3 e 7475-T651 soldadas por FSW, foram avaliadas as superfícies de diferentes regiões da solda, pela técnica de espectroscopia de fotoelétrons de raios-X (XPS, do inglês $X$-Ray Photoelectron Spectroscopy), antes e após exposição em solução de 0,1 $\mathrm{M}$ de $\mathrm{Na}_{2} \mathrm{SO}_{4}+1$ $\mathrm{mM}$ de $\mathrm{NaCl}$. Esta é uma técnica de análise da superfície que permite determinar a composição química do material estudado, assim como informações sobre o estado de oxidação de certos elementos e sobre as naturezas de ligações.

A caracterização da composição química e das espessuras de óxidos de alumínio das amostras foi realizada por um analisador VSW HA 100 - VSW Scientific Instrument LTDA ${ }^{\circledR}$ (Manchester, Inglaterra), alocado no Laboratório de Fìsica de Superfícies (GFS), do Instituto de Física Gleb Wataghin, da Universidade Estadual de Campinas.

O princípio da técnica é baseado sobre o fenômeno fotoelétrico, sendo os fótons monoenergéticos de Al Ka (usado neste trabalho), com energia de 1486,6 eV, emitidos sobre a superfície do material estudado, que é confinado numa câmara com ultra-vácuo, a fim de evitar a contaminação pela atmosfera residual. A incidência desses fótons faz com que os elétrons da amostra adquiram energia cinética $E_{c}$, que passam a ser denominados como fotoelétrons. Esses fotoelétrons percorrem o material, interagindo com os outros elétrons presentes por meio de colisões elásticas e inelásticas, onde alguns desses elétrons conseguem atravessar a superfície e, dessa maneira, são detectados por um analisador de elétrons (ver Figura 4.13). 


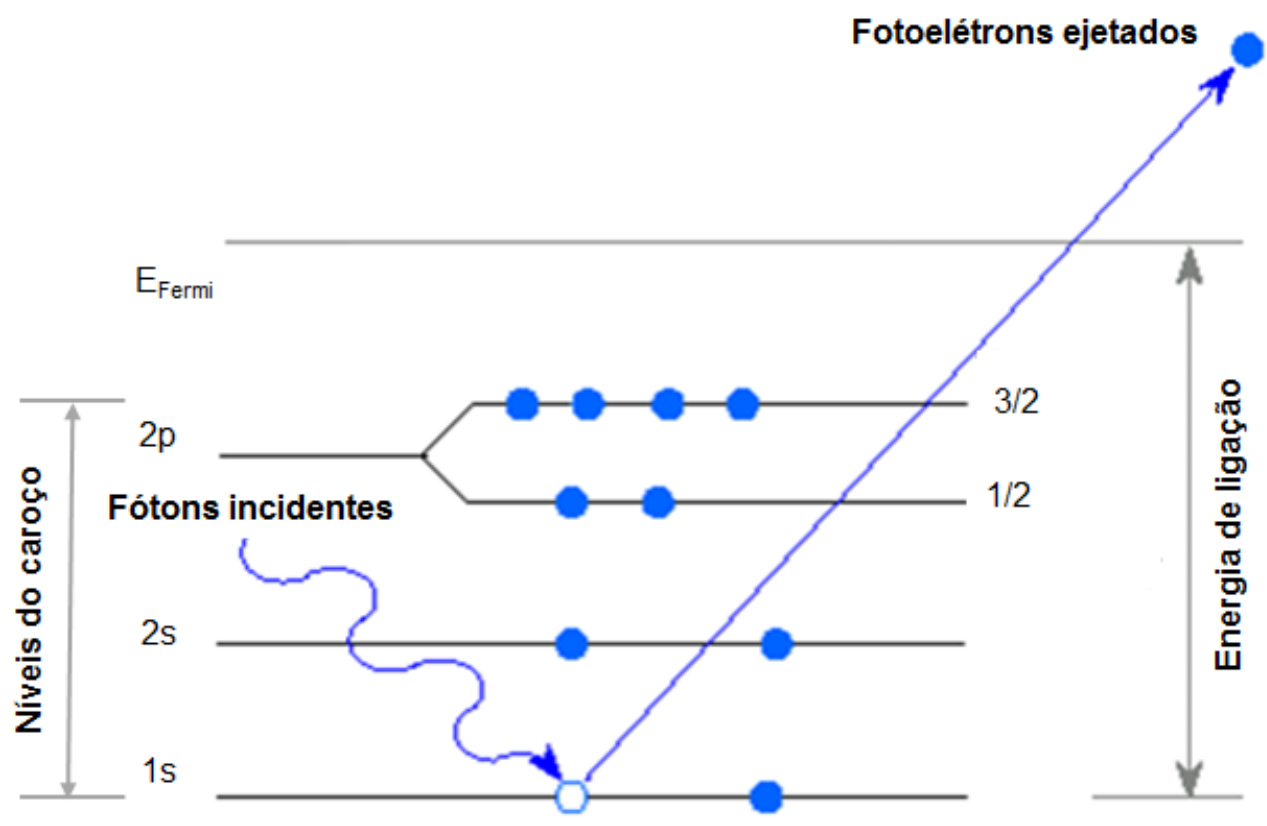

Figura 4.13: Efeito fotoelétrico

A energia cinética $\left(E_{c}\right)$ dos fotoelétrons ejetados é obtida pela equação de Einstein:

$$
\mathrm{E}_{\mathrm{c}}=h v-\mathrm{E}_{\mathrm{b}}-\phi
$$

Onde $h v$ é a energia do fóton incidente (neste trabalho: 1486,6 eV), $E_{b}$ é a energia de ligação deste elétron em relação ao nível de Fermi e $\phi$ é a função de trabalho do analisador.

O detector de elétrons contabiliza a quantidade de fotoelétrons com determinada energia cinética num certo intervalo de tempo. Através da captação desses dados obtidos pelo detector, torna-se possível a plotagem de um espectro da contagem de elétrons (intensidade) em função da energia de ligação, conforme mostra a equação 4.9. A identificação dos elementos presentes na superfície é feita diretamente pela determinação das energias de ligação dos picos obtidos no espectro, oriundos dos fotoelétrons dos níveis mais internos (níveis do caroço). A intensidade dos picos fornece informação quantitativa sobre a composição da superfície, enquanto que a posição exata do pico indica o estado químico do átomo emissor (Briggs e Seah, 1976).

Uma característica importante do XPS é a sua capacidade de distinguir o mesmo átomo em diferentes ambientes químicos, que é possível em razão da energia de ligação de um elétron no átomo ser sensível às mudanças que podem ocorrer na densidade de carga em torno desse átomo, causadas geralmente pela formação de novas ligações químicas, como a oxidação. Esse fato causa um deslocamento na energia de ligação de todos os 
elétrons do átomo, que podem variar de 0,1 eV a 7 eV (Barbieri et al., 2004; Prabhakaran e Ogino, 1995).

Como o interesse na utilização desta técnica foi a verificação das possíveis evoluções de produtos de corrosão e, consequentemente, diferentes estados de oxidação da camada de passivação das ligas de alumínio, antes e após exposição em solução corrosiva, foram determinadas as espessuras das camadas de óxido.

Quando a camada de óxido das ligas de alumínio é relativamente pequena (entre 7,5 e 8,5 nm), os picos dos espectros de XPS podem distinguir o alumínio metálico e o óxido de alumínio, conforme as diferentes energias de ligação características de cada uma delas, conforme apresenta a Figura 4.14 (Strohmeier, 1990).

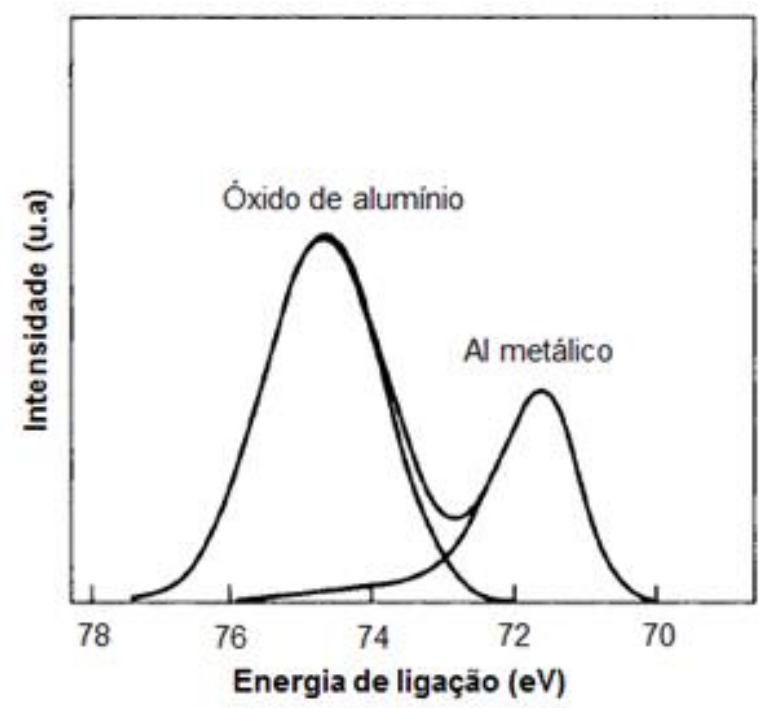

Figura 4.14: Espectro de XPS, em alta resolução, mostrando as diferentes energias de ligação dos picos de alumínio (Al2p), alumínio metálico e óxido de alumínio, obtidos de uma liga de alumínio 5086 (adaptado de Strohmeier, 1990)

A comparação entre as intensidades relativas dos picos de alumínio (Al2p), ou seja, do óxido de alumínio e do alumínio metálico, permitem a determinação da espessura relativa da camada de óxido. Carlson (1982) demonstrou que, quando um metal tem um filme de óxido presente em sua superfície, a intensidade relativa do óxido (o) e do metal (m) é fornecida pelos picos de XPS, de acordo com a seguinte equação:

$$
d=\lambda_{o} \operatorname{sen} \theta \ln \left[\frac{N_{m} \lambda_{m}}{N_{o} \lambda_{o}} \frac{I_{o}}{I_{m}}+1\right]
$$

onde: $I_{m}$ e lo são as intensidades das áreas dos picos do metal e do óxido, respectivamente; $\mathrm{N}_{m}$ e $\mathrm{N}_{\mathrm{o}}$ são os volumes das densidades dos átomos de metal e do óxido, respectivamente; $\lambda_{m}$ e $\lambda_{o}$ são os caminhos livres inelásticos dos fotoelétrons apropriados no 
metal e no óxido, respectivamente (em $\breve{A}$ ); d é a espessura da camada de óxido (em $\breve{A}$ ), e $\theta$ é o ângulo de saída do elétron em relação à superfície da amostra. Ressalta-se que, esta equação assume uma camada simples e uniforme.

As análises, por XPS, foram divididas da seguinte maneira:

1. Amostra do MB da liga 2024-T3 antes da exposição, após 8 horas e após 24 horas em solução de $0,1 \mathrm{M}$ de $\mathrm{Na}_{2} \mathrm{SO}_{4}+1 \mathrm{mM}$ de NaCl;

2. Amostra do MB da liga 7475-T651 antes da exposição, após 8 horas e após 24 horas em solução de $0,1 \mathrm{M}$ de $\mathrm{Na}_{2} \mathrm{SO}_{4}+1 \mathrm{mM}$ de NaCl;

3. Amostra da região do nugget da solda das ligas 2024-T3 e 7475-T651 antes da exposição, após 8 horas e após 24 horas em solução de $0,1 \mathrm{M}$ de $\mathrm{Na}_{2} \mathrm{SO}_{4}$ $+1 \mathrm{mM}$ de NaCl;

4. Amostra do MB da liga 2024-T3, retirada da amostra das ligas 2024-T3 e 7475T651, soldadas por FSW, após 8 horas e 24 horas, respectivamente, em solução de $0,1 \mathrm{M}$ de $\mathrm{Na}_{2} \mathrm{SO}_{4}+1 \mathrm{mM}$ de $\mathrm{NaCl}$;

5. Amostra do MB da liga 7475-T651, retirada da amostra das ligas 2024-T3 e 7475-T651, soldadas por FSW, após 8 horas e 24 horas, respectivamente, em solução de $0,1 \mathrm{M}$ de $\mathrm{Na}_{2} \mathrm{SO}_{4}+1 \mathrm{mM}$ de $\mathrm{NaCl}$.

As áreas dos MB da amostra soldada foram analisadas em regiões com distâncias acima de $20 \mathrm{~mm}$ da interface entre as duas ligas. A princípio foi realizada uma análise dos elementos químicos encontrados na superfície da amostra, com o auxílio do software QB4. A concentração dos principais elementos químicos encontrados nas superfícies das amostras foi determinada usando as seções de choque de Scofield (1976) e considerando a região superficial. 


\section{RESULTADOS E DISCUSSÃO}

\subsection{Caracterização microestrutural das ligas 2024-T3 e 7475-T651, soldadas por FSW}

Como o processo de soldagem por FSW gera diferentes zonas microestruturais, que podem ser sítios de maior sucetibilidade à corrosão, foram usadas técnicas que permitissem uma melhor compreenssão das microestruturas formadas nas diferentes zonas das ligas 2024-T3 e 7475-T651 soldadas por FSW.

\subsubsection{Microscopia óptica e definição dos limites das zonas microestuturais}

A Figura 5.1 ilustra a imagem da superfície de uma amostra que compreende todas as zonas formadas após a soldagem por FSW nas ligas 2024-T3 e 7475-T651. A imagem foi adquirida após polimento e ataque com reagente Keller. É possível notar que o nugget exibe uma cor cinza mais clara em relação às outras zonas formadas, além de ser possível ver as diferenças microestruturais associadas a cada uma das ligas, o que indica que a ação da ferramenta de soldagem não provoca uma mistura extensiva delas (Donatus et al., 2015).

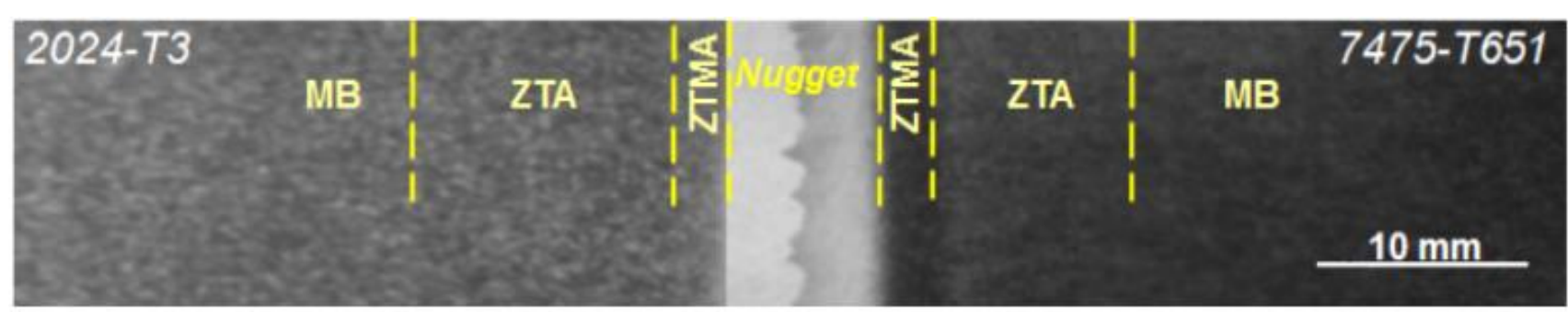

Figura 5.1: Macrografia das ligas 2024 e 7475 soldadas por FSW

A Figura 5.2 mostra as micrografias ópticas das diferentes regiões formadas na superfície da amostra das ligas 2024-T3 e 7475-T651 soldadas por FSW. O ataque com reagente Keller foi utilizado para revelar a estrutura dos grãos das zonas microestruturais formadas nas ligas 2024-T3 e 7475-T651 após o processo de soldagem por FSW. É possível observar que o ataque não permitiu revelar os grãos nas regiões do nugget de ambas as ligas, devido às suas pequenas dimensões ou em razão do atrito causado pela ferramenta durante o processo de soldagem. 

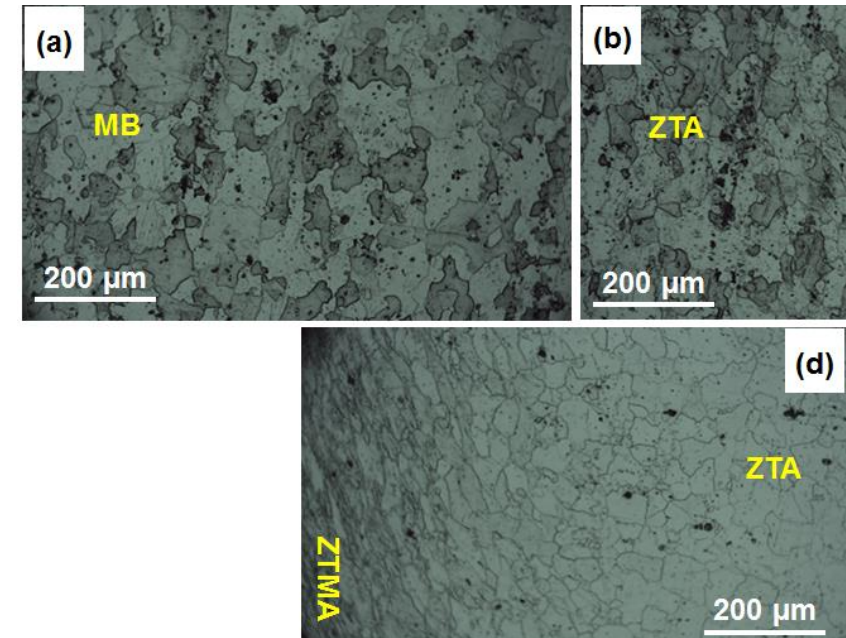
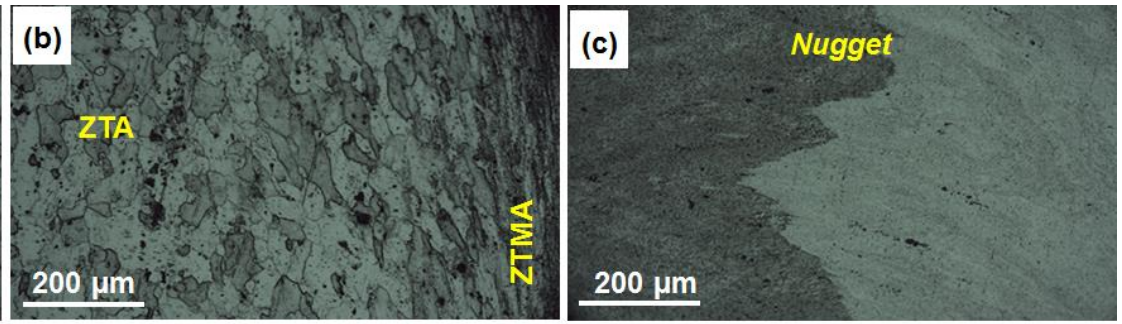

(e)

MiB

$200 \mu \mathrm{m}$

Figura 5.2: Micrografias ópticas das diferentes regiões formadas na superfície da amostra das ligas 2024-T3 e 7475-T651, soldadas por FSW, com aumento de 10 vezes: (a) MB da 2024-T3; (b) ZTA/ZTMA da 2024-T3; (c) nugget; (d) ZTA/ZTMA da 7475-T651; (e) MB da 7475-T651.

Com relação à definição das zonas microestruturais, o nugget e a ZTMA puderam ser definidos de acordo com as imagens microscópicas obtidas, ou seja, o nugget não apresentou grãos revelados (Figura 5.2(C)) e as ZTMAs apresentram grãos alongados para ambas as ligas (Figuras 5.2 (b) e 5.2 (d)). As micrografias ópticas da seção transversal reforçam essas definições, conforme mostra a Figura 5.3.

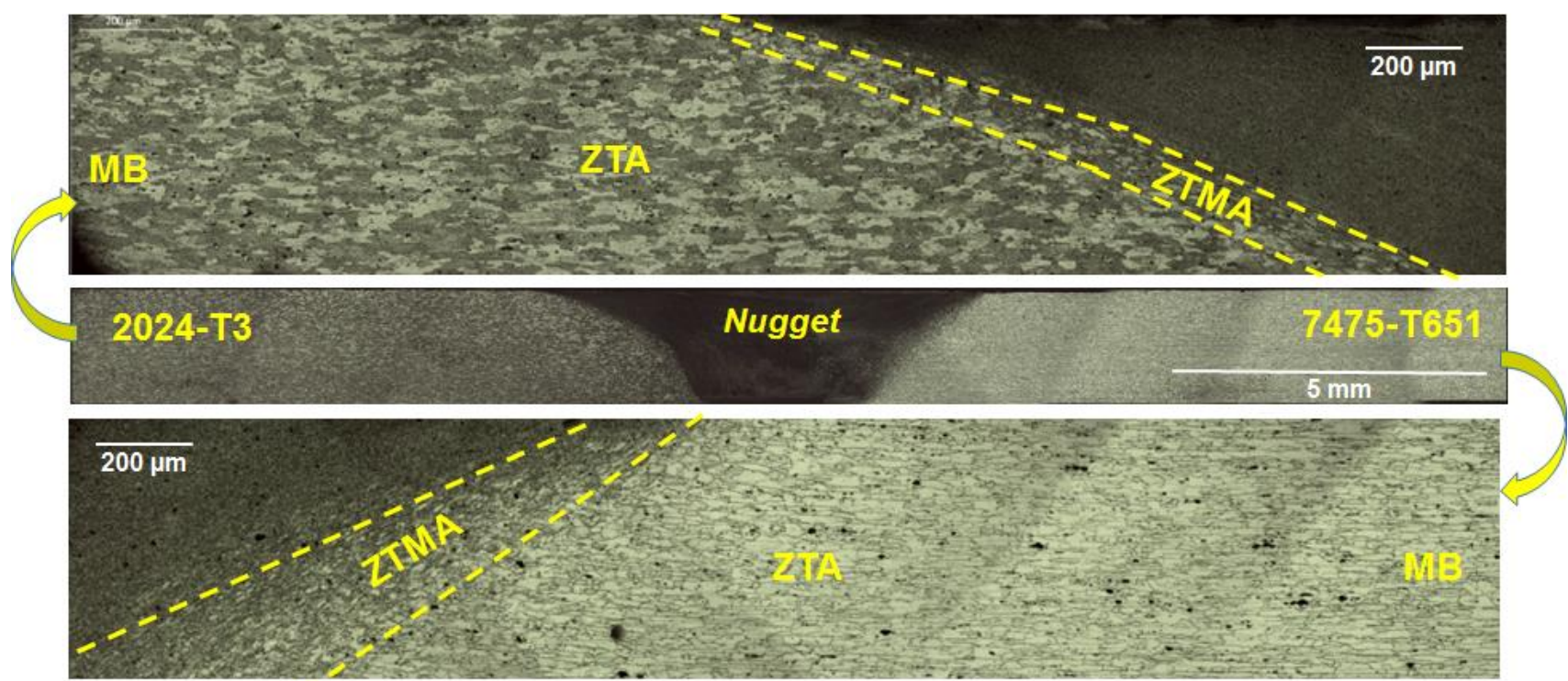

Figura 5.3: Micrografias ópticas das diferentes regiões formadas na seção transversal da amostra das ligas 2024-T3 e 7475-T651, soldadas por FSW.

As ZTAs dos dois metais, entretanto, não puderam ser definidas pelas análises microestruturais analisadas com microscopia óptica, por apresentarem grãos de mesmo tamanho (ver Figuras 5.2 e 5.3). Para a definição do limite das ZTAs das ligas 2024-T3 e 7475-T651 recorreu-se à literatura (Jaryiaboon et al., 2007; Frigaard et al., 2001). Considerando que a liga 2024-T3 é naturalmente envelhecida, as zonas GPB e os 
precipitados de fase S" (zonas GPB2) são dissolvidas nas zonas de solda, onde as temperaturas atingem valores equivalentes ao primeiro pico (B da Figura 3.4), endotérmico (aproximadamente $220^{\circ} \mathrm{C}$ ), podendo ser reprecipitados após o processo de soldagem, proporcionando uma recuperação parcial da microestrutura original da liga. Por outro lado, o crescimento de fases $S$ '(S), que ocorrem a temperaturas superiores a $250{ }^{\circ} \mathrm{C}$ (pico $\mathrm{C}$ da Figura 3.4) (Parel et al., 2010), deve ser um processo irreversível, provocando mudanças microestruturais significativas na microestrutura da liga. Portanto, para a liga 2024-T3, assumimos que a ZTA é limitada a gradientes de temperatura não superiores à $250{ }^{\circ} \mathrm{C}$. Para diferentes velocidades de rotação e deslocamento, Jaryiaboon et al. (2007) determinaram que a temperatura máxima de um termopar posicionado a $16 \mathrm{~mm}$ da linha central da solda variou entre $250^{\circ} \mathrm{C}$ e $320^{\circ} \mathrm{C}$, aproximadamente, de acordo com os parâmetros de soldagem. A partir de valores experimentais e simulação computacional, Frigaard et al. (2001) determinaram o perfil térmico ao longo das chapas soldadas por FSW, para a simulação particular apresentada onde a temperatura a $16 \mathrm{~mm}$ da linha central da solda era $225^{\circ} \mathrm{C}$. Tendo em conta estes valores relatados, o limte de ZTA da liga 2024-T3 foi estabalecido a $16 \mathrm{~mm}$ da linha central da solda, como mostra a Figura 5.1.

Para as análises da ZTA da liga 7475-T651, os gradientes de temperatura também foram limitados à $250^{\circ} \mathrm{C}$. Essa temperatura corresponde à mesma adotada por Mahoney et al. (1998) para limitar a ZTA durante a análise dos gradientes térmicos de uma liga AA7075T651 soldada por FSW. Eles argumentaram que, dentro deste limite de temperatura, 0 superaquecimento dos precipitados de MgZn2 leva a precipitados com tamanho de 20-30 $\mathrm{nm}$, que não foram encontrados nugget, mas no BM em tamanhos menores (10-20 nm). Dessa maneira, os autores limitaram a ZTA a uma distância de $11 \mathrm{~mm}$, que foi o valor limite estabelecido, conforme apresenta a Figura 5.1.

\subsubsection{Microscopia eletrônica de transmissão (TEM)}

A Figura 5.4 apresenta as imagens obtidas por microscopia eletrônica de transmissão (TEM) das diferentes zonas microestruturais formadas na liga 2024-T3, após a soldagem por FSW das ligas 2024-T3 e 7475-T651. 

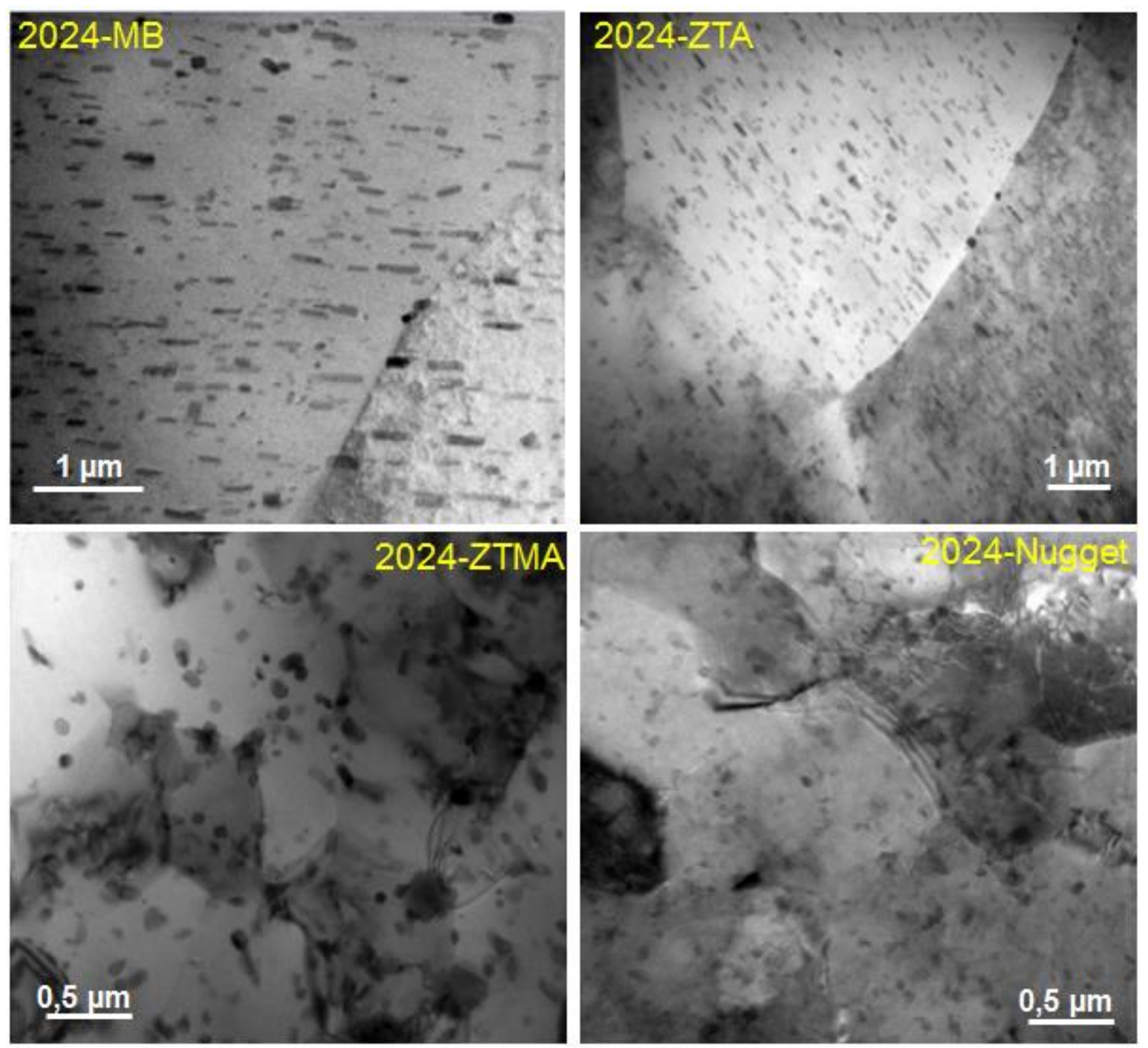

Figura 5.4: Micrografias obtidas por TEM das diferentes regiões da liga 2024-T3 formadas após a soldagem por FSW das ligas 2024-T3 e 7475-T651.

Conforme as imagens apresentadas na Figura 5.4, as microestruturas do MB e da ZTA da liga 2024-T3 são muito semelhantes, com uma grande quantidade de dispersóides em formato de bastonetes dentro dos grãos presentes nessas zonas, além de alguns precipitados irregulares em menores quantidades. A fim de compreender a composição química desses dispersóides e precipitados, foram realizadas análises com EDS, conforme demonstram as Figuras 5.5 ((a) e (b)). 


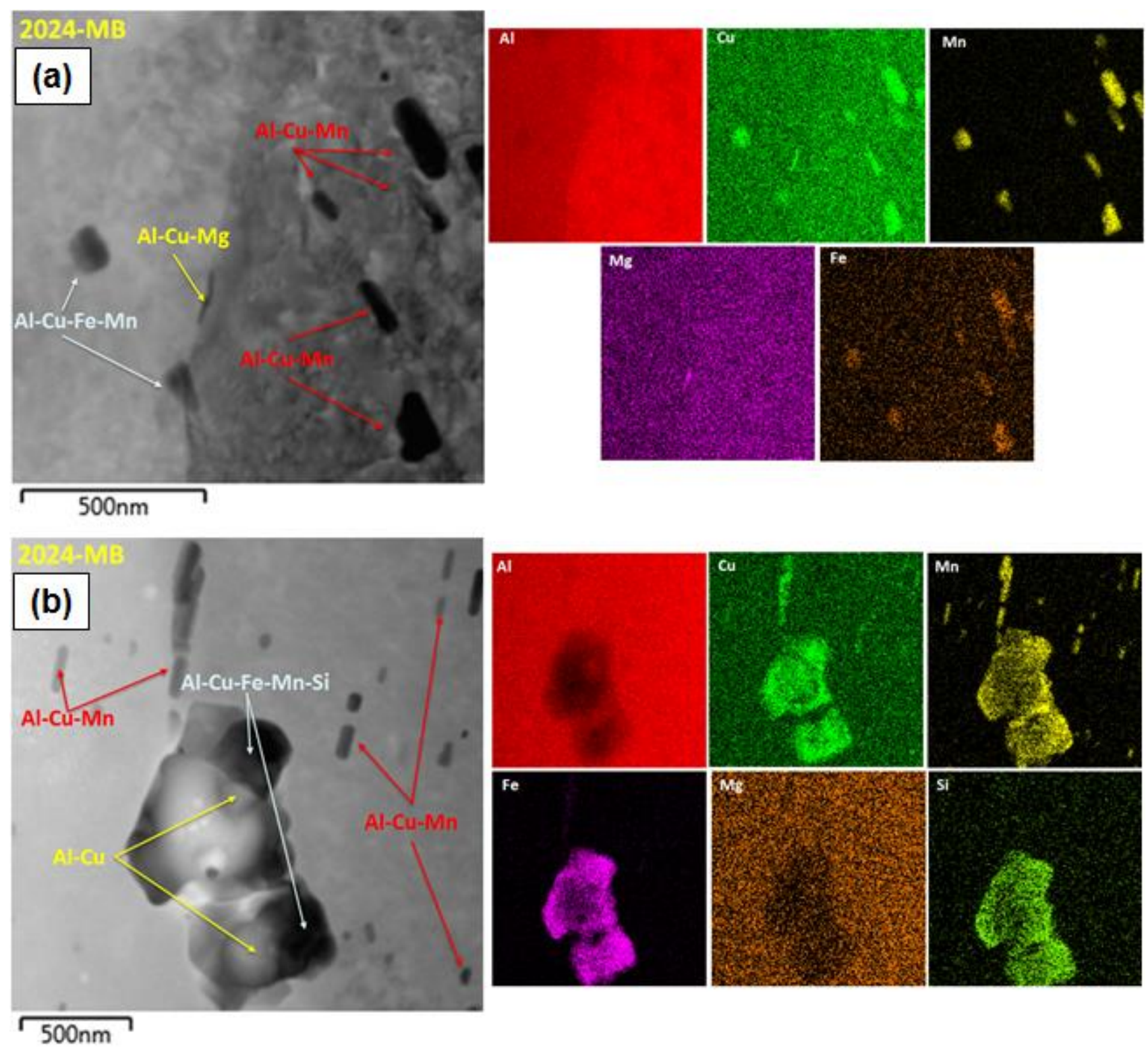

Figura 5.5: Micrografias obtidas por HAADF-STEM de precipitados encontrados no MB da liga 2024T3

As análises por EDS permitiram caracterizar quimicamente os diferentes precipitados encontrados no MB e na ZTA da liga 2024-T3. Os dispersóides em formato de bastonetes são ricos em Cu e Mn, e de acordo com Guillaumin (1999), suas dimensões variam de 200 nm a 500 nm e são denominados como dispersóides Al-Cu-Mn. Além dos dispersóides AlCu-Mn, também foi encontrado um fino precipitado de fase $S\left(\mathrm{Al}_{2} \mathrm{CuMg}\right)$ no contorno de grão, formado possivelmente durante o envelhecimento natural da liga. Foram encontrados ainda, precipitados com aproximadamente $1000 \mathrm{~nm}$, com composições químicas variadas, como mostra a Figura 5.5 (b), onde o precipitado apresenta em algumas regiões composição referente à fase $\theta(\mathrm{Al}-\mathrm{Cu})$ e em outras por $\mathrm{Al}-\mathrm{Cu}-\mathrm{Fe}-\mathrm{Mn}-\mathrm{Si}$. 
Na ZTMA e no nugget da liga 2024-T3 (ver Figura 5.4), as microestruturas se diferem às microestruturas do $\mathrm{MB}$ e da ZTA, com menores quantidades de dispersóides $\mathrm{Al}-\mathrm{Cu}-\mathrm{Mn}$ em forma de bastonetes e com a formação de sub-grãos. Isto se deve, provavelmente, à fragmentação dos bastonetes devido à fricção causada pela soldagem por FSW ou por dissolução e reprecipitação, devido à alta temperatura atinigida na ZTMA da liga 2024-T3. Também foram observadas partículas grosseiras. As Figuras 5.6 ((a) e (b)) mostram as análises químicas, por EDS, dos precipitados encontrados na ZTMA da liga 2024-T3.
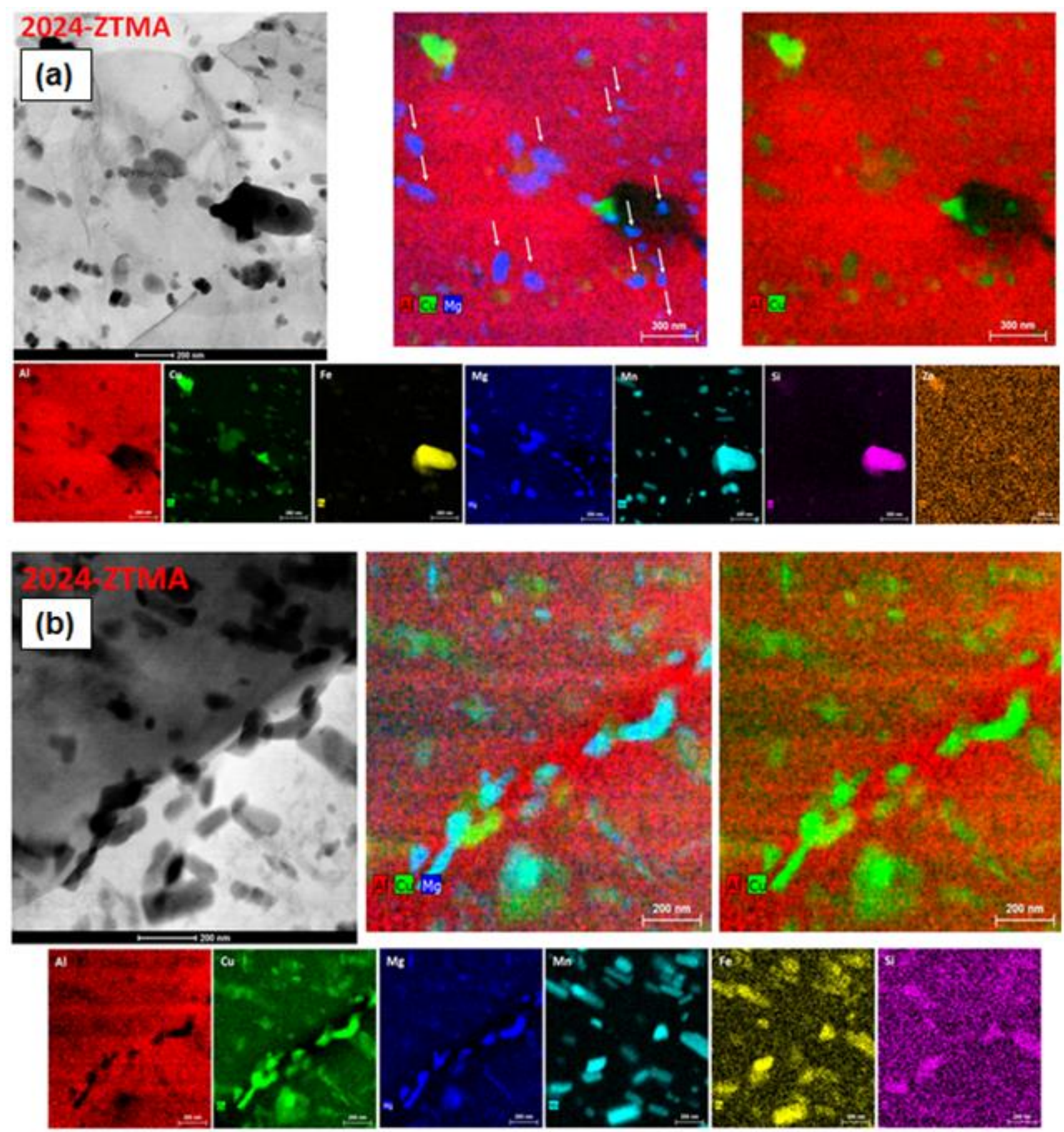
Figura 5.6: Micrografias obtidas por HAADF-STEM de precipitados encontrados na ZTMA da liga 2024-T3

Conforme as análises apresentadas pelas Figuras 5.6 ((a) e (b)), os dispersóides AlCu-Mn realmente mudaram de formato, mas ainda estão presentes na ZTMA. Nos contornos de grãos houve uma formação de precipitados grosseiros de fase $\mathrm{S}\left(\mathrm{Al}_{2} \mathrm{CuMg}\right)$. Bousquet et al. (2011) mostraram que os precipitados S'(S) são gradualmente formados em detrimento aos dispersóides de Al-Cu-Mn a partir da região da ZTA em direção à ZTMA da liga 2024T3. Este resultado sugere que ocorre precipitação da fase S'(S) na ZTMA nas condições atingidas. A comparação da ZTMA com o nugget mostra claramente diminuição na concentração de partículas grosseiras e dispersóides sugerindo a dissolução parcial destes nas temperaturas atingidas (ver Figura 5.4).

A Figura 5.7 apresenta as imagens obtidas por TEM das diferentes zonas microestruturais formadas na liga 7475-T651, após a soldagem por FSW das ligas 2024-T3 e 7475-T651. 

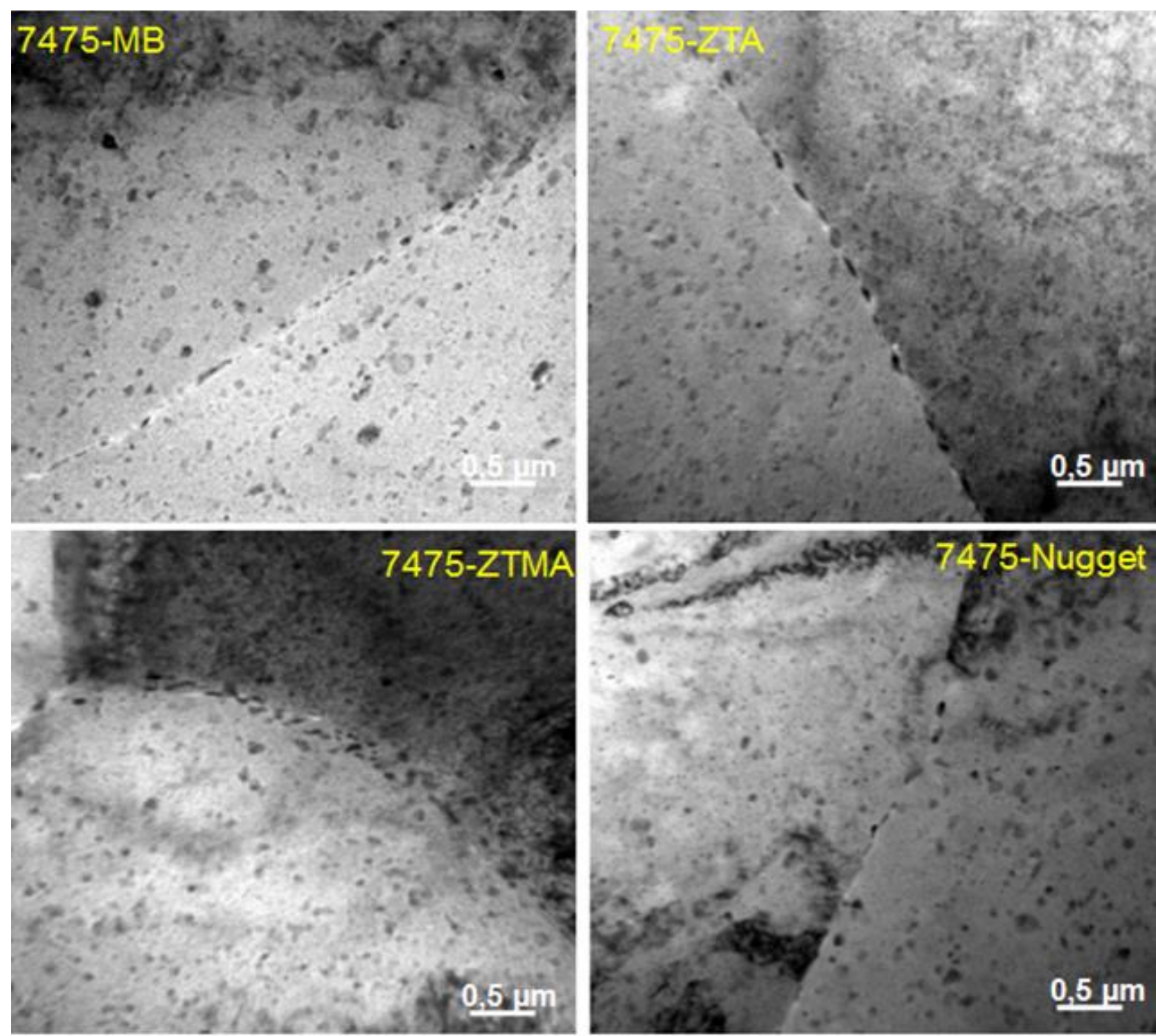

Figura 5.7: Micrografias obtidas por TEM das diferentes regiões da liga 7475-T651 formadas após a soldagem por FSW das ligas 2024-T3 e 7475-T651.

A microestrutura do MB da liga 7475-T651 mostra distribuição fina de precipitados intragranulares e intergranulares com tamanhos da ordem de 20 a $50 \mathrm{~nm}$ e uma zona estreita, vizinha aos contornos de grãos (CG), livre de precipitados. A ZTA em relação ao MB mostra o engrossamento dos precipitados intergranulares e aumento da zona livre de precipitados, além disso, a dissolução dos precipitados intragranulares mais grosseiros. Na ZTMA da liga 7475-T651, há aumento significativo da quantidade desses precipitados nos contornos de grãos, o que sugere que nesta região, a temperatura de solubilização foi atingida e que alguns precipitados dissolvidos se reprecipitaram, preferencialmente, ao longo dos contornos de grãos. Na ZTMA e no nugget, a distribuição dos precipitados intragranulares não é homogênea sendo dependente da orientação do grão. Reprecipitação heterogênea sobre discordâncias deve ter ocorrido durante o resfriamento. No nugget, os precipitados parecem ter resultado de reprecipitação durante o ciclo térmico, uma vez que a redistribuição 
dos precipitados é dependente da estrutura de discordâncias. No nugget, a precipitação sugerida em empilhamento de discordâncias, indica que estes são locais preferenciais para nucleação e crescimento de precipitados. Resultados similares foram observados na literatura para ligas da série 7xxx soldadas por FSW, publicados por Su et al., (2003) e Puydt et al. (2014), para as ligas 7050-T651 e 7020-T652, respectivamente.

As Figuras 5.8 ((a) e (b)) apresentam as análises, realizadas por EDS, dos precipitados encontrados no MB e na ZTMA da liga 7475-T651, respectivamente.
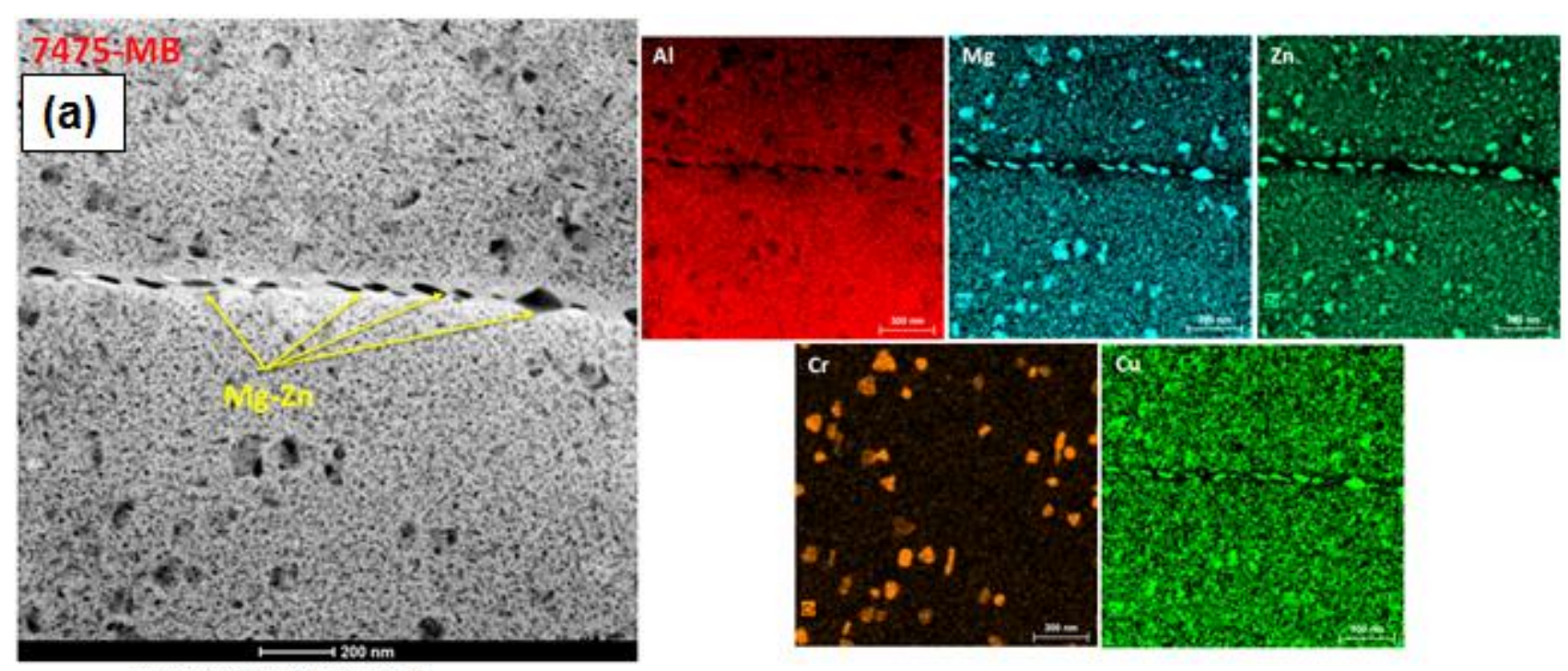

STEM Bright Field micrograph
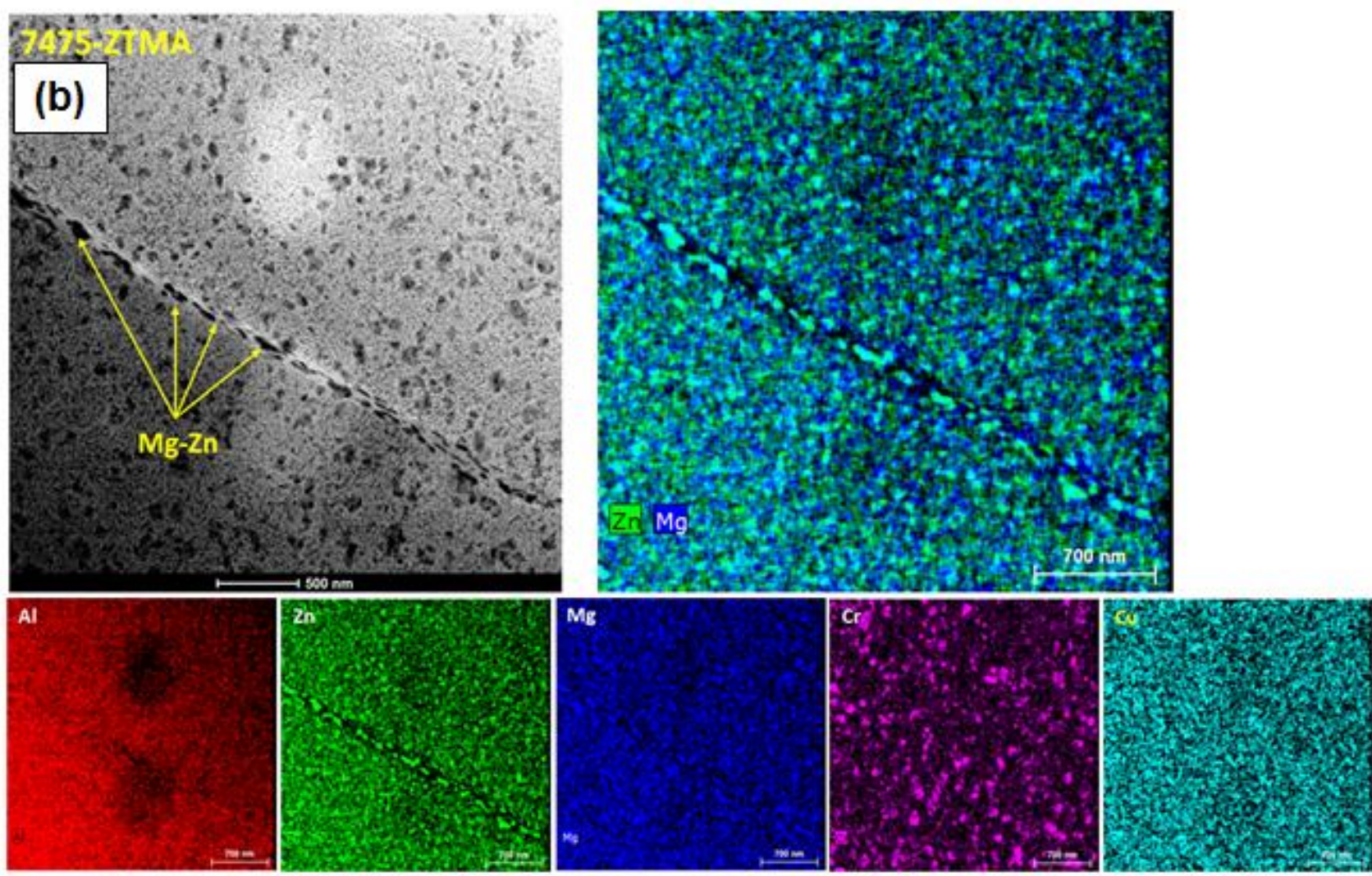
Figura 5.8: Micrografias obtidas por HAADF-STEM de precipitados encontrados no MB (a) e na ZTMA (b) da liga 7475-T651.

Conforme as análises apresentadas na Figuras 5.8 ((a) e (b)), observa-se que os precipitados intergranulares, encontrados no MB e na ZTMA da liga 7475-T651, são constituídos de MgZn ou seja, são de fase $\eta$ 'e $\eta$. Foi possível observar também que, houve grande quantidade desses precipitados (de fase $\eta^{\prime}$ e $\eta$ ) no meio dos grãos, ou seja, precipitados intragranulares. Além disso, foi verificado que diversos precipitados intragranulares continham $\mathrm{Cr}$ em suas composições e que, na ZTMA, havia maior quantidade desses precipitados ricos em $\mathrm{Cr}$ em relação ao $\mathrm{MB}$.

\subsubsection{Calorimetria exploratória diferencial (DSC)}

A Figura 5.9 apresenta os termogramas, obtidos após análise por DSC (Differential Scanning Calorimetry) do MB, da ZTA e da ZTMA da liga 2024-T3.

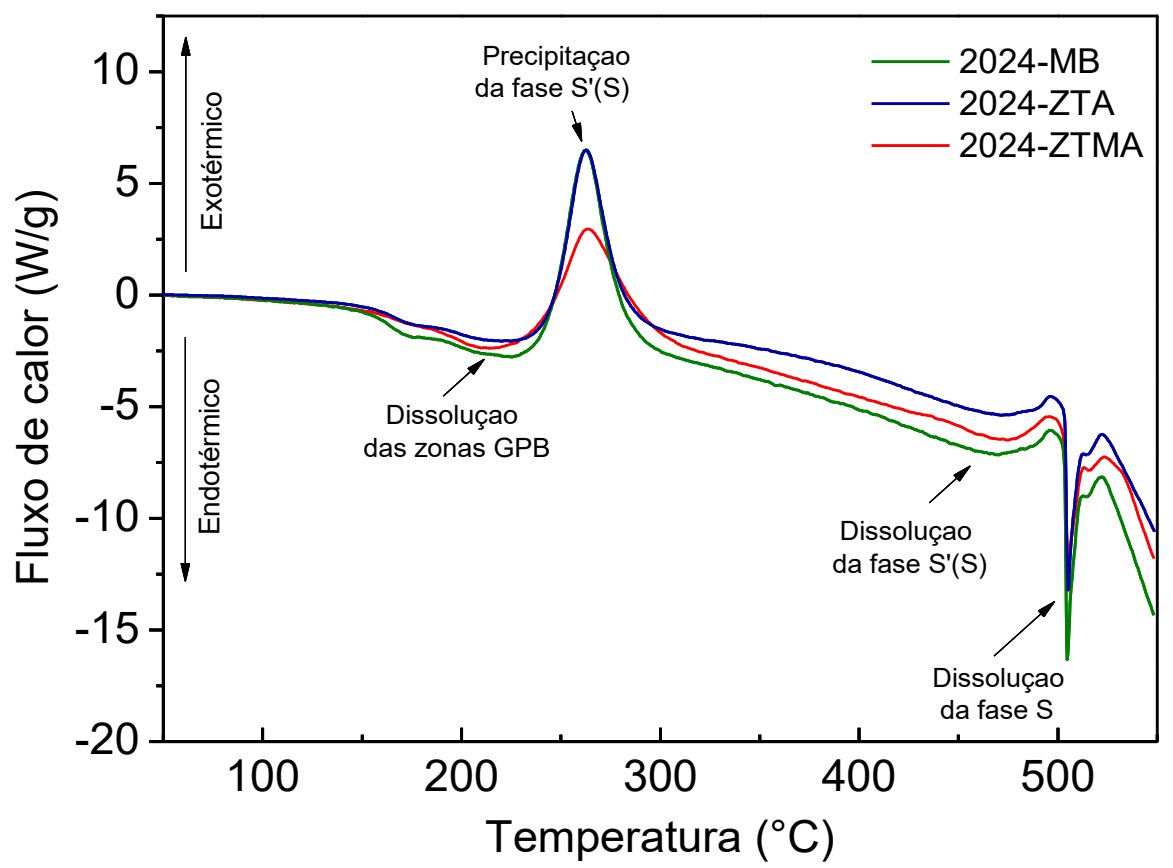

Figura 5.9: Análises por DSC das diferentes zonas da liga 2024-T3, formadas após o processo de soldagem por FSW.

$\mathrm{Na}$ análise dos termogramas de DSC da liga 2024-T3 (Figura 5.9), o primeiro pico (endotérmico), referente à dissolução das zonas GPB não mostra diferenças significativas entre as três zonas analisadas. Este pico está associado à quantidade de energia necessária para que as zonas GPB sejam dissolvidas na liga. O segundo pico (exotérmico) é relacionado à formação da fase $S^{\prime}(S)$. Nota-se diferença entre as alturas dos picos correspondentes à ZTMA e às demais zonas testadas, MB e ZTA. O menor pico (menor quantidade de calor liberada) na ZTMA é explicado pela menor quantidade de energia 
liberada na formação de novos precipitados de fase S'(S). Isto se deve ao fato de parte destes precipitados já estarem presentes na ZTMA, devido a sua precipitação durante o processo de soldagem, em virtude do fluxo de calor e atrito nesta zona. Quanto ao terceiro pico (endotérmico) que se refere à dissolução da fase S'(S), não foi possível observar uma clara distinção entre eles que permitisse fazer inferências sobre a presença destas fases. Os resultados deste trabalho são apoiados pela literatura (Genevois et al., 2006), assim como para o quarto pico endotérmico, referente à dissolução de fase $S$.

A Figura 5.10 apresenta os termogramas, obtidos após análise por DSC (Differential Scanning Calorimetry) do MB, da ZTA e da ZTMA da liga 7475-T651.

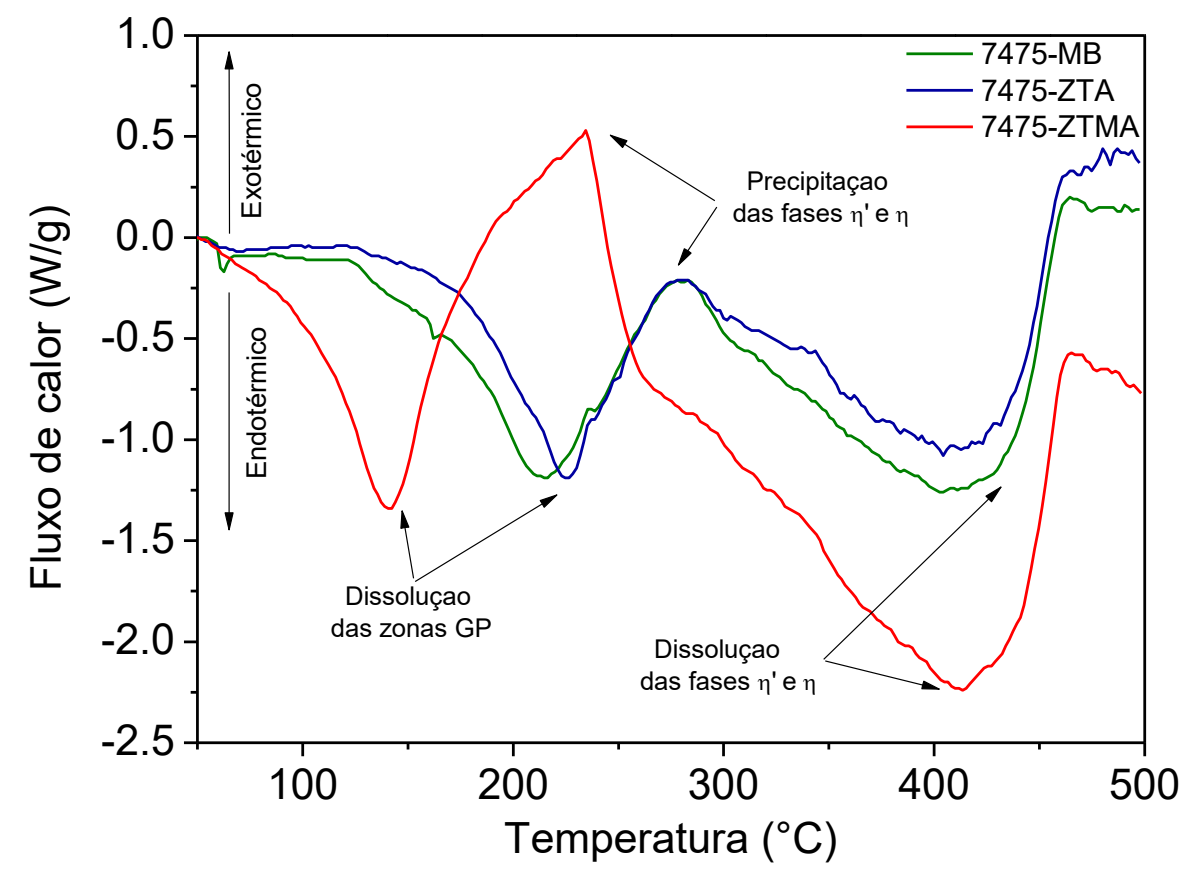

Figura 5.10: Análises por DSC das diferentes zonas da liga 7475-T651, formadas após o processo de soldagem por FSW.

Os termogramas de DSC das zonas MB, ZTA e ZTMA da liga 7475-T651 (Figura 5.10), mostraram grande diferenças entre a ZTMA e as zonas ZTA e MB desta liga. O primeiro pico (endotérmico) refere-se à dissolução das zonas GP. Este pico ocorre em temperaturas mais baixas para a ZTMA, indicando que esta dissolução seja favorecida nesta última zona em relação às outras duas, as quais apresentaram comportamento muito similar. Este comportamento pode ser associado ao fato de algumas zonas GP já terem sido dissolvidas na ZTMA em consequência do fluxo de calor durante o processo de soldagem, e por isso terem necessitado menor temperatura em relação ao $\mathrm{MB}$ e à ZTA. O segundo pico (exotérmico) relaciona-se à formação das fases $\eta^{\prime} / \eta\left(\mathrm{MgZn}_{2}\right)$. Os picos relacionados com o MB e a ZTA são muito próximos, indicando que a quantidade de energia liberada durante a 
precipitação destas fases, $\eta^{\prime} / \eta$, é similar nas duas zonas. A liberação de energia durante a precipitação de $\eta$ '/ $\eta$ na ZTMA, entretanto, é muito maior e ocorre em menores temperaturas que nas duas outras zonas, indicando maior facilidade de precipitação dessas fases na ZTMA. Estas fases precipitam preferencialmente nos contornos de grãos da liga o que é prejudicial à resistência à corrosão intergranular. $O$ terceiro pico (endotérmico) é associado à dissolução das fases $\eta^{\prime} / \eta\left(M g Z n_{2}\right)$. A maior energia necessária para dissolução destas fases na ZTMA pode ser explicada pelos precipitados $\eta^{\prime} / \eta\left(\mathrm{MgZn}_{2}\right)$ já formados nesta zona, principalmente nos contornos de grãos da ZTMA durante soldagem, em comparação ao MB e ZTA. Os resultados sugerem necessidade de menor quantidade de energia para a dissolução das fases $\eta$ '/ $\eta$ na ZTA em relação ao MB, provavelmente devido à dissolução de algumas destas fases nas temperaturas atingidas na ZTA. As micrografias da Figura 5.7 indicam dissolução de fases grosseiras do MB na ZTA. Adler e Delasi (1977), LaDelpha et al. (2009) e e Bush et al. (2016) também observaram por temogrmas de DSC, em ligas da série 7xxx, grande diferença de comportamento entre a ZTMA e as zonas ZTA e MB.

\subsubsection{Ensaio de microdureza}

A dureza é uma das propriedades mais afetadas quando há diferenças microestruturais, em razão das diferentes regiões formadas, conforme os tamanhos de grãos e formação ou dissolução de precipitados endurecedores. As medidas de microdureza Vickers, ao longo das regiões formadas após a soldagem por FSW das ligas 2024-T3 e 7475T651 auxiliam na avaliação das zonas microestruturais formadas. A microdureza das ligas 2024-T3 e 7475-T651 soldadas por FSW, foram avaliadas e os perfis obtidos são apresentados na Figura 5.11. 


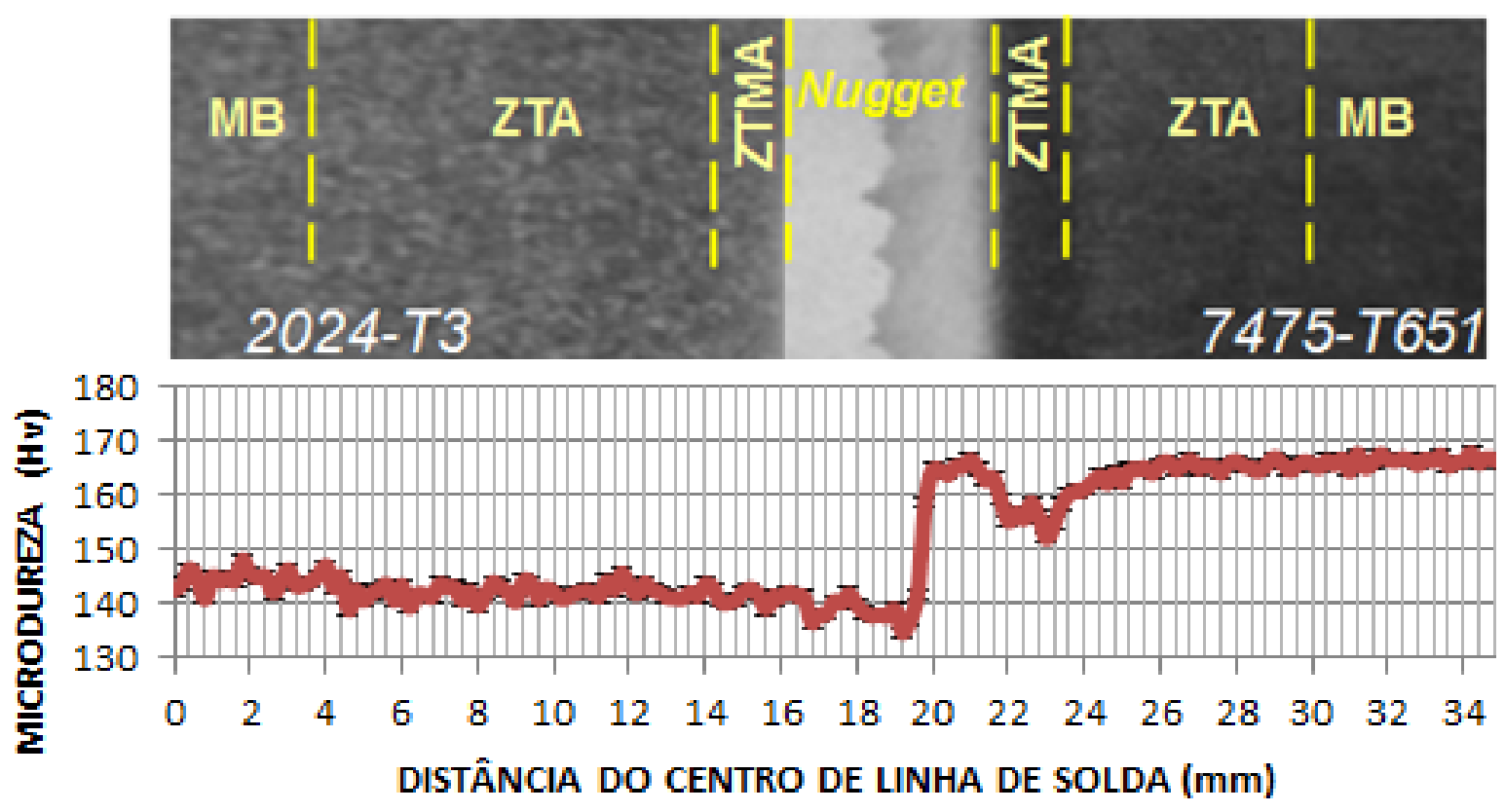

Figura 5.11: Perfis de microdureza, obtidos pela área varrida das ligas 2024-T3 e 7475-T651, soldadas por FSW.

As medidas de microdureza Vickers ao longo de uma linha na superfície das ligas 2024-T3 e 7475-T651, que atravesse todas as zonas afetadas e não afetadas pela soldagem por FSW, auxiliam na caracterização das diferentes microestruturas formadas. A Figura 5.11 mostra uma leve tendência à diminuição da dureza da liga 2024-T3 desde o MB até o nugget, embora com valores muito próximos para o MB e a ZTA, entre 140 e $145 \mathrm{Hv}$, de acordo com as análises por microscopia óptica, por TEM e por DSC, onde foi verificado que os grãos e as microestruturas apresentaram grande similaridade nos resultados. Tendência mais clara de queda da microdureza foi notada desde a ZTA para a ZTMA e desta para o nugget. A literatura (Srinivasan et al., 2005; Amancio-Filho et al., 2008) também indica queda da microdureza entre a ZTMA e o nugget da liga 2024-T3, com valores entre 135 e $140 \mathrm{Hv}$. Este resultado pode, a princípio, parecer incoerente uma vez que a deformação mecânica do processo de soldagem diminui o tamanho dos grãos da microestrutura, o que causaria aumento de dureza. Entretanto, as altas temperaturas atingidas nessa região permitem a dissolução de precipitados endurecedores, a formação de precipitados de fase S'(S) e coalescimento destes, bem como, dependendo da temperatura atingida, a dissolução de parte dstes, o que tende a reduzir os valores de microdureza. Mesmo após o resfriamento, as zonas GPB endurecedoras, que são formadas a partir das fases $S^{\prime}(S)$, dissolvidas pelo efeito da alta temperatura, não são suficientes para permitir aumento significativo da microdureza, conforme Bousquet et al. (2011). 
Uma vez que a liga 7475-T651 é mais dura que a liga 2024-T3, ocorre um brusco aumento da microdureza Vickers na região da interface entre as duas ligas. $\mathrm{O}$ valor de microdureza Vickers medido no nugget da 7475-T651 foi próximo a $165 \mathrm{Hv}$. O MB e a ZTA da liga 7475-T651 apresentaram valores de microdureza muito próximos ( 165 Hv), pois ambas as zonas apresentam microestruturas muito similares, conforme visto nas análises por microscopia óptica, por DSC e por TEM. Os resultados, todavia, mostram uma redução expressiva de dureza na ZTMA. Os resultados de DSC indicaram que a dissolução das zonas GP é favorecida na ZTMA em comparação à ZTA e MB. Além disso, apesar da indicação de maior quantidade de precipitados $\eta^{\prime} / \eta\left(M \mathrm{MZn}_{2}\right)$ na ZTMA em relação ao MB e ZTA, estes se localizam preferencialmente ao longo dos contornos de grãos, sendo menos frequentes intragranularmente. Estas seriam as possíveis causas para a diminuição da microdureza na ZTMA da liga 7475-T651.

\subsubsection{Microscopia eletrônica de varredura (SEM)}

A Figura 5.8 apresenta as partículas intermetálicas ou partículas grosseiras, através das imagens obtidas por microscópio eletrônico de varredura (SEM), das diferentes zonas formadas após soldagem, por FSW, das ligas 2024-T3 e 7475-T651. A Figura 5.12 apresenta as imagens obtidas por SEM, com baixo aumento, a fim de se observar a densidade de partículas grosseiras nas diferentes zonas ao longo das ligas 2024-T3 e 7475-T651, soldadas por FSW, onde os pontos brancos representam essas partículas. Vale lembrar que, essas partículas não participam do endurecimento da liga, porém elas desempenham um papel importante na suscetibilidade à corrosão localizada. 

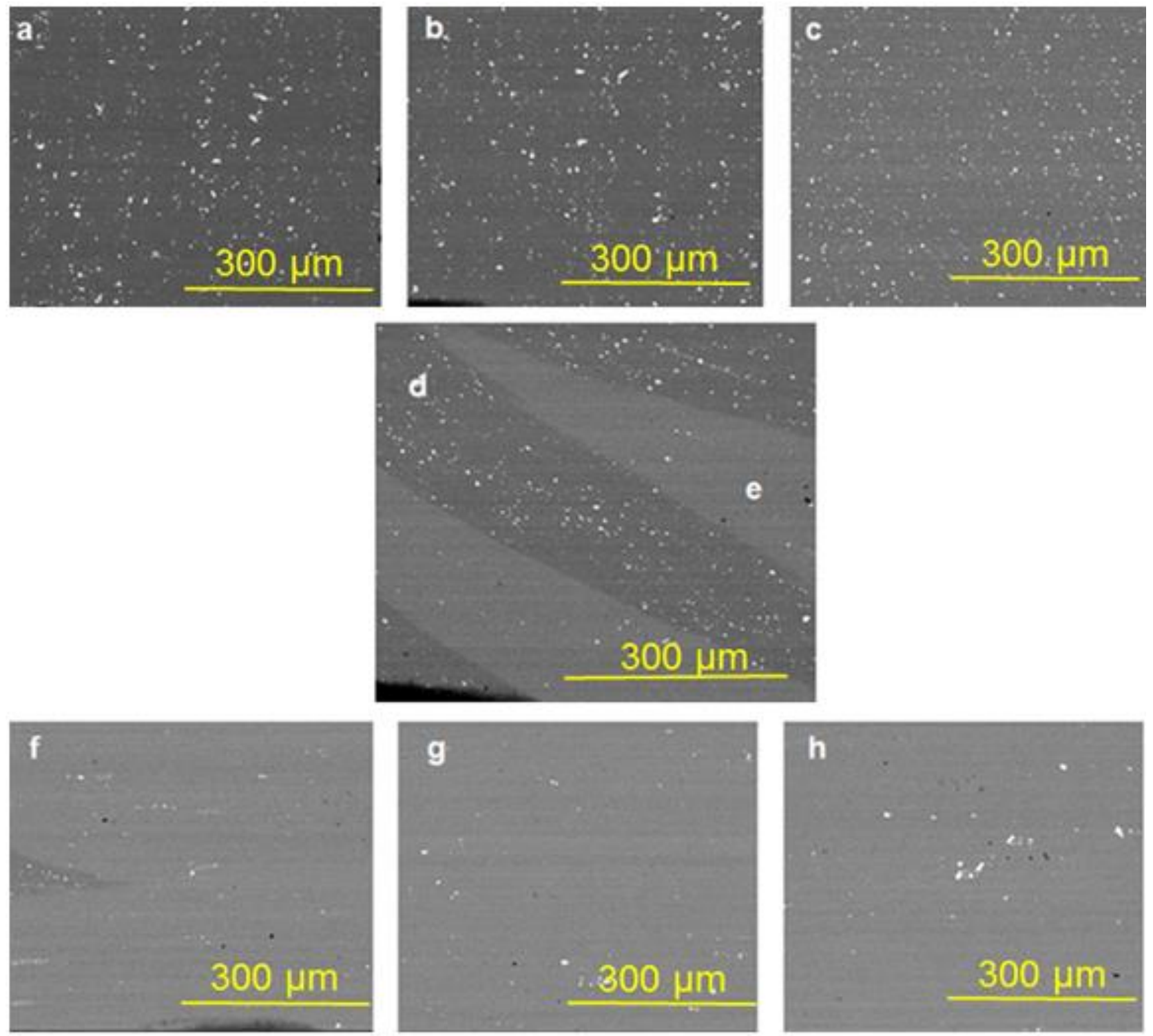

Figura 5.12: Fotomicrografias obtidas por microscopita eletrônica de varredura das diferentes regiões formadas após a soldagem, por FSW, das ligas 2024-T3 e 7475-T651: (a) MB da 2024-T3; (b) ZTA da 2024-T3; (c) ZTMA da 2024-T3; (d) nugget da 2024-T3; (e) nugget da 7475-T651; (f) ZTMA da 7475-T651; (g) ZTA da 7475-T651 e; (h) MB da 7475-T651.

Levando-se em consideração apenas as zonas formadas na liga 2024-T3, por possuírem uma quantidade muito maior e visível de partículas intermetálicas na região na ZTMA e no nugget (Figuras 5.12-c e 5.12-d), as partículas intermetálicas se alinham seguindo o movimento circular do pino da ferramenta de solda, que arrasta a liga e seus precipitados, assim como quebra alguns deles. Nota-se então que essas partículas intermetálicas possuem menores dimensões em relação ao MB (Figura 5.12-a) e à ZTA (Figura 5.12-b). Destaca-se que, apenas as partículas intermetálicas ricas em Al, $\mathrm{Cu}, \mathrm{Fe}, \mathrm{Mn}$ e Si se quebram durante o movimento de rotação da ferramenta. No MB da liga 2024-T3 (Figura 5.12-a), é possível verificar uma maior quantidade de partículas intermetálicas grosseiras presentes, ou seja, não foram fragmentadas pela ação mecânica da ferramenta. 
Com relação às partículas intermetálicas da liga 7475-T651, observa-se que no nugget (Figura 5.12-e) e na ZTMA (Figura 5.12-f), as partículas também se alinham seguindo o movimento circular do pino da ferramenta de solda. Observa-se que, para esta liga, há uma quantidade muito menor de partículas intermetálicas, em relação à liga 2024-T3. A Figura 5.13 apresenta as análises das distribuições das partículas intermetálicas, das diferentes regiões das ligas após soldagem por FSW, através das imagens obtidas por microscópio eletrônico de varredura, com o auxílio do software ImageJ.
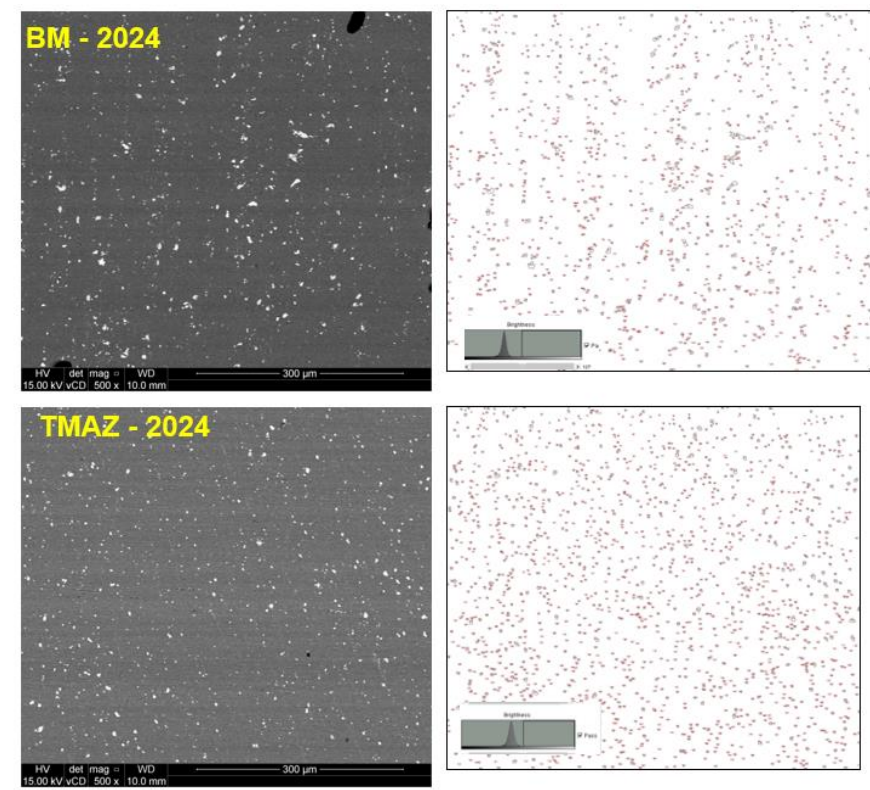

HAZ - 7475
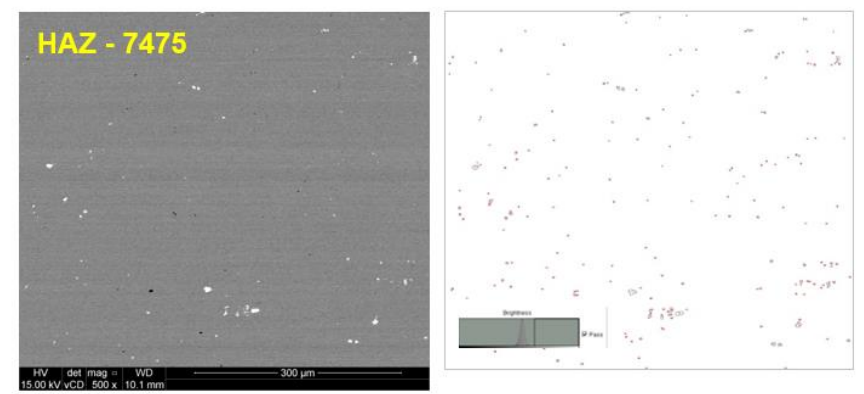
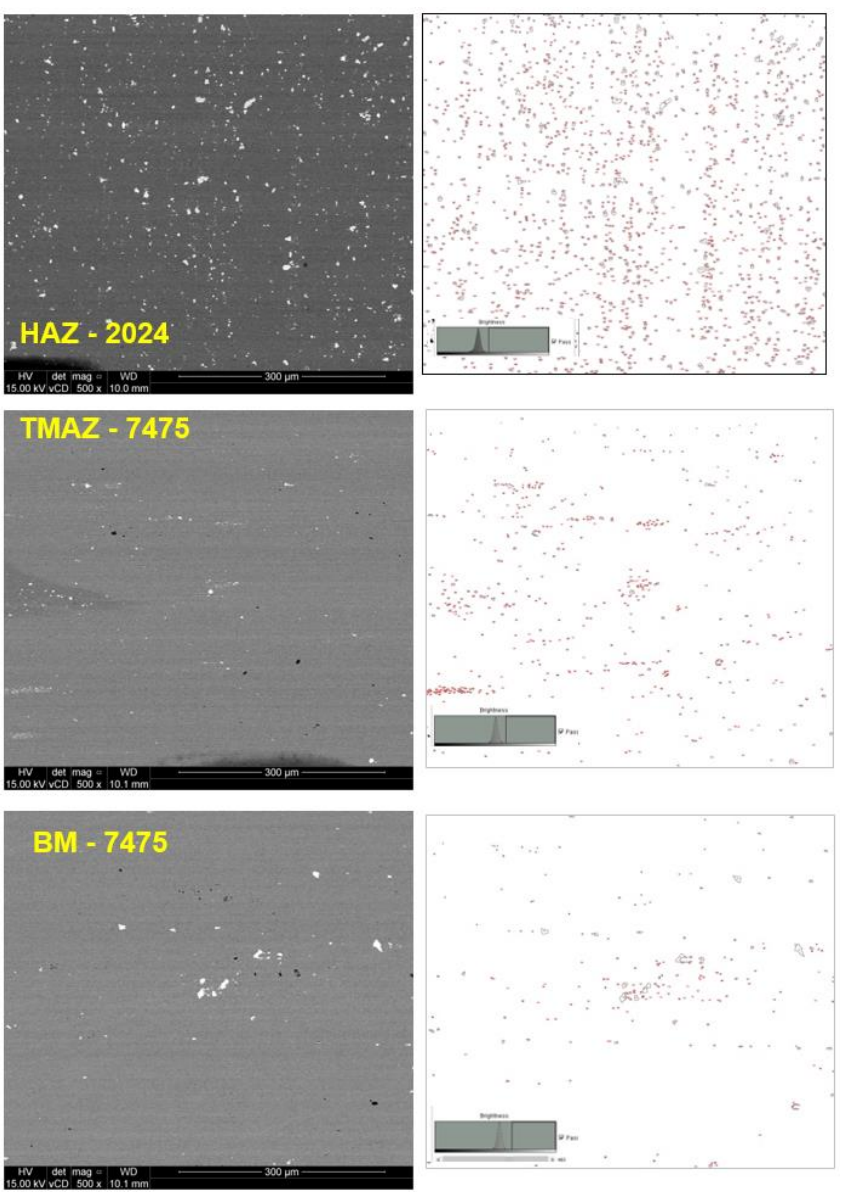

Figura 5.13: Análises das distribuições de precipitados, das diferentes regiões das ligas após soldagem por FSW, através das imagens obtidas por microscópio eletrônico de varredura, com o auxílio do software ImageJ.

A Tabela 5.2 apresenta as análises das distribuições das partículas intermetálicas nas diferentes zonas formadas após a soldagem, por FSW, das ligas 2024-T3 e 7475-T651. Pela análise visual das imagens da Figura 5.9 e pela análise dos diâmetros médios dos precipitados (ver Tabela 5.1), nas diferentes zonas formadas, observa-se que há uma quebra das partículas intermetálicas no nugget e na ZTMA, em razão da passagem do ombro da ferramenta de soldagem por FSW, e por isso ocorre uma redução do diâmetro médio das partículas intermetálicas nessas zonas. 
Tabela 5.1: Análises das distribuições dos precipitados nas diferentes zonas formadas após a soldagem, por FSW, das ligas 2024-T3 e 7475-T651

\begin{tabular}{cc} 
Zona & $\begin{array}{c}\text { Diâmetro médio das partículas } \\
\text { intermetálicas }(\boldsymbol{\mu m})\end{array}$ \\
\hline $\mathbf{2 0 2 4 - M B}$ & 2,04 \\
$\mathbf{2 0 2 4 - Z T A}$ & 1,99 \\
$\mathbf{2 0 2 4 - Z T M A}$ & 1,36 \\
$\mathbf{7 4 7 5 - Z T M A}$ & 1,07 \\
$\mathbf{7 4 7 5 - Z T A}$ & 2,46 \\
$\mathbf{7 4 7 5 - M B}$ & 1,82
\end{tabular}

A Figura 5.14 apresenta as análises dos principais tipos de partículas intermetálicas encontradas nas diferentes ligas e suas respectivas regiões após soldagem por FSW.
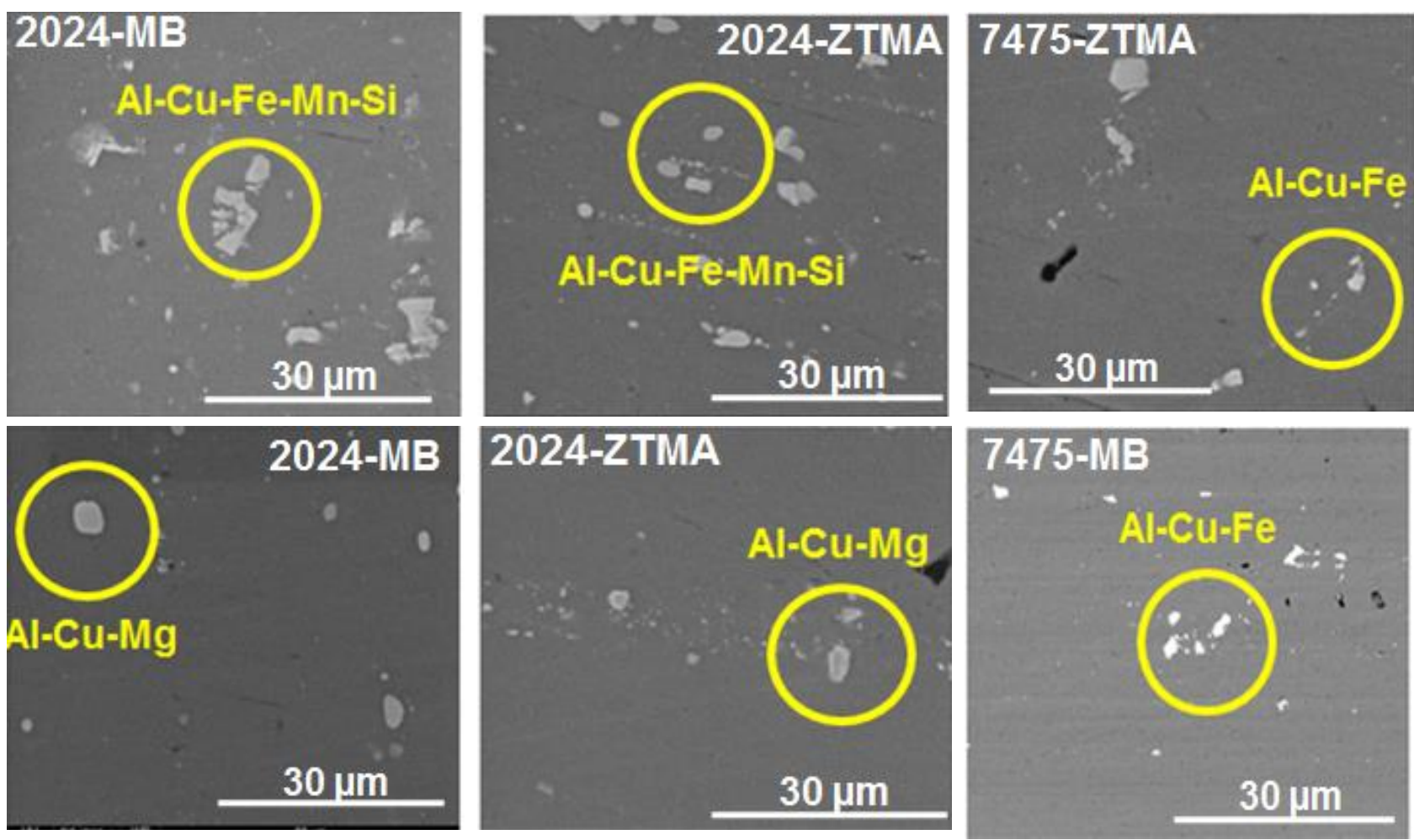

Figura 5.14: Análises dos tipos de precipitados principais, nas diferentes ligas e as respectivas regiões após soldagem por FSW.

De acordo com a Figura 5.14, é possível verificar que as principais partículas intermetálicas formadas são as de Al-Cu-Fe-Mn-Si e Al-Cu-Mg (fase S), para a liga 2024-T3, e o precipitado de Al-Cu-Fe, para a liga 7475-T651. É importante notar que as partículas intermetálicas de Al-Cu-Fe-Mn-Si, da liga 2024-T3, assim como as partículas de Al-Cu-Fe, da liga 7475-T651, são quebradas durante o processo de soldagem por FSW, pois evidenciase em ambas as ZTMAs pequenos cometas formados e redução dos tamanhos de algumas partículas. 


\subsection{Avaliação da resistência a diferentes formas de corrosão das ligas soldadas}

Alguns ensaios de imersão com soluções pouco e muito agressivas foram realizados, a fim de compreender suas influências, bem como das diferentes zonas microestruturais formadas nas ligas 2024-T3 e 7475-T651 soldadas por FSW.

\subsubsection{Ensaio de imersão em solução de ágar-ágar}

Na Figura 5.15 é apresentada a evolução de corrosão das ligas 2024-T3 e 7475-T651 soldadas por FSW, durante exposição a solução de ágar-ágar (indicador de pH, 0,7 M de $\mathrm{NaCl}$ e ágar-ágar), por período de 8 horas. $\mathrm{O}$ objetivo principal da realização deste ensaio foi identificar a região mais suscetível à corrosão, supondo-se acoplamento galvânico, conforme discutido anteriormente, e se baseando em alguns estudos que utilizaram esta mesma técnica, a qual oferece uma maneira fácil e sensível para identificar as regiões anódica e catódica, resultantes de reações eletroquímicas (Jariyaboon, 2007; Donatus, 2015).

Neste ensaio, as regiões catódica e anódica são indicadas pela ateração de pH, sendo as áreas com colorações de amarela à laranja as zonas ácidas, correspondentes aos sítios anódicos, ou seja, as áreas de corrosão, resultantes da dissolução do alumínio e, consequentemente, a hidrólise de íons de alumínio, conforme as equações 5.1 e 5.2 .

$$
\begin{array}{r}
\mathrm{Al}_{(\mathrm{s})} \rightarrow \mathrm{Al}^{3+}{ }_{(\text {aq })}+3 \mathrm{e}^{-} \text {(eq. 5.1) } \\
\mathrm{Al}^{3+}{ }_{(\text {aq })}+\mathrm{H}_{2} \mathrm{O}_{(\mathrm{l})} \leftrightarrow \mathrm{AlOH}^{2+}+\mathrm{H}^{+}{ }_{(\text {aq })} \text { (eq. 5.2) }
\end{array}
$$

As áreas verdes às azuis indicam regiões básicas, correspondentes aos sítios catódicos, resultantes da redução do oxigênio (equação 5.3).

$$
\mathrm{O}_{2(\text { aq })}+2 \mathrm{H}_{2} \mathrm{O}_{(l)}+4 \mathrm{e}^{-} \rightarrow 4 \mathrm{OH}^{-} \text {(aq) }
$$




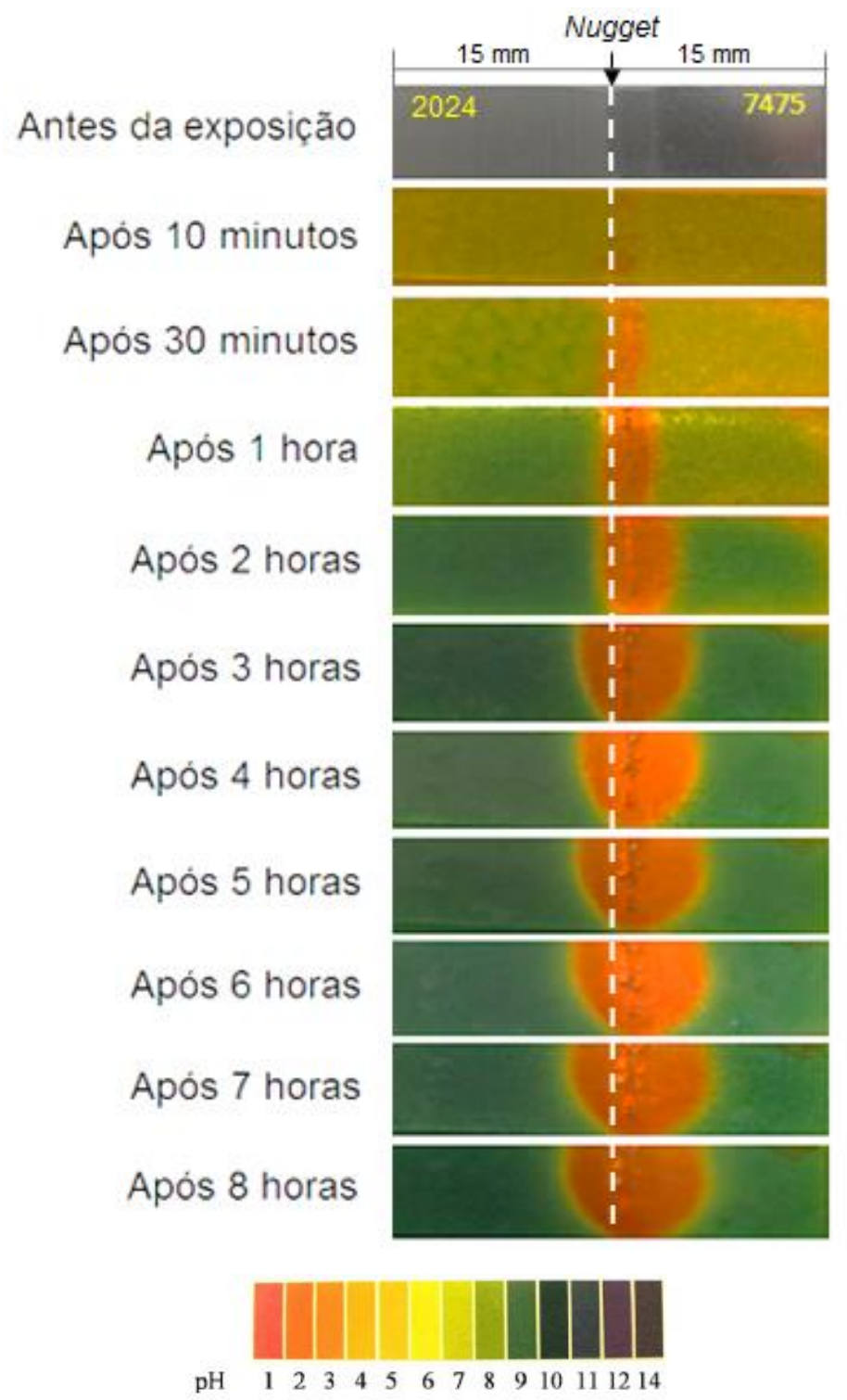

Figura 5.15: Imagens, seguidas por tempo de exposição em solução de ágar-ágar.

As imagens apresentadas na Figura 5.15 mostram claramente que a liga que contém Zn (7475-T651) se comporta anodicamente em relação à liga contendo Cu (2024-T3) (Hollingsworth and Hunsicker, 1990; Buchheit, 1995; Dix, 1998). Além disso, eles mostram que as reações anódicas estão concentradas perto das zonas soldadas, como encontrado para diferentes sistemas de ligas (Lumsdem, 2003; Jariyaboon, 2011; Bugarin, 2016). Após apenas 10 minutos de imersão, uma ligeira zona alaranjada começa a desenvolver-se na região do nugget sobre o lado da liga 7475-T651. À medida que o ensaio prossegue, esta zona inicialmente se espalha para o restante da região do nugget da liga 7475-T651 (durante cerca de 30 minutos) e depois gradualmente se estende até a ZTA de ambas as ligas. No entanto, a área anódica da liga 7475-T651 permaneceu sempre maior do que a da liga 2024T3. Por fim, as regiões anódicas parecem ser restringidas às áreas da nugget e da TMAZ, 
enquanto que para a liga 7475-T651, a atividade anódica se desenvolve bem além, alcançando a ZTA.

A Figura 5.16 apresenta uma imagem ampliada da zona soldada, após 8 horas de ensaio em solução de ágar-ágar, onde evidencia-se a presença de várias protuberâncias, correspondentes à evolução do gás hidrogênio que ocorre na região que possui uma reatividade exacerbada. Nesta região específica, correspondente à interface entre a ZTMA e a ZTA da liga 7475-T651, a taxa de corrosão é fortemente aumentada. Essa evolução de gás hidrogênio já foi relatada por outros autores e tem sido atribuída ao desenvolvimento de forte corrosão localizada (pite e ataques intergranulares) dentro de certas regiões de um material (Zhou et al., 2012). De acordo com o mecanismo proposto, as paredes da fenda formada, devido ao ataque localizado, seriam mais nobres do que a frente de propagação da corrosão (ponta da fenda); agindo como um cátodo interno, onde a reação de redução de hidrogênio teria lugar (Zhou et al., 2012).

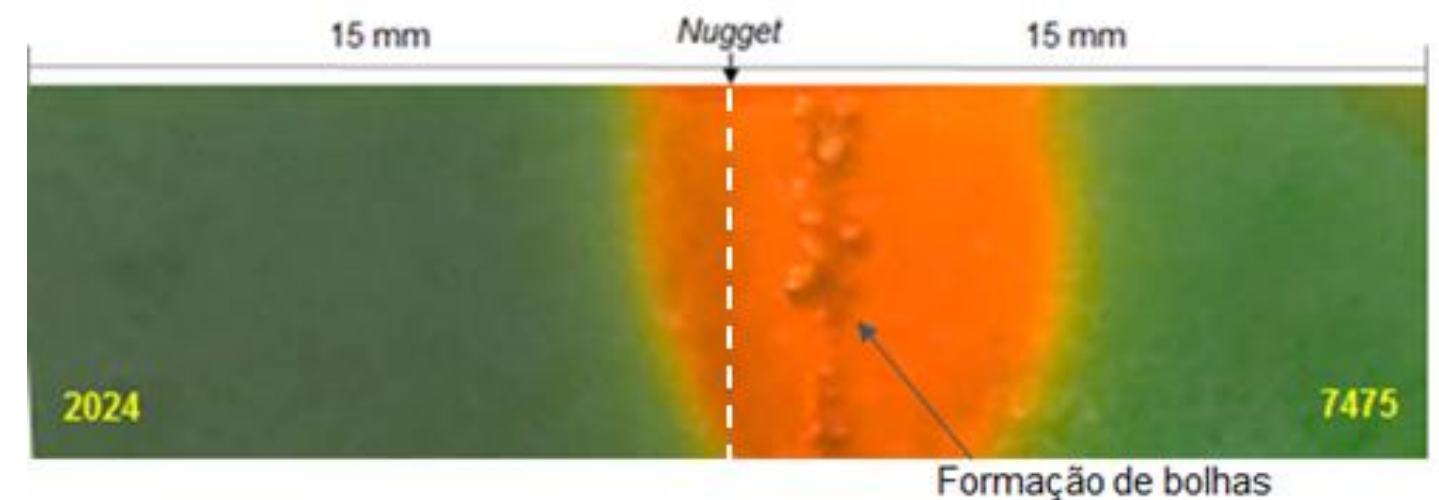

Figura 5.16: Aumento da imagem da amostra exposta em solução de ágar-ágar, após 8 horas de imersão.

A maior suscetibilidade à corrosão pode ser atribuída à maior concentração de precipitados intergranulares endurecedores de fase $\eta\left(\mathrm{MgZn}_{2}\right)$ nesta região (interface entre ZTMA e ZTA), que são anódicos em relação à matriz. É nesta zona que ocorreu a maior concentração de precipitados de fase $\eta\left(\mathrm{MgZn}_{2}\right)$ nos contornos de grãos (ver Figura 5.7). O ataque intenso nessa região, com geração de cátions metálicos, resultou em hidrólise e acidificação localizada, o que por sua vez, promoveu a continuação do processo corrosivo. Nesta condição, parte da corrente catódica do processo deve-se à reação de evolução de hidrogênio, o que deve resultar na diminuição da contribuição da reação de redução do oxigênio, retardando o avanço da cor laranja a partir de 4 horas de ensaio. O pH muito baixo (ordem de 2) formado nesta região, fez com que parte das reações eletroquímicas ficassem 
concentradas nessa região. Neste $\mathrm{pH}$ e potenciais medidos $(-500 \mathrm{mV}$ Ag/AgCl, resultados mais a frente) o alumínio sofre corrosão.

Com o intuito de entender o comportamento à corrosão, em razão do acoplamento galvânico entre as diferentes ligas, e avaliar a região mais suscetível à corrosão (nugget/ZTMA da liga 7475-T651), foi realizado um ensaio de verificação à corrosão intergranular, de acordo com a norma ASTM G110-97, em solução agressiva.

As ligas das séries 2xxx e 7xxx tendem a sofrer corrosão intergranular (ASTM G11097). Em estudo de uma liga da série 7xxx, especificamente da liga 7108-T79, foi verificado que os precipitados do MB desta liga são distribuídos uniformemente no interior dos grãos, mas na ZTMA, a fase de equilíbrio termodinâmico precipita nos contornos dos grãos alguns precipitados intergranulares anódicos em relação à matriz, tornando-se o potencial negativo nesta região, sendo favoráveis à dissolução anódica e á corrosão intergranular (Wadeson et al., 2006.

Como foi possível observar uma maior densidade de precipitados intergranulares de fase $\eta\left(\mathrm{MgZn}_{2}\right)$ na ZTMA da liga 7475-T651, conforme as análises realizadas por TEM, e sabendo que essa fase é anódica em relação à matriz, presume-se que esses precipitados, em exposição à solução corrosiva, sejam dissolvidos previamente e, seguidos pelo ataque preferencial dos contornos de grãos.

\subsubsection{Verificação da corrosão intergranular}

A Figura 5.17 mostra uma macrografia da superfície da amostra das ligas 2024-T3 e 7475-T651 soldadas por FSW, durante os primeiros minutos do ensaio do comportamento à corrosão intergranular. Em seguida, são mostradas as imagens, obtidas por SEM, das diferentes regiões formadas pelo processo de soldagem por FSW, após o ataque (6 horas de exposição) com a solução do ensaio de comportamento à corrosão intergranular, onde foi possível observar que, assim como na solução de ágar-ágar, a região mais atacada foi a ZTMA da 7475-T651, inclusive com a formação de bolhas na mesma região. 


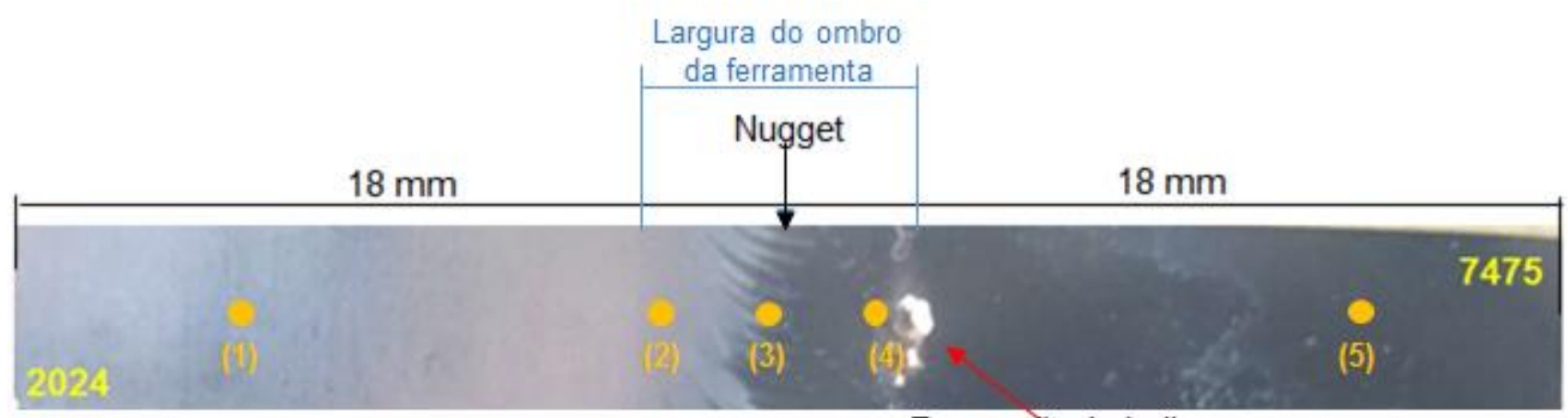

Formação de bolhas
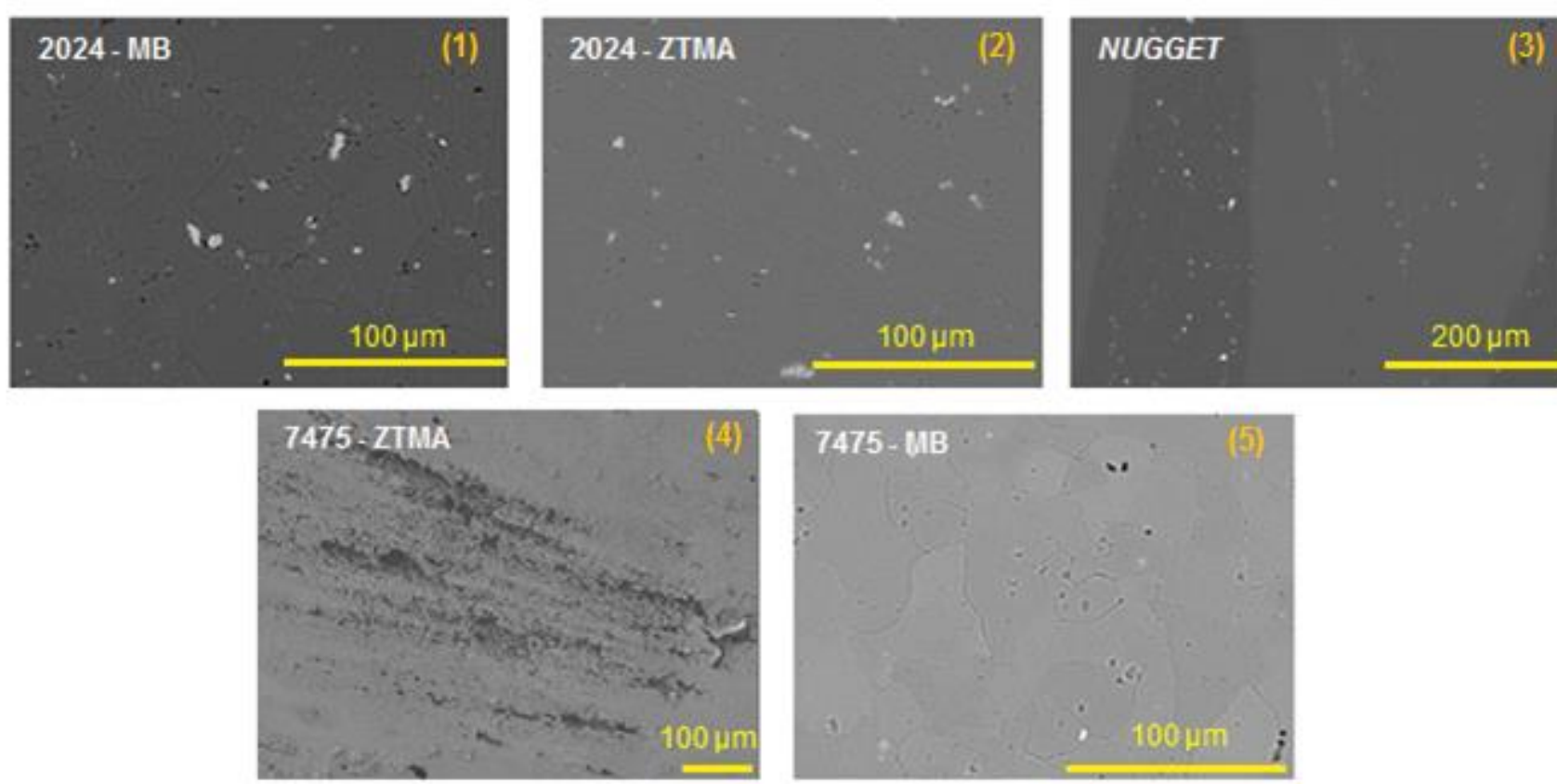

Figura 5.17: Macrografia da superfície da amostra das ligas 2024-T3 e 7475-T651, soldadas por FSW, durante os primeiros minutos em exposição ao ensaio do comportamento à corrosão intergranular. Abaixo, as micrografias obtidas por SEM, após o ataque.

De acordo com as micrografias, obtidas por SEM, apresentadas pela Figura 5.17, é visível o ataque preferencial na região da ZTMA da liga 7475-T651, conforme a micrografia (4) da Figura 5.17. Essas deformações verificadas, por SEM, na superfície da ZTMA da liga 74575-T651, após o ataque, se deve ao fato da corrosão intergranular formada (ver Figuras 5.18(d) e 5.18(e)). Também é possível verificar um pequeno ataque no nugget da liga 7475_ T651 (Figura 5.18(c)). 

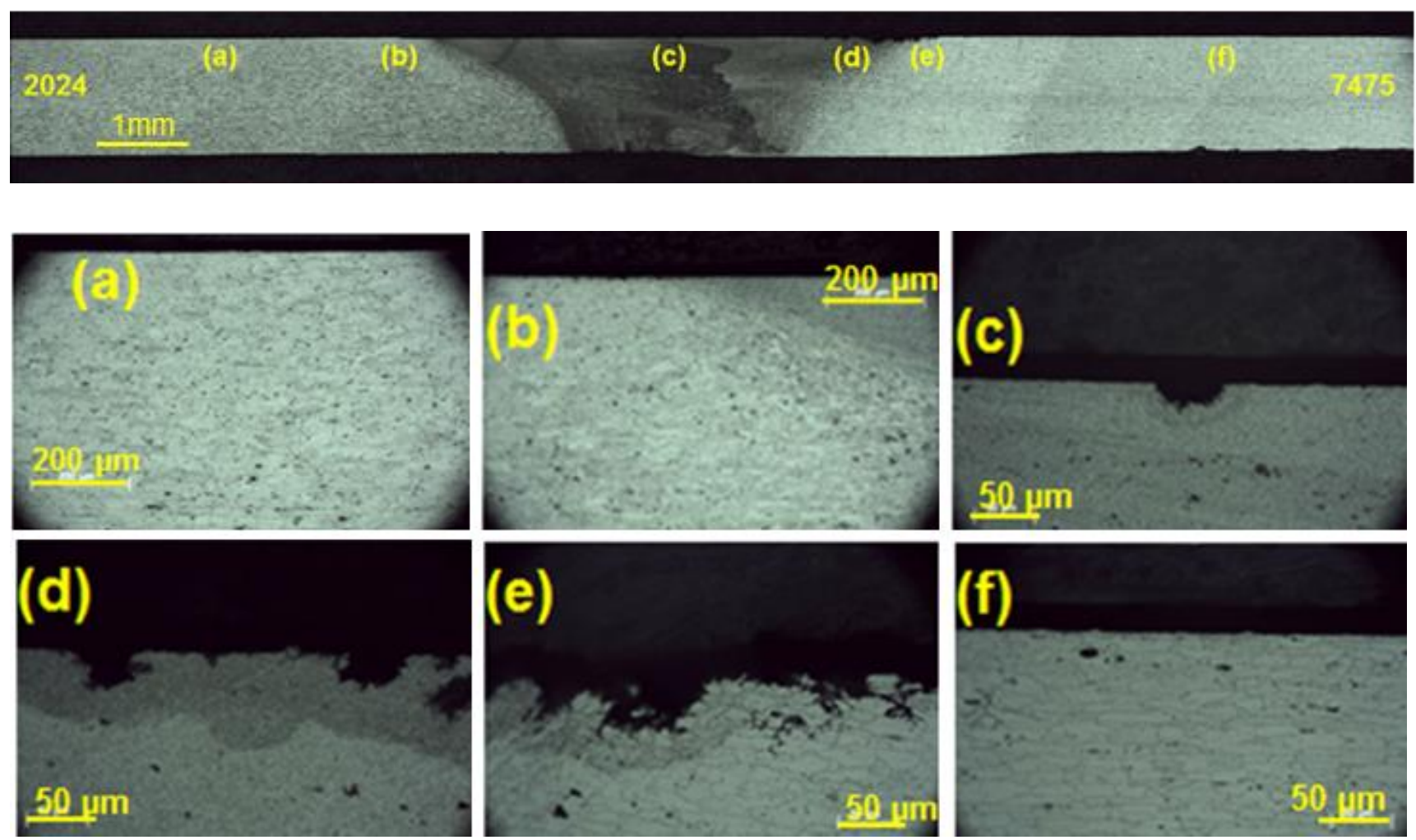

Figura 5.18: Imagens obtidas por micoscopia óptica da seção transversal da amostra após o ataque para verificação do comportamento à corrosão intergranular.

Os ataques verificados no nugget e na ZTMA da liga 7475-T651, inclusive com o destacamento de alguns grãos, evidencia a suscetibilidade à corrosão da liga 7475-T651 em relação à liga 2024-T3, que permanece intacta, e da preferência pela região da ZTMA da liga 7475-T651, cuja presunção do fato seja a maior densidade de precipitados endurecedores intergranulares de fase $\eta\left(\mathrm{MgZn}_{2}\right)$, que atuam como regiões anódicas à matriz e, por isso, favorecem a corrosão intergranular.

Sabe-se que a evolução da corrosão intergranular gera produtos de corrosão que se acumulam na região entre os grãos formados, gerando um campo de tensão que induz esse tipo de evolução da corrosão intergranular, que é denominada corrosão por esfoliação. A fim de complementar o estudo sobre o comportamento à corrosão das ligas soldadas, se avaliou o comportamento das ligas 2024-T3 e 7475-T651 soldadas por FSW, em solução agressiva para avaliar o comportamento à corrosão por esfoliação.

\subsubsection{Verificação da corrosão por esfoliação}

A Figura 5.19 mostra a imagem obtida nos primeiros 10 minutos do ensaio de corrosão por esfoliação, onde se observa um ataque forte e uma quantidade enorme de bolhas 
formadas na ZTMA da liga 7475-T651, o que continua de acordo com as análises vistas em exposições em soluções de ágar-ágar e na verificação de corrosão intergranular.

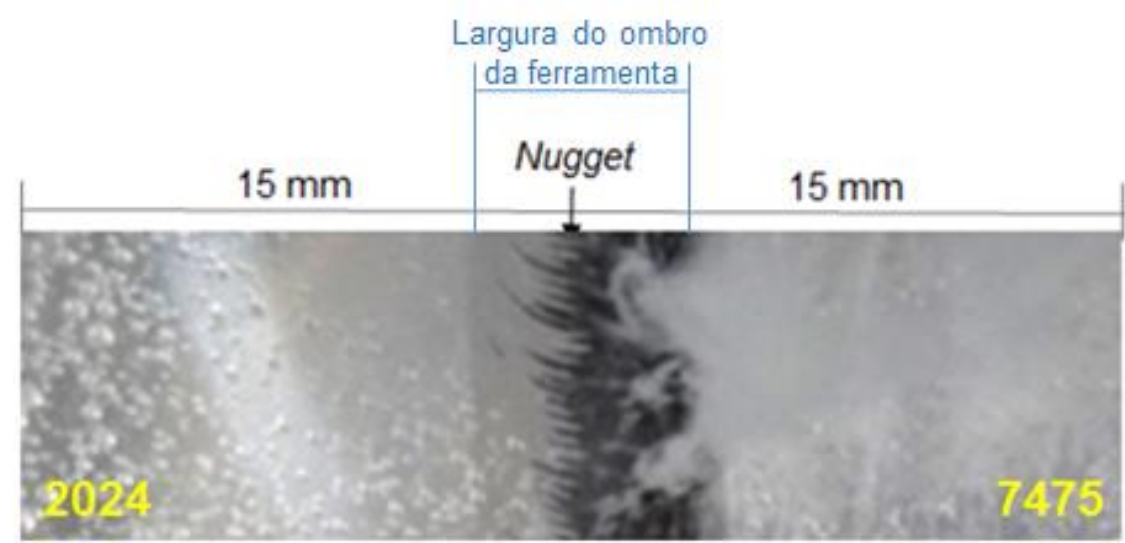

Figura 5.19: Macrografia da amostra após 10 minutos em solução para verificação do comportamento à corrosão por esfoliação.

Como a solução de ataque de corrosão por esfoliação é muito agressiva, evidenciamse formação de bolhas por toda a amostra já nos primeiros minutos de exposição em solução. A enorme quantidade de bolhas formadas na ZTMA da liga 7475-T651 mostra que, possivelmente, seja em razão de um forte acoplamento galvânico na interface entre as duas ligas, sendo ela mais anódica em relação à liga 2024-T3, e também devido à maior suscetibilidade à corrosão que esta zona apresenta. Essas bolhas devem ser, possivelmente, em razão da evolução de íons de $\mathrm{H}^{+}{ }_{(a q)}$, enquanto que as bolhas formadas ao longo de toda a liga 2024-T3, provavelmente, são oriundas da redução de oxigênio, como consequência da formação de uma região mais anódica que sua vizinhança.

A Figura 5.20 apresenta as imagens das superfícies das amostras dos MB das ligas 2024-T3 (Figura 5.20(a)) e 7475-T651 (Figura 5.20(c)), e dessas ligas soldadas por FSW (Figura 5.20(b)), após imersão, durante 48 horas, em solução altamente corrosiva para a verificação de resistência à corrosão por esfoliação, conforme a norma ASTM G-34.

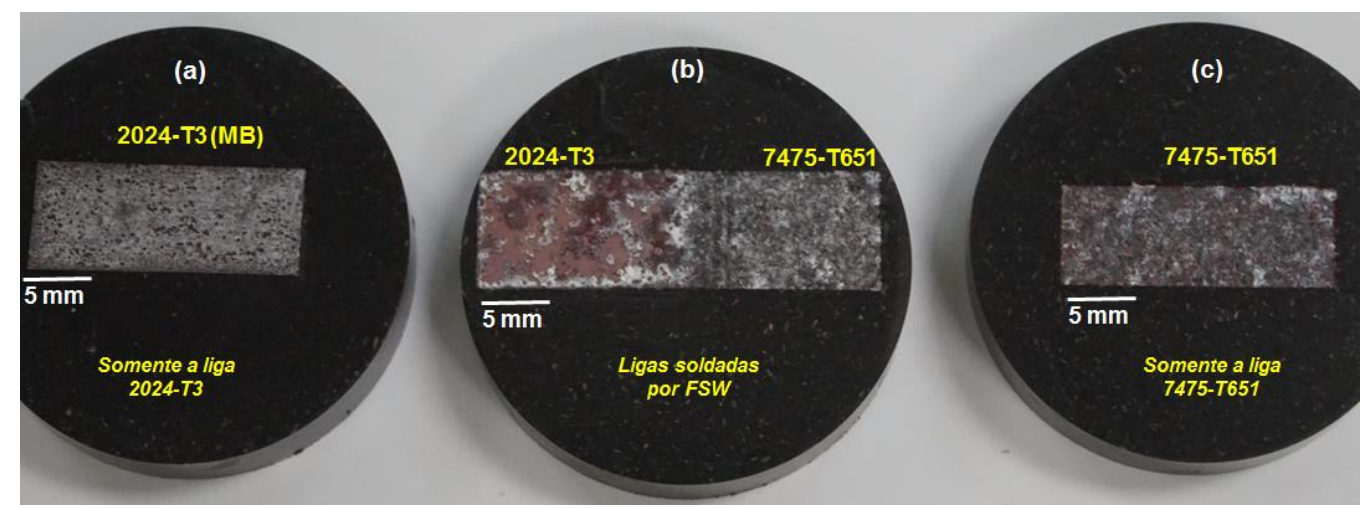

Figura 5.20: Fotografias das amostras dos MB das ligas 2024 e 7475 e da amostra das ligas 2024 e 7475 soldadas por FSW, após ataque para verificação do comportamento à corrosão por esfoliação. 
Observa-se que, a liga 7475-T651 sofre forte corrosão por esfoliação, seja apenas quando o seu MB é exposto, seja quando em contato com a liga 2024-T3, após soldagem. Já a liga 2024-T3, apesar de apresentar ataque corrosivo nos dois casos, fica aparentemente mais protegida quando soldada e em contato com a amostra 7475-T651, possivelmente pelo acoplamento galvânico, conforme visto anteriormente.

A Figura 5.21 apresenta as imagens, obtidas por microscopia óptica, das seções transversais das amostras dos MB das ligas 2024-T3 (Figura 5.21(b)) e 7475-T651 (Figura 5.21(c)), e dessas ligas soldadas por FSW (Figura 5.21(a)), após 48 horas de imersão, em solução altamente corrosiva para a verificação de resistência à corrosão por esfoliação, conforme a norma ASTM G-34, seguida por polimento e ataque com reagente Keller.

(a)

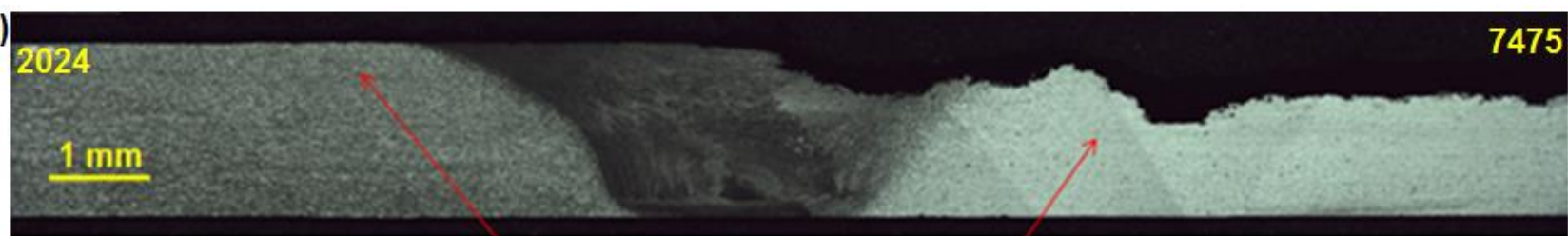

(b)
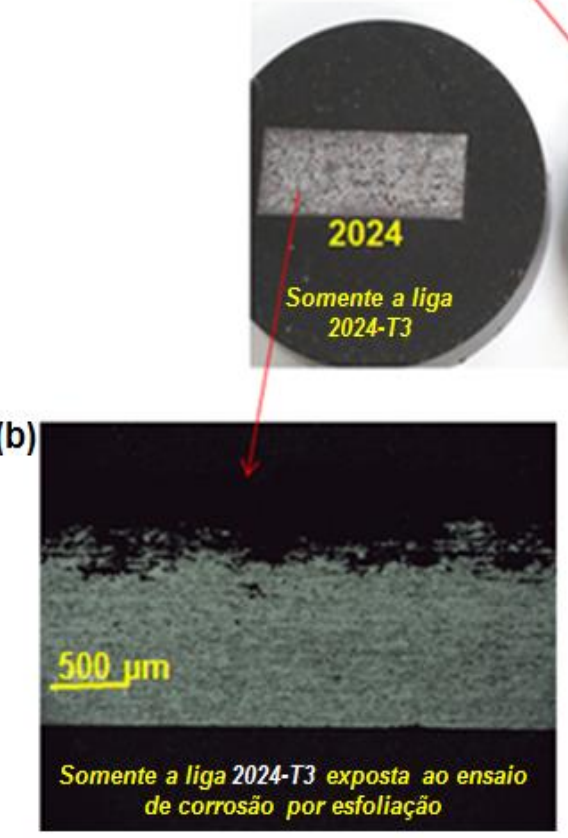

2024

Somente a liga 2024-T3

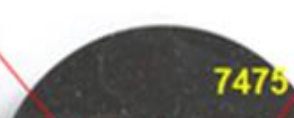

$747:$

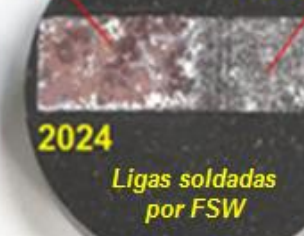

2024

por FSW

Figura 5.21: Micrografias ópticas das seções transversais das ligas 2024 e 7475 separadas e soldadas por FSW, após ataque para verificação do comportamento à corrosão por esfoliação.

É possível observar que a amostra do MB da liga 2024-T3 (Figura 5.21(b)) apresenta corrosão por efoliação. Entretanto, quando em contato com a liga 7475-T651, através de soldagem por FSW, a mesma liga não sofre ataque. Isso se deve ao fato de que, para este caso, a liga 7475-T651 age como ânodo de sacríficio, por ser a liga mais anódica nesse par galvânico. 
A amostra do MB da liga 7475-T651 (Figura 5.21(c)) apresenta corrosão por esfoliação, entretanto esse ataque é menos severo ao ataque que essa liga sofre quando soldada, por FSW, com a liga 2024-T3, pois como dito anteriormente, a liga 7475-T651 age como ânodo de sacrifício.

Como o ataque é muito agressivo na verificação de corrosão por esfoliação, não foi possível observar qual zona da liga 7475-T651 (liga mais anódica), entre as diferentes zonas formadas pelo processo de soldagem por FSW foi a mais suscetível à corrosão, como no caso dos ensaios com soluções de ágar-ágar e de verificação da corrosão intergranular. Entretanto, foi possível notar, perfeitamente, que a liga 7475-T651 é anódica em relação à liga 2024-T3, em meios altamente agressivos.

\subsubsection{Ensaios de imersão em solução de $0,1 \mathrm{M}$ de $\mathrm{Na}_{2} \mathrm{SO}_{4}+1 \mathrm{mM}$ de $\mathrm{NaCl}$}

Para a avaliação da resistência à corrosão das ligas de alumínio 2024-T3 e 7475T651 soldadas por FSW, via técnicas eletroquímicas, optou-se pelo uso de solução pouco corrosiva, composta de 0,1 $\mathrm{M}$ de $\mathrm{Na}_{2} \mathrm{SO}_{4}+1 \mathrm{mM}$ de $\mathrm{NaCl}$. Apesar dos íons cloretos serem os mais utilizados nos estudos de corrosão das ligas de alumínio, pois provocam desestabilização da camada passiva, a ideia principal foi analisar o comportamento das ligas, em soluções que contenham íons sulfatos, que contribuem com a melhoria do comportamento passivo das ligas de alumínio, e dessa forma retardam a aparição de pites que interferem nas análises da avaliação da suscetibilidade das amostras à corrosão localizada (Aballe, 2001; Boag, 2010; Blanc e Lavelle, 1997). A inclusão de $1 \mathrm{mM}$ de $\mathrm{NaCl}$ à solução foi devido ao fato do eletrodo de referência de $\mathrm{Ag} / \mathrm{AgCl}$ necessitar de uma pequena quantidade de íons cloretos para sua estabilização. A ideia principal na escolha dessa solução pouco agressiva foi tentar verificar as possíveis diferenças entre os potenciais eletroquímicos distintos das ligas, assim como de suas zonas formadas após o processo de soldagem por FSW.

Antes da realização dos ensaios eletroquímicos, foi verificado o comportamento à corrosão das ligas 2024-T3 e 7475-T651 soldadas por FSW, através de macrografias, antes da exposição da amostra (ver Figura 5.22(a)) e após 24 horas de exposição (ver Figura 5.22(b)), em solução de 0,1 $\mathrm{M}$ de $\mathrm{Na}_{2} \mathrm{SO}_{4}+1 \mathrm{mM}$ de $\mathrm{NaCl}$. 
(a)

MB-2024
ZTMA-2024
Nugget

ZTMA-7475
MB-7475

\section{(b)}

2024-T3

7475-T651

Figura 5.22: Macrografias ópticas das superfícies das amostras das ligas 2024-T3 e 7475-T651, soldadas por FSW: (a) antes da exposição; (b) após 8 horas e; (c) 24 horas de exposição em solução de $0,1 \mathrm{M}$ de $\mathrm{Na}_{2} \mathrm{SO}_{4}+1 \mathrm{mM}$ de $\mathrm{NaCl}$.

Observa-se, na Figura 5.22, que - visualmente - o lado da liga 2024-T3 apresenta estar mais corroído. A fim de compreender a interferência das partículas intermetálicas no comportamento de resistência à corrosão, em solução de $0,1 \mathrm{M}$ de $\mathrm{Na}_{2} \mathrm{SO}_{4}+1 \mathrm{mM}$ de $\mathrm{NaCl}$, foram obtidas micrografias, obtidas por SEM, de 5 zonas distintas, antes da exposição da amostra em solução, após 8 horas e após 24 horas de exposição. As zonas escolhidas (identificadas na Figura 5.22(a)) foram: MB da liga 2024-T3 (ver Figura 5.23); ZTMA da liga 2024-T3 (ver Figura 5.24); nugget entre as duas ligas (ver Figuras 5.25 e 5.26); ZTMA da liga 7475-T651 (ver Figura 5.27) e; MB da liga 7475-T651 (ver Figura 5.28). 

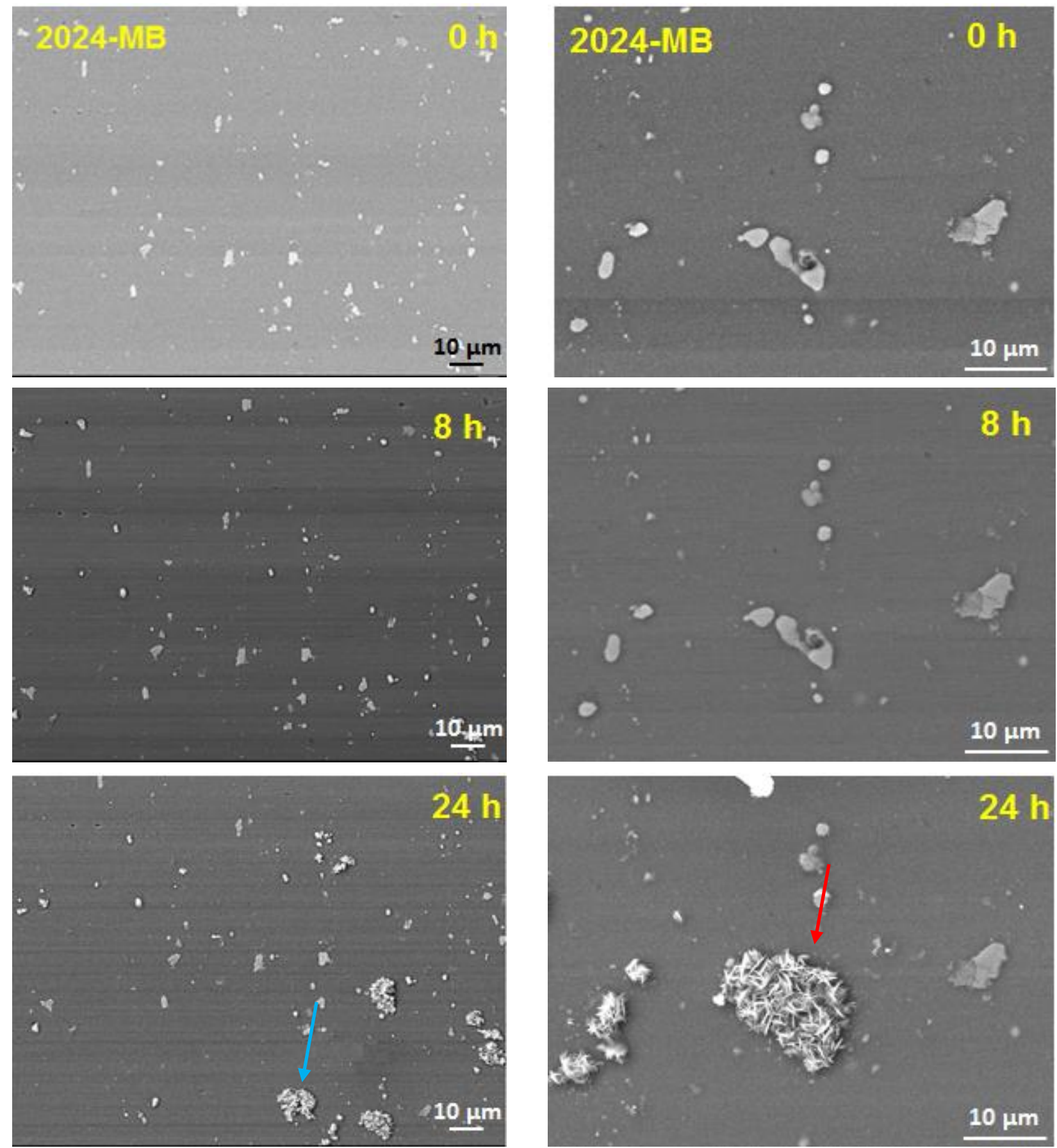

Figura 5.23: Micrografias obtidas por SEM do MB da liga 2024-T3, antes de exposição, após 8 horas e após 24 horas de exposição em solução de $0,1 \mathrm{M}$ de $\mathrm{Na}_{2} \mathrm{SO}_{4}+1 \mathrm{mM}$ de $\mathrm{NaCl}$. As fotos à direita foram tiradas com maior aumento da mesma região das fotos à esquerda.

A Figura 5.23 mostra que, após 24 horas de exposição em solução de $0,1 \mathrm{M}$ de $\mathrm{Na}_{2} \mathrm{SO}_{4}+1 \mathrm{mM}$ de $\mathrm{NaCl}$, o MB da liga 2024-T3 apresentou uma grande quantidade de dissolução de algumas partículas ou produtos de corrosão formados e depositados preferencialmente nessas partículas, que possivelmente eram mais ativas, durante 0 processo corrosivo das ligas 2024-T3 e 7475-T651, soldadas por FSW. 

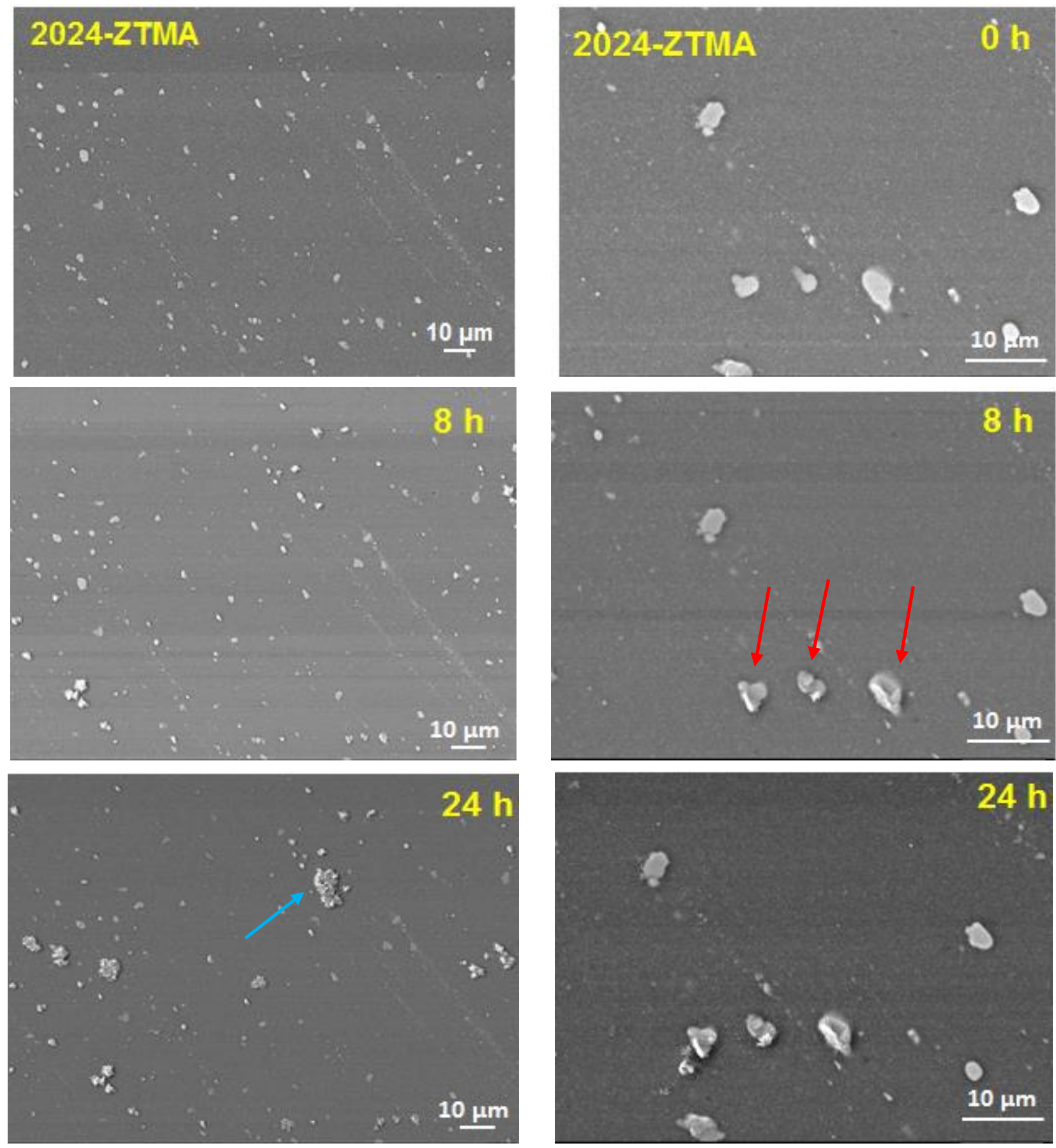

Figura 5.24: Micrografias obtidas por SEM da ZTMA da liga 2024-T3, antes de exposição, após 8 horas e após 24 horas de exposição em solução de $0,1 \mathrm{M}$ de $\mathrm{Na}_{2} \mathrm{SO}_{4}+1 \mathrm{mM}$ de $\mathrm{NaCl}$. As fotos à direita foram tiradas com maior aumento da mesma região das fotos à esquerda

A Figura 5.24 mostra que, após 24 horas de exposição em solução de $0,1 \mathrm{M}$ de $\mathrm{Na}_{2} \mathrm{SO}_{4}+1 \mathrm{mM}$ de NaCl, a ZTMA da liga 2024-T3 apresentou uma grande quantidade de dissolução de algumas partículas ou produtos de corrosão formados e depositados preferencialmente nessas partículas, que possivelmente eram mais ativas, durante 0 processo corrosivo das ligas 2024-T3 e 7475-T651, soldadas por FSW. Entretanto, para esta zona, foi possível observar algumas partículas intermetálicas ativas já com 8 horas de exposição, conforme a indicação das setas em vermelho. 

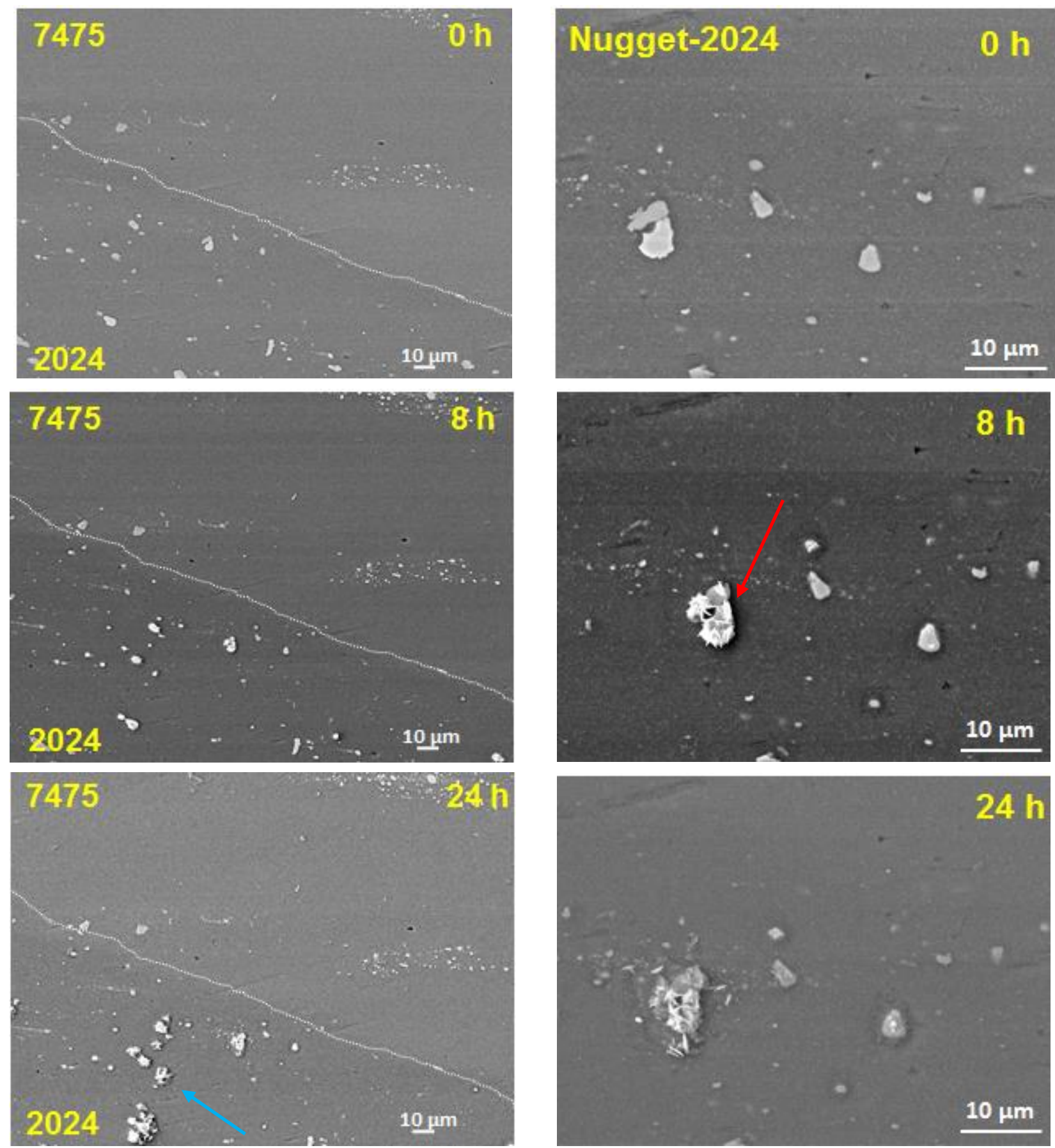

Figura 5.25: Micrografias obtidas por SEM do nugget das ligas 2024-T3 e 7475-T651, soldadas por FSW, antes de exposição, após 8 horas e após 24 horas de exposição em solução de 0,1 M de $\mathrm{Na}_{2} \mathrm{SO}_{4}+1 \mathrm{mM}$ de $\mathrm{NaCl}$. As fotos à direita foram tiradas com maior aumento da mesma região das fotos à esquerda, referentes à parte da liga 2024-T3.

A Figura 5.25 mostra que, após 24 horas de exposição em solução de $0,1 \mathrm{M}$ de $\mathrm{Na}_{2} \mathrm{SO}_{4}+1 \mathrm{mM}$ de NaCl, o nugget da liga 2024-T3 apresentou uma grande quantidade de dissolução de algumas partículas ou produtos de corrosão formados e depositados preferencialmente nessas partículas, que possivelmente eram mais ativas, durante 0 processo corrosivo das ligas 2024-T3 e 7475-T651, soldadas por FSW. Entretanto, para esta 
zona, foi possível observar algumas partículas intermetálicas ativas já com 8 horas de exposição, conforme a indicação das setas em vermelho.
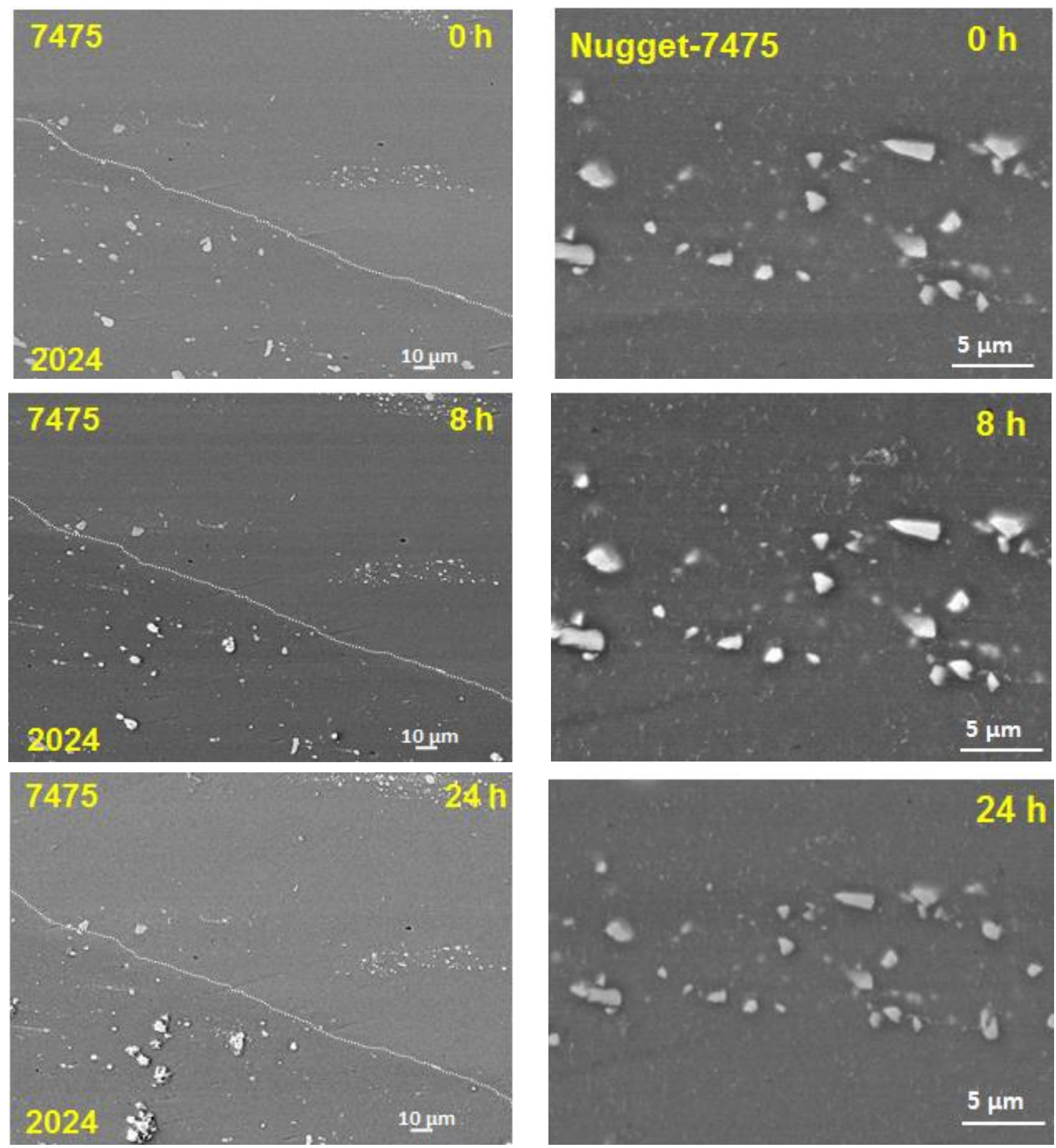

Figura 5.26: Micrografias obtidas por SEM do nugget das ligas 2024-T3 e 7475-T651, soldadas por FSW, antes de exposição, após 8 horas e após 24 horas de exposição em solução de $0,1 \mathrm{M}$ de $\mathrm{Na}_{2} \mathrm{SO}_{4}+1 \mathrm{mM}$ de $\mathrm{NaCl}$. As fotos à direita foram tiradas com maior aumento da mesma região das fotos à esquerda, referentes à parte da liga 7475-T651.

Com relação às partículas intermetálicas da liga 7475-T651 (ver Figura 5.26), não foi possível identificar qualquer diferença visual, antes e após a exposição da amostra em 
solução, ou seja, suas partículas intermetálicas não se tornaram ativas e, provavelmente, não sofreram ataques.
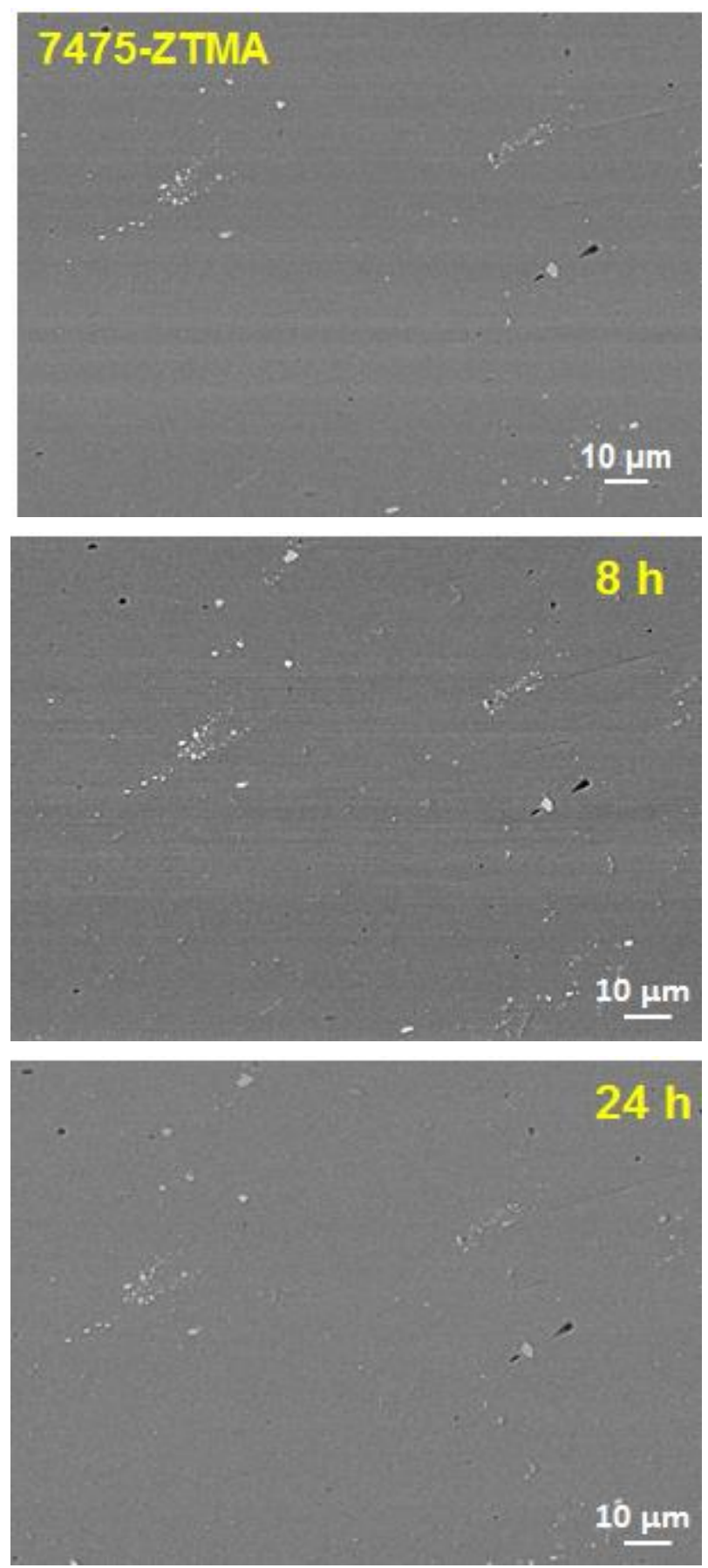
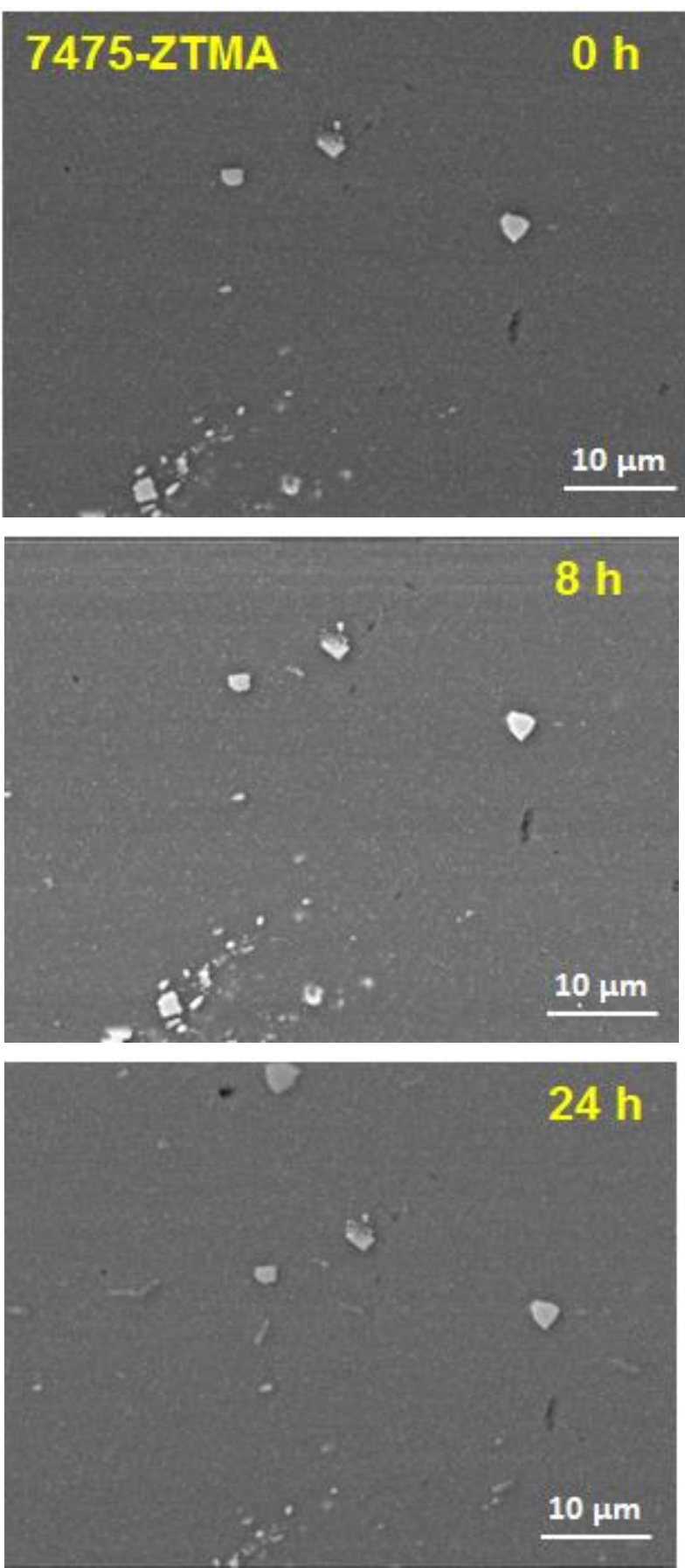

Figura 5.27: Micrografias obtidas por SEM da ZTMA da liga 7475-T651, antes de exposição, após 8 horas e após 24 horas de exposição em solução de $0,1 \mathrm{M}$ de $\mathrm{Na}_{2} \mathrm{SO}_{4}+1 \mathrm{mM}$ de $\mathrm{NaCl}$. As fotos à direita foram tiradas com maior aumento da mesma região das fotos à esquerda.

A Figura 5.27 mostra que, após 24 horas de exposição em solução de $0,1 \mathrm{M}$ de $\mathrm{Na}_{2} \mathrm{SO}_{4}+1 \mathrm{mM}$ de $\mathrm{NaCl}$, a ZTMA da liga 7475-T651 não apresentou qualquer partícula intermetálica ativa ou qualquer suspeita de ataque corrosivo, ou seja, se mantiveram intactas durante o processo corrosivo. 

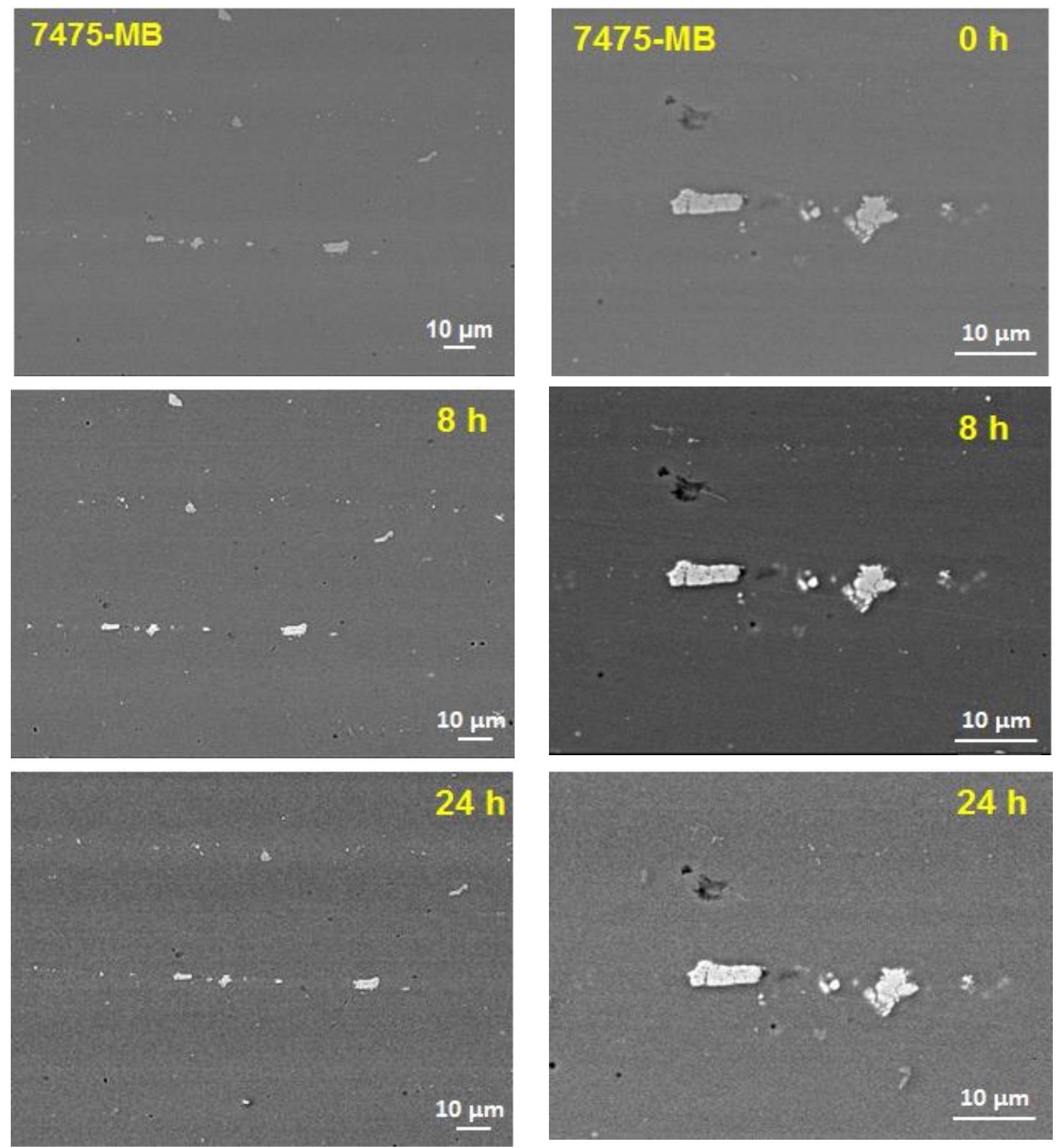

Figura 5.28: Micrografias obtidas por SEM do MB da liga 7475-T651, antes de exposição, após 8 horas e após 24 horas de exposição em solução de $0,1 \mathrm{M}$ de $\mathrm{Na}_{2} \mathrm{SO}_{4}+1 \mathrm{mM}$ de $\mathrm{NaCl}$. As fotos à direita foram tiradas com maior aumento da mesma região das fotos à esquerda.

A Figura 5.28 mostra que, após 24 horas de exposição em solução de $0,1 \mathrm{M}$ de $\mathrm{Na}_{2} \mathrm{SO}_{4}+1 \mathrm{mM}$ de $\mathrm{NaCl}$, o MB da liga 7475-T651 não apresentou qualquer partícula intermetálica ativa ou qualquer suspeita de ataque corrosivo, ou seja, se mantiveram intactas durante o processo corrosivo.

De acordo com as imagens mostradas nas Figuras 5.23 a 5.28, é possível notar que as partículas intermetálicas da ZTMA e do nugget da liga 2024-T3 se tornam ativas após 8 
horas de exposição em solução de $0,1 \mathrm{M}$ de $\mathrm{Na}_{2} \mathrm{SO}_{4}+1 \mathrm{mM}$ de $\mathrm{NaCl}$. Isso mostra aparentemente - que a região da liga 2024-T3 próxima à interface sofre uma maior ação do acoplamento galvânico entre as ligas. Após 24 horas de exposição em solução, é extremamente notório a dissolução de partículas intermetálicas ou deposição de produtos de corrosão em grande parte das partículas intermetálicas da liga 2024-T3, o que mostra que a grande quantidade de partículas intermetálicas presentes nesta liga, por apresentarem potenciais de corrosão diferentes aos da matriz, comportam-se como micropilhas.

Com o intuito de avaliar a evolução da corrosão de algumas partículas intermetálicas, ao longo das 24 horas de exposição em solução de 0,1 $\mathrm{M}$ de $\mathrm{Na}_{2} \mathrm{SO}_{4}+1 \mathrm{mM}$ de $\mathrm{NaCl}$, foram obtidas imagens com maior ampliação e, com auxílio do equipamento EDS. Algumas delas foram identificadas antes da exposição e após 8 horas de exposição em solução. As partículas intermetálicas escolhidas também pertenciam às 5 zonas distintas (identificadas na Figura 5.22(a)): MB da liga 2024-T3 (ver Figura 5.23); ZTMA da liga 2024-T3 (ver Figura 5.24); nugget da liga 2024-T3 (ver Figura 5.25); nugget da liga 7475-T651 (Figura 5.26); ZTMA da liga 7475-T651 (ver Figura 5.27) e; MB da liga 7475-T651 (ver Figura 5.28).

Com relação às partículas intermetálicas da liga 7475-T651, observou-se que, em todas as zonas formadas, não houve qualquer indício de ativação de qualquer partícula. $O$ fato pode ser dado, supostamente, à troca favorável entre os produtos de corrosão dissolvidos da matriz da liga 7475-T651 reagirem com mais facilidade aos sítios catódicos formados pelas dissoluções das partículas intermetálicas da liga 2024-T3.

O fato da liga 2024-T3 estar visívelmente mais corroída em relação à liga 7475-T651, após exposição de 24 horas em solução de $0,1 \mathrm{M}$ de $\mathrm{Na}_{2} \mathrm{SO}_{4}+1 \mathrm{mM}$ de $\mathrm{NaCl}$, pode ser explicado pela maior ativação desse sítio catódico, em razão da grande maioria de partículas intermetálicas presentes na liga 2024-T3, cuja corrosão prioritária em relação aos precipitados intergranulares, também anódicos em relação às respectivas matrizes, ser favorecida pelas maiores áreas específicas, nesta solução pouco agressiva.

Com o auxílio de microanálises semi-quantitativas por EDS, foram feitas análises de 3 partículas intermetálicas de cada zona formada após soldagem por FSW, antes da exposição e após 8 horas de exposição em solução de $0,1 \mathrm{M}$ de $\mathrm{Na}_{2} \mathrm{SO}_{4}+1 \mathrm{mM}$ de $\mathrm{NaCl}$, conforme mostra a Figura 5.29. 

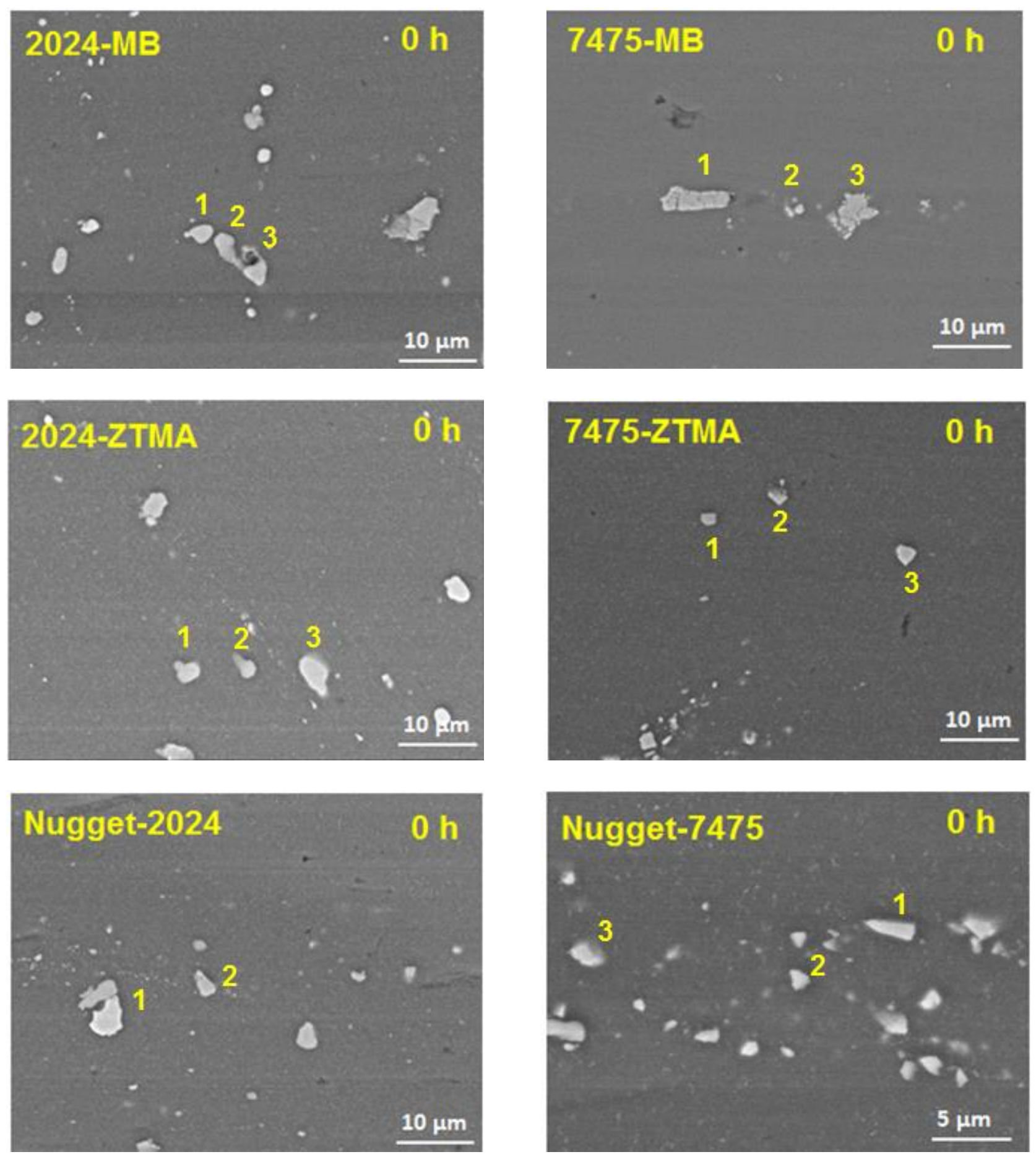

Figura 5.29: Imagens obtidas por microscopia eletrônica de varredura, seguidas por tempo de exposição em solução de $0,1 \mathrm{M}$ de $\mathrm{Na}_{2} \mathrm{SO}_{4}+1 \mathrm{mM}$ de $\mathrm{NaCl}$, durante 8 horas.

As análises por EDS foram feitas com a finalidade de se verificar em quais regiões as partículas intermetálicas eram ou se tornavam mais rapidamente ativas. Destaca-se que, para essas análises, foram consideradas as relações $\mathrm{Cu} / \mathrm{Mg}$, para as partículas intermetálicas da liga 2024-T3, e Cu/Fe, para as partículas da liga 7475-T651, de maneira a reduzir os erros estatísticos, conforme apresentam as Tabelas 5.2 e 5.3, respectivamente. 
Tabela 5.2: Microanálises semi-quantitativas por EDS, das regiões da liga 2024-T3

\begin{tabular}{|c|c|c|c|c|c|c|c|c|c|}
\hline \multirow[t]{2}{*}{ Região } & \multirow{2}{*}{$\begin{array}{c}\text { Elemento } \\
(\% \mathrm{~m} .)\end{array}$} & \multicolumn{2}{|c|}{ Partícula 1} & \multicolumn{2}{|c|}{ Partícula 2} & \multicolumn{2}{|c|}{ Partícula 3} & \multirow{2}{*}{$\begin{array}{c}\text { Média } 0 \\
\text { hora }\end{array}$} & \multirow{2}{*}{$\begin{array}{c}\text { Média } 8 \\
\text { horas }\end{array}$} \\
\hline & & Oh & $8 \mathrm{~h}$ & Oh & $8 \mathrm{~h}$ & Oh & $8 \mathrm{~h}$ & & \\
\hline \multirow{3}{*}{ MB } & $\mathrm{Cu}$ & 20,88 & 21,30 & 17,78 & 18,49 & 22,21 & 23,27 & & \\
\hline & Mg & 16,88 & 18,25 & 14,12 & 14,11 & 20,24 & 18,35 & & \\
\hline & Relação & 1,24 & 1,15 & 1,26 & 1,31 & 1,10 & 1,27 & 1,20 & 1,24 (> 3\%) \\
\hline \multirow{3}{*}{ ZTMA } & $\mathrm{Cu}$ & 19,68 & 20,31 & 15,00 & 12,76 & 23,18 & 24,75 & & \\
\hline & Mg & 17,43 & 15,84 & 10,43 & 6,08 & 21,65 & 20,35 & & \\
\hline & Relação & 1,12 & 1,28 & 1,44 & 2,10 & 1,07 & 1,21 & 1,21 & 1,53 (> 26\%) \\
\hline \multirow{3}{*}{ Nugget } & $\mathrm{Cu}$ & 21,30 & 19,78 & 19,57 & 24,47 & - & - & & \\
\hline & Mg & 17,75 & 14,48 & 17,08 & 18,27 & - & - & & \\
\hline & Relação & 1,2 & 1,37 & 1,14 & 1,34 & - & - & 1,17 & 1,36 (> 16\%) \\
\hline
\end{tabular}

Tabela 5.3: Microanálises semi-quantitativas por EDS, das regiões da liga 7475-T651

\begin{tabular}{|c|c|c|c|c|c|c|c|c|c|}
\hline \multirow[t]{2}{*}{ Região } & \multirow{2}{*}{$\begin{array}{c}\text { Elemento } \\
(\% \mathrm{~m} .)\end{array}$} & \multicolumn{2}{|c|}{ Partícula 1} & \multicolumn{2}{|c|}{ Partícula 2} & \multicolumn{2}{|c|}{ Partícula 3} & \multirow{2}{*}{$\begin{array}{c}\text { Média } 0 \\
\text { hora }\end{array}$} & \multirow{2}{*}{$\begin{array}{c}\text { Média } 8 \\
\text { horas }\end{array}$} \\
\hline & & Oh & $8 \mathrm{~h}$ & Oh & $8 \mathrm{~h}$ & Oh & $8 \mathrm{~h}$ & & \\
\hline não & $\mathrm{Cu}$ & 16,65 & 17,38 & 14,06 & 13,76 & 17,28 & 17,74 & & \\
\hline \multirow{2}{*}{ MB } & $\mathrm{Fe}$ & 9,15 & 9,29 & 7,50 & 6,05 & 8,54 & 9,10 & & \\
\hline & Relação & 1,82 & 1,87 & 1,87 & 2,27 & 2,02 & 1,95 & 1,90 & $2,03(>6,8 \%)$ \\
\hline \multirow{3}{*}{ ZTMA } & $\mathrm{Cu}$ & 4,95 & 4,77 & 11,33 & 10,46 & 16,81 & 17,65 & & \\
\hline & $\mathrm{Fe}$ & 8,43 & 8,64 & 5,42 & 4,43 & 8,67 & 9,15 & & \\
\hline & Relação & 0,59 & 0,55 & 2,09 & 2,36 & 1,93 & 1,92 & 1,54 & $1,61(>4,5 \%)$ \\
\hline \multirow{3}{*}{ Nugget } & $\mathrm{Cu}$ & 15,75 & 14,91 & 12,31 & 11,17 & 15,75 & 16,66 & & \\
\hline & $\mathrm{Fe}$ & 7,38 & 7,45 & 5,30 & 4,97 & 7,38 & 7,75 & & \\
\hline & Relação & 2,13 & 2,00 & 2,32 & 2,25 & 2,13 & 2,15 & 2,19 & $2,13(<2,7 \%)$ \\
\hline
\end{tabular}

As análises por EDS mostraram uma ativação mais efetiva na ZTMA e no nugget da liga 2024-T3, não havendo uma mudança significativa nas diferentes regiões da liga 7475T651. A liga 2024-T3, principalmente as zonas próximas à interface, são as regiões mais afetadas nos primeiros tempos durante o processo eletroquímico, possivelmente, pelo fato da interface ser a região mais ativa do acoplamento galvânico.

Durante as análises, verificou-se o surgimento de produtos de corrosão sobre algumas partículas intermetálicas presentes na ZTMA e no nugget da liga 2024-T3, após 8 horas de exposição em solução de $0,1 \mathrm{M}$ de $\mathrm{Na}_{2} \mathrm{SO}_{4}+1 \mathrm{mM}$ de $\mathrm{NaCl}$. Produtos com as mesmas características também foram notados no MB da liga 2024-T3, após 24 horas de exposição em solução. A fim de compreender a composição química desses compostos, foram realizadas análises por EDS de algumas partículas intermetálicas que continham esses produtos, onde constatou-se que tais produtos de corrosão apresentavam óxido de zinco em suas composições. A Tabela 5.4 apresenta a composição química dos produtos de corrosão indicados por setas azuis nas Figuras 5.23, 5.24 e 5.25. 
Tabela 5.4: Composições químicas dos produtos de corrosão encontrados sobre as partículas intermetálicas do MB, da ZTMA e do nugget da liga 2024-T3 (ver Figuras 5.23, 5.24 e 5.25), após 24 horas de exposição em solução de $0,1 \mathrm{M}^{2}$ de $\mathrm{Na}_{2} \mathrm{SO}_{4}+1 \mathrm{mM}$ de $\mathrm{NaCl}$.

\begin{tabular}{lccccccccc}
\hline & $\mathbf{O}$ & $\mathbf{M g}$ & $\mathbf{A l}$ & $\mathbf{S}$ & $\mathbf{C l}$ & $\mathbf{M n}$ & $\mathbf{F e}$ & $\mathbf{C u}$ & $\mathbf{Z n}$ \\
\hline 2024-MB & 12,29 & 8,60 & 34,94 & 0,51 & 0,83 & 0,33 & 0,35 & 38,50 & 3,37 \\
2024-ZTMA & 14,03 & 4,72 & 47,12 & - & 2,05 & 0,54 & 0,99 & 25,52 & 4,15 \\
Nugget (2024) & 21,20 & 0,29 & 50,36 & 1,92 & 2,01 & 0,48 & 0,45 & 2,69 & 20,22 \\
\hline
\end{tabular}

A Tabela 5.4 relata os resultados da análise semi-quantitativa, obtida por EDS, realizada em cima das partículas intermetálicas da liga 2024-T3, nas diferentes regiões: MB, ZTMA e nugget. Os resultados mostram claramente a presença de Zn, cuja quantidade diminui conforme aumenta a distância da interface soldada. No entanto, o Zn está presente em solução sólida da liga 7475-T651 e não na microestrutura nem nos compostos intermetálicos da liga 2024-T3. Propõe-se assim que, quando as duas ligas são acopladas pela soldagem, a polarização catódica da liga 2024-T3 aumenta a reação de redução de oxigênio acima das partículas intermetálicas. A análise por SEM indica que esta reação é contrabalanceada pela dissolução seletiva de $\mathrm{Zn}$, a partir da solução sólida da matriz da liga 7475-T651. Os íons Zn difundem / migram para as regiões catódicas para precipitarem-se como oxi-hidróxidos de $\mathrm{Zn}$. Curiosamente, os dados apresentados na Tabela 5.4 mostram uma precipitação preferencial de produtos de Zn acima da fase S (Al-Cu-Mg), de acordo com sua maior tendência a sustentar a reação catódica (assim a formação de íons hidróxido) quando a comparação é feita com a reatividade das partículas intermetálicas de Al-Cu-FeMn-(Si) (Paussa et. al., 2012).

\subsection{Caracterização eletroquímica da resistência à corrosão das ligas soldadas}

Para a avaliação da resistência à corrosão das ligas de alumínio 2024-T3 e 7475T651 soldadas por FSW, via técnicas eletroquímicas, também foi adotada a solução $0,1 \mathrm{M}$ de $\mathrm{Na}_{2} \mathrm{SO}_{4}+1 \mathrm{mM}$ de $\mathrm{NaCl}$, considerada de baixa corrosividade. Os íons sulfato adsorvem na superfície das ligas de alumínio, contribuindo para a passivação destas e, consequentemente, retardando a nucleação de pites e, portanto, a quebra do filme passivo (Aballe, 2001; Boag, 2010; Blanc e Lavelle, 1997).

A Figura 5.30 apresenta a evolução dos potenciais em circuito aberto (OCP), em função do tempo (durante 8 horas), para amostras dos MB das ligas 2024-T3 (4,8 cm² de área exposta) e 7475-T651 (4,8 cm² de área exposta) e para amostra das ligas 2024-T3 e 
7475-T651 soldadas por FSW (4,8 cm² de área exposta, sendo: 1,65 cm² da ZTA (2024) / $1,5 \mathrm{~cm}^{2}$ da ZTMA + nugget / 1,65 $\mathrm{cm}^{2}$ da ZTA (7475)), em solução de 0,1 $\mathrm{M}$ de $\mathrm{Na}_{2} \mathrm{SO}_{4}+1$ $\mathrm{mM}$ de $\mathrm{NaCl}$.

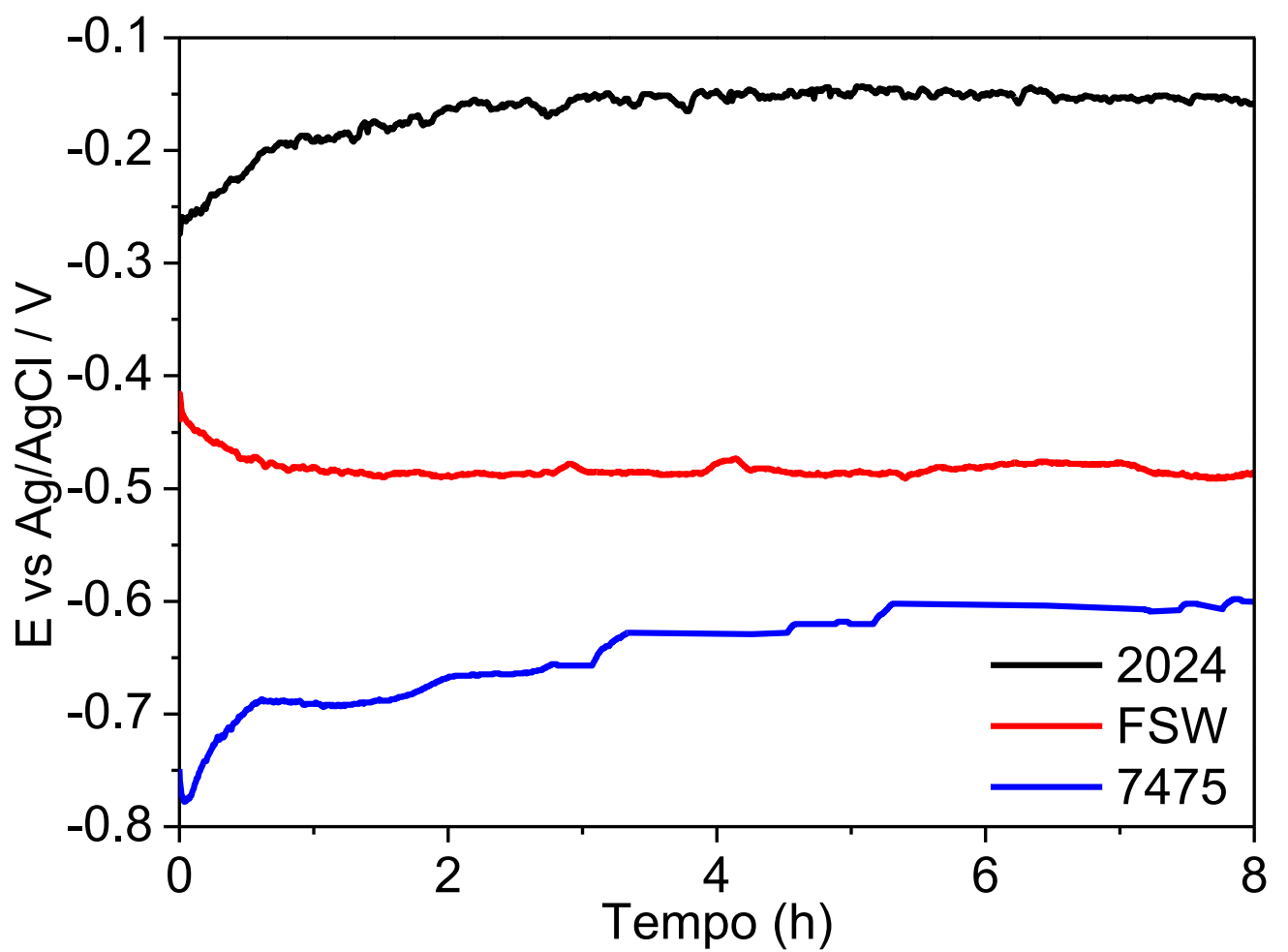

Figura 5.30: Curvas de potencial em circuito aberto das ligas 2024-T3 e 7475-T651, e destas soldadas por FSW, em solução de $0,1 \mathrm{M}$ de $\mathrm{Na}_{2} \mathrm{SO}_{4}+1 \mathrm{mM}$ de $\mathrm{NaCl}$.

Após duas horas em solução, as ligas apresentaram potenciais estáveis. No caso da liga 2024-T3, o valor do potencial de circuito aberto (OCP) se estabiliza em

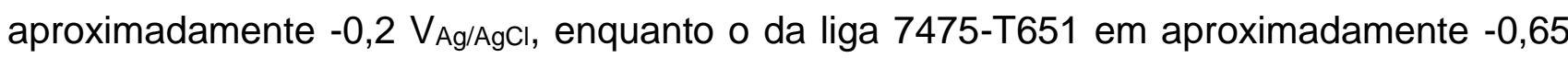

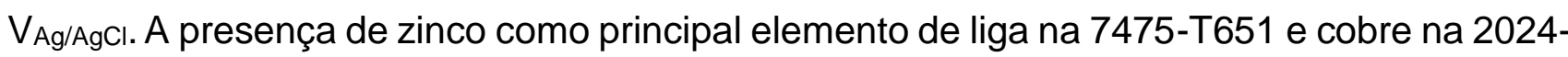
T3 é a causa destes potenciais (Hollingsworth e Hubsicker, 1990; Dix, 1998). O OCP da amostra das ligas 2024-T3 e 7475-T651 soldadas por FSW estabilizou em aproximadamente $-0,5 \mathrm{~V}$ Ag/AgCl. Estes resultados estão de acordo com um acoplamento galvânico quando as ligas são soldadas por FSW, levando a uma polarização catódica da liga 2024-T3 e a uma polarização anódica da liga 7475-T651. Como resultado, a diferença de potencial entre as duas ligas individuais e a razão superficial de cada material irá conduzir a cinética de corrosão de todo o sistema. Entretanto, isto não pode ser apenas visto como dois materiais diferentes formando uma interface bem definida, e a heterogeneidade devida ao processo de soldagem por FSW também afetará a reatividade da interface, o que reforça o interesse em usar técnicas eletroquímicas locais. 
As curvas de polarização catódica e anódica para as amostras dos MB das ligas 2024T3 e 7475-T651, e para a amostra das ligas 2024-T3 e 7475-T651 soldadas por FSW, em solução de 0,1 M de $\mathrm{Na}_{2} \mathrm{SO}_{4}+1 \mathrm{mM}$ de $\mathrm{NaCl}$, são apresentadas nas Figuras 5.31 e 5.32, respectivamente. As curvas foram obtidas após 2 horas de imersão, com velocidade de varredura de $0,166 \mathrm{mVs}^{-1}$, e iniciadas em potenciais $\pm 30 \mathrm{mV}$ em relação ao OCP.

De acordo com as curvas de polarização catódica, mostradas na Figura 5.31, observa-se que para as três curvas referentes às amostras dos MB da liga 2024-T3 e da liga 7475-T651, e da amostra das ligas 2024-T3 e 7475-T651 soldadas por FSW, ocorrem evidentes controles por difusão, indicando dessa maneira que o oxigênio é a espécie que se reduz em todos os casos.

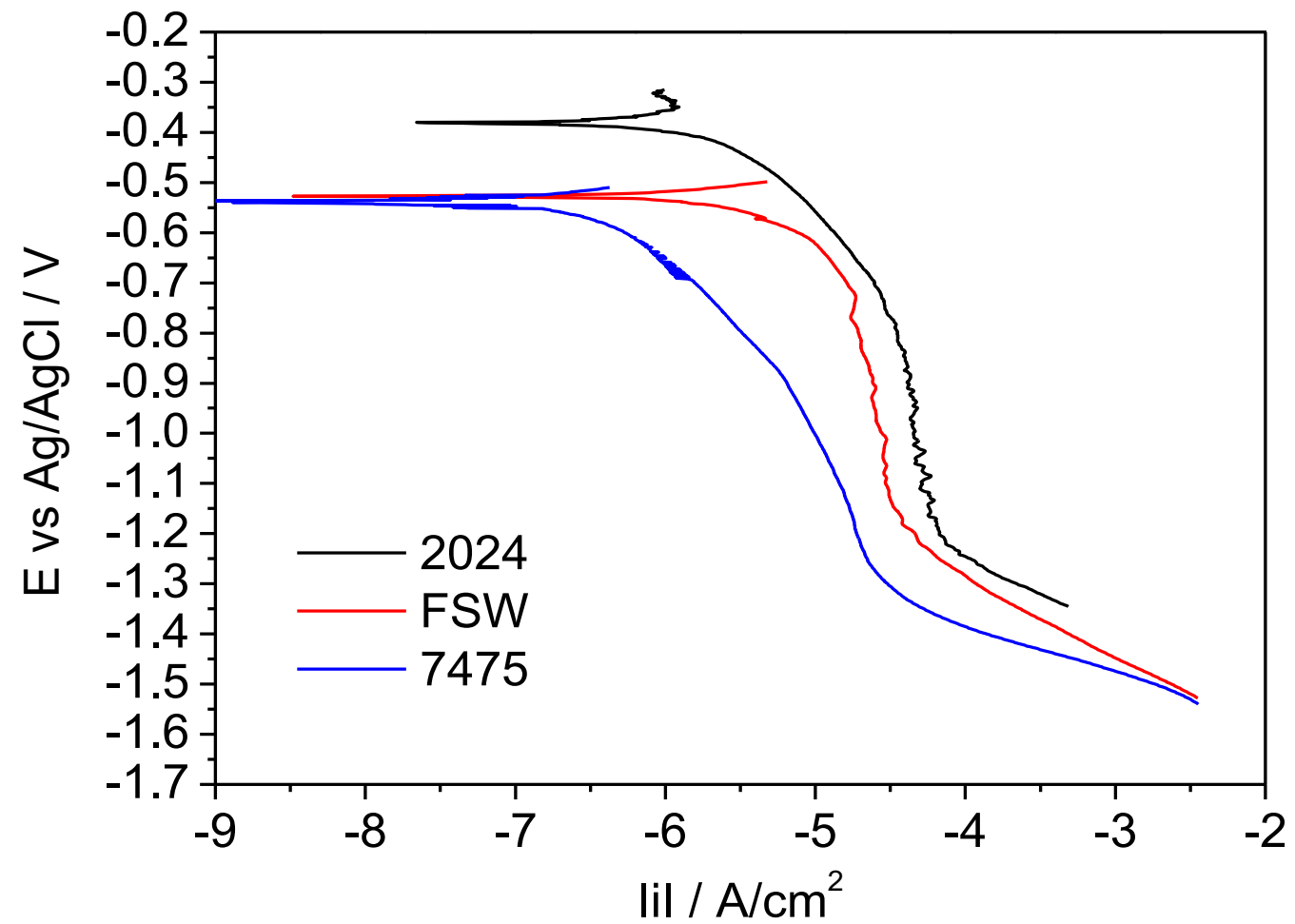

Figura 5.31: Curvas de polarização catódica das ligas 2024-T3 e 7475-T651, e destas soldadas por FSW, em solução de $0,1 \mathrm{M}$ de $\mathrm{Na}_{2} \mathrm{SO}_{4}+1 \mathrm{mM}$ de $\mathrm{NaCl}$.

A intensidade deste processo para cada amostra é proporcional à quantidade de partículas intermetálicas presentes em cada liga (2024-T3 > amostra das ligas 2024-T3 e 7475-T651 soldadas por FSW > 7475-T651). Conforme discutido anteriormente, as partículas intermetálicas são locais preferenciais para a reação catódica (Buchheit, 1997; Jata, 2000; Zhang, 2003), como também foi demonstrado por Birbilis e Buchheit (2005) e Paussa et al. (2012) utilizando a técnica de microcélula eletroquímica para liga da série 7XXX e a liga 2024, em solução neutra de cloreto. Os autores também mostraram que um aumento na quantidade de cobre na partícula intermetálica aumenta muito a atividade catódica 
(Birbilis e Buchheit, 2005). Esta questão é importante para a atividade de corrosão das ligas 2024-T3 sob as condições em que as curvas catódicas foram adquiridas, ou seja, após 2 horas de imersão, uma vez que já poderia ter ocorrido um extensivo desligamento de partículas intermetálicas de fase S de Al-Cu-Mg (Boag et al., 2011).

As curvas de polarização anódica das amostras dos MB das ligas 2024-T3 e 7475T651, e da amostra das ligas 2024-T3 e 7475-T651 soldadas por FSW, mostradas na Figura 5.32, apresentaram diferentes características passivas.

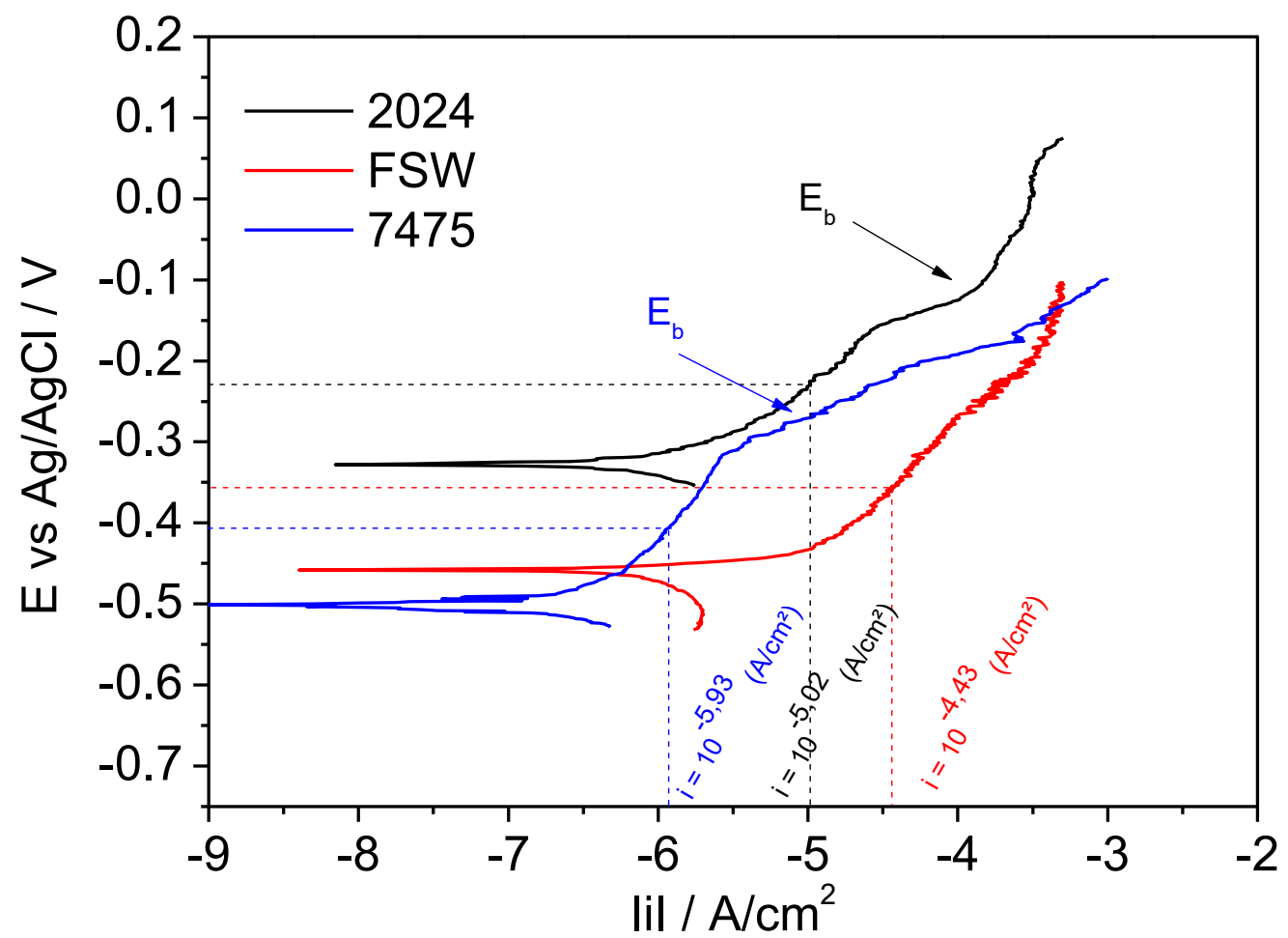

Figura 5.32: Curvas de polarização anódica das ligas 2024-T3 e 7475-T651, e destas soldadas por FSW, em solução de $0,1 \mathrm{M}$ de $\mathrm{Na}_{2} \mathrm{SO}_{4}+1 \mathrm{mM}$ de $\mathrm{NaCl}$.

A liga 7475-T651 apresenta uma região passiva bem definida, com uma corrente passiva na faixa de $10^{-6} \mathrm{~A} \mathrm{~cm}^{2}$ e um potencial de ruptura $\left(\mathrm{E}_{\mathrm{b}}\right)$ de cerca de $-0,3 \mathrm{~V} \mathrm{Ag} / \mathrm{AgCl}$. $\mathrm{A}$ liga 2024-T3 apresenta uma região pseudo-passiva, caracterizada por um aumento constante da corrente e um potencial de ruptura $\left(E_{b}\right)$ a cerca de $-0,1 \mathrm{~V} / \mathrm{g} / \mathrm{AgCl}$, enquanto que para a amostra das ligas 2024-T3 e 7475-T651 soldadas por FSW foi observado um processo controlado por ativação. Nesta figura, as linhas tracejadas são desenhadas para um potencial correspondente a (VocP $+100 \mathrm{mV})$, a fim de avaliar a taxa de reação para um mesmo sobrepotencial (assim com relação ao potencial de corrosão). Eles mostram que o processo anódico é muito mais intenso para a amostra soldada do que para os dois MB (uma e duas ordens de magnitude para a corrente). Curiosamente, no potencial de corrosão, a liga 7475-T651 mostra uma corrente de corrosão baixa e não deve corroer rapidamente. No 
entanto, o acoplamento galvânico devido à soldagem desloca o seu potencial para um valor mais anódico, levando a uma corrosão intensa no lado da liga 7475-T651 da solda, de acordo com o teste ágar-ágar mostrado na Figura 5.15. Além disso, este processo de corrosão também deve levar em conta o lado catódico da reação, que resulta tanto das alterações microestruturais geradas durante a soldagem por FSW associado à polarização catódica das partículas intermetálicas da liga 2024-T3, que sustentam uma taxa de reação catódica mais elevada (Paussa et al., 2012).

Ensaios de espectroscopia de impedância eletroquímica (EIS) foram realizados nos MB das ligas 2024-T3 e 7475-T651, e na amostra das ligas 2024-T3 e 7475-T651 soldadas por FSW, em solução de $0,1 \mathrm{M}$ de $\mathrm{Na}_{2} \mathrm{SO}_{4}+1 \mathrm{mM}$ de $\mathrm{NaCl}$, durante 8 horas. A Figura 5.33 apresenta os diagramas de Nyquist como forma de comparação do comportamento à corrosão entre as ligas separadas e soldadas, a fim de verificar o comportamento do possível acoplamento galvânico.

Em boa concordância com as curvas de polarização anódica, os resultados mostram que a soldagem das duas ligas reduz muito a resistência à corrosão da amostra das ligas 2024-T3 e 7475-T651 soldadas por FSW, enquanto a maior impedância é observada para a liga 7475-T651. A impedância desta última liga aumenta com o tempo de imersão, enquanto as impedâncias da liga 2024-T3 e da amostra com ambas as ligas soldadas diminuem. A melhor resistência à corrosão da liga 7475-T651 deve estar ligada ao baixo teor de impurezas presentes nesta liga quando comparada com outras ligas de alumínio de alta resistência (Birbilis e Buchheit, 2005). Por outro lado, a menor impedância da liga 2024-T3 e a diminuição da resistência com o tempo de imersão podem ser justificadas pela grande densidade de partículas intermetálicas encontradas em sua microestrutura, como discutido na literatura (Bessone, 1992; Birbilis, 2005; Hughes, 2011). O acoplamento galvânico entre duas ligas com grandes diferenças de OCP (como mostrado na Figura 5.31), bem como as modificações microestruturais induzidas pelo processo de soldagem são as principais razões para o comportamento de impedância da amostra das ligas soldadas por FSW quando comparado com os dois respectivos MB. 

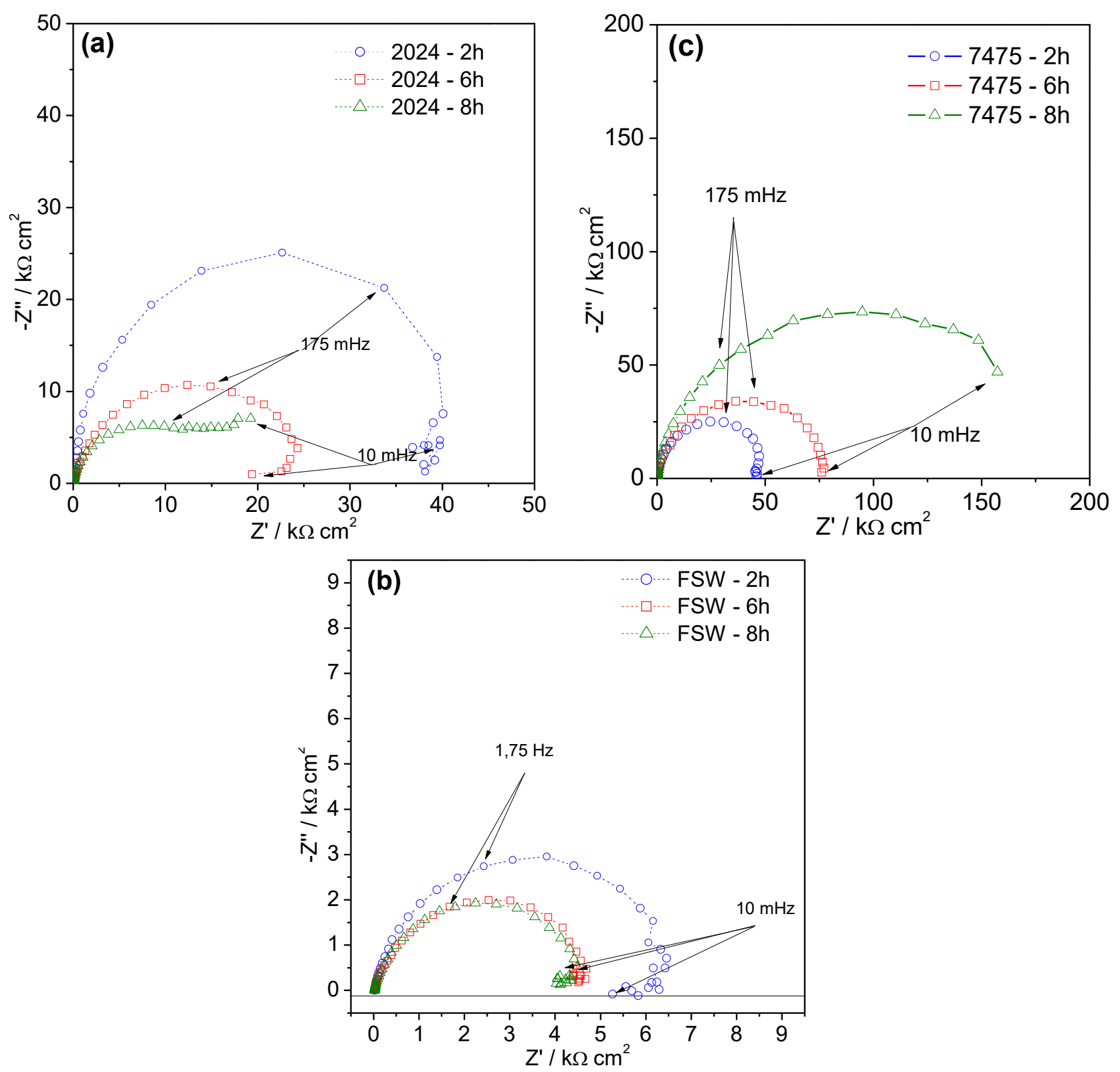

Figura 5.33: Especroscopias de impedância (globais) das ligas: (a) 2024-T3; (b) 2024-T3 e 7475T651, soldadas por FSW, e; (c) 7475-T651, em solução de 0,1 $\mathrm{M}_{\text {de }} \mathrm{Na}_{2} \mathrm{SO}_{4}+1 \mathrm{mM}$ de $\mathrm{NaCl}$.

Com exceção dos diagramas obtidos para as duas ligas após 8 horas de imersão, todos os resultados de impedância apresentam a mesma característica, ou seja, um arco capacitivo de alta freqüência (AF) seguido de um arco indutivo de baixa freqüência (BF). Para o alumínio e suas ligas, o arco capacitivo em alta frequência foi atribuído a uma conexão em série da capacitância da camada fina de óxido presente na superfície metálica e a capacidade de dupla camada em paralelo com uma resistência à transferência de carga (De Wil, 1996; Aoki, 2001; Queiroz, 2008). Em relação ao arco indutivo, em baixa frequência, vários autores relatam a presença de tal característica para o alumínio puro, em diferentes meios. Por exemplo, Bessone et al. (1992) encontraram arcos indutivos para o alumínio puro em diferentes concentrações de solução de cloreto, assim como meios contendo sulfato e 
tartrato. De Wit e Ledrerink (1996), em solução de sulfato de sódio acidificada, e Aoki et al. (2001), em meio ácido cítrico. Em todos os casos, a presença desse arco foi associada ao processo de adsorção. Em relação aos diagramas adquiridos após 8 horas de imersão para as duas ligas, é provável que, para a liga 7475-T651, a melhoria das propriedades protetoras da camada de óxido deslocasse o circuito indutivo para freqüências mais baixas, enquanto que para a liga 2024-T3, parece que um processo controlado pela difusão começa a ser o passo determinante da taxa da resposta EIS, o que poderia estar associado à reação de redução nas partículas intermetálicas.

Em seguida, foram realizados ensaios de EIS com a amostra das ligas 2024-T3 e

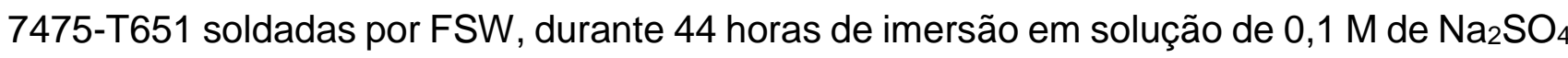
+ 1 mM de NaCl. Os diagramas de Nyquist são mostrados na Figura 5.34.
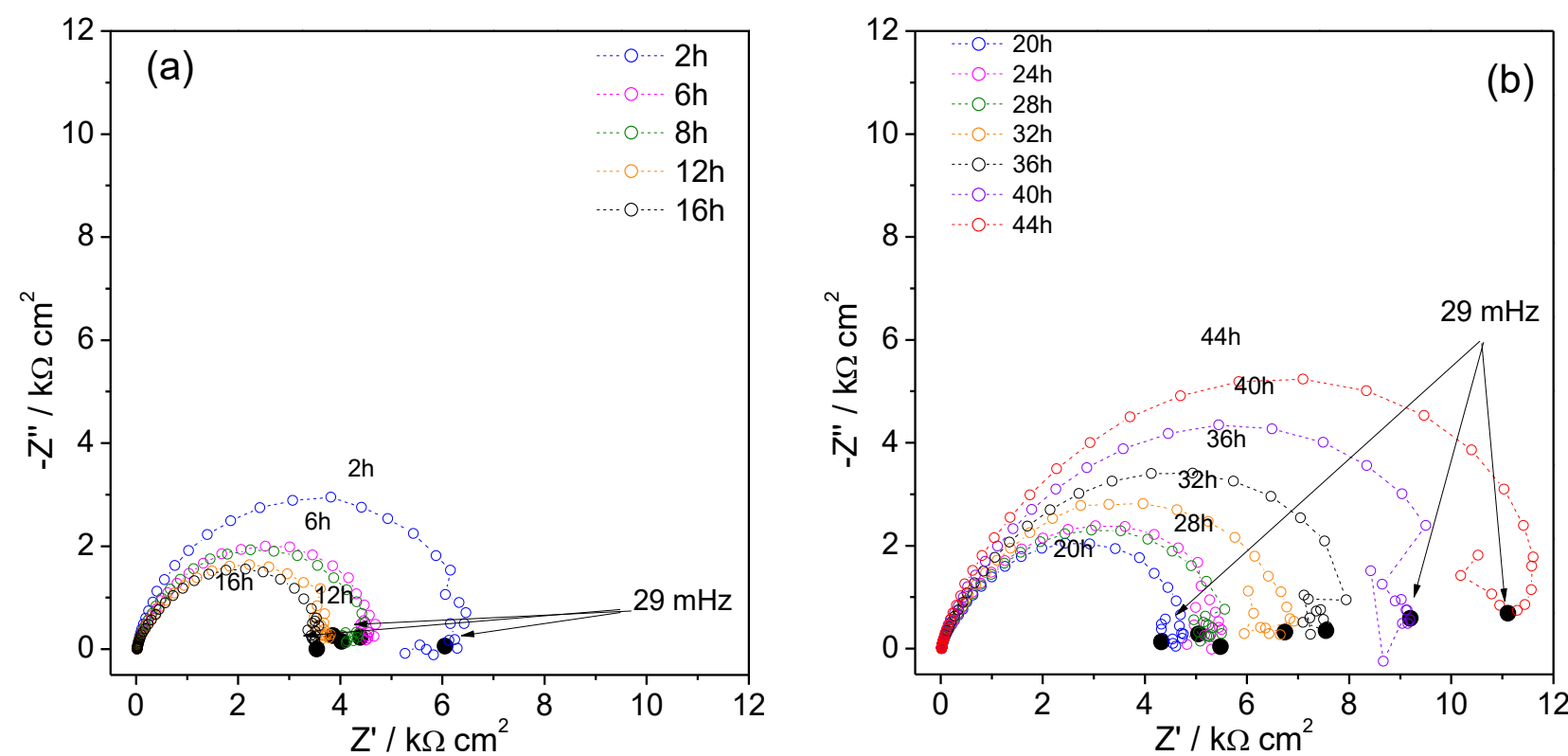

Figura 5.34: Espectroscopias de impedância (global) das ligas 2024-T3 e 7475-T651, soldadas por FSW, durante 44 horas, em solução de $0,1 \mathrm{M}$ de $\mathrm{Na}_{2} \mathrm{SO}_{4}+1 \mathrm{mM}$ de $\mathrm{NaCl}$.

Os resultados indicam ataque do meio corrosivo à superfície das ligas soldadas até 16 horas de ensaio. O aumento de impedância a partir deste tempo de imersão (16 horas) até o fim do ensaio (44 horas) pode ser causado pela precipitação de produtos de corrosão sobre regiões ativas das duas ligas, conforme sugerem as imagens apresentadas nas Figuras 5.23 a 5.28, que apresenta a formação de produtos de corrosão sobre as partículas intermetálicas da liga 2024-T3, para 24 horas de imersão.

A fim de compreender melhor esse possível acoplamento galvânico e o comportamento das diferentes ligas quando soldadas, foram realizados alguns ensaios para 
verificação da impedância, após polarizações catódicas e anódicas de amostras dos MB das ligas 2024-T3 e 7475-T651.

A ideia do estudo foi de simular o comportamento que cada liga teria, individualmente, quando soldadas e expostas a condições de acoplamento galvânico, ou seja, a liga 7475T651, com menor OCP, sofrendo uma espécie de polarização anódica e a liga com maior OCP, 2024-T3, sofrendo uma espécie de polarização catódica.

Para isso, a amostra de cada liga foi deixada em potencial de $-500 \mathrm{mV} \mathrm{Ag}_{\mathrm{AgCl}}$, que é o potencial aproximado das ligas soldadas, em solução de $0,1 \mathrm{M}$ de $\mathrm{Na}_{2} \mathrm{SO}_{4}+1 \mathrm{mM}$ de $\mathrm{NaCl}$ (Figura 5.31) e, em seguida foram realizados os ensaios de impedância respectivos, mantendo-se o potencial em $-500 \mathrm{mV}$ Ag/AgCl. A Figura 5.35 apresenta 0 espectro de

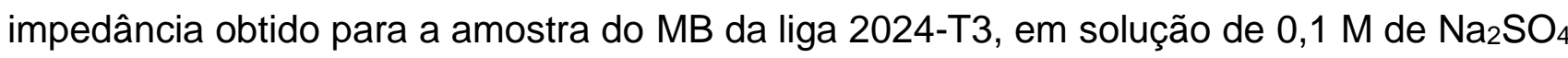
+ $1 \mathrm{mM}$ de $\mathrm{NaCl}$, após 2 horas em potencial de $-500 \mathrm{mV}$ Ag/AgCl, em comparação ao espectro da amostra exposta 2 horas em potencial em circuito aberto.

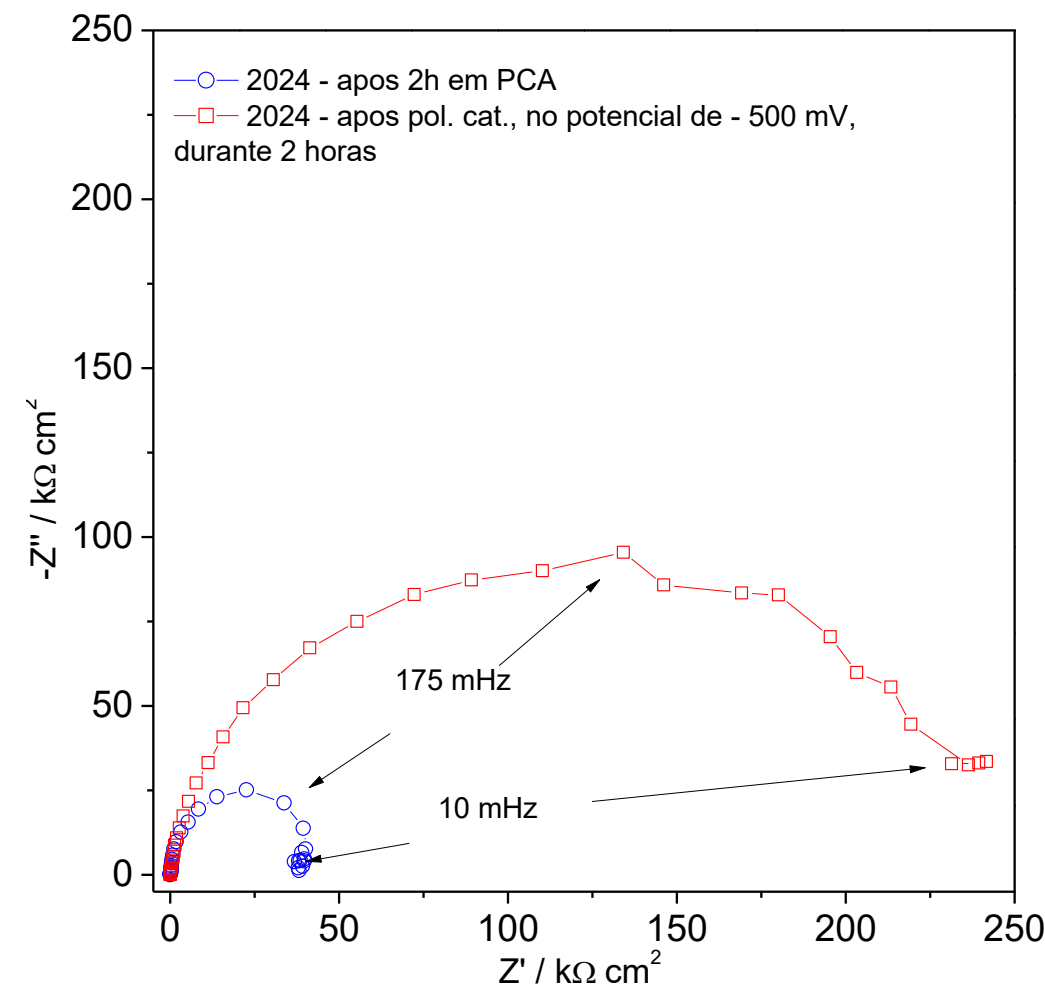

Figura 5.35: Espectroscopias de impedância da liga 2024-T3, após 2 horas em OCP (azul), e após 2

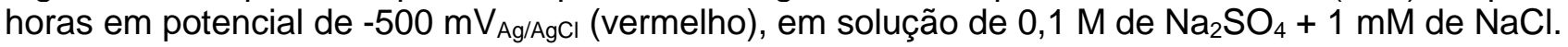

A polarização catódica da liga 2024-T3 resultou em aumento da impedância, porém deve-se considerar que a área catódica real (precipitados ricos em cobre na superfície da liga) é muito inferior à área total considerada nos resultados. 
Como a liga 7475-T651 sofre uma polarização anódica quando soldada com a liga 2024-T3, esta liga separada foi colocada em potencial de $-500 \mathrm{mV}$ Ag/AgCl, que é o potencial

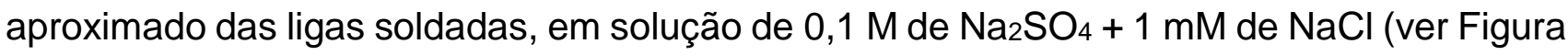
5.31). Em seguida, foram realizados os diagramas de impedância respectivos, mantendo-se o potencial em -500 mV Ag/AgCl. A Figura 5.36 apresenta o espectro de impedância obtido para a amostra do MB da liga 7475-T651, em solução de 0,1 M de $\mathrm{Na}_{2} \mathrm{SO}_{4}+1 \mathrm{mM}$ de $\mathrm{NaCl}$, após 2 horas em potencial de $-500 \mathrm{mV}$ Ag/AgCl, em comparação ao espectro da amostra exposta 2 horas em potencial em circuito aberto.

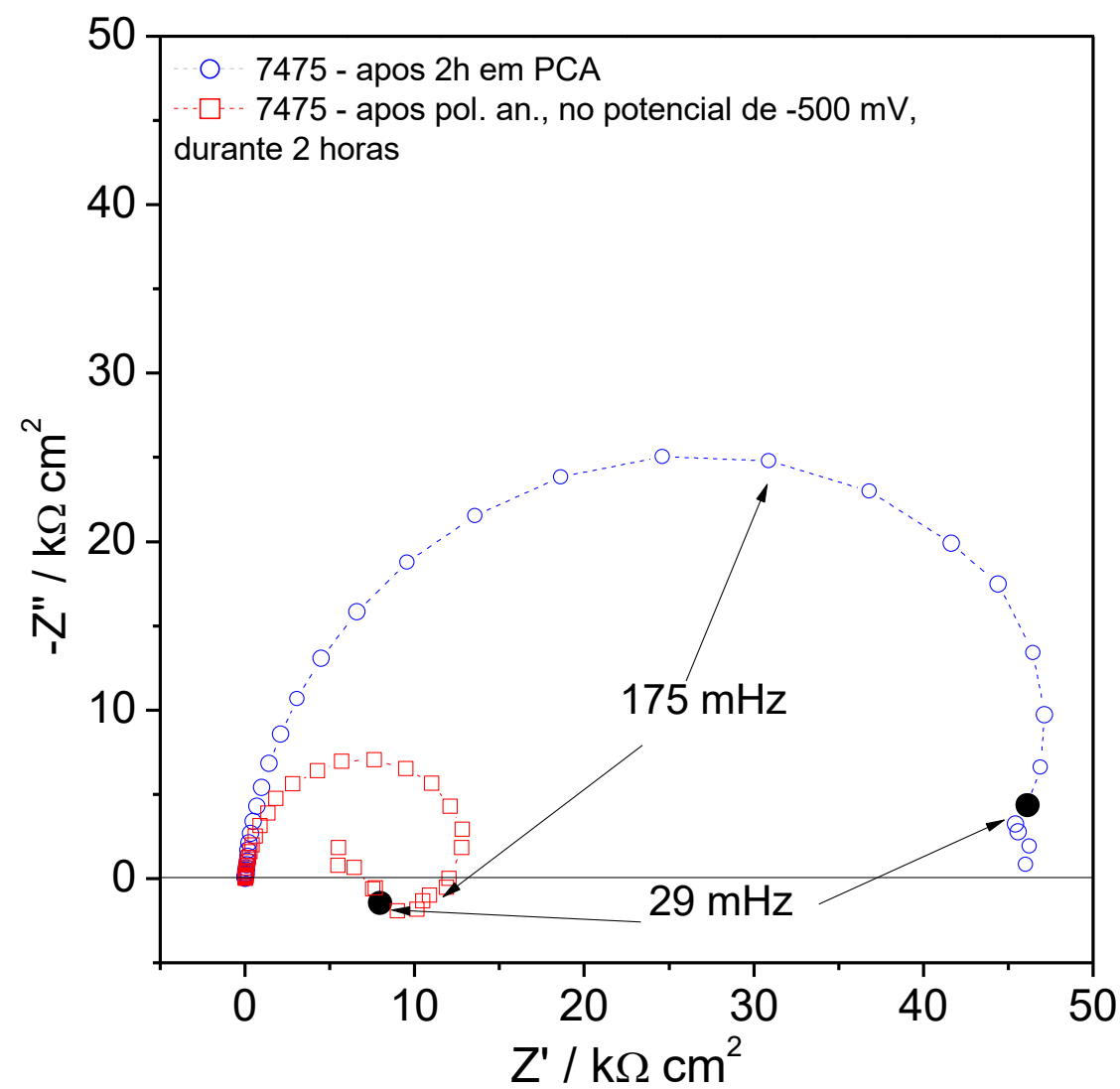

Figura 5.36: Espectroscopias de impedância da liga 7475-T651, após 2 horas em OCP (azul), e após 2 horas em potencial de $-500 \mathrm{mV}_{\mathrm{Ag} / \mathrm{AgCl}}$ (vermelho), em solução de $0,1 \mathrm{M}$ de $\mathrm{Na}_{2} \mathrm{SO}_{4}+1 \mathrm{mM} \mathrm{de} \mathrm{NaCl}$.

Observa-se nos espectros da Figura 5.36 que a polarização anódica da liga 7475 T651, por duas horas, resultou em grande redução da impedância desta liga, possivelmente pela pela quebra da camada de passivação, evidenciado pela constante de tempo indutiva, em baixa frequência, que possui a mesma frequência dos arcos indutivos vistos nos espectros da amostra com as ligas 2024-T3 e 7475-T651 soldadas por FSW (ver Figura 5.34). 


\subsubsection{Caracterização eletroquímica local}

Com o objetivo de investigar a resistência à corrosão das diferentes zonas afetadas pelo processo de soldagem por FSW das duas ligas de alumínio, foram realizados ensaios eletroquímicos com o intuito de verificar o comportamento das diferentes zonas, seja individualmente ou como na prática (amostras dissimilares soldadas por FSW).

\subsubsection{Caracterização eletroquímica com micro-célula (abertura de ø 1,0 mm)}

Este ensaio envolveu o uso de célula eletroquímica com exposição de uma área circular delimitada por um o-ring de 1,0 mm de diâmetro. O o-ring foi centralizado buscandose restringir a área exposta ao meio corrosivo às zonas: MB, ZTA e ZTMA das ligas 2024T3 e 7475-T651, bem como a região do nugget entre as duas ligas. A Figura 5.37 apresenta o esquema de posicionamento da célula eletroquímica nas diferentes zonas ensaiadas.

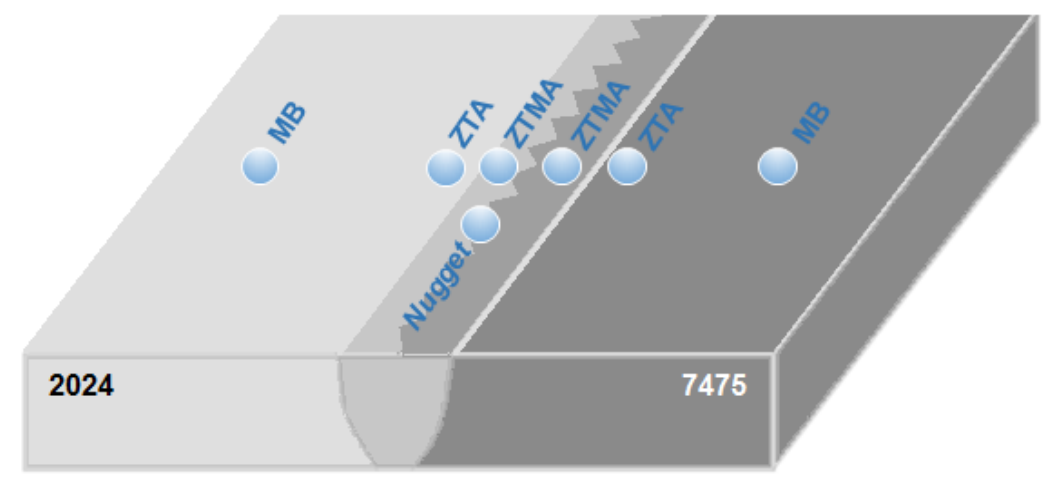

Figura 5.37: Esquema de posicionamento da micro-célula nas distintas zonas formadas após o processo de soldagem por FSW das ligas 2024-T3 e 7475-T651.

A Figura 5.38 apresenta as evoluções dos potenciais em circuito aberto (OCP), em função do tempo (durante 1 hora), em solução de $0,1 \mathrm{M} \mathrm{de} \mathrm{Na}_{2} \mathrm{SO}_{4}+1 \mathrm{mM}$ de $\mathrm{NaCl}$. 


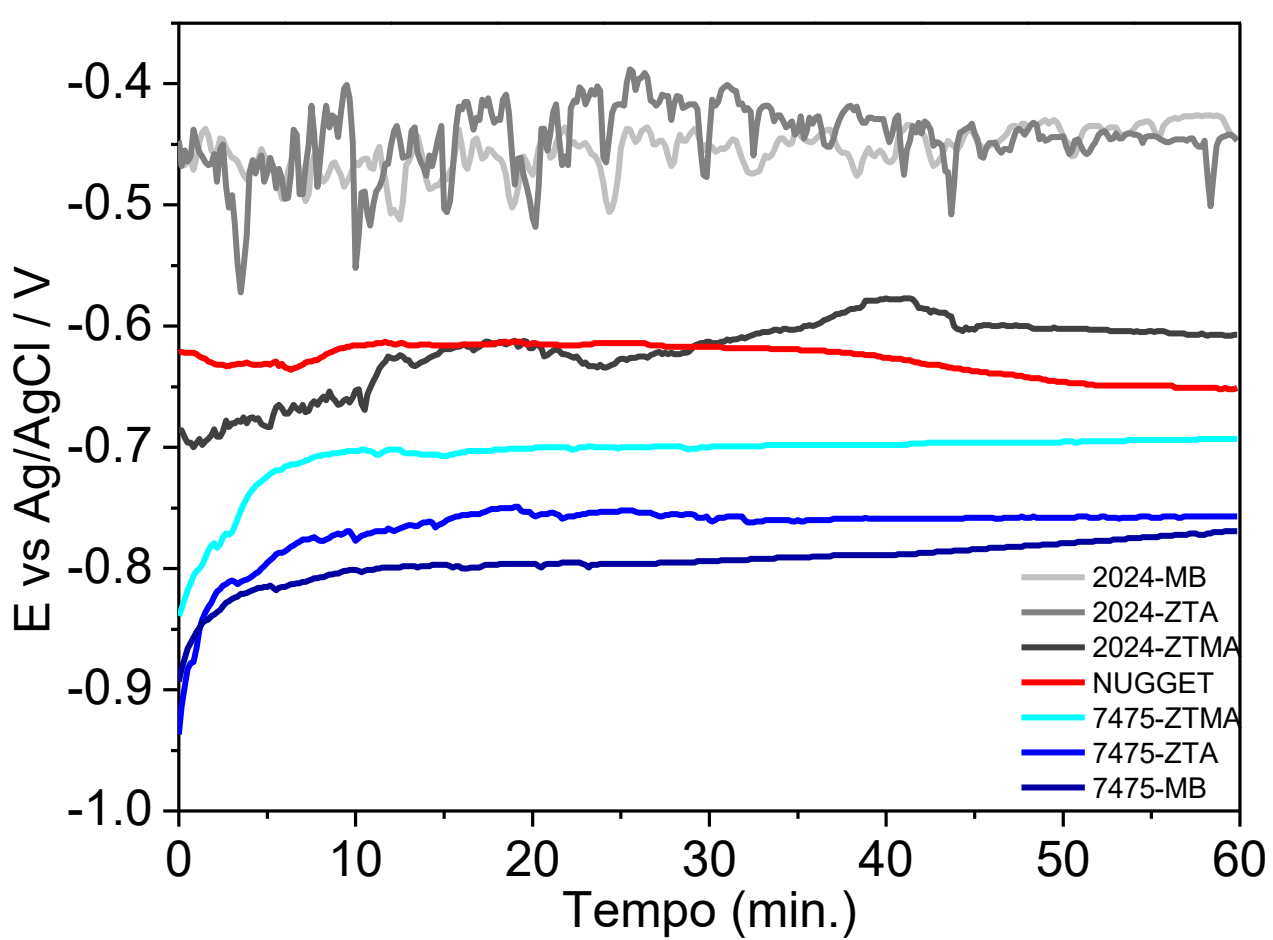

Figura 5.38: Curvas de potencial em circuito aberto das diferentes regiões formadas após o processo de soldagem por FSW das ligas 2024-T3 e 7475-T651, em solução de 0,1 M de $\mathrm{Na}_{2} \mathrm{SO}_{4}+1 \mathrm{mM}$ de $\mathrm{NaCl}$.

Como após uma hora de imersão em solução, as diferentes zonas das ligas apresentavam potenciais estáveis, os ensaios eletroquímicos foram realizados após este período de tempo. Estes resultados, assim como os globais, indicam claramente a presença de um acoplamento galvânico entre as ligas 2024-T3 e 7475-T651 e, também, entre as diferentes zonas formadas após o processo de soldagem por FSW, com exceção do MB e da ZTMA da liga 2024-T3, que apresentaram praticamente o mesmo comportamento.

As curvas de polarização anódica para as diferentes regiões formadas após a soldagem, em solução de $0,1 \mathrm{M}$ de $\mathrm{Na}_{2} \mathrm{SO}_{4}+1 \mathrm{mM}$ de $\mathrm{NaCl}$, são apresentadas na Figura 5.39. As curvas foram obtidas após 1,5 hora de imersão, com velocidade de varredura de $0,500 \mathrm{mVs}^{-1}$, e iniciadas num potencial $30 \mathrm{mV}$ mais negativo que o OCP. 


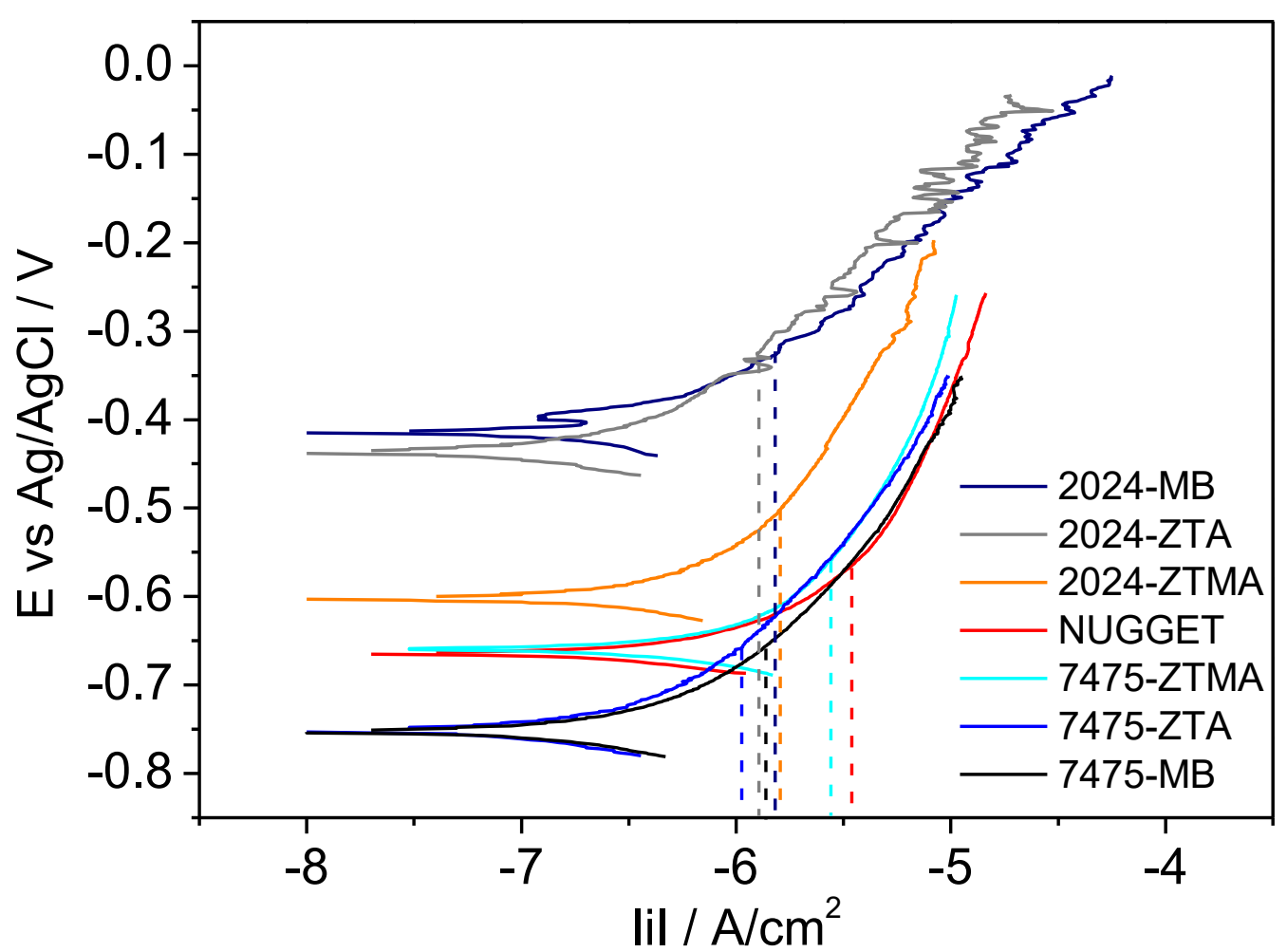

Figura 5.39: Curvas de polarização anódica das diferentes regiões formadas após o processo de soldagem por FSW das ligas 2024-T3 e 7475-T651, em solução de 0,1 M de $\mathrm{Na}_{2} \mathrm{SO}_{4}+1 \mathrm{mM}$ de $\mathrm{NaCl}$.

Conforme apresentam as curvas de polarização anódica da Figura 5.39, e as correntes analisadas em $\mathrm{E}_{\text {corr }}(+100 \mathrm{mV})$, observa-se maior densidade de corrente para as regiões do nugget e das ZTMAs das ligas 7475-T651 e 2024-T3, respectivamente. O resultado é interessante, pois se assemelham aos resultados obtidos em escalas maiores (ver Figura 5.32).

Em relação ao MB e à ZTA da liga 2024-T3, ambas as curvas apresentam tendência à quebras da camada de passivação e possuem correntes maiores às correntes referentes ao MB e à ZTA da liga 7475-T651. Em linhas gerais, pode-se verificar que as regiões da zona da mistura entre as duas ligas, ou seja, no nugget e nas respectivas ZTMAs, em razão do acoplamento galvânico e das microestruturas formadas, as correntes são maiores e as respectivas camadas de passivação são menos protegidas.

Os espectros de impedância para as diferentes regiões formadas após a soldagem, em solução de $0,1 \mathrm{M}$ de $\mathrm{Na}_{2} \mathrm{SO}_{4}+1 \mathrm{mM}$ de $\mathrm{NaCl}$, são apresentados na Figura 5.40. 


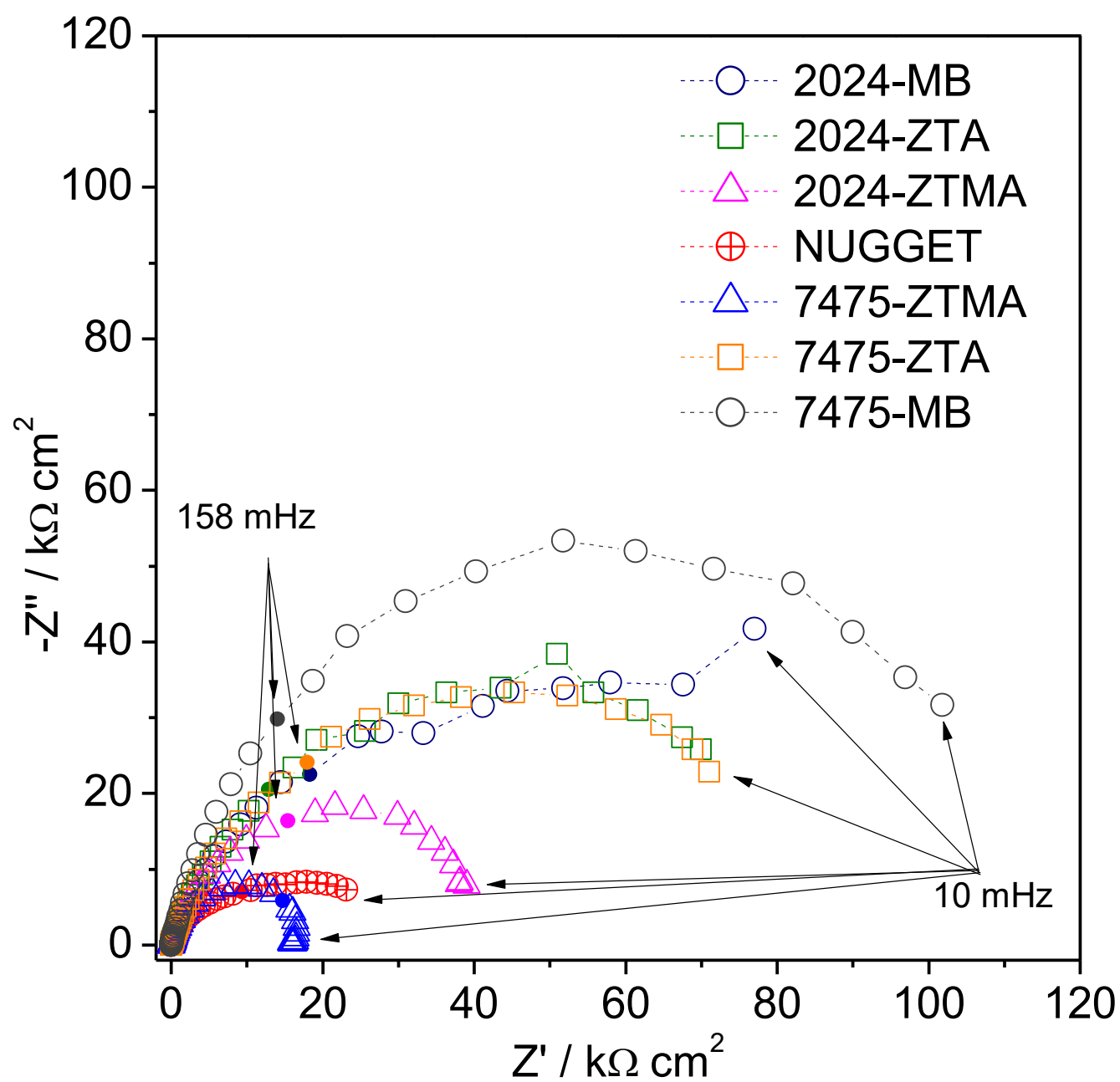

Figura 5.40: Espectroscopias de impedância locais das diferentes regiões formadas após o processo de soldagem por FSW das ligas 2024-T3 e 7475-T651, em solução de 0,1 M de 0,1 $\mathrm{M}_{\text {de }} \mathrm{Na}_{2} \mathrm{SO}_{4}+$ $1 \mathrm{mM}$ de $\mathrm{NaCl}$.

As espectroscopias de impedância apresentadas na Figura 5.40 mostram que os valores das impedâncias das ZTMAs das duas ligas, assim como o nugget apresentaram os menores valores, devido à alta atividade local eletroquímica presente na região da interface das ligas, onde as ligas estão misturadas e, em razão da possível formação de um acoplamento galvânico. É importante destacar que, os valores de impedância encontrados para a região do nugget apresentam maiores valores em relação ao acoplamento das ligas em amostra com maior área (ver Figura 5.33). Além disso, a ZTMA da liga 2024-T3 apresenta maior quantidade de partículas intermetálicas de fase $S$, que são anódicas em relação à matriz e, por isso, podem favorecer o processo de corrosão. Já a ZTMA da liga 7475-T651 apresenta precipitados intergranulares de fase $\eta\left(\mathrm{MgZn}_{2}\right)$, que também são anódicos em relação à matriz, e contribuem para a corrosão intergranular. 


\subsubsection{Espectroscopia de impedância local (LEIS)}

Outra técnica local utilizada foi o ensaio de espectroscopia de impedância local (LEIS), onde toda a superfície material a ser estudado é imerso em solução, ou seja, não apenas as zonas microestruturais distintas, como nos últimos ensaios locais realizados, o que permite que possam ser avaliados todos os possíveis pares galvânicos, seja entre as diferentes microestruturas das zonas formadas pelo processo de soldagem FSW, seja pelas diferenças de potenciais de corrosão entre duas ligas distintas.

O objetivo da utilização desta técnica foi estudar as impedâncias locais nas ligas 2024T3 e 7475-T651 soldadas por FSW, verificando dessa maneira os mecanismos de corrosão quando as ligas estão unidas, a fim de se observar suas diferenças, em razão da posição e do tempo de imersão em solução.

As medidas de impedância local foram realizadas com o auxílio do sistema de equipamento e célula eletroquímica descritos em 'Materiais e Métodos', em solução de 0,1 $\mathrm{M}$ de $\mathrm{Na}_{2} \mathrm{SO}_{4}$. Vale ressaltar que, os resultados com a adição de pequena quantidade de íons cloretos podem prejudicar a resolução em alta frequência, no sentido de se verificar um possível acoplamento galvânico e, por esse motivo, foi utilizada a solução apenas com 0,1 $\mathrm{M}$ de $\mathrm{Na}_{2} \mathrm{SO}_{4}$ para esta técnica, a fim de melhorar a visualização desses resultados. Como o potencial de corrosão da amostra das ligas 2024-T3 e 7475-T651 soldadas por FSW se estabiliza após 2 horas, os primeiros espectros de impedância foram realizados após este tempo e, como forma de comparar a evolução dos produtos de corrosão, as mesmas medidas foram realizadas após 6 e 8 horas de exposição, respectivamente. $O$ bi-eletrodo foi inserido extremamente próximo à superfície do eletrodo de trabalho e com o auxílio do motor de posicionamento e cada medida foi realizada em distâncias de $1 \mathrm{~mm}$, seguindo o sentido da liga 2024-T3 ao sentido da liga 7475-T651, passando pela região da solda (FSW).

O esquema de posicionamento do bi-eletrodo, para cada ponto de medida da impedância local é mostrado na Figura 5.41. Observa-se que foram realizadas 11 medidas diferentes, em cada tempo de exposição, sendo: dois pontos colocados na região da ZTA da liga 2024-T3; três pontos na ZTMA/nugget da liga 2024-T3; um ponto na interface (nugget) das duas ligas; três pontos na ZTMA/nugget da liga 7475-T651 e dois pontos na região da ZTA da liga 7475-T651. Todos os pontos foram colocados em sequência, de forma a tentar verificar as diferenças de comportamentos nas regiões mais próximas em relação às mais distantes das soldas. 


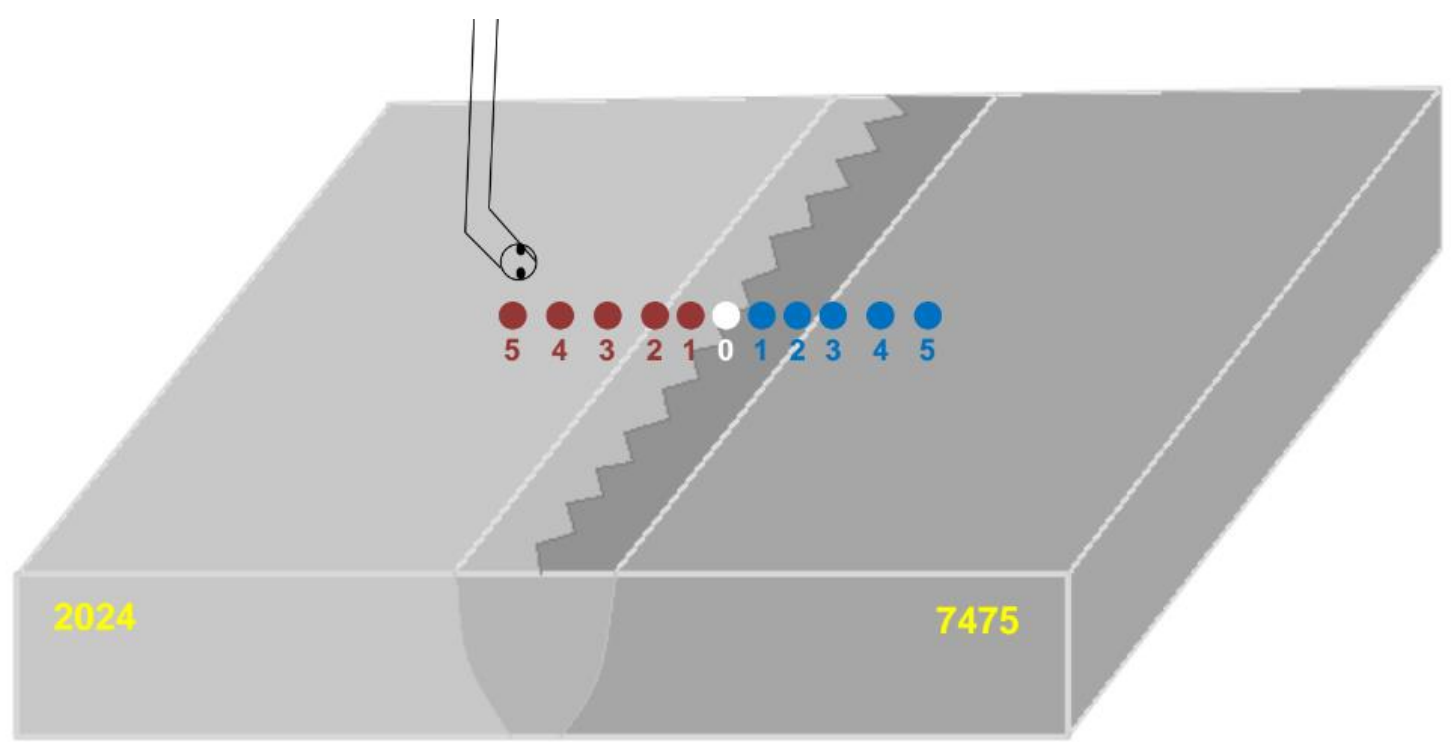

Figura 5.41: Esquema de posicionamento do bi-eletrodo, ao longo da amostra das ligas 2024 e 7475 soldadas por FSW.

A seguir, serão apresentados os espectros de impedância global e local. É importante destacar, antes do início da verificação dos espectros que, os limites em baixa frequência das curvas de impedâncias locais são menores do que na impedância global, em virtude da geometria do bi-eletrodo e de perturbações, que não permitem captar os pontos de valores em baixa frequência.

Os espectros de impedância global da amostra das ligas 2024-T3 e 7475-T651 soldadas por FSW, exposta em solução de $0,1 \mathrm{M}$ de $\mathrm{Na}_{2} \mathrm{SO}_{4}$, durante 44 horas, são apresentados na Figura 5.42. 


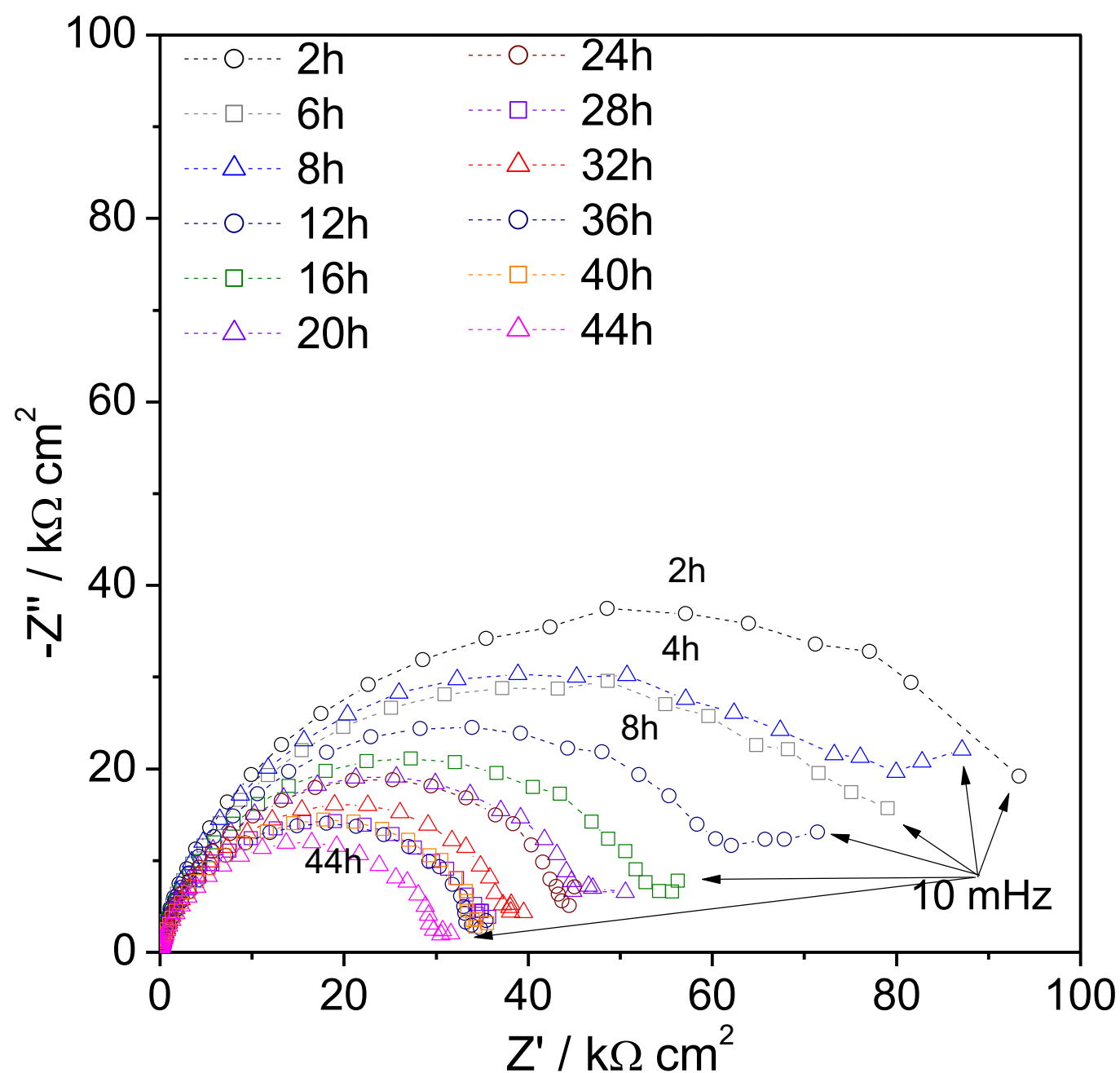

Figura 5.42: Espectroscopias de impedância (global) das ligas 2024-T3 e 7475-T651, destas soldadas por FSW, durante 44 horas, em solução de $0,1 \mathrm{M}$ de $\mathrm{Na}_{2} \mathrm{SO}_{4}$.

Verifica-se que as curvas de impedância reduzem seus valores progressivamente, de 2 horas até 44 horas, indicando um ataque gradativo do filme passivo pela solução de $0,1 \mathrm{M}$ de $\mathrm{Na}_{2} \mathrm{SO}_{4}$.

Nas Figuras 5.43, 5.44 e 5.45 são apresentados os espectros de impedância local (Nyquist), realizados em solução de $0,1 \mathrm{M}$ de $\mathrm{Na}_{2} \mathrm{SO}_{4}$, de 2 horas até 8 horas de exposição. Abaixo de cada curva local são mostradas, em aumento de escala, as regiões de alta frequência, onde é possível observar arcos indutivos nos pontos analisados da parte da liga 2024-T3, sendo o tamanho desses arcos cada vez menores, à medida que se distancia da interface da solda e se caminha em direção ao MB (região mais afastada da solda).

Os resultados apresentados na Fig. 5.43 mostram alguns aspectos interessantes na região de alta frequência. Foi observada a presença de componentes imaginários da impedância na região de alta freqüência. Essas contribuições dependem da localização da sonda acima da zona soldada, e assim não podem ser atribuídas a um artefato de medição. 
Além disso, numa série de artigos, Huang et al. (2007-(a),(b),(c)) demonstraram que a resposta EIS de um sistema pode apresentar um comportamento complexo para a componente ôhmica na região de alta frequência, devido à geometria do eletrodo embutido, o que resulta em distribuições de corrente e potencial limitadas na borda do eletrodo, de acordo com o trabalho de Newman (1966). Além disso, este tipo de resposta em alta frequência foi observado no primeiro trabalho sobre LEIS realizado, onde foi utilizado um sistema de cinco eletrodos por Lillard et al. (1992), mas sem qualquer explicação sobre a sua origem.

Mais recentemente, as investigações realizadas em eletrodos modelo ( $\mathrm{Al}$ / Cu (Lacroix et al., 2012) e Al / Mg (Lacroix et al., 2009)), para estudar o acoplamento galvânico por LEIS, mostraram que a interface formada por dois materiais diferentes induz uma distribuição não uniforme de corrente e potencial na superfície de cada um dos eletrodos acoplados (Huang et al., 2007 (c)). A partir de experimentos e simulações numéricas, esses autores demonstraram a importância das contribuições normais e radiais para a densidade de corrente local para um sistema simétrico de eixos. De maneira importante, foi mostrado que estas contribuições são responsáveis pelo comportamento em alta frequência observado na resposta LEIS e são sensíveis à posição da sonda em relação à interface que forma o acoplamento galvânico (Huang et al., 2011; Patil et al., 2013). Esta característica dos arcos indutivos é mais relevante quando a sonda é colocada perto da interface soldada (Figuras 5.43, 5.44 e 5.45), isto é, à medida que o bi-eletrodo se aproxima da interface entre as diferentes ligas de alumínio, e de acordo com a interpretação da literatura deste comportamento em alta frequência, observa-se uma distribuição de corrente normal acima da liga 2024-T3 e uma distribuição de corrente radial acima da liga 7475-T651 (Huang et al., 2007-(a),(b),(c)). 


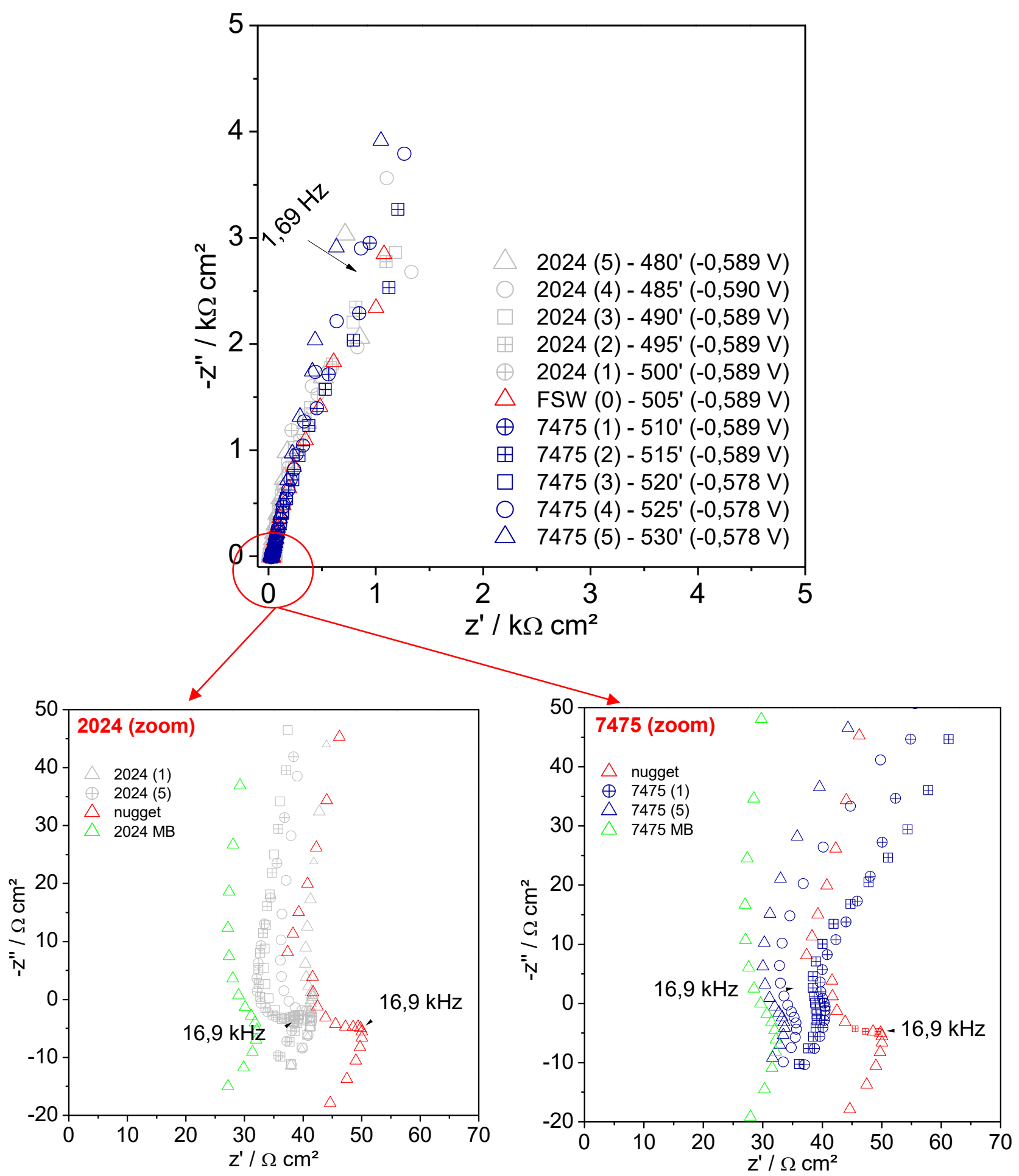

Figura 5.43: Espectroscopias de impedância local (Nyquist) das ligas 2024 e 7475, destas soldadas por FSW, após 2 horas de imersão em solução de $0,1 \mathrm{M}$ de $\mathrm{Na}_{2} \mathrm{SO}_{4}$. 


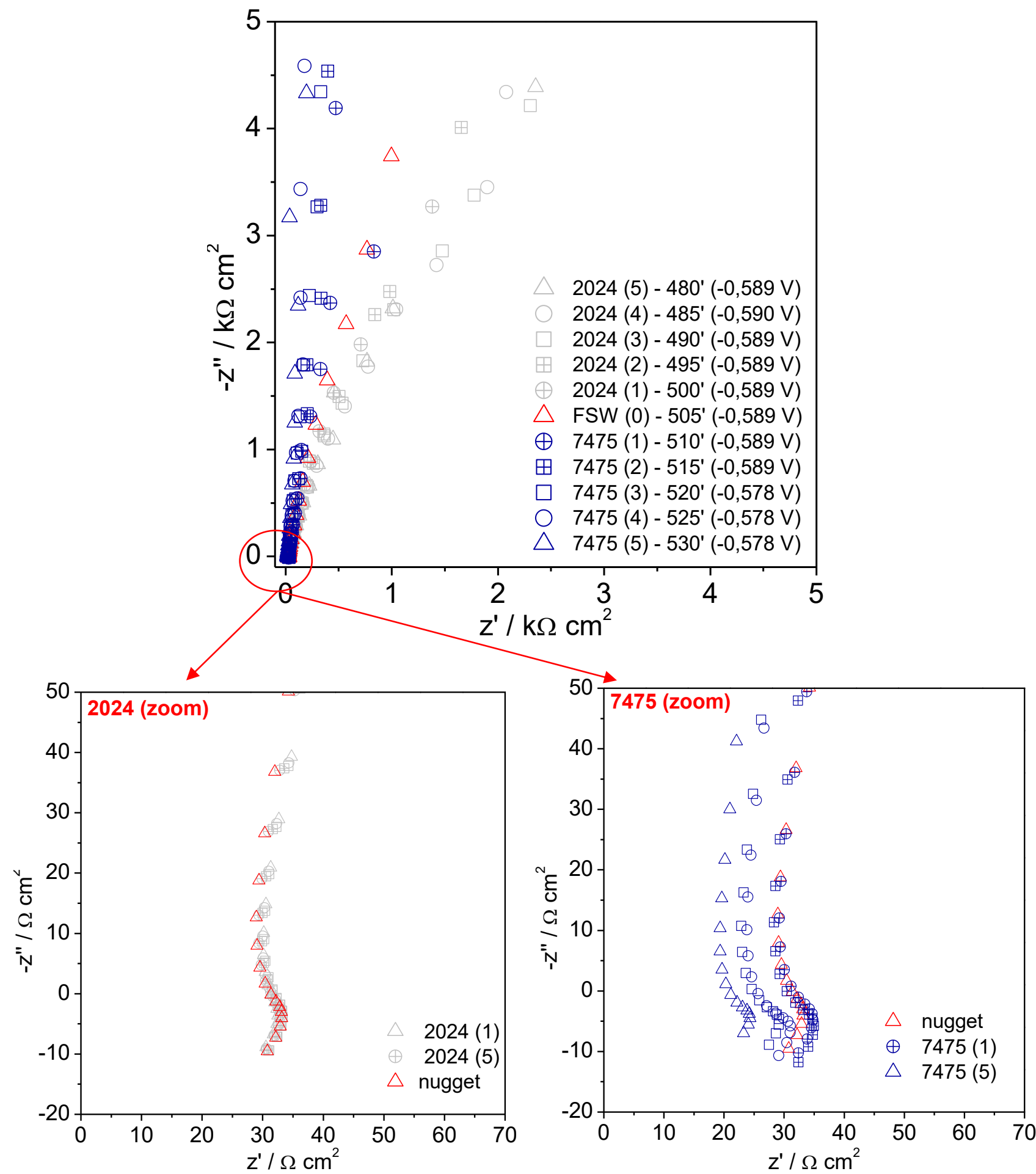

Figura 5.44: Espectroscopias de impedância local (Nyquist) das ligas 2024 e 7475, destas soldadas por FSW, após 6 horas de imersão em solução de $0,1 \mathrm{M}$ de $\mathrm{Na}_{2} \mathrm{SO}_{4}$. 


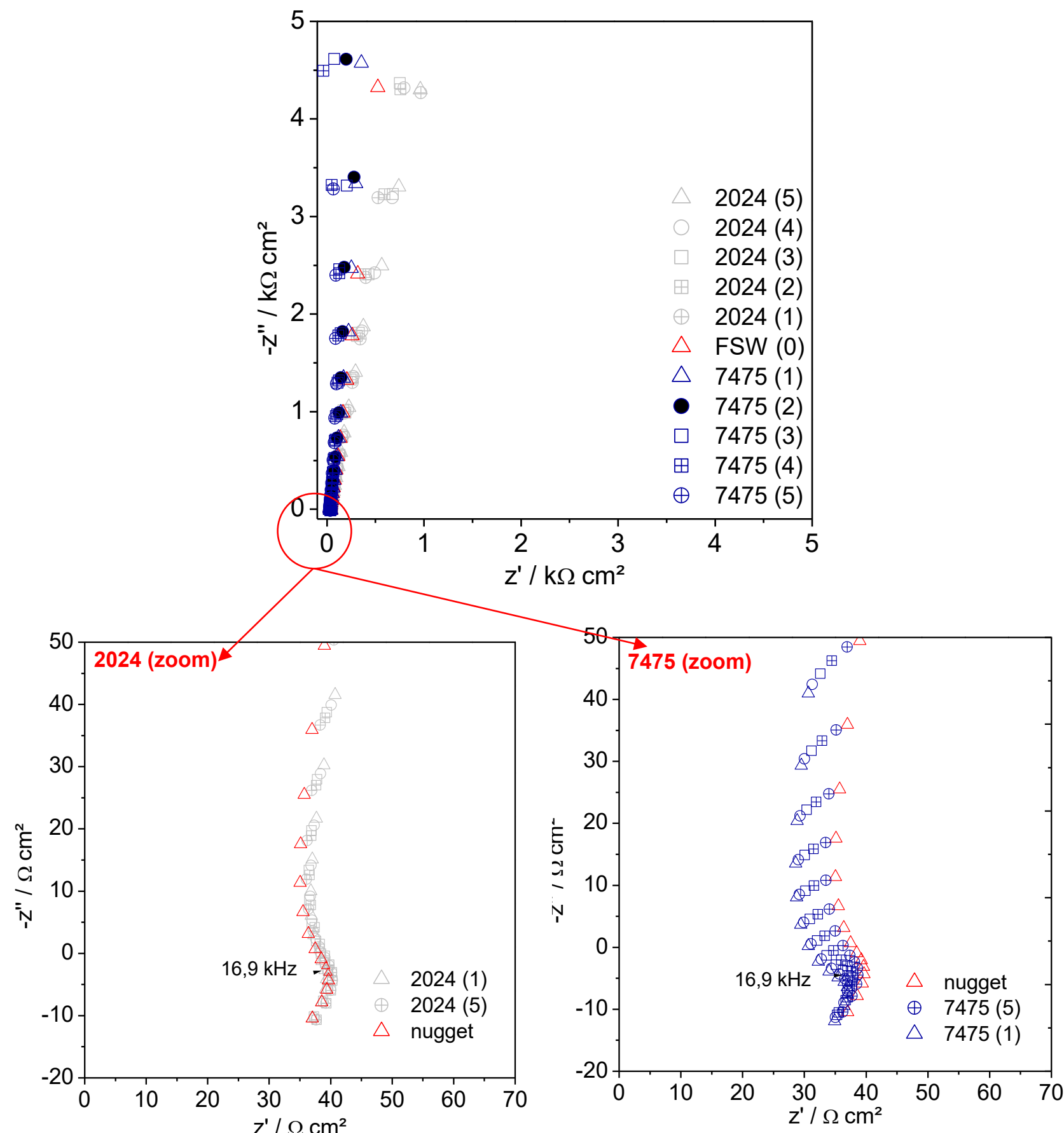

Figura 5.45: Espectroscopias de impedância local (Nyquist) das ligas 2024 e 7475, destas soldadas por FSW, após 8 horas de imersão em solução de $0,1 \mathrm{M}$ de $\mathrm{Na}_{2} \mathrm{SO}_{4}$.

Além disso, os arcos indutivos observados em alta freqüência são mais evidentes para períodos de teste mais curtos (2 horas - Figura 5.43) e tendem a desaparecer com tempos de exposição maiores (6 horas e 8 horas - Figuras 5.44 e 5.45 ). Isto pode ser devido a um crescimento do filme passivo e ao efeito inibidor dos íons de sulfato sobre as ligas de alumínio em função do tempo. Também não se pode excluir uma contribuição da precipitação de produtos de corrosão que bloqueiam a superfície das zonas corroídas. 
No trabalho realizado por Jorcin et al. (2008), usando a mesma solução $(0,1 \mathrm{M}$ de $\mathrm{Na}_{2} \mathrm{SO}_{4}$ ) na análise da liga Al-Cu, produzida em laboratório, após uma hora de exposição, os tamanhos dos arcos indutivos eram idênticos, independendente da posição do microeletrodo. $O$ fato dessa estabilização pode ser devido à estabilização do potencial de corrosão da liga teórica dos pesquisadores ser mais estável às ligas comerciais 2024-T3 e 7475-T651. No trabalho realizado por Lacroix et al. (2012), na análise das ligas teóricas Al-Cu/Al-Cu-Mg, usando também a mesma solução $\left(0,1 \mathrm{M}\right.$ de $\left.\mathrm{Na}_{2} \mathrm{SO}_{4}\right)$, foi observado que os arcos indutivos da parte Al-Cu-Mg, assim como nos espectros de impedância local da região da liga 2024T3, eram maiores quanto mais próximos se situavam da região da interface entre as duas ligas (região central da solda), devido à constrição de linhas dos campos de potencial nesta região. Com o aumento da exposição da amostra em solução, entretanto, o efeito do acoplamento galvânico é reduzido. Os espectros de impedância (Bode), apresentados na Figura 5.46, auxiliam a compreensão. 

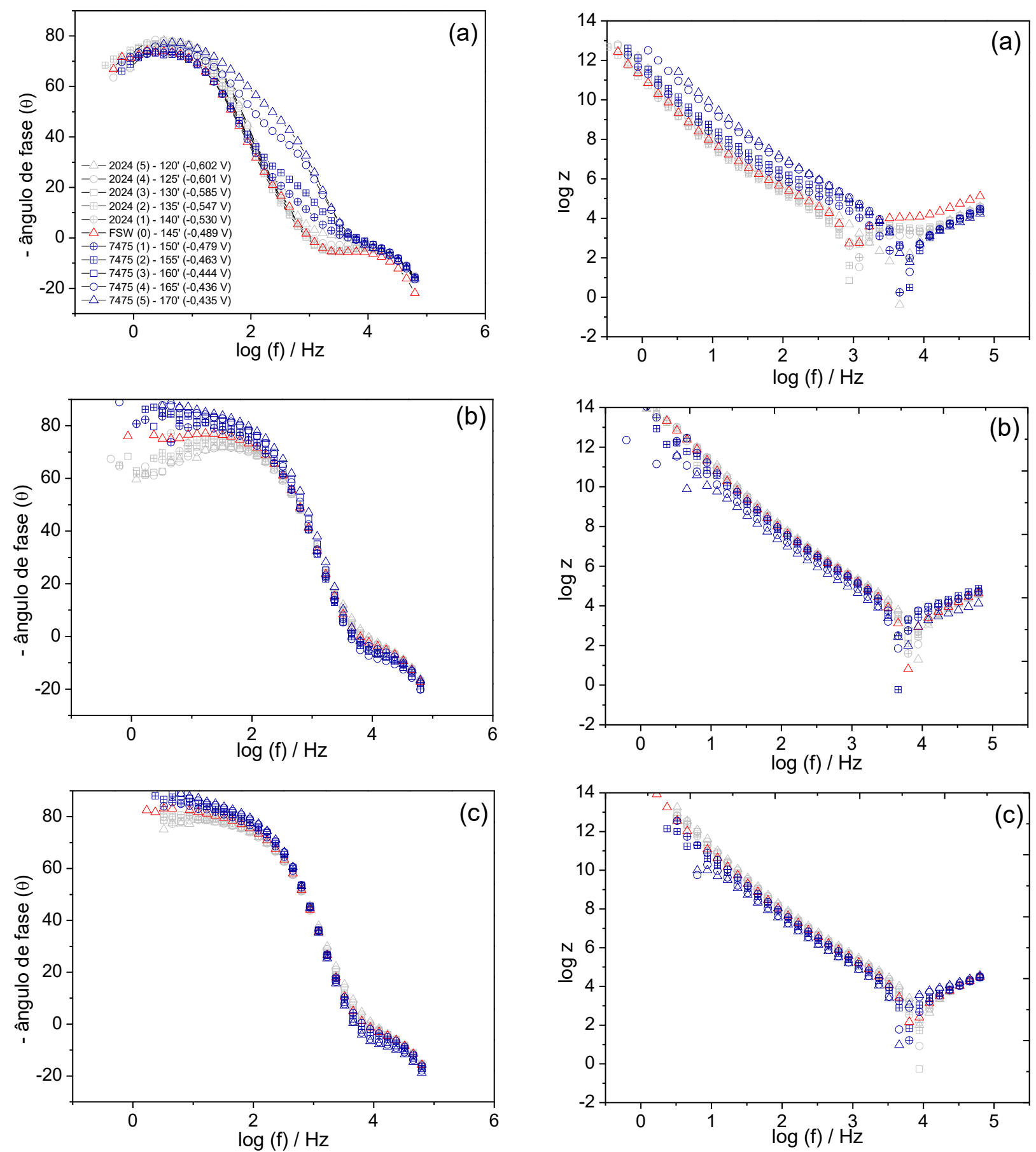

Figura 5.46: Espectroscopias de impedância local (Bode) das ligas 2024 e 7475, destas soldadas por FSW, em solução de 0,1 M de $\mathrm{Na}_{2} \mathrm{SO}_{4}$ : (a) após 2 horas de imersão; (b) após 6 horas de imersão e; (c) após 8 horas de imersão.

Conforme os espectros de impedância local, foi observado que durante as primeiras duas horas de exposição da amostra das ligas 2024-T3 e 7475-T651 soldadas por FSW em solução de 0,1 M de $\mathrm{Na}_{2} \mathrm{SO}_{4}$, há um forte acoplamento galvânico entre as ligas. Como descrito anteriormente, os arcos indutivos em alta frequência, que mostram esse acoplamento galvânico são devido à constrição de linhas dos campos de potencial nesta 
região e não devem ser relacionados aos comportamentos anódico e catódico das ligas diferentes ligas soldadas.

\subsection{Comportamento à corrosão na seção transversal}

Alguns ensaios foram realizados com o intuito de comparar as superfícies de topo e a seção transversal e verificar se ambas apresentavam o mesmo comportamento, pois a ponta da ferramenta de soldagem é cônica, modificando os tamanhos das ZTMAs e do nugget na extensão da amostra.

\subsubsection{Ensaio de imersão em solução de ágar-ágar}

O primeiro ensaio foi o de verificação da evolução de corrosão das ligas 2024-T3 e 7475-T651 soldadas por FSW, durante o processo de exposição em solução de ágar-ágar, pelo período de 8 horas, conforme mostra a Figura 5.47.

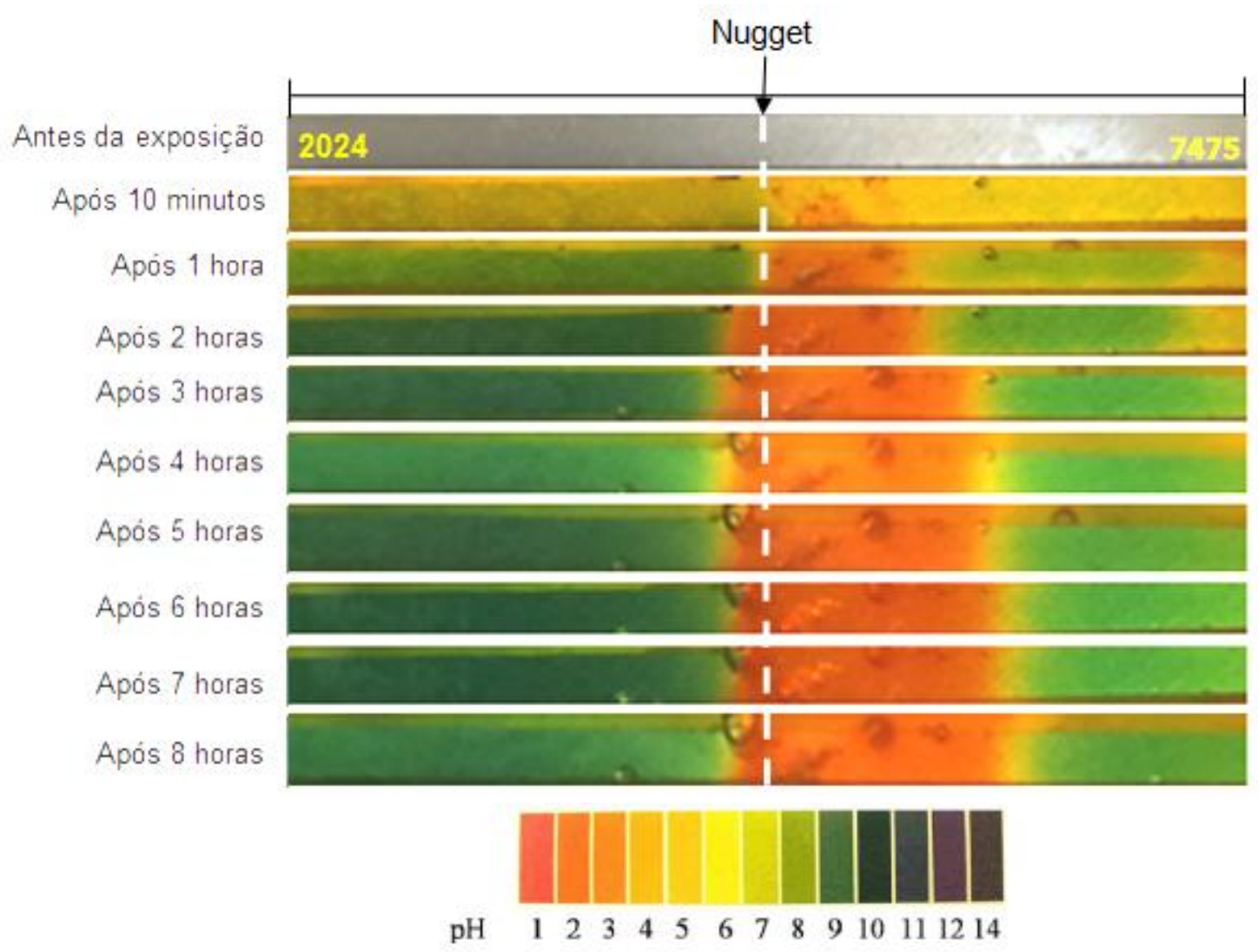

Figura 5.47: Imagens, seguidas por tempo de exposição em solução de ágar-ágar, na seção transversal da amostra. 
Assim como os resultados obtidos na superfície de topo (Figura 5.15), na seção transversal o comportamento foi o mesmo, ou seja, com o passar do tempo, a região anódica vai se expandindo pelo nugget, ZTMA e ZTA da liga 7475-T651, e pelo nugget da liga 2024T3. Foi também realizado o ensaio de espectroscopia de impedância local (LEIS), mas sem sucesso, devido ao pequeno tamanho da espessura do material ( $2 \mathrm{~mm}$ ) e, com isso, a sonda (bi-eletrodo) não ser capaz de fazer a leitura.

\subsubsection{Espectroscopia eletroquímica de varredura (SECM)}

Ensaios de microscopia eletroquímica de varredura (SECM) foram realizados na seção transversal da amostra soldada, conforme o esquema de posicionamento da sonda (ultra micro-eletrodo) nas diferentes zonas das ligas observadas após o processo de soldagem, conforme ilustra a Figura 5.48.

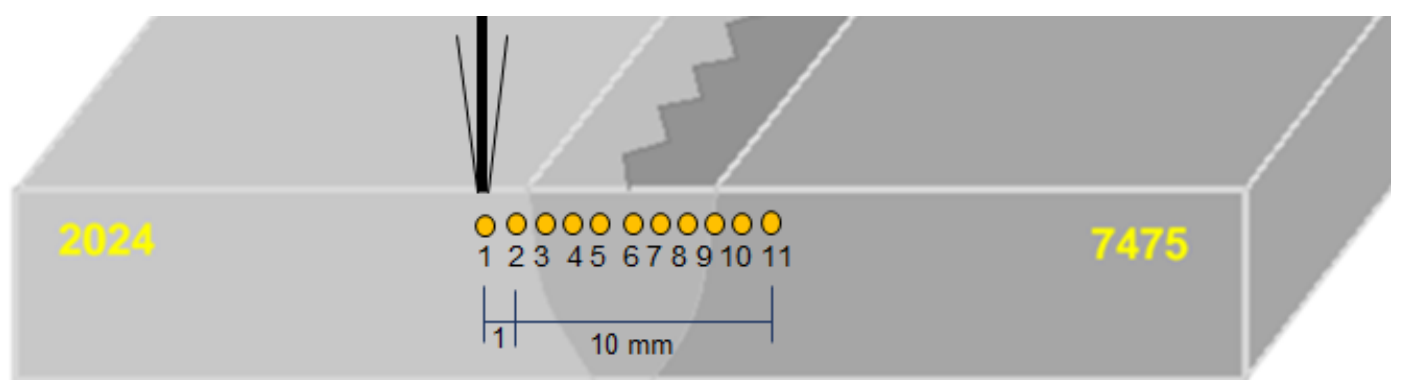

Figura 5.48: Esquema de posicionamento da sonda (ultra micro-eletrodo) do microscópio eletroquímico de varredudra nas distintas zonas formadas após o processo de soldagem por FSW das ligas 2024-T3 e 7475-T651.

A Figura 5.49 mostra as curvas de aproximação, obtidas por SECM, realizadas em locais diferentes sobre a seção transversal da amostra das ligas 2024-T3 e 7475-T651 soldadas por FSW, ao potencial de corrosão, após 7 minutos de imersão em solução de 0,1 $\mathrm{M}$ de $\mathrm{Na}_{2} \mathrm{SO}_{4}+$ hidroquinona $+0,005 \mathrm{M}$ de $\mathrm{H}_{2} \mathrm{SO}_{4}$. Essas curvas foram utilizadas para encontrar a taxa de transferência de carga heterogênea na interface (Bard, 2001; Sidane, 2015). As curvas foram plotadas em função da corrente normalizada, que é a corrente de estado estacionário medida no momento em que a sonda está longe do substrato, em relação à distância normal, que é o raio da sonda. As curvas de aproximação foram plotadas com um procedimento simples usando a equação teórica do feedback positivo, assumindo que a taxa de reação no substrato segue a relação de Butler-Volmer (Wei et al., 1995). As curvas de aproximação são úteis para encontrar a taxa de transferência de carga heterogênea em uma interface (Lo et al., 2006). 


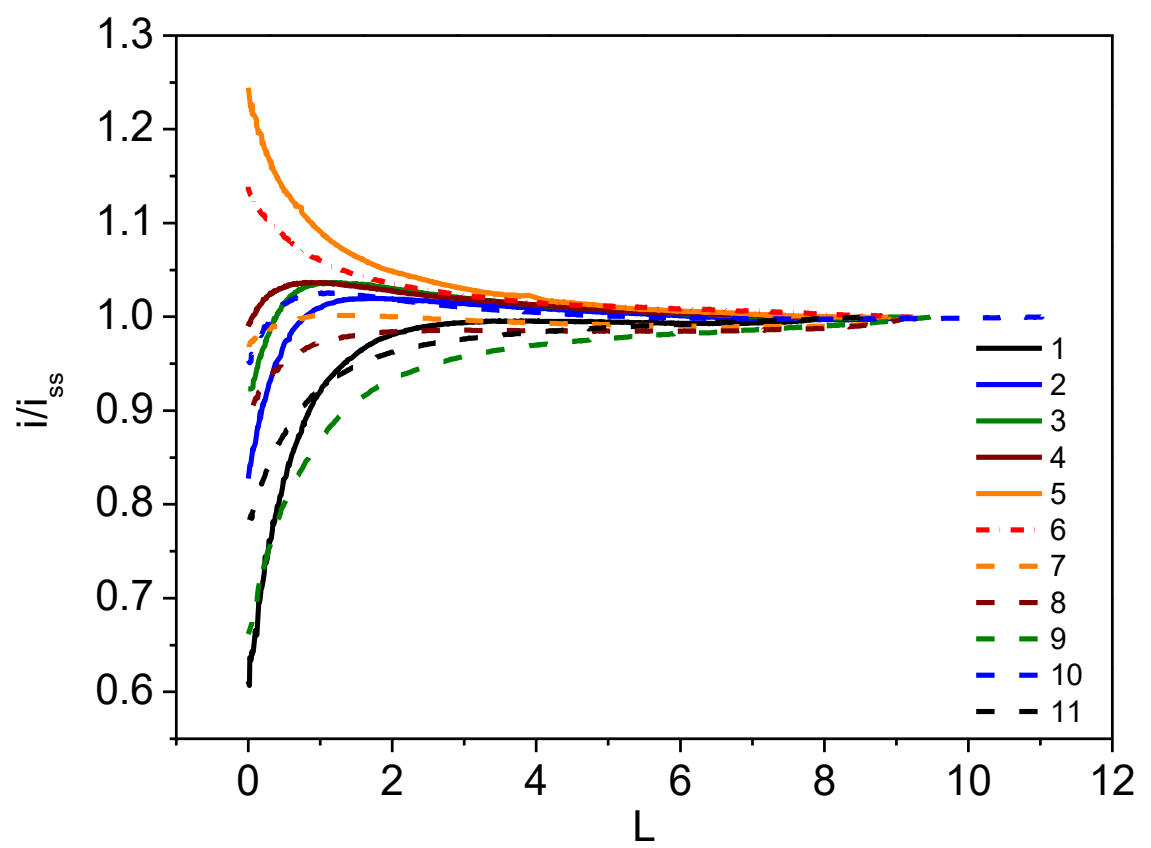

Figura 5.49: Curvas de aproximação obtidas por microscopia eletroquímica de varredura nas diferentes regiões da seção transversal da amostra das ligas 2024 e 7475 soldadas por FSW, indicadas na Figura 5.48, após 7 minutos de exposição em solução de 0,1 M de $\mathrm{Na}_{2} \mathrm{SO}_{4}+0,01 \mathrm{M}$ de Hidroquinona $+5 \mathrm{mM}$ de $\mathrm{H}_{2} \mathrm{SO}_{4}$.

Foi possível notar nas curvas de aproximação plotadas em potencial de circuito aberto, depois de 7 minutos de exposição em solução de 0,1 $\mathrm{M}$ de $\mathrm{Na}_{2} \mathrm{SO}_{4}$ + hidroquinona + 0,005 $\mathrm{M} \mathrm{H}_{2} \mathrm{SO}_{4}$, que as regiões próximas à interface entre as duas ligas, especificamente as regiões do nugget e da ZTMA, foram ativadas rapidamente, isto é, possuem cinética de reação maior que outras regiões. Observa-se também que, as curvas de aproximação da liga 2024-T3 (linhas contínuas) apresentaram feedbacks positivos mais altos em comparação com os mesmos pontos de posição da liga 7475-T651 (linhas tracejadas). O gráfico apresentado na Figura 5.50 permite uma melhor compreensão da reatividade de cada ponto. 


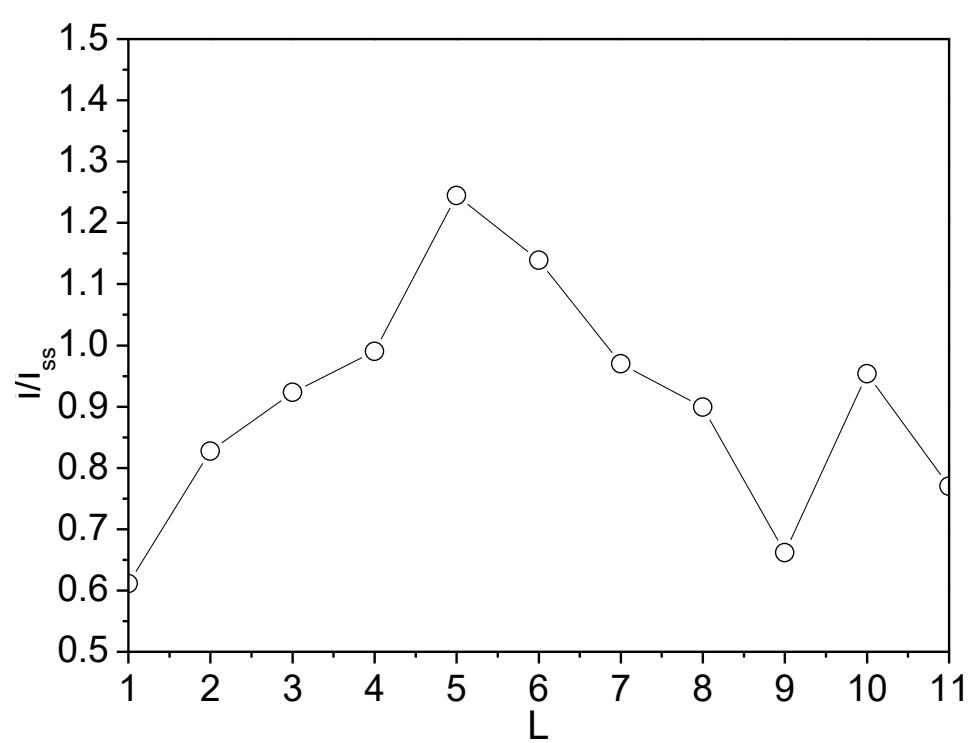

Figura 5.50: Corrente final de cada ponto medido com o auxílio de curvas de aproximação obtidas por SECM nas diferentes regiões da amostra das ligas 2024-T3 e 7475-T651, soldadas por FSW, após 7 minutos de exposição em solução de 0,1 $\mathrm{M}$ de $\mathrm{Na}_{2} \mathrm{SO}_{4}+0,01 \mathrm{M}$ de Hidroquinona $+5 \mathrm{mM}$ de $\mathrm{H}_{2} \mathrm{SO}_{4}$.

Pode-se observar que, à medida que se aproxima da interface entre as duas ligas, há uma maior velocidade na atividade, devido ao acoplamento galvânico, como foi sugerido pelo teste de solução ágar-ágar e resultados em potencial de circuito aberto. Observou-se também que, para os pontos mais distantes da interface entre os dois metais, houve comportamento de corrente constante, após 7 minutos de exposição, possivelmente devido a um menor efeito de acoplamento galvânico nessas regiões. No entanto, quando a ponta do SECM estava mais próxima do centro da solda, ocorreu um crescimento da corrente, causada pelo acoplamento galvânico, como foi verificado por Sidane et al. (2015). A única exceção foi a corrente medida no ponto 9 (Figura 5.48), que apresentou uma corrente final inferior às correntes das curvas de aproximação mais distantes da linha central de soldagem, em razão da constante cinética presente neste ponto.

Os espectros das curvas de aproximação obtidas por SECM, nos pontos indicados pela Figura 5.51, após 52 minutos de exposição em solução de 0,1 M de $\mathrm{Na}_{2} \mathrm{SO}_{4}+0,01 \mathrm{M}$ de Hidroquinona $+5 \mathrm{mM}$ de $\mathrm{H}_{2} \mathrm{SO}_{4}$, são mostrados pela Figura 5.51 


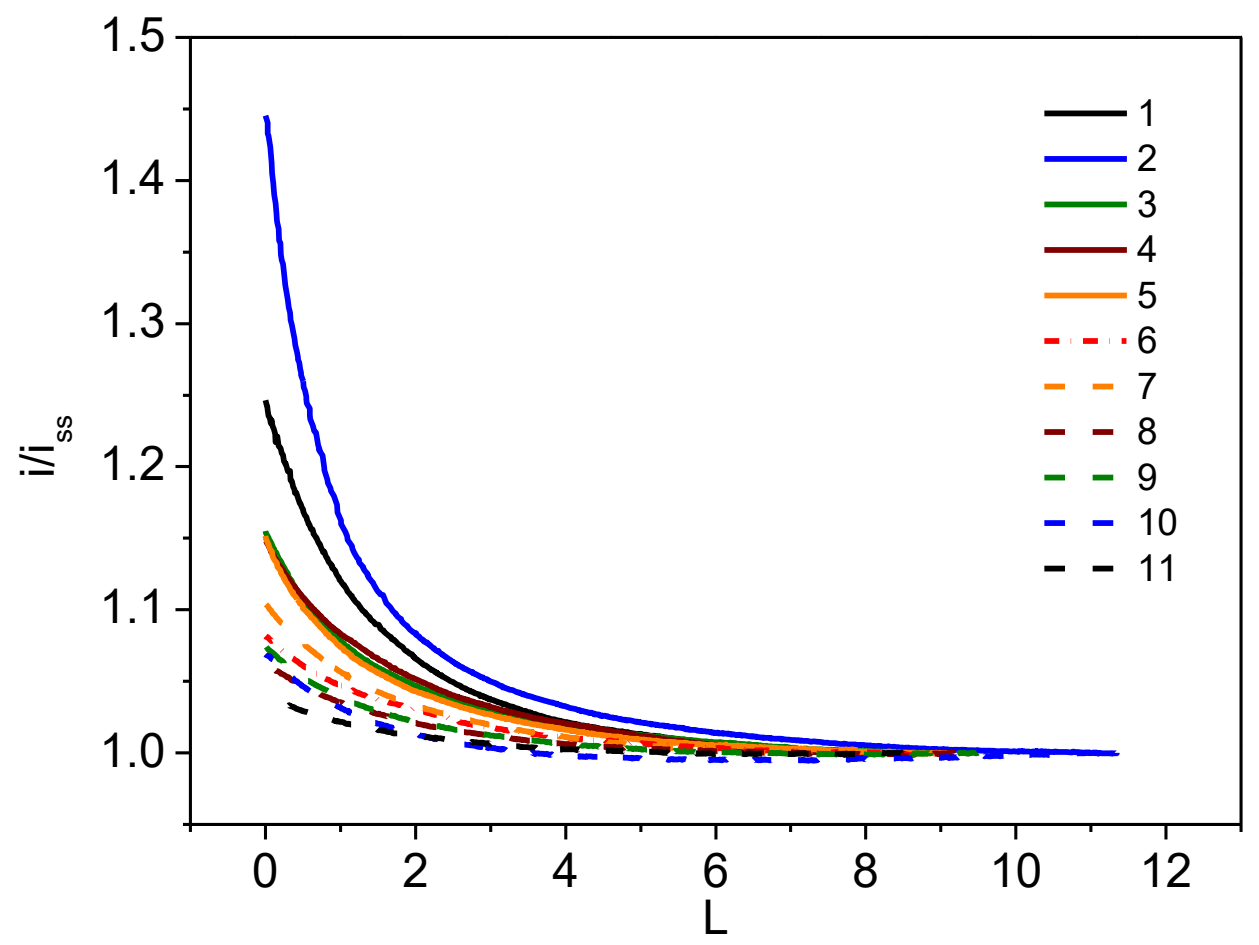

Figura 5.51: Curvas de aproximação obtidas por microscopia eletroquímica de varredura nas diferentes regiões da seção transversal da amostra das ligas 2024 e 7475 soldadas por FSW, indicadas na Figura 5.48, após 52 minutos de exposição em solução de $0,1 \mathrm{M}$ de $\mathrm{Na}_{2} \mathrm{SO}_{4}+0,01 \mathrm{M}$ de Hidroquinona $+5 \mathrm{mM}^{\text {de }} \mathrm{H}_{2} \mathrm{SO}_{4}$.

Verificou-se nas curvas de aproximação, após 52 minutos de exposição em solução

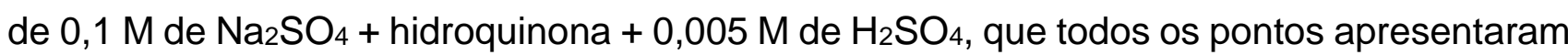
feedback positivo e, portanto, não houve diferença entre os diferentes pontos, ou seja, não foi notado qualquer acoplamento galvânico.

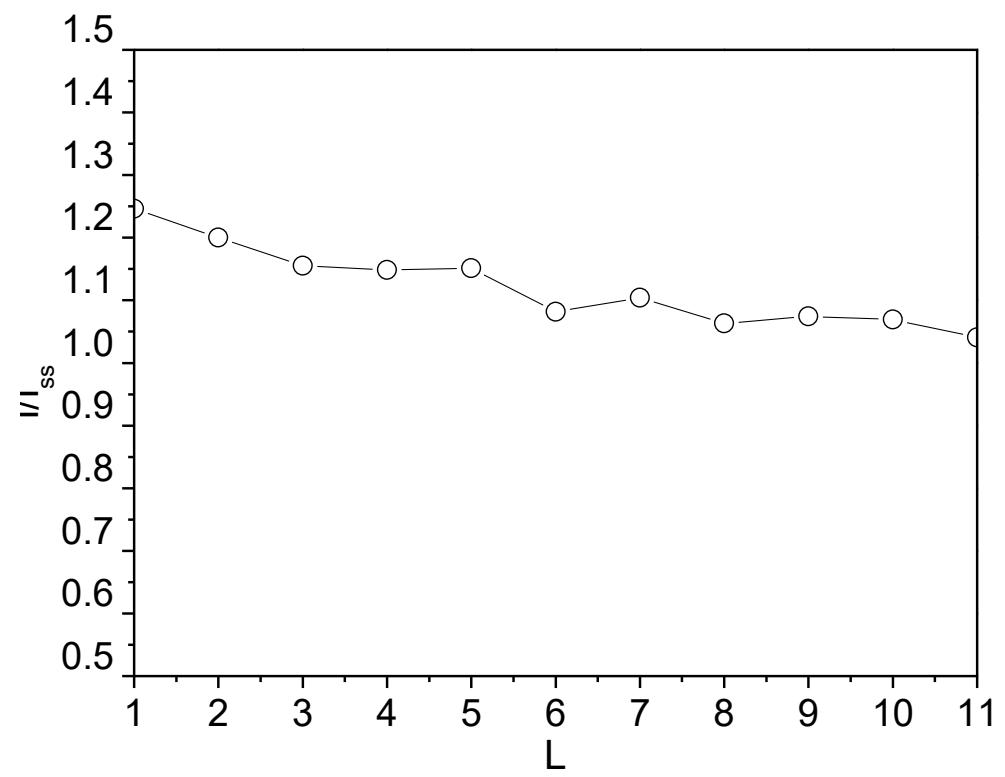

Figura 5.52: Corrente final de cada ponto medido com o auxílio de curvas de aproximação obtidas por SECM nas diferentes regiões da amostra das ligas 2024-T3 e 7475-T651, soldadas por FSW, após 52 minutos de exposição em solução de $0,1 \mathrm{M}$ de $\mathrm{Na}_{2} \mathrm{SO}_{4}+0,01 \mathrm{M}$ de Hidroquinona $+5 \mathrm{mM}$ de $\mathrm{H}_{2} \mathrm{SO}_{4}$. 
Pode-se observar que, após 52 minutos de imersão, todos os feedbacks são positivos e mostram resultados próximos. Entretanto, a linhas sólidas, referentes aos pontos analisados da parte da liga 2024-T3 são mais positivos, em razão das reações ocorridas com as partículas intermetálicas de fase $\mathrm{S}\left(\mathrm{Al}_{2} \mathrm{CuMg}\right)$ desta liga, como mostrado pelas micrografias obtidas por SEM (Figuras 5.23 a 5.28). Além de diminuir a potência do acoplamento galvânico ao longo do tempo, esses produtos de corrosão também são responsáveis pelo comportamento constante de diferentes pontos após 52 minutos de exposição.

\subsection{Comportamento superficial antes e após exposição à corrosão}

A fim de compreender melhor a influência dos processos eletroquímicos quando as amostras das ligas 2024-T3 e 7475-T651 são soldadas conjuntamente, formando dessa maneira um acoplamento galvânico, alguns ensaios foram realizados para o entendimento dos possíveis produtos de corrosão formados e seu papel na redução de resistência das respectivas camadas passivas.

Em sequência à análise realizada por SEM/EDS, durante 24 horas de exposição em solução de de $0,1 \mathrm{M}$ de $\mathrm{Na}_{2} \mathrm{SO}_{4}+1 \mathrm{mM}$ de $\mathrm{NaCl}$, conforme mostraram as Figuras 5.23 a 5.28, foram realizadas novas imagens e análises por EDS das 5 diferentes zonas formadas (MB (2024/7475); ZTMA (2024/7475) e nugget), após uma exposição de 144 horas na mesma solução. Em seguida, foi verificado o comportamento da camada passiva, através de análises por XPS, durante 24 horas de exposição.

A Figura 5.53 apresenta as imagens obtidas por SEM, do MB da liga 2024-T3, da ZTMA da liga 2024-T3, do nugget, do ZTMA da liga 7475-T651 e do MB da liga 7475-T651, respectivamente, após 144 horas de exposição em solução de 0,1 $\mathrm{M}$ de $\mathrm{Na}_{2} \mathrm{SO}_{4}+1 \mathrm{mM}$ de $\mathrm{NaCl}$. 

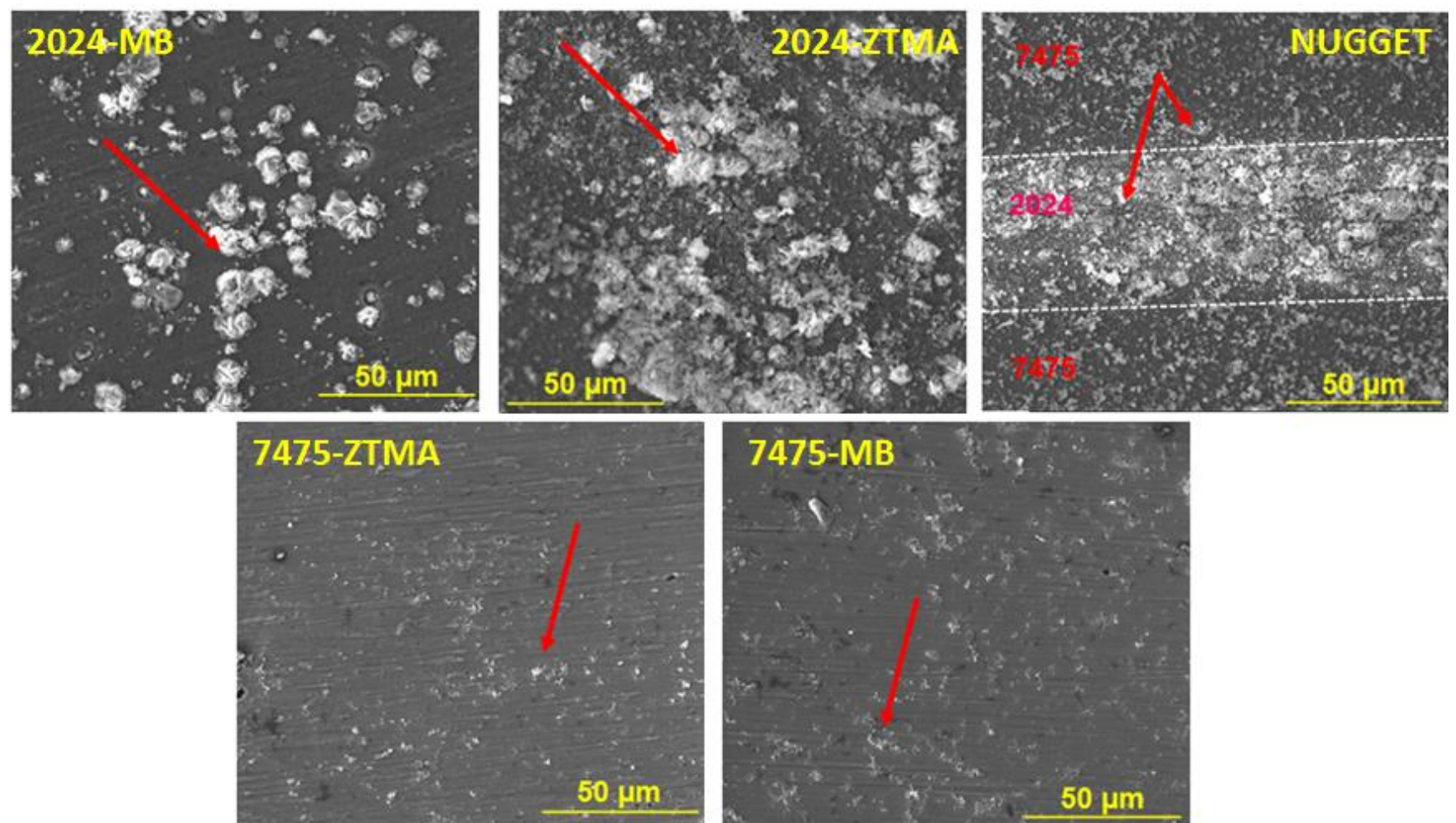

Figura 5.53: Micrografias obtidas por SEM, do MB da liga 2024-T3, da ZTMA da liga 2024-T3, do nugget, do ZTMA da liga 7475-T651 e do MB da liga 7475-T651, respectivamente, após 144 horas de exposição em solução de $0,1 \mathrm{M}$ de $\mathrm{Na}_{2} \mathrm{SO}_{4}+1 \mathrm{mM}$ de $\mathrm{NaCl}$.

Foi possível notar que, após 144 horas de exposição, houve formação massiva de produtos de corrosão, conforme mostram as setas vermelhas indicativas para o MB, a ZTMA e o nugget da liga 2024-T3. Vale ressaltar que, esses produtos aumentam de quantidade à medida que se aproximam da interface com a liga 7475-T651, em razão da maior reativade dessa região, conforme visto nos resultados eletroquímicos apresentados anteriormente. $A$ análise dos produtos de corrosão foi realizada por EDS, onde constatou se tratar de óxido de zinco, conforme mostra a Tabela 5.5.

Na ZTMA e no MB da liga 7475-T651, ocorreu a formação de produtos de corrosão, assim como para as regiões da liga 2024-T3, mas em menores quantidades, conforme mostram as setas vermelhas indicativas. Tal fato deve-se, possivelmente, à menor quantidade de partículas intermetálicas que essa liga possui, fazendo com que haja menor quantidade de micro-pilhas formadas e, consequentemente, menores quantidades de deposição de produtos de corrosão. A análise desses produtos foi realizada por EDS, onde constatou se tratar de óxido de zinco também, conforme mostra a Tabela 5.5. 
Tabela 5.5: Composições químicas das partículas encontradas nas diferentes zonas formadas nas ligas 2024-T3 e 7475-T651, soldadas por FSW, após 144 horas de exposição em solução de 0,1 M de $\mathrm{Na}_{2} \mathrm{SO}_{4}+1 \mathrm{mM}$ de NaCl .

\begin{tabular}{lcccccccccc}
\hline & $\mathbf{O}$ & Na & Al & Si & Mg & S & Mn & Fe & Cu & Zn \\
\hline 2024-MB & 22,7 & 0,5 & 31,2 & 0,22 & - & 1,8 & 1,9 & 2,9 & 12,1 & 26,7 \\
2024-ZTMA & 44,7 & 2,3 & 18,8 & 1,2 & - & 2,3 & - & - & 2,8 & 27,8 \\
Nugget (2024) & 44,0 & 1,0 & 15,3 & 1,6 & - & 3,8 & - & - & - & 34,3 \\
Nugget (7475) & 46,6 & - & 30,8 & 1,8 & 1,0 & 3,0 & - & - & - & 16,7 \\
7475-ZTMA & 12,2 & - & 80,4 & 0,4 & 2,3 & - & - & - & - & 4,0 \\
7475-MB & 29,3 & - & 58,6 & 0,7 & 3,3 & 1,6 & - & 1,9 & - & 4,6 \\
\hline
\end{tabular}

A Tabela 5.5 mostra que o zinco foi encontrado em todos os produtos analisados, seja sobre a liga 2024-T3 ou a 7475-T651, embora se observe que as maiores concentrações foram obsevadas na região do nugget e ZTMA da 2024-T3, possivelmente em razão da maior ação do acoplamento galvânico nestas regiões. É interessante ressaltar novamente que os produtos ricos em zinco são encontrados principalmente sobre a liga 2024-T3, que não contém zinco. A presença deste sobre a liga 2024-T3, portanto, indica dissolução preferencial do zinco da liga 7475-T651 e a migração/difusão destes íons da solução para regiões vizinhas e sobre a solda. Por sua vez, a dissolução preferencial do magnésio na liga 2024-T3 favorece a troca química, causando a deposição de zinco sobre a liga 2024-T3 e a posterior oxidação do zinco depositado formando produtos óxidos.

\subsubsection{Análise superficial por XPS}

Haja visto que as análises por SEM/EDS permitiram mostrar a evolução de produtos de corrosão, por interferência do acoplamento galvânico, assim como os ensaios eletroquímicos permitiram mostrar este acoplamento galvânico e a perda de resistência das ligas 2024-T3 e 7475-T651, devido a este acoplamento galvânico quando estão soldadas, foi realizado um estudo da análise das superfícies das amostras, por XPS, dos MB das ligas 2024-T3 e 7475-T651 e das mesmas soldadas por FSW, a fim de compreender a diferença de comportamento das respectivas superfícies. Também foram realizadas análises do nugget, com as mesmas condições. A estruturação da sequência das análises foi apresentada em Materiais e Métodos, no item 4.2. 
A Tabela 5.6 apresenta as composições químicas das superfícies das amostras, obtidas por XPS, do MB da liga 2024-T3, soldadas e não soldadas por FSW, sem exposição, após 8 horas e 24 horas de exposição em solução de de 0,1 $\mathrm{M}$ de $\mathrm{Na}_{2} \mathrm{SO}_{4}+1 \mathrm{mM}$ de $\mathrm{NaCl}$.

Tabela 5.6: Composições químicas das superfícies das amostras, obtidas por XPS, do MB da liga 2024-T3, soldadas e não soldadas por FSW, sem exposição, após 8 horas e 24 horas de exposição em solução de de $0,1 \mathrm{M}$ de $\mathrm{Na}_{2} \mathrm{SO}_{4}+1 \mathrm{mM}$ de $\mathrm{NaCl}$.

\begin{tabular}{lccccc}
\hline & $\mathbf{A l}$ & $\mathbf{C u}$ & $\mathbf{M g}$ & $\mathbf{0}$ & $\mathbf{Z n}$ \\
\hline Sem exposição & 41,97 & 0,17 & 0,23 & 57,63 & 0 \\
Amostra sem solda (após 8 horas) & 38,11 & 0,19 & 0 & 61,70 & 0 \\
Amostra sem solda (após 24 horas) & 31,66 & 0,38 & 0 & 67,95 & 0 \\
Amostra soldada (após 8 horas) & 46,59 & 0,35 & 0 & 51,89 & 1,17 \\
Amostra soldada (após 24 horas) & 37,74 & 0,38 & 0 & 60,06 & 1,81 \\
\hline
\end{tabular}

Conforme os resultados apresentados na Tabela 5.6, nota-se que para a amostra do MB da liga 2024-T3, sem soldagem, ocorre um leve enriquecimento de cobre após 24 horas e um empobrecimento de magnésio, de acordo com os resultados obtidos por EDS, onde o magnésio presente nas partículas de fase $S$ são dissolvidos e, com isso, ocorre um aumento do teor de cobre.

Com relação aos resultados da amostra do MB da liga 2024-T3, soldada por FSW com a liga 7475-T651, o mesmo comportamento é notado em relação ao enriquecimento do cobre, porém após 8 horas de exposição em solução já se observa o enriquecimento notado para as 24 horas de exposição da liga sem solda, assim como o empobrecimento de magnésio. Para essa amostra, entretanto, nota-se a presença de zinco, que aumenta com o tempo, de acordo com os resultados apresentados por EDS, na Tabela 5.6. Vale salientar que a Tabela 5.6 mostra a detecção de zinco na superfície da liga 2024-T3 que foi ensaiada soldada à liga 7475-T651. O zinco não faz parte da composição química da liga 2024-T3 (0,03 \% em massa). Portanto, a dissolução dos íons zinco da liga 7475-T651 resultam na deposição deste elemento em alguns sítios da liga 2024-T3 e a quantidade depositada aumenta com o tempo de exposição ao meio.

A Tabela 5.7 apresenta as composições químicas das superfícies das amostras, obtidas por XPS, do MB da liga 7475-T651, soldadas e não soldadas por FSW, sem exposição, após 8 horas e 24 horas de exposição em solução de de $0,1 \mathrm{M}$ de $\mathrm{Na}_{2} \mathrm{SO}_{4}+1$ $\mathrm{mM}$ de $\mathrm{NaCl}$. 
Tabela 5.7: Composições químicas das superfícies das amostras, obtidas por XPS, do MB da liga 7475-T651, soldadas e não soldadas por FSW, sem exposição, após 8 horas e 24 horas de exposição em solução de $0,1 \mathrm{M}$ de $\mathrm{Na}_{2} \mathrm{SO}_{4}+1 \mathrm{mM}$ de $\mathrm{NaCl}$.

\begin{tabular}{lccccc}
\hline & Al & Cu & Mg & O & Zn \\
\hline Sem exposição & 47,50 & 0,06 & 0,21 & 51,99 & 0,21 \\
Amostra sem solda (após 8 horas) & 37,39 & 0,06 & 0 & 61,67 & 0,88 \\
Amostra sem solda (após 24 horas) & 37,32 & 0,05 & 0 & 60,49 & 1,68 \\
Amostra soldada (após 8 horas) & 42,36 & 0,04 & 0 & 56,74 & 0,85 \\
Amostra soldada (após 24 horas) & 33,42 & 0,07 & 0 & 65,22 & 1,28 \\
\hline
\end{tabular}

Os resultados apresentados na Tabela 5.7 mostram dissolução seletiva do Mg da liga para ambas as condições ensaiadas, soldada ou não soldada. O enriquecimento em zinco na superfície da liga 7475-T651, soldada ou não soldada, é acompanhado pelo empobrecimento em alumínio, indicando que apesar da dissolução do zinco no meio corrosivo, comprovada pelo aparecimento de produtos de corrosão da liga 7475-T651 na liga 2024-T3, há dissolução preferencial do alumínio da superfície da primeira o que resulta em enriquecimento em zinco.

A Tabela 5.8 apresenta as composições químicas das superfícies das amostras, obtidas por XPS, do nugget das ligas 2024-T3 e 7475-T651, soldadas por FSW, sem exposição, após 8 horas e 24 horas de exposição em solução de de $0,1 \mathrm{M}$ de $\mathrm{Na}_{2} \mathrm{SO}_{4}+1$ $\mathrm{mM}$ de $\mathrm{NaCl}$.

Tabela 5.8: Composições químicas das superfícies das amostras, obtidas por XPS, do nugget das ligas 2024-T3 e 7475-T651, soldadas por FSW, sem exposição, após 8 horas e 24 horas de exposição em solução de de $0,1 \mathrm{M}$ de $\mathrm{Na}_{2} \mathrm{SO}_{4}+1 \mathrm{mM}$ de $\mathrm{NaCl}$.

\begin{tabular}{lccccc} 
& $\mathbf{A l}$ & $\mathbf{C u}$ & $\mathbf{M g}$ & $\mathbf{0}$ & $\mathbf{Z n}$ \\
\hline Sem exposição & 44,55 & 0,08 & 0,60 & 54,17 & 0,59 \\
Após 8 horas de exposição & 37,28 & 0,24 & 0 & 60,96 & 1,52 \\
Após 24 horas de exposição & 37,71 & 0,75 & 0 & 59,66 & 1,88 \\
\hline
\end{tabular}

Os resultados da Tabela 5.8 mostram enriquecimento em cobre e zinco no nugget $\mathrm{e}$ empobrecimento em alumínio e magnésio. Em comparação com a composição da superfície das ligas soldadas (2024-T3 e 7475-T651) após exposição ao meio corrosivo, o que se observa no nugget é o maior enriquecimento em cobre e zinco com o tempo de exposição ao meio, provavelmente como efeito do acoplamento galvânico entre as duas ligas.

Quanto ao alumínio (Al2p), principal elemento metálico na superfície das amostras, os espectros de XPS foram analisados individualmente. Os espectros de alumínio (Al2p) 
possuem alumínio metálico e óxido ou hidróxidos de alumínio, sendo necessária uma análise da relação de suas áreas obtidas pelos ajustes (fittings), conforme apresenta o próximo item.

\subsubsection{Análise por XPS da camada de passivação da liga 2024-T3}

Os espectros de XPS de alta resolução para o alumínio (Al2p) para a liga 2024-T3, (a) sem solda antes da exposição, (b) sem solda após 8 horas, (c) sem solda após 24 horas, (d) com solda após 8 horas e, (e) com solda após 24 horas em solução 0,1 M de $\mathrm{Na}_{2} \mathrm{SO}_{4}+1$ mM de $\mathrm{NaCl}$ são apresentados na Figura 5.54 .
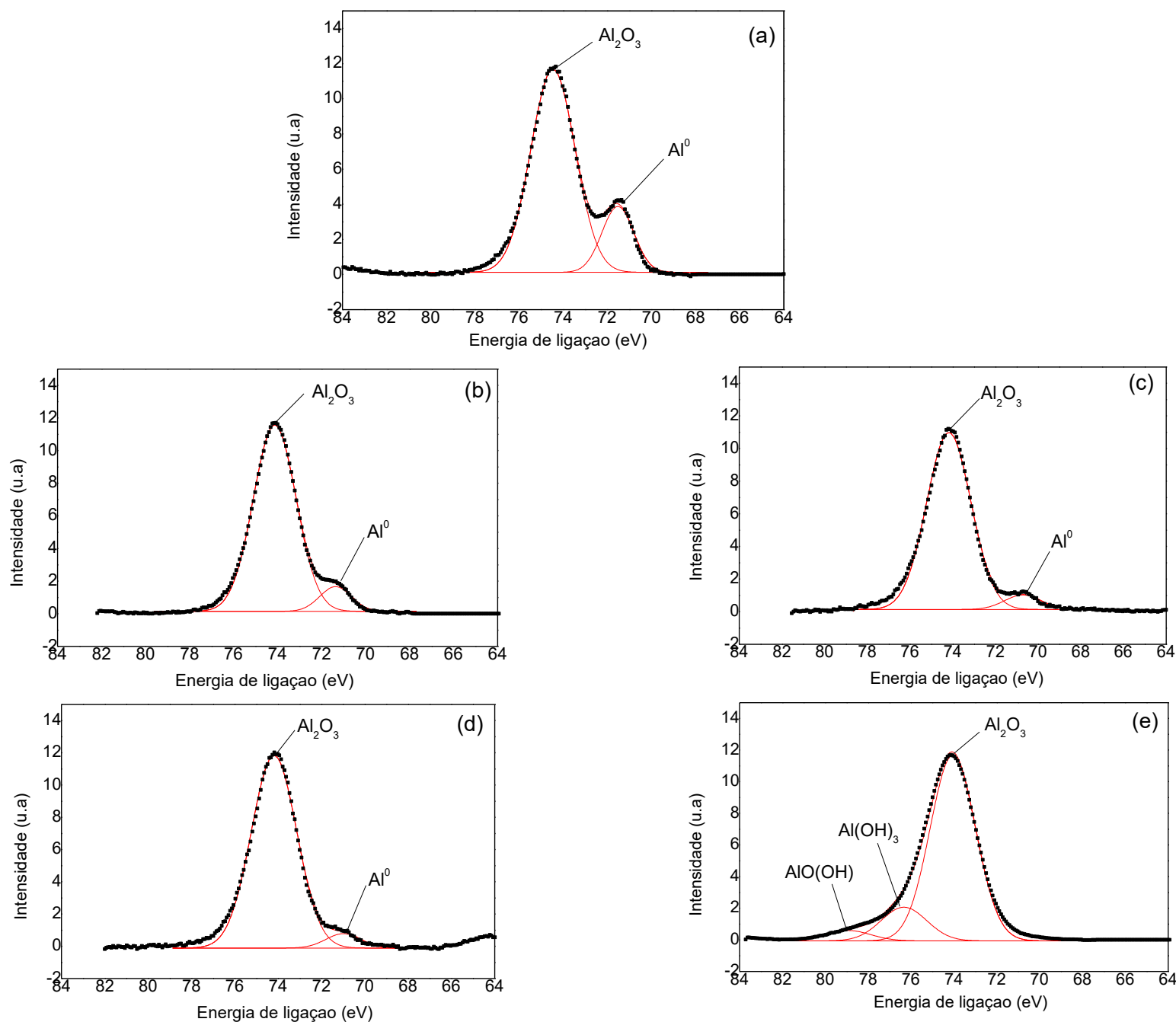

Figura 5.54: Espectros de alta resolução para o alumínio (AI2p) obtidos por XPS, da liga 2024-T3, (a) sem solda antes da exposição, (b) sem solda após $8 \mathrm{~h}$, (c) sem solda após 24 h, (d) com solda após $8 \mathrm{~h} \mathrm{e},(\mathrm{e})$ com solda após $24 \mathrm{~h}$ em solução $0,1 \mathrm{M}$ de $\mathrm{Na}_{2} \mathrm{SO}_{4}+1 \mathrm{mM}$ de $\mathrm{NaCl}$.

A Tabela 5.9 apresenta as relações de óxido de alumínio/óxido metálico e hidróxidos de alumínio/óxido de alumínio obtidos pelas áreas dos ajustes (fiilting) dos espectros das Figuras 5.54 (a até e), assim como as espessuras das camadas de óxidos. O espectro de 
Al2p para a liga 2024-T3 antes da exposição, após ajuste permite a diferenciação química entre o alumínio metálico $(71,5 \mathrm{eV})$ e o óxido de alumínio $(74,5 \mathrm{eV})$. A relação $\mathrm{Al}_{2} \mathrm{O}_{3}$ para $\mathrm{Al}^{0}$ é de $81,1 \%$ e a espessura dessa camada é de 5,4 nm (Tabela 5.9). Os resultados para a liga 2024-T3 não soldada (Figura 5.54-a) mostraram que a razão $\mathrm{Al}_{2} \mathrm{O}_{3} / \mathrm{Al}^{0}$ aumenta com o tempo de exposição em solução 0,1 $\mathrm{M}$ de $\mathrm{Na}_{2} \mathrm{SO}_{4}+0,1 \mathrm{M}$ de $\mathrm{NaCl}$, passando de 91,1\% a 93,6\%, assim como as respectivas espessuras dos óxidos, que passam de 7,6 a 8,6 nm (Tabela 5.9). Esses resultados mostram o crescimento da camada de óxido nas primeiras 8 horas de exposição ao meio, indicando que a diminuição da impedância mostrada na Figura 5.33 não pode ser associada a ataque generalizado do filme passivo, mas ataque localizado na interface entre os precipitados e a matriz.

No caso da liga 2024-T3 soldada por FSW, os resultados do ajuste mostraram maiores valores de espessura de camada de óxido $(9,0 \mathrm{~nm})$ em relação à liga sem solda (7,6 nm). Todavia, para 24 horas de exposição ao meio, foram detectados hidróxidos de alumínio, $\mathrm{AlO}(\mathrm{OH})$ e $\mathrm{Al}(\mathrm{OH})_{3}$ na superfície desta liga, sugerindo que a camada de óxido formada na liga soldada durante exposição ao meio seja menos resistente, sendo mais facilmente hidratada em comparação à ensaiada na condição não soldada. Neste caso, não foi possível determinar a espessura da camada de óxido, pois não foi permitida a determinação do $\mathrm{Al}^{0}$. Tal resultado sugere que o acoplamento galvânico afeta as propriedades do filme passivo sobre a liga 2024-T3, tornando-o mais frágil e mais facilmente atacado pelo meio, resultando na formação de $\mathrm{AlO}(\mathrm{OH})$ e $\mathrm{Al}(\mathrm{OH})_{3}$. Esse resultado também explica parcialmente a diminuição de impedância observada para as ligas ensaiadas soldadas, como ilustra a Figura 5.33(b).

Tabela 5.9: Valores normatizados dos fittings dos espectros das Figuras 5.54 (a até e) do MB da liga 2024-T3, in natura e soldada com a liga 7475-T651 por FSW, após diferentes tempos de exposição em solução de $0,1 \mathrm{M}$ de $\mathrm{Na}_{2} \mathrm{SO}_{4}+1 \mathrm{mM}$ de $\mathrm{NaCl}$.

\begin{tabular}{cccccc}
\hline & 0 hora & $\begin{array}{c}\mathbf{8} \text { horas } \\
\text { sem solda }\end{array}$ & $\begin{array}{c}\text { 24 horas } \\
\text { sem solda }\end{array}$ & $\begin{array}{c}\text { 8 horas } \\
\text { com solda }\end{array}$ & $\begin{array}{c}\text { 24 horas } \\
\text { com solda }\end{array}$ \\
\hline $\mathbf{A l}_{2} \mathbf{O}_{3} / \mathbf{A l}^{\mathbf{0}}$ & 81,1 & 91,1 & 93,6 & 94,5 & 100 \\
$\begin{array}{c}\text { Hidróxidos de alumínio / } \mathbf{A l}^{0} \\
\text { Espessura }(\mathbf{n m})\end{array}$ & - & - & - & - & 19,1 \\
\hline
\end{tabular}




\subsubsection{Análise por XPS da camada de passivação da liga 7475-T651}

A Figura 5.55 mostra os espectros de alta resolução obtidos por XPS para o alumínio (Al2p), referentes à superfície da liga 7475-T651, (a) sem solda antes da exposição, (b) sem solda após 8 horas de exposiçao, (c) sem solda após 24 horas de exposiçao, (d) com solda após 8 horas de exposiçao e, (e) com solda após 24 horas de exposiçao em solução $0,1 \mathrm{M}$ de $\mathrm{Na}_{2} \mathrm{SO}_{4}+1 \mathrm{mM}$ de NaCl .
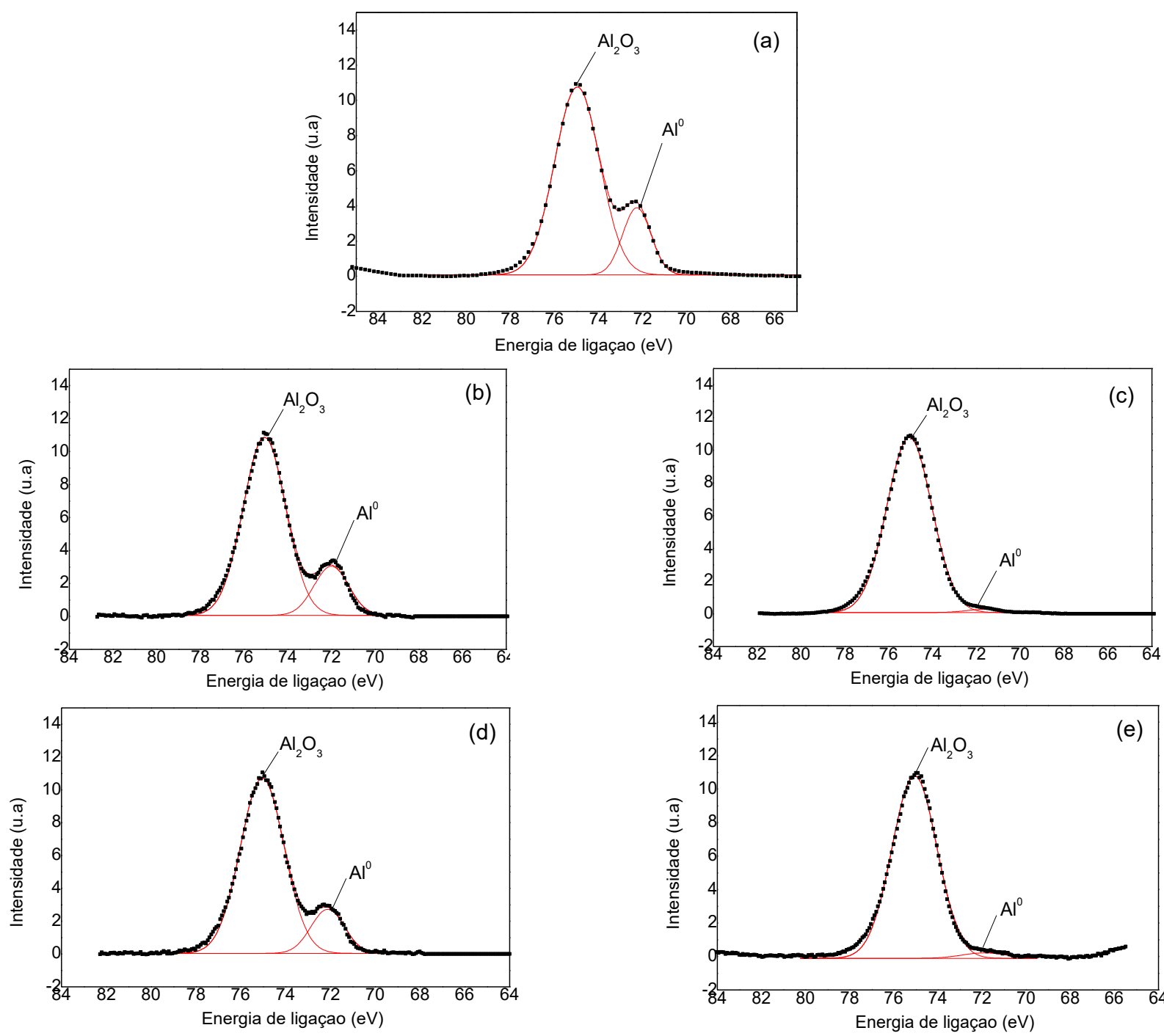

Figura 5.55: Espectros de alta resolução para o alumínio (Al2p), obtidos por XPS para a superfície da liga 7475-T651, (a) sem solda antes da exposição, (b) sem solda após 8 h, (c) sem solda após 24

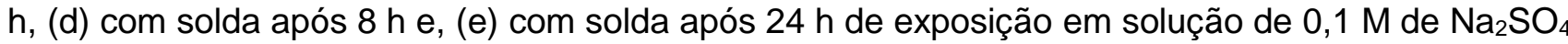
$+1 \mathrm{mM}$ de $\mathrm{NaCl}$.

A Tabela 5.10 mostra os resultados dos ajustes da relação $\mathrm{Al}_{2} \mathrm{O}_{3}$ / $\mathrm{Al}^{0}$ indicando para a liga uma razão de $81,7 \%$ e espessura da camada de óxido de alumínio formada ao ar de $5,5 \mathrm{~nm}$. 
Foi estimada uma espessura de 5,5 nm também para a camada de óxido sobre a liga 7475-T651 após 8 horas de exposição ao meio (Tabela 5.10), indicando que nesse período não ocorreu crescimento significativo da camada. Entre 8 horas e 24 horas de exposição à solução, todavia, a espessura aumentou de $5,5 \mathrm{~nm}$ para $12,5 \mathrm{~nm}$. Similarmente, para a liga 7475-T651 ensaiada soldada, após 8 horas de exposição ao meio a espessura estimada de camada de óxido foi 5,9 nm, e entre 8 horas e 24 horas, a camada atinge espessura de 10,9 $\mathrm{nm}$. Estes resultados mostram uma cinética mais lenta de crescimento do filme sobre a liga 7475-T651. Vale ressaltar que nas primeiras 8 horas de ensaio ocorreu dissolução seletiva de magnésio da superfície. Parte do zinco foi dissolvida da superfície no meio, sendo encontrado sobre a liga 2024-T3, além de ocorrer empobrecimento em alumínio na superfície. Este ataque à superfície da liga deve ser responsável pela baixa variação da espessura nas primeiras 8 horas de ensaio. Entre 8 horas e 24 horas de ensaio, todavia foi observado grande aumento de espessura, e os filmes são mais espessos sobre esta liga do que sobre a 2024-T3.

Após 24 horas de exposição em solução, há um aumento significativo da razão $\mathrm{Al}_{2} \mathrm{O}_{3} / \mathrm{Al}^{0}$ e da espessura da camada de óxido, passando de 83,9\% a 97,2\%, e de 5,5 $\mathrm{nm}$ a 10,9 nm, respectivamente (ver Tabela 5.10). Ou seja, são resultados inferiores aos encontrados para o MB da liga 7475-T651, sem solda, sugerindo dessa maneira, que o acoplamento galvânico neste caso, diminui a quantidade de produtos corrosivos, possivelmente pela preferência na deposição dos produtos formados por esta liga, nos sítios da liga 2024-T3, como mostrado pelas imagens das Figuras 5.23 a 5.28, obtidas por SEM, e pela análise em EDS, que mostraram a formação de produtos de corrosão de óxido de zinco.

A Tabela 5.10 apresenta as relações de óxido de alumínio/óxido metálico obtidos pelas áreas dos fittings dos espectros das Figuras 5.55 (a até e), assim como as espessuras das camadas de óxidos.

Tabela 5.10: Valores normatizados dos fittings dos espectros das Figuras 5.55 (a até e) do MB da liga 7475-T651, in natura e soldada com a liga 2024-T3 por FSW, após diferentes tempos de exposição em solução de $0,1 \mathrm{M}$ de $\mathrm{Na}_{2} \mathrm{SO}_{4}+1 \mathrm{mM}$ de $\mathrm{NaCl}$

\begin{tabular}{cccccc} 
& $\mathbf{0}$ hora & $\begin{array}{c}\mathbf{8} \text { horas sem } \\
\text { solda }\end{array}$ & $\begin{array}{c}\mathbf{2 4} \text { horas sem } \\
\text { solda }\end{array}$ & $\begin{array}{c}\mathbf{8} \text { horas com } \\
\text { solda }\end{array}$ & $\begin{array}{c}\text { 24 horas } \\
\text { com solda }\end{array}$ \\
\hline $\mathbf{A l}_{2} \mathbf{O}_{3} / \mathbf{A l}^{\mathbf{0}}$ & 81,7 & 81,7 & 98,4 & 83,9 & 97,2 \\
Espessura $(\mathbf{n m})$ & 5,5 & 5,5 & 12,5 & 5,9 & 10,9 \\
\hline
\end{tabular}




\subsubsection{Análise por XPS da camada de passivação do nugget das ligas 2024-T3 e 7475- T651 soldadas por FSW}

A Figura 5.56 mostra os espectros de alta resolução obtidos por XPS para o alumínio (Al2p), referentes ao nugget das ligas 2024-T3 e 7475-T651 soldadas por FSW, (a) antes da exposição, (b) após 8 horas de exposição e, (c) após 24 horas de exposição em solução de $0,1 \mathrm{M}$ de $\mathrm{Na}_{2} \mathrm{SO}_{4}+1 \mathrm{mM}$ de NaCl .
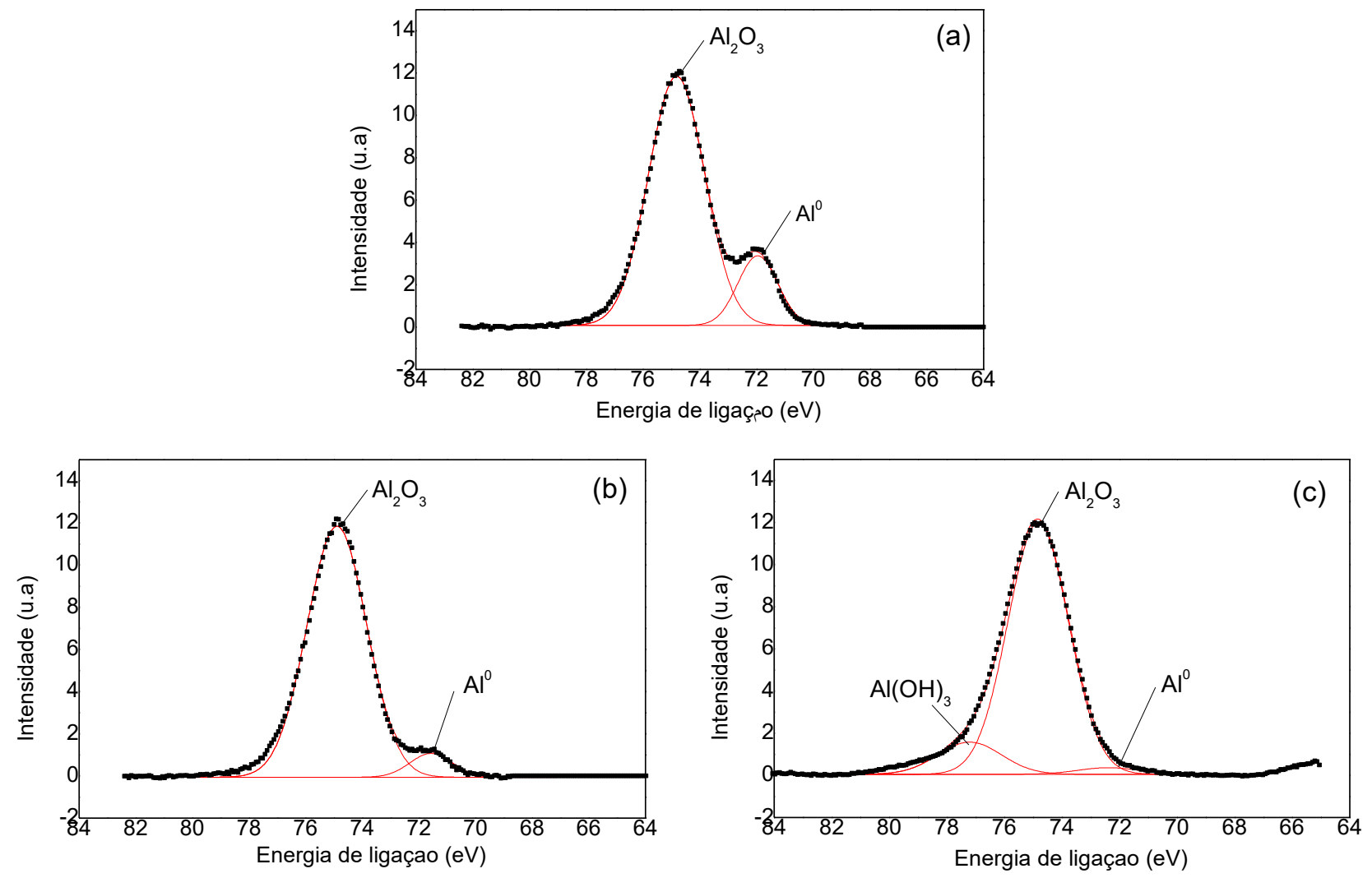

Figura 5.56: Espectros de alta resolução para o alumínio (Al2p), obtidos por XPS para a superfície do nugget das ligas 2024-T3 e 7475-T651 soldadas por FSW, (a) antes da exposição, (b) após 8 horas de exposição e, (c) após 24 horas de exposição em solução de $0,1 \mathrm{M}$ de $\mathrm{Na}_{2} \mathrm{SO}_{4}+1 \mathrm{mM}$ de $\mathrm{NaCl}$.

A Tabela 5.11 apresenta as relações de óxido de alumínio/óxido metálico e hidróxidos de alumínio/óxido de alumínio obtidos pelas áreas dos ajustes (fiilting) dos espectros das Figuras 5.56 (a até $\mathrm{c}$ ), assim como as espessuras das camadas de óxidos. O espectro de Al2p para o nugget antes da exposição, após ajuste permite a diferenciação química entre 0 alumínio metálico $(72,0 \mathrm{eV})$ e o óxido de alumínio $(74,8 \mathrm{eV})$. A relação $\mathrm{Al}_{2} \mathrm{O}_{3}$ para $\mathrm{Al}{ }^{0}$ é de $83,5 \%$ e a espessura dessa camada é de $5,8 \mathrm{~nm}$ (Tabela 5.12). Os resultados para o nugget antes da exposição (Figura 5.56-a) mostraram que a razão $\mathrm{Al}_{2} \mathrm{O}_{3} / \mathrm{Al}{ }^{0}$ aumenta com o tempo de exposição em solução $0,1 \mathrm{M}$ de $\mathrm{Na}_{2} \mathrm{SO}_{4}+1 \mathrm{mM}$ de $\mathrm{NaCl}$, passando de $93,7 \%$ (após 8 horas) a 97,4\% (após 24 horas), assim como as respectivas espessuras dos óxidos, que 
passam de 8,6 nm (após 8 horas) a 11,5 nm (após 24 horas), conforme mostra a Tabela 5.11. Esses resultados mostram o crescimento da camada de óxido nas primeiras 8 horas de exposição ao meio, indicando que a diminuição da impedância mostrada na Figura 5.33(b) não pode ser associada a ataque generalizado do filme passivo, mas ataque localizado na interface entre os precipitados e a matriz.

Tabela 5.11: Valores normatizados dos fittings dos espectros das Figuras 5.56 (a até c) do nugget das ligas 2024-T3 e 7475-T651, soldadas por FSW, após diferentes tempos de exposição em solução

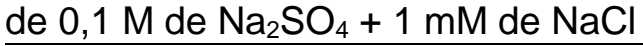

0 hora 8 horas 24 horas

\begin{tabular}{cccc}
\hline $\mathbf{A l}_{2} \mathbf{O}_{3} / \mathbf{A l}^{\mathbf{0}}$ & 83,5 & 93,7 & 97,4 \\
Hidróxidos de alumínio / $\mathbf{A l}^{\mathbf{0}}$ & - & - & 13,3 \\
Espessura $(\mathbf{n m})$ & 5,8 & 8,6 & 11,5 \\
\hline
\end{tabular}

Comparando-se os resultados das duas ligas ensaiadas na condição soldada, podese dizer que a liga 7475-T651 apresenta, inicialmente, cinética de crescimento do filme passivo mais lenta que a liga 2024-T3 porém, para tempos entre 8 horas e 24 horas, é favorecida sobre a liga 7475-T651 em relação à liga 2024-T3. 


\section{CONCLUSÕES}

Os resultados deste trabalho mostraram efeito significativo do processo de soldagem por FSW na microestrutura das ligas 2024-T3 e 7475-T651, mais especificamente no nugget ou zona de mistura e nas zonas termomecanicamente afetadas. No nugget ocorreu recristalização dinâmica. Na ZTMA da liga 2024-T3, os resultados sugerem que ocorreu precipitação de fase $\mathrm{S}^{\prime}(\mathrm{S})$, e quebra de bastonetes (dispersóides Al-Cu-Mn). Não foram observadas diferenças significativas entre as microestruturas do metal base (MB) e da zona termicamente afetada (ZTA). Na ZTMA da liga 7475-T651 houve uma precipitação seletiva de precipitados endurecedores de fase $\eta\left(M \mathrm{Zn}_{2}\right)$ nos contornos de grãos, os quais são anódicos em relação à matriz.

A resistência à corrosão das ligas foi fortemente influenciada pela microestrutura das várias zonas formadas pelo processo de soldagem por FSW, sendo a ZTMA da liga 7475T651 e o nugget as regiões mais suscetíveis à corrosão.

Os ensaios eletroquímicos mostraram acoplamento galvânico entre as duas ligas soldadas. Durante acoplamento galvânico, a liga 7475-T651 atua como ânodo, enquanto a liga 2024-T3, como cátodo. O acoplamento galvânico causou diminuição na resistência da da camada passiva de filme óxido, o que foi indicado tanto pelos resultados de polarização como de espectroscopia de impedância eletroquímica.

Os ensaios de espectroscopia de impedância local (LEIS) também sugeriram acoplamento galvânico entre as duas ligas, indicado por arcos indutivos nos resultados obtidos para tempos curtos de exposição, particularmente nas zonas próximas à interface entre as duas ligas soldadas, os quais diminuíam à medida que o bi-eletrodo se afastava dessa interface. Uma alta atividade eletroquímica em consequência do acoplamento galvânico na interface entre as duas ligas foi também indicada pelos resultados de microscopia eletroquímica de varredura realizada na seção transversal da junta soldada. $\mathrm{O}$ mesmo comportamento foi observado para a seção transversal da amostra, com o auxílio da técnica de microscopia eletroquímica de varredura (SECM).

A elevada atividade eletroquímica devido ao acoplamento galvânico foi também evidenciada pela precipitação de produtos de corrosão da liga 7475-T651 sobre a liga 2024T3. Além disso, resultou no enriquecimento em cobre e zinco na superfície das ligas. 


\section{SUGESTÕES PARA TRABALHOS FUTUROS}

As sugestões para trabalhos futuros são:

- Estudar a melhoria da aquisição de dados em baixa frequência da técnica de espectroscopia de impedância local (LEIS).

- Utilizar o sistema de tri-eletrodos a fim de comparar os resultados de impedância local radial e local normal.

- Investigar o comportamento das mesmas ligas com diferentes parâmetros de soldagem.

- Uso de tratamentos superficiais e térmicos no material utilizado neste estudo e investigação do comportamento frente à corrosão após tais tratamentos. 


\section{REFERÊNCIAS BIBLIOGRÁFICAS}

ABALLE, A. ; BETHENCOURT, M. ; BOTANA, F. J.; CANO, M. J.; MARCOS, M. Localized alkaline corrosion of alloy AA50836 in neutral $3.5 \% \mathrm{NaCl}$ solution, Corrosion Science, v 43, n 9, p 1657-1674, 2001.

ADLER, P.N.; DELASI, R. Calorimetric studies of 7000 series aluminium alloys: II. Comparison of 7075, 7050 and RX720 alloys, Metallurgical and Materials Transactions A, v. 8, pp 1177-1184, 1977.

AKINLABI, E.T.; ANDREWS, A.; AKINLABI, S.A. Effects of processing parameters on corrosion properties of dissimilar friction stir welds of aluminium and copper, Trans Nonferrous Met Soc China., v. 24, p. 1323-30, 2014.

AMANCIO-FILHO, S.T.; SHEIKHI, S.; DOS SANTOS, J.F.; BOLFARINI, C. Preliminary study on the microstructure and mechanical properties of dissimilar friction stir welds in aircraft aluminium alloys 2024-T351 and 6056-T4, Journal of materials processing technology, v. 206, p. 132-142, 2008

AMERICAN SOCIETY FOR METALS. Metals Handbook. v 2. Ohio: ASM International, 1990. 1328 p. $\left(10^{\text {th }}\right.$ ed.)

AMERICAN SOCIETY FOR TESTING AND MATERIALS. Standard practice for evaluating intergranular corrosion resistance of heat treatable aluminium alloys by immersion in sodium chloride + hydrogen peroxide solution, ASTM G110-97.

ANDREATTA, F.; LOHRENGEL, M. M.; TERRYN, H.; de WIT, J. H. W. Electrochemical characterisation of aluminium AA7075-T6 and solution heat treated AA7075 using a microcapillary cell, Electrochimica Acta, v 48, n 20-22, p 3239-3247, 2003.

ANNERGREN, I.; ZOU, F.; THIERRY, D. Application of localized electrochemical techniques to study kinectis of initiation and propagation during pit growth, Electrochimica Acta, v 44, n 24, p 4383-4393, 1999.

AOKI, I.V.; BERNARD, M. C.; CORDOBA DE TORRESI, S.I.; DESLOUIS, C.; DE MELO, H.G.; JOIRET, S.; TRIBOLLET, B. Ac-impedance and Raman spectroscopy study of the electrochemical behaviour of pure aluminium in citric acid media, Electrochimica Acta, v. 46, p 1871-1878, 2001.

ASSOCIAçÃO BRASILEIRA DO ALUMINIO - ABAL, Fundamentos e Aplicações do alumínio, São Paulo, editora ABAL, maio 2007.

AVAL, H.J. Influences of pin profile on the mechanical and microstructural behaviors in dissimilar friction stir welded AA6082-AA7075 butt Joint, Mater. Des., v. 67, p. 413-421, 2015.

BAGARYATSHY, Y.A. Structural changes on aging Al-Cu-Mg alloys, Dokl Akad, SSSR, v. 87, p. 397, 1952.

BARBIERI, P. F.; DE SIERVO, A.; CARAZZOLLE, M. F.; LANDERS, R.; KLEIMAN, G. G. $\{X P S\}$ and $\{X A E S\}$ study of $\mathrm{Ag}-\mathrm{Pd}$ and $\mathrm{Cu}-\mathrm{Ni}$ alloys: spectra, shifts and electronic structure 
information, Journal of Electron Spectroscopy and Related Phenomena, v 135, n. 2-3, p. 113-118, 2004.

BARBUCCI, A.; BRUZZONE, G.; DELUCCHI, M.; PANIZZA, M. ; CERISOLA, G. Breakdown of passivity of aluminium alloys by intermetalic phases in neutral chloride solution, Intermetallics, v 8, n 3, p 305-315, 2000.

BARD, A. J.; FAN, F.-R. F.; KWAK, J.; LEV., O. Scanning electrochemical microscopy. Introduction and principles, Anal. Chem., v. 61, p. 132, 1989.

BARD, A.J. Introduction and principles, in: A.J. Bard, M.V. Mirkin, Scanning Electrochemical Microscopy, Marcel Dekker, Inc., New York, 2001,pp. 1-16.

BARIL, G.; GALICIA, G.; DESLOUIS, C.; PEBERE, N.; TRIBOLLET, B.; VIVIER, V. An Impedance Investigation of hte Mechanism of Pure Magnesium Corrosion in Sodium Sulfate Solutions. Journal of the Electrochemical Society, v 154, n 2, p 108, 2007.

BASTOS, A. C.; SIMÕES, A. M.; GONZALES, S.; GONZALEZS-GARCIA, Y.; SOUTO, R. M. Application of the scanning electrochemical microscope to the examination of organic coatings on metallic substrates, Progress in Organic Coating, v 53, n 3, p 177-182, 2005.

BAYET, E.; HUET, F.; KEDDAM, M.; OGLE, K.; TAKENOUTI, H. A Novel Way of Measuring Local Electrochemical Impedance Using a Single Vibrating Probe, Journal of the Electrochemical Society, n 144, p 87, 1997.

BERTONCELLO, J.C.B.; MANHABOSCO, S.M.; DICK, L.F.P. Corrosion study of the friction stir lap joint of AA7050-T76511 on AA2024-T3 using the scanning vibrating electrode technique, Corrosion Science, v. 94, p. 359-363, 2015.

BESSONE, B.; SALINAS, D. R.; MAYER, C. E.; EBERT, M.; LORENZ, W. J. An EIS study of aluminium barrier-type oxide films formed in different media, Electrochimica Acta, v 37, p 2283-2290, 1992.

BINNIG, G.; ROHRER, H.; GERBER, CH.; WEIBEL, E. Phys. Rev. Lett., v. 49, p. 57, 1982.

BINNIG, G.; SMITH, D. P. E. Single-tube three-dimensional scanner for scanning tunnelling microscopy, Rev. Sci. Instr., v. 57, p. 1688, 1986.

BIRBILIS, N.; BUCHHEIT, R. G. Electrochemical characteristics of intermetallic phases in aluminum alloys an experimental survey and discussion, Journal of The Electrochemical Society, v 152, p B140-B151, 2005.

BIRBILIS, N.; CAVANAUGH, M. K.; BUCHHEIT, R. G. Electrochemical behaviour and localized corrosion associated with Al7Cu2Fe particles in aluminium alloy 7075-T651, Corrosion Science, v 48, n 12, p 4202-4215, 2006.

BLANC, C.; GASTAUD, S.; MANKOWSKI, G. Mechanistic Studies of the Corrosion of 2024 Aluminium Alloy in Nitrate Solutions, Journal of the Electrochemical Society, v 150, n 8, p B396-B404, 2003. 
BLANC, C.; LAVELLE, B.; MANKOWSKI, G. The role of precipitates enriched with copper on the susceptibility to pitting corrosion of the 2024 aluminium alloy, Corrosion Science, v 39, n 3, p 495-510, 1997.

BLANC, C.; LAVELLE, B.; MANKOWSKI, G. The Role of Precipitates Enriched with Copper on the Susceptibility to Pitting Corrosion of the 2024 Aluminium Alloy. Mater. Sci. Forum, 1996, 217-222, 1559-1564.

BLANC, C.; PEBERE, N.; TRIBOLLET, B.; VIVIER, V. Galvanic couplign between copper and aluminium in a thin-layer cell, Corrosion Science, n 52, p 991-995, 2010.

BOAG, A.; TAYLOR, R. J.; MUSTER, T. H.; GOODMAN, N.; McCULLOCH, D.; RYAN, C.; ROUT, B.; JAMIESON, D.; HUGHES, A. E. Stable pit formation on 2024-T3 in a $\mathrm{NaCl}$ environment, Corrosion Science, v 52, n 1, p 90-103, 2010.

BOAG, A.; HUGHES, A.E.; GLENN, A.M.; MUSTER, T.H.; MCCULLOCH, D. Corrosion of AA2024-T3 Part I: Localised corrosion of isolated IM particles, Corrosion Science, v 53, p 17-26, 2011.

BOISIER, G.; PORTAIL, N.; PÉBÈRE, N. Corrosion inhibition of 2024 aluminium alloy vy sodium decanoate, Electrochimica Acta, v.55, p. 6182-6189, 2010.

BOUSQUET, A.; POULON-QUINTIN, A.; PUIGGALLI, M.; DEVOS, O.; TOUZET, M. Relationship between microstructure, microhardness and corrosion sensivity of an 2024-T3 friction stir welded joint, Corrosion Science, n 53, p 3026-3034, 2011.

BRIGGS, D.; SEAH, M.P. Practical Surface Analysis by AES and XPS, John Wiley and Sons, Chichester and New York, 1983.

BUCHHEIT, R. G. A compilation of corrosion potentials reported for intermetallic phases in aluminum alloys, Journal of the Electrochemical Society, v 142, p 3994-3996, 1995.

BUCHHEIT, R. G.; BOGER, R. K.; CARROLL, M. C.; LEARD, R. M.; PAGLIA, C.; SEARLES, $\mathrm{J}$. L. The electrochemistry of intermetallic particles and localized corrosion in Al alloys, Journal of the Minerals, Metals and Materials Society, v 53, n 7, p 29-33, 2001.

BUCHHEIT, R. G.; GRANT, R. P.; HLAVA, P. F.; MCKENZIE, B.; ZENDER, G. L; Local Dissolution Phenomena Associated with $S$ Phase $\left(\mathrm{Al}_{2} \mathrm{CuMg}\right)$ Particles in Aluminium Alloy 2024-T3, Journal of the Electrochemical Society, v 144, n 8, p 2621, 1997.

BUCHHEIT, R. G.; MARTINEZ, M. A.; MONTES, L. P. Evidence for Cu lon Formation by Dissolution and Dellaoyng the Al2CuMg Intermetallic Compound in Rotating Ring-Disk Collection Experiments, Journal of the Electrochemical Society, v 147, n 1, p 119, 2000.

BUGARIN, A. F. S.; QUEIROZ, F. M.; TERADA, M.; DE MELO, H. G.; COSTA, I. Localized Corrosion Resistance of Dissimilar Aluminum Alloys Joined by Friction Stir Welding (FSW), Key Engineering Materials, v 710, p 41-46, 2016.

BUSH, R.; KIYOTA, M.; KIYOTA, C. Characterization of a Friction Stir Weld in Aluminum Alloy 7055 Using Microhardness, Electrical Conductivity, and Differential Scanning 
Calorimetry (DSC), Metallurgical and Materials Transactions A, v. 47, p 3522-3532, 2016.

CALLISTER JR., W. D., Fundamentos da Ciência e Engenharia dos Materiais, $2^{\mathrm{a}}$ ed., Rio de Janeiro, LTC, 2006, ISBN: 85-216-1515-9.

CAMPBELL, P.A.; GLEDHILL, H.C.; BROWN, S.R.; TURNER, I.G. Vacuum plasma sprayed hydroxyapatite coatings on titanium alloy substrates: surface characterization and observation of dissolution processes using atomic force microscopy, $\boldsymbol{J}$ Vac Sci Technol B, v. 14, p. 1167-72, 1996.

CAMPESTRINI, P. Microstructure-related quality of conversion coating on aluminium alloys. 2002. 220 p. Tese de Doutorado. TUDelft, Holanda, 2002.

CAMPESTRINI, P.; TERRYN, H.; HOVESTAD, A.; de WIT J. H. W. Formation of a ceriumbased conversion coating on 2024: relationship with the microstructure, Surface and Coatings Technology, v 176, n 3, p 365-381, 2004.

CARLSON, T. A. Basic assumptions and recent developments in quantitative XPS, Surf. Interface Anal., v. 4, p.125, 1982.

CHEN, G. S.; GAO, M.; WEI, R. P. Microconstituent-induced pitting corrosion in aluminium alloy 2024-T3, Corrosion, v 52, n 1, p 8-15, 1996.

CHENG, Y. L.; ZHANG, Z.; CAO, F. H.; LI, J. F.; ZHANG, J. Q.; WANG, J. M.; CAO, C. N. A sturdy of the corrosion of aluminium alloy 2024-T3 under thin electrolyte layers, Corrosion Science, v 46, n7, p 1649-1667, 2004.

CODBEN, R. Training in Aluminium Application Technologies (TALAT). Lecture 1501. Aluminium: Physical Properties, Characteristics and Alloys. The Welding Institute, 1991.

COLE, E. G.; FEHRENBACHER, A.; DUFFIE, N. A.; ZINN, M. R.; PFEFFERKORN, F. E.; FERRIER, N. J. Weld temperature effects during friction stir welding of dissimilar aluminum alloys 6061-t6 and 7075-t6, Int J Adv Manuf Technol.,v. 71, p. 643-652, 2014.

DAVIS, J. R. Aluminium and Aluminium Alloys. ASM International Materials Park, $\mathrm{OH}, 784 \mathrm{p}$. ISBN: 087170496X, 1993.

DAVIS, J. R. Aluminium and aluminium alloys. Materials Park, OH: ASM International, 1993. $784 \mathrm{p}$.

DAVIS, J. R. Corrosion of Aluminium and Aluminium Alloys. ASM International Materials Park, OH, 313 p. ISBN: 0871706296, 1999.

DAVOODI, A.; PAN, J.; LEYGRAF, C.; NORGREN, S. The Role of Intermetallic Particles in Localized Corrosion of Aluminium Alloy Studied by SKPFM and Integrated AFM/SECM, Journal of the Electrochemical Society, n 155, p 138-146, 2008.

DE WIT, J. H. W.; LENDERINK, H. J. W. Electrochemical impedance spectroscopy as a tool to obtain mechanistic information on the passive behaviour of aluminium, Electrochimica Acta, v 41, p 1111-1119, 1996. 
DE WITT, J. H. W. Local potential measurements with the SKPFM on aluminium alloys, Electrochemica Acta, v 49, n 17-18, p 2841-2850, 2004.

DESCHAMPS, A. Influence de la prédéformation et des traitements thermiques sur la microstructure et les propriétés mécaniques des alliages Al-Zn-Mg-Cu. Tese de Doutorado, Matériaux et Génie des Procédés, INP Grenoble, 1997.

DIMITROV, N.; MANN, J.; SIERADZKI, K. Copper redistribution during corrosion of aluminium alloys, Journal of the Electrochemical Society, v 146, p 98-102, 1999.

DITTRICH, D.; STANDFUSS, J.; LIEBSCHER, J.; BRENNER, B.; BEYER, E. Laser Beam Welding of Hard to Weld Al Alloys for a Regional Aircraft Fuselage Design - First Results. Physics Procedia, n. 12, p 113-122, 2011.

DIX, E. H.; RAND, J.; BOWMAN, J. Metals Handbook ASM, p. 804, 1998.

DONATUS, U. ; THOMPSON, G.E. ; ZHOU, X. ; WANG, J. ; CASSELL, A. ; BEAMISH, K. Corrosion Susceptibility of Dissimilar Friction Stir Welds of AA5083 and AA6082 Alloys. MaterialsCharacterization, 107, 85-97, 2015.

DUBOST, P.; SAINFORT, B. Durcissement par precipitation des alliages d'aluminium. Rapport technique, Techniques de l'Ingénieur, M240, 1991.

DUQUESNAY, D. L. ; UNDERHILL, P. R .; BRITT, H. J. Fatigue and crack growth from corrosion damage in 7075-T6511 aluminium alloy under aircraft loading, Int. J. Fatigue, v. 25, p. 371-377, 2003.

DURSUN, T.; SOUTIS, C; Recent developments in advanced aircraft aluminium alloys. Materials and Design, n 56, p 962-871, 2014.

DWIGHT, J.; Aluminium Design and Construction. New York: Routledge, 1999, 320 p.

EVANS, A. C. Physiological relationships between insects and their host plants. I. The effect of the chemical composition of the plant on reproduction and production of winged forms in Brevicoryne brassicae, L. Ann. appl. Biol., v. 25, p. 558-572, 1938.

FAVRE, M.; LANDOLT, D. The influence of gallic acid on the reduction of rust on painted steel surfaces, Corrosion Sci, v.34, p. 1481, 1993.

FERRARI, J. V.; DE MELO, H. G.; KEDDAM, M.; ORAZEM, M. E.; PEBERE, N.; TRIBOLLET, B.; VIVIER, V., Influence of normal and radial contributions of local current density on local electrochemical impedance spectroscopy. Electrochimica Acta, v 60, p 244-252, 2012.

FIORAVANTI, A. S. Soldagem por FSW de ligas de alumínio ALCLAD 2024-T3 e AA7075T6. 2008. 93 p. Dissertação (Mestrado em Processos de Fabricação) - Universidade Federal do Rio Grande do Sul, Porto Alegre, 2009.

FRANKEL, G.S. Pitting corrosion of metals a review of the critical factors, J. Electrochem. Soc., v. 145, p. 2186, 1998. 
FRATEUR, I.; HUANG, V. M-W.; ORAZEM, M.E. ; TRIBOLLET, B.; VIVIER, V. Experimental issues associated with measurement of local electrochemical impedance, J. Electrochem. Soc., v. 54, n. 12, p. C719-C727, 2007.

FRIGAARD, O.; GRONG, O.; MIDLING, O.T. A process model for friction stir welding of age hardening aluminum alloys, Metallurgical and Materials Transactions A, v 32, p 1189-1200, 2001.

GALICIA, G. A. Etude par spectroscopie d'impédance globale et locale de la corrosion du magnesium et des alliages de magnesium AZ91. 2006. 180 p.. Tese de Doutorado. Université Paris VI, Paris, França, 2006.

GENEVOIS., C, Genèse des microstructures lors du soudage par friction malaxage d'alliages d'aluminium de la série 2000 \& 5000 et comportement mécanique résultant, Thèse sci, INPG Grenoble, França, 2004.

GENEVOIS, C.; FABREGUE, D.; DESCHAMPS, A.; POOLE, W.J. On the coupling between precipitation and plastic deformation in relation with friction stir welding of AA2024 T3 aluminium alloy, Mater. Sci. Eng. A, v. 441 p. 39-48, 2006.

GENTIL, V. 2012 Corrosão 6 a Ed. Rio de Janeiro LTC.

GUILLAUMIN, V.; MANKOWSKY, G. Localized corrosion of 2024-T351 aluminium alloy in chloride media. Corrosion Science, n 41, p 421-438, 1999.

$\mathrm{HATCH}$, J. E. Aluminium: Properties and Physical Metallurgy, American Society for Materials, p 424, 1983.

HATCH, J. E. Aluminium: properties and physical metallurgy. Ohio: ASM International, 1990, $424 \mathrm{p}$.

HOFFMAN, J.; SATHISH, S.; SHELL, E. B.; FASSBENDER, S.; MEYENDORF, N. Acoustic Imaging Techniques for Characterization of Corrosion, Springer Series in Materials Science, V. 67, p 294-322, 2004.

HOLLINGSWORTH, E. H.; HUNSICKER, H. Y. Corrosion of aluminum and aluminum alloys vol 30, Handbook ASM, p.583-609, 1990.

HUANG, V. M-W.; VIVIER, V.; WU, S. L.; ORAZEM, M. E.; PEBERE, N.; TRIBOLLET, B., The Apparent Constant-Phase-Element Behavior of a Disk Electrode with Faradaic Reactions - A Global and Local Impedance Analysis. Journal of The Electrochemical Society, v 154, p c99-c107, 2007.

HUANG, V.M.-W.; VIVIER, V.; ORAZEM, M.E.; PÉBÈRE, N.; TRIBOLLET, B. J. The apparent constant-phase-element behavior of an ideally polarized blocking electrode a global and local impedance analysis, J. Electrochem. Soc., v 154, p C81-C88, 2007. 
HUANG, V.M.-W.; VIVIER, V.; FRATEUR, I.; ORAZEM, M.E.; TRIBOLLET, B. J. The global and local impedance response of a blocking disk electrode with local constant-phase-element behavior, J. Electrochem. Soc., v 154, p C89-C98, 2007.

HUANG, V. M-W.; WU, S. L.; ORAZEM, M. E.; PEBERE, N.; TRIBOLLET, B.; VIVIER, V., Local eletrochemical impedance spectroscopy: A review and some recent developments. Electrochimica Acta, v 56, p 8048-8057, 2011.

HWANG, Y-M.; KANG, Z.W.; CHIOU, Y-CHSU, H.H. Experimental study on temperature distributions within the workpiece during friction stir welding of aluminum alloys, International Journal of Machine Tools and Manufacture, V. 48, P. 778-787, 2008.

HUGHES, A. E.: BOAG, A. M.; GLENN, A. M.; MCCULLOCH, D.; MUSTER, T. H.; RYAN, C.; LUO, C.; ZHOU, X.; THOMPSON, G. E. Corrosion of 2024-T3 Part II: Co-operative corrosion, Corrosion Science, v 53, p 27-39, 2011.

HUMPHREYS, F.J.; HATHERLY, M. Recrystallization and Related Annealing Phenomena, Pergamon Press, Oxford, 1995.

IDRAC, J.; MANKOWSKI, G.; THOMPSON, G.; SKELDON, P.; KIHN, Y.; BLANC, C. Galvanic corrosion of aluminium-copper model alloys, Electrochimica Acta, v. 52, n 27, p 7626-7633, 2007.

JAFFE, L. F.; NUCCITELLI, R. An ultrasensitive vibrating probe for measuring steady extracellular currents, J. Cell Biol., v. 63, p. 614--628, 1974.

JAKAB, M. A.; LITTLE, D. A.; SCULLY, J. R. Experimental and modelling studies of the oxygen reduction reaction on 2024-T3, Journal of the Electrochemical Society, v 152, p B311-B320, 2005.

JAKAB, P. L. Wood to Metal: The Structural Origins of the Modern Airplane. Journal of Aircraft, v 36, n 6, 1999.

JARIYABOON, M.; DAVENPORT, A.; AMBAT, R;. CONNOLLY, B.; WILLIAMS, S.; PRICE, $D$. The effect of welding parameters on the corrosion behaviour of friction stir welded. Corrosion Science, n 49, p 877-909, 2007.

JARIYABOON, M.; BOUSQUET, E.; POULON-QUINTIN, A.; PUIGGALI, M.; DEVOS, O.; TOUZET, M. Relationship between microstructure, microhardness and corrosion sensitivity of an AA 2024-T3 friction stir welded joint, Corrosion Science, v 53, p 3026-3034, 2011.

JATA, K. V.; SEMIATIN, S. L. Continuous dynamic recrystallization during friction stir welding of high strength aluminum alloys, Scripta Materialia, v 43, p 743-749, 2000.

JENA, A. K.; GUPTA, A. K.; CHATURVEDI, M. C. A differential scanning calorimetric investigation of precipitation kinetics in the Al-1.53 wt\% Cu-0.79 wt\% Mg alloy, Acta Metall, v. 37, p. 885-895, 1989. 
JENSEN, M.; GUERARD, A.; TALLMAN, D.; BIERWAGEN, G. Studies of Electron Transfer at Aluminium Alloy Surfaces by Scanning Electrochemical Microscopy, Journal of the Electrochemical Society, n 155, p 324-332, 2008.

JORCIN, J.; BLANC, C.; PEBERE, N.; TRIBOLLET, B. ; VIVIER, V. Galvanic coupling between pure copper and pure aluminium, Journal of the Electrochemical Society, v 155, p C46-C51, 2008.

JUNIOR, A.R. Estrutura integral por Soldagem por Atrito "Friction Stir Welding - FSW - Requisitos básicos para o projeto estrutural. 2003. 247 p. Dissertação (Mestrado em Mecânica dos Sólidos e Estruturas) - Instituto Tecnológico de Aeronáutica, São José dos Campos, 2003.

KANG, J; FU, R. D.; LUAN, G. H.; DONG, C. L.; HE, M. In-situ investigation on the pitting corrosion behaviour of friction stir welded joint of 2024-T3 aluminium alloy. Corrosion Science, v 52, p 620-626, 2010.

KANYANEE, T.; FUEKHAD, P.; GRUDPAN, K. Micro coulometric titration in a liquid drop, Talanta, v. 115, p. 258-262, 2013.

KIM, Y. G. Et al. Three defects types in friction stir welding of aluminium die casting alloy. Materials Science and Engineering: A, v 415, n 1-2, p 250-254, 2006.

KOLICS, A. ; THOMAS, A. E. ; WIECKOWSI. In-Situ Radiotracter and Electrochemical Study of Sulfate Accumulation on Al-2024 Alloy, Langmuir, v 11, n 12, p 4605-4608, 1995.

KUNTZ-LAGUERRE, C. Contribution à l'étude de la comprehension des phénomènes chimiques engendrant la corrosion feuilletante des alliages d'aluminium et de la quantification de cette corrosion. 1997. 188 p. Tese de Doutorado. Université Paris VI, 1997.

LACROIX, L.; BLANC, C.; PEBERE, N.; TRIBOLLET, B.; VIVIER, V. Localized Approach to Galvanic Coupling in an Aluminium-Magnesium System, Journal of the Electrochemical Society, v 156, n 8, p 259-265, 2009.

LACROIX, L.; BLANC, C.; PEBERE, THOMPSON, G. E.; N.; TRIBOLLET, B.; VIVIER, V. Simulating the galvanic coupling between S-Al2 CuMg phase particles and the matrix of 2024 aerospace aluminium alloy, Corrosion Science, n 64, p 213-221, 2012.

LADELPHA, A.D.P.; NEUBING, H.; BISHOP, D.P. Metallurgical assessment of an emerging Al-Zn-Mg-Cu P/M alloy, Materials Sience and Engineering: A, v. 520, p 105-113, 2009.

LI, Y.; MURR, L.E.; MCCLURE, J.C. Flow visualization and residual microstructures associated with the friction-stir welding of 2024 aluminium to 6061 aluminium, Materials Science and Engineering, v. A271, p. 213, 1999.

LI, J. F.; ZHENG, Z. Q.; LI, S. C.; CHEN, W. J.; REN, W. D.; ZHAO, X. S. Simulation study on function mechanism of some precipitates in localized corrosion of Al alloys. Corrosion Science, v. 49, p. 2436-2449, 2007. 
LI, D.; MU, C.; CAI, S.; LIN, W. Ultrasonic irradiation in the enzymatic extraction of collagen. Ultrason. Sonochem., v.16, p.605-609, 2009.

LIAO, C. M.; OLIVE, J. M.; GAO, M.; WEI, R. P. In-situ monitoring of pitting corrosion in aluminium alloy 2024, Corrosion, v 54, v 6, p 451-458, 1998.

LILLARD, R. S.; MORAN, P. J.; ISAACS, H. S. A Novel Method for Generating Quantitative Local Electrochemical Impedance Spectroscopy, Journal of the Electrochemical Society, n 139, p 1007, 1992.

LO, I. H.; FU, Y.; LIN, C. J.; TSAI, W. T. Effect of electrolyte composition on the active-topassive transition behavior of 2205 duplex stainless steel in $\mathrm{H} 2 \mathrm{SO} 4 / \mathrm{HCl}$ solutions, Corros. Sci., v 48, p 696-708, 2006.

LUMSDEM, J.; MAHONEY, M.; RHODES, C.; POLLOCK, G. Corrosion Behavior of FrictionStir-Welded AA7050-T7651, Corrosion Science, n 59, p 212-219, 2003.

MACASKILL, I. A.; LADELPHA, A. D. P.; MILLIGAN, J. H.; FULTON, J.; BISHOP, D. P. Effects of hot and cold deformation on the mechanical performance of Alumix 431D, Powder Metall., v. 52, 304-310, 2009.

MACHADO, L.D.B.; MATOS, J. DO R. Análise térmica diferencial e calorimetria exploratório diferencial. In: CANEVAROLO JÚNIOR, S. V. (Org.). Técnicas de Caracterização de Polímeros. São Paulo: Artliber Editora Ltda., 2004, p. 229-261.

MAHONEY, M. W.; RHODES, C. G.; FLINTOFF, J. G.; BINGEL, W. H.; SPURLING, R. A. Properties of friction-stir-welded 7075 T651 aluminum, Metallurgical and Materials Transactions A, v 29, p 1955-1964, 1998.

MANSFELD, F.; KENDIG, M.; TSAI, S. Evaluation of corrosion behavior of coated metals with AC impedance measurements, Corrosion, v. 38, p. 478, 1982.

MATRUKANITZ, R. P. Selection and weldability of heat-treatable aluminium alloys. ASM Handbook-Welding, Brazing and Soldering 6, p 528-536, 1990.

MENDOZA, A. R.: CORVO, F. Outdoor and indoor atmospheric corrosion of non-ferrous metals. Corrosion Science, v. 42, p. 1123, 2000.

MILANI, M.R.; CARDOSO, A.A. Construction and performance of a drop cell for the nephelometric determination of sulfur dioxide, Microchemical Journal, v. 74, p. 75-82, 2003.

MIRKIN, M. V.; HORROCKS, B. R. Electroanalytical measurements using the scanning electrochemical microscope, Analytica Chimica Acta, v 406, n 2, p 119-146, 2000.

MIRKIN, M. V.; NOGALA, W.; VELMURUGAN, J.; WANG, Y. Scanning electrochemical microscopy in the $21^{\text {st }}$ century. Update 1: five years after, Physical Chemistry Chemical Physics, n 13, p 21196-21212, 2011.

NANDAN, R.; DEBROY, T.; BHADESHIA, H. K. D. H. Recent Advances in Friction Stir Welding Process. Progress in Material Science, v 54, p 980-1023, 2008. 
NEWMAN, J. S. J. Resistance for flow of current to a disk, J. Electrochem. Soc., v 113, p 501-502, 1966.

OBISPO, H. M.; MURR, L. E.; ARROWOOD, R. M.; TRILLO, E. A. Copper deposition during the corrosion of aluminium alloy 2024 in sodium chloride solutions, Journal of Material Science, v 35, n 14, p 3479-3495, 2000.

OLEA, C. A. W. Influence of energy input in friction stir welding on structure evolution and mechanical behaviour of precipitation-hardening in aluminium alloys (2024-T351? AA6013-T6 and Al-Mg-Sc). 2008. 149 p. Tese de Doutorado - Institute of Materials Research, Ruhr, Universität Bochum, Bochum, Alemanha, 2008.

PAGLIA, C. S.; BUCHHEIT, R. G. The time-temperature-corrosion susceptibility in a 7050T7451 friction stir weld. Materials Science Engineering A, v 492, p 250-254, 2008.

PAREL, T.S.; WANG, S.C.; STARINK, M.J. Hardening of an Al-Cu-Mg alloy containing Types I and II S phase precipitates, Materials and Design, v 31, p S2-S5, 2010.

PARK, J.K.; ARDELL, A.J. Effect of retrogression and reaging treatments on the microstructure of Ai-7075-T651, Metall. Trans, v. 15, p. 1531, 1984.

PATIL, H. S.; SOMAN, S. N. Effect of weld parameter on mechanical and metallurgical properties of dissimilar joints AA6082-AA6061 in T6 condition produced by FSW, Frattura ed Integrità Strutturale, v 24, p 151-160, 2013.

PAUSSA, L.; ANDREATTA, F.; ROSERO NAVARRO, N.C.; DURÁN, A.; FEDRIZZI, L. Study of the effect of cerium nitrate on AA2024-T3 by means of electrochemical micro-cell technique, Electrochimica Acta, v 70, p 25-33, 2012.

POSADA, M. ; MURR, L. E. ; NIOU, C. S; Exfolliation and related microstructures in 2024 aluminium body skins on aging aircraft, Materials and Characterization, v 38, p 259-272, 1997.

POURBAIX, M. Atlas des équilibres électrochimiques. Gauthiers-Villas et Cie Ed., Paris, France, 1963.

POURBAIX, M.; MURPHY, G. W. Atlas of Electrochemical Equilibria in Aqueous Solutions. Science, v. 154, p 168-175. 1966.

PRABHAKARAN, K.; OGINO, T. Oxidation of Ge(100) and Ge(111) surfaces: an \{UPS\} and \{XPS\} study, Surface Science, v. 325, n. 3, p. 263-271, 1995.

PUYDT, Q.; FLOURIOT, S.; RINGEVAL, S.; GEUSER, F.; PARRY, G.; DESCHAMPS, A. Relationship between microstructure, strenght, and fracture in an Al-Zn-Mg electron beam weld : Part I : Microstructure Characterization, Metallurgical and Materials Transactions A, v. 45, pp 6129-6140, 2014.

QUEIROZ, F.M.; MAGNANI, M.; COSTA, I.; DE MELO, H.G. Investigation of the corrosion behaviour of AA2024-T3 in low concentrated chloride media, Corrosion Science, v. 50, p. 2646-2657, 2008. 
RANGANATH, R.; ANIL LUMAR, V.; NANDI, V.S.; BHATT, R.R.; MURALIDHARA, B.K. Multistage Heat Treatment of Aluminum Alloy AA7049, Trans. Nonferrous Met. Soc. China, v. 23, p. 1570-1575, 2013.

RATCHEV, P.; VERLINDEN, B.; DE SMET, P.; VAN HOUTTE, P. Precipitation hardening of an Al-4.2 wt. \% Mg 0.6 wt. \% Cu alloy, Acta Mater, v. 46, p. 3523-3533, 1998.

REBOUL, M.; DEVELAY, R. Corrosion des alliages d'aluminium. Dans les Techniques de L'Ingénieur, v COR 325. Editions T.I., 1997.

RINGER, S. P.; QUAN, G. C.; SAKURAI, T. Microstructural evolution in high strength microalloyed aluminium alloys, J. Mater. Sci. Eng., v. 250A, p. 120-125, 1998.

ROBSON, J. D. ; PRANGNELL, P. B. Dispersoid precipitation and process modelling in zirconium containing commercial aluminium alloys, Acta Materials, v 49, p 599-613, 1999.

ROBINSON, M.J. Mathematical modelling of exfoliation corrosion in high strength aluminium alloys, Corros. Sci., v. 22, p.775-790, 1982.

ROBINSON, M.J.; JACKSON, N.C. The influence of grain structure and intergranular corrosion rate on exfoliation and stress corrosion cracking of high strength $\mathrm{Al}-\mathrm{Cu}-\mathrm{Mg}$ alloys, Corros. Sci., v. 41, p. 1013-1028, 1999.

RUSSEL, K. C.; AARONSON, H. I. Precipitation Processes in Solids, Proceedings of a Symposium Sponsered by the TMS-AIME Heat Treatment Committee, p 87, 1978.

SANCHEZ, M.; GAMBY, J.; PERROT, H.; ROSE, D.; VIVIER, V., Microelectrochemistry of copper in $\mathrm{NaCl}$ solution: Comparison between conventional microelectrode and microelectrochemical cell. Electrochemistry Comunications, v 12, p 1230-1232, 2010.

SARVGHAD-MOGHADDAM, M.; PARVIZI, R.; DAVOODI, A.; HADDAD-SABZEVAR, M.; IMANI, A. ESTABLISHINGA, correlation between interfacial microstructures and corrosion initiation sites in Al/Cu joints by SEM-EDS and AFM-SKPFM, Corros Sci, v. 79, p. 148-58, 2014.

SCHMUTZ, P.; FRANKEL, G. S. Characterization of 2024-T3 by Scanning Kelvin Probe Force Microscopy, Journal of the Electrochemical Society, v 145, n 7, p 2285-2295, $1998 \mathrm{~b}$.

SCHNEIDER, J.A.; NUNES, A.C. Thermo-Mechanical Processing in Friction Stir Welds. Minerals, Metals \& Materials Soc, pp. 43-51, 2003.

SCOFIELD J.H., Hartre-Slater Subshell Photoionization Cross-Sections at 1253.6 and 1486.6eV. J. Electron Spectroscopy and Related Phenomena, v 8, p 129, 1976.

SEREBRENNIKOVA, I.; WHITE, H. S. Electrochem. Solid-State Lett., v. 4, p. B4 - B6, 2001.

SHAO, M.; FU, Y.; HU, R.; LIN, C. A Study on pitting corrosion of aluminium alloy 2024-T3 by scanning microreference electrode technique, Material Science and Engineering, A 344, p 323-327, 2003. 
SHIH, H.C.; HO, N.J.; HUANG, J.C. Precipitation behaviors in Al-Cu-Mg and 2024 aluminium alloys, Metallurgical and Materials Transactions A, v. 27A, p2479, 1996.

SIDANE, D.; BOUSAUET, E.; DEVOS, O.; PUIGGALI, M.: TOUZET, M.; VIVIER, V.; POULON-QUINTIN, A. Local electrochemical study of friction stir welded aluminium alloy assembly, Journal of Eletroanalytical Chemistry, v 737, p 206-211, 2015.

SILCOCK, J. M. The structural ageing characteristics of $\mathrm{Al}-\mathrm{Cu}-\mathrm{Mg}$ alloys with copper:magnesium weight ratios of 7:1 and 2.2:1, J. Inst. Met, v. 89, p. 203-210, 1960.

SONG, M.; KOVACEVIC, R. Thermal modeling of friction stir welding in a moving coordinate system and its validation. International Journal of Machine Tools \& Manufacture, v. 43, pp. 605-615, 2003.

SOUTO, R. M.; GONZALES-GARCIA, Y.; GONZALES, S. In situ monitoring of electroative species by using the scanning electrochemical microscope. Application to he investigation of degradation precesses at defective coated metals, Corrosion Science, v 47, n 12, p 3312 3323, 2005.

SRINIVASAN, P.B.; DIETZEL, W.; ZETTLER, R.; DOS SANTOS, J.F.; SIVANA, V. Stress corrosion cracking susceptibility of friction stir welded AA7075-AA6056 dissimilar joint, Materials Science and Engineering A, v. 392, p. 292-300, 2005.

STRASS, B.; WAGNER, G.; CONRAD, C.; WOLTER, B.; BENFER, S.; FÜRBETH, W. Realization of $\mathrm{Al} / \mathrm{Mg}$-Hybrid-Joints by Ultrasound Supported Friction Stir Welding Mechanical Properties, Microstructure and Corrosion Behavior, Adv Mater Res, v. 521-35, p. 966-967, 2014.

STROHMEIER, B. R. An ESCA Method for Determining the Oxide Thickness on Aluminium Alloys, Surf.Interface Anal., v. 15, p. 51, 1990.

STROMBECK, A. et al. Fracture Toughness Behaviour of FSW Joints in Aluminium Alloys. In: $1^{\text {st }}$ INTERNATIONAL SYMPOSIUM ON FRICTION STRI WELDING, 1., 1999, Califórnia. Proceedings. Thousands Oaks, 1999.

SU, J.-Q.; NELSON, T.W; MISHRA, R.;. MAHONEY, M. Microstructural investigation of friction stir welded 7050-T651 aluminium. Acta Materialia, 51, 713-729, 2003.

SULLIVAN, A.; ROBSON, J.D. Microstructural properties of friction stir welded and postweld heat-treated 7449 aluminium alloy thick plate, Materials Science and Engineering A, v. 478, p. 351-360, 2008.

SUN, P.; LAFORGE, F.O.; MIRKIN, M.V. Scanning electrochemical microscopy in the $21 \mathrm{st}$ century, Phys. Chem. Chem. Phys., v. 9, p. 802, 2007.

SZLARSKA-SMIALOWSKA, Z. Pitting corrosion of aluminium, Corrosion Science, v 41, $\mathrm{n}$ 9, p 1743-1767, 1999.

THE TWI MAGAZINE. A flying success story for friction stir welding, n 122, p 1, 2003. 
THE WELDING INSTITUTE (TWI). Materials joining technology home page. Disponível em: www.twi.co.uk. Acessado em: 20 ago. 2015.

THREADGRILL, P. L.; LEONARD, A. J.; SCERCLIFF, H. R.; WITHERS, P. J. Friction stir welding of aluminium alloys. International Materials Reviews, v 54, p 49-93, 2009.

TOTTEN, G.E.; MACKENZIE, D.S. Eds., Handbook of Aluminum: Vol. 1 - Physical Metallurgy and Processes, Marcel Dekker Inc., New York, NY, 2003.

TROMPETTE, J. L.; ARURAULT, L.; FONTORBER, S.; MASSOT, L. Influence of the anion specifity on the electrochemical corrosion of anodized aluminium substrates, Electrochimica Acta, v 55, n8, p 2901-2910, 2010.

VARGEL, C. Corrosion de l'aluminium. Dunod, 1999.

VARGEL Christian. Corrosion of aluminium. Elsevier Amsterdam, 626 p, ISBN: 008044954 pg 105, 2004.

VENTOSA, E.; SCHUHMANN, W. Scanning electrochemical microscopy of Li-ion batteries, Phys. Chem. Chem Phys., v. 17, p. 28441-28450, 2015.

WADESON, D.A. Corrosion behaviour of friction stir welding AA7108-T79 aluminium alloy, Corrosion Science, v. 48, p. 887-897, 2006.

WANG, S. C.; STARINK, M. J. Two types of S phase precipitates in Al-Cu-Mg alloys, Acta Materialia, v 55, n 3, p 933-941, 2007.

WEI, C.; BARD, A.; MIRKIN, M. Scanning electrochemical microscopy. 31. Application of SECM to the study of charge transfer processes at the liquid/liquid interface, J. Phys. Chem. v 99, p 16033-16042, 1995.

WEI, R. P.; LIAO, C. M. ; GAO, M. A transmission electron microscopy study of constituentparticle-induced corrosion in 7075-T6 and 2024-T3 aluminium alloys, Metallurgical and Materials Transactions A: Physical Metallurgy and Materials Science, v 29, n 4, p 11531160, 1998.

WERENSKIOLD, J.C.; DESCHAMPS, A.; BRÉCHET, Y. Characterization and modeling of precipitation kinetics in an Al-Zn-Mg alloy. Materials Science and Engineering, v. 293, p. 267-274, 2000.

WITTSTOCK, G.; BURCHARDT, M.; PUST, S. E.; SHEN, Y;. ZHAO, C. Scanning Electrochemical Microscopy for Direct Imaging of Reactions Rates, Angewandte Chemie International Edition, n 46, p 1584-1617, 2007.

WLOKA, J.; VIRTANEN, S. Microstructural Effects on the Corrosion Behavior of High-Stenght Al-Zn-Mg-Cu Alloys in an Overaged Condition, Journal of the Electrochemical Society, $v$ 154, n 8, p C411-C423, 2007.

ZAHRA, A.M.; ZAHRA, C.Y. Comment on 'Positron lifetime study of an Al-1.7 at.\% Mg-1.1 at.\%Cu alloy', Philosophical Magazine Letters, v. 82, p. 9, 2002. 
ZHANG, W.; FRANKEL, G. S. Transitions between pitting and intergranular corrosion in 2024. Electrochimica Acta, v 48, p 1193-1210, 2003.

ZHOU, X.; LUO, C.; HASHIMOTO, T.; HUGHES, A.E.; THOMPSON, G.E. Study of the effect of cerium nitrate on AA2024-T3 by means of electrochemical micro-cell technique, Corrosion Science, v 58, p 299-306, 2012.

ZOU, F.; THIERRY, D.; ISAACS, H. S. A High-Resolution Probe for Localized Electrochemical Impedance Spectroscopy Measurements, Journal of the Electrochemical Society, n 144, p 1957, 1997. 